Portland State University

PDXScholar

$1-1-2010$

\title{
Participatory Action Research with Dignity Village: an Action Tool for Empowerment within a Homeless Community
}

Heather Irene Mosher

Portland State University

Follow this and additional works at: https://pdxscholar.library.pdx.edu/open_access_etds Let us know how access to this document benefits you.

Recommended Citation

Mosher, Heather Irene, "Participatory Action Research with Dignity Village: an Action Tool for Empowerment within a Homeless Community" (2010). Dissertations and Theses. Paper 36. https://doi.org/10.15760/etd.36

This Dissertation is brought to you for free and open access. It has been accepted for inclusion in Dissertations and Theses by an authorized administrator of PDXScholar. Please contact us if we can make this document more accessible: pdxscholar@pdx.edu. 
Participatory Action Research with Dignity Village:

An Action Tool for Empowerment within

a Homeless Community

by

Heather Irene Mosher

A dissertation submitted in partial fulfillment of the requirements for the degree of

Doctor of Philosophy
in
Systems Science: Psychology

Dissertation Committee:

Ellen Skinner, Chair

Susan Finley

Pauline Jivanjee

Yves Labissiere

George G. Lendaris

Eric Mankowski

Portland State University

(C) 2010 


\begin{abstract}
With homelessness continuing to rise over the past two decades, disenfranchised unhoused people have sparked a national movement to build for themselves democratically governed communities of affordable housing. Dignity Village, in Portland Oregon, is one of the longest running and most organized selfhelp housing communities in the nation. This paper presents a theoretical systemsbased model of a developmental pathway out of homelessness in the U.S. that has as one of its key steps membership and participation in humane and dignified "self-help micro-housing" communities such as Dignity Village.

This research involved working collaboratively with Dignity Village on a participatory action research (PAR) project aimed at understanding and facilitating processes for mobilizing community and socio-political engagement. The research process involved a team of up to 24 co-researchers (nine attended meetings regularly) working once weekly over 15 months, with consultation from the broader Village community throughout. The research followed a systems approach to creating five action tools as multiple points of leverage to create long-term positive change within the community. One point of leverage utilized participatory video methodology to cocreate a video action tool as an orientation video for newcomers, intended to build cooperative relationships and facilitate empowerment within the community. The impact of the research process was documented on multiple levels in the community using multiple data sources.
\end{abstract}


Data were analyzed using an inductive approach to identify key themes and processes that influenced participation and empowerment in the community. The predominant themes suggested three paradoxical tensions that were creating barriers to change in the community. This PAR process attempted to create movement beyond these barriers. Findings suggested that four main changes occurred in the community during and after the research: a) an increase in collaborative participation, b) enhanced engagement and sense of community, c) an emergence of critical consciousness, and d) changes in the organizational leadership/power structure.

These findings are critically examined and discussed with respect to the effectiveness of utilizing this PAR process to facilitate community empowerment. A portion of this dissertation (Results section) was created in video format to enhance report accessibility for community partners and other non-academic audiences. 


\section{ACKNOWLEDGEMENTS}

I would like to thank the many people who have contributed to the creation of this research. First and foremost, I am grateful to the participants and co-researchers in this study for working as a team, week after week for over a year, even under the most challenging of times. Thank you to Alan Rocheleau ("Big Al”), Alan Shipley ("Red”), Alfred, "Cami," Dave Hirschman (“Dog Dave”), David Carpenter (“Dread”), Dean Marchioni, Louis Wilhelms, Lydia Kushner, Michael Moore, Robert Sterling, Jr., Roeac Crotzer (“'Roe”), Stephanie Van Hauten, Thomas Marchak, and Tom Mundel (“Big Tom”). A very special thanks to Chrysler Chelle, Gaye Reyes, Kenneth McMichael, Laura Brown, Ross Bennett, Susan Parker, Tami Jaha, Timothy McCarthy and Travis Ougheltree. Your commitment to this research and to Dignity Village was remarkable and inspiring, and your support for me was extraordinary. I will treasure it always.

I also want to express my sincere thanks to my committee members who supported my explorations into new terrain: Ellen Skinner, Susan Finley, Pauline Jivanjee, Yves Labissiere, George G. Lendaris, and Eric Mankowski.

And, lastly, I would like to especially thank Wendy Kohn who was a vital and constant source of encouragement and support throughout this entire journey. 


\section{TABLE OF CONTENTS}

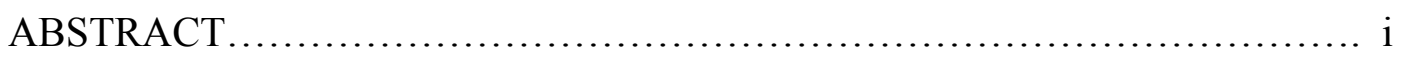

ACKNOWLEDGEMENTS ............................................. ii

LIST OF TABLES ......................................................... ix

LIST OF FIGURES..............................................................

PREFACE .............................................................. xii

CHAPTER ONE: INTRODUCTION ........................................

Research Setting .......................................................

State of Dignity Village at Beginning of Research (late 2005) .......................... 4

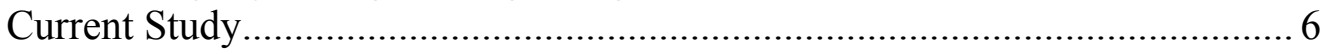

Style of Dissertation........................................................ 10

Structure of Dissertation...................................................

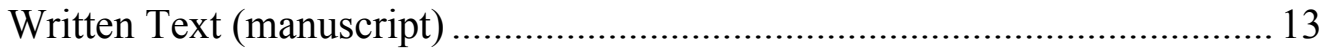

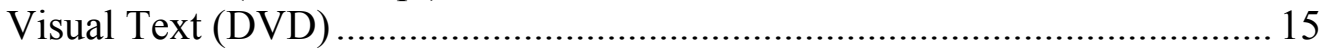

CHAPTER TWO: FRAMING THE RESEARCH............................17

Entering the Research Setting........................................... 18

A Typical Research Day in December ..................................................... 18

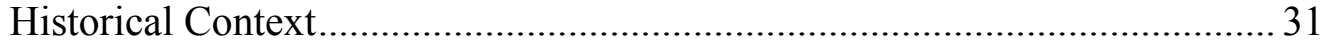

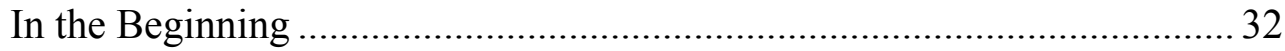

The Socio-Political Context ........................................................................... 33

The Last Illegal Campsite - 17th and Saviour …………………………........35

The Leaf Composting Yard ........................................................................ 41

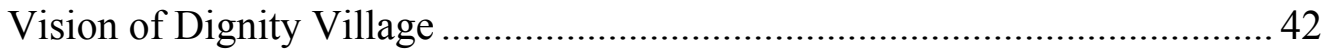

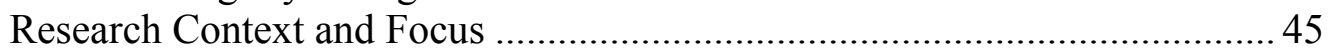

Political Activism ……………………................................................... 47

Collective Identity and External Social Networks …………………….......57

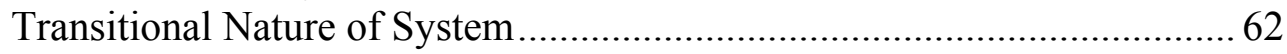

Perceived Power and Inequality ............................................................... 67

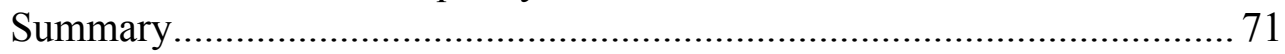

The Lens through Which This Story Unfolds..................................73

My Relationship to Dignity Village ........................................................... 74

Development of my Role and Agenda .................................................... 75

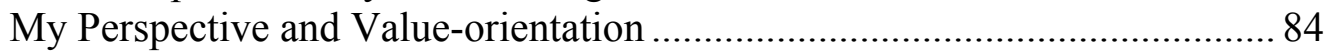

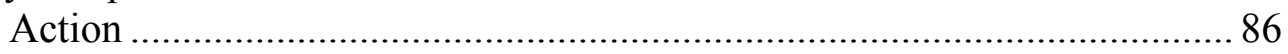

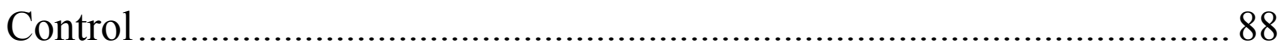

Representation and Authority .............................................................. 91

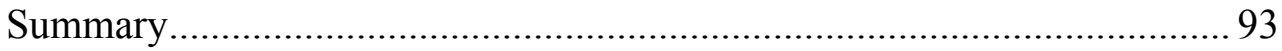


CHAPTER THREE: LITERATURE REVIEW ...............................95

Multiple Perspectives in the Literature..................................96

Individual-Personal Perspective on Homelessness ....................................... 99

Academic Literature from the I-perspective.......................................... 102

Dominant Responses to Homelessness from the I-Perspective................. 103

Societal-Structural Perspective on Homelessness ........................................ 109

View of Academic Literature from the S-perspective............................ 110

Societal Responses to Homelessness from the S-Perspective.................. 114

Community-Contextual Perspective on Homelessness ............................... 119

View of Academic Literature from the C-perspective ........................... 120

View of Societal Responses to Homelessness from the C-Perspective .... 127

Summary and Synthesis of I-S-C Perspectives ...................................... 134

CHAPTER FOUR: A SYSTEMS PERSPECTIVE...........................136

Limitations of Perspectives and Their Suggested Solutions...................137

Dominant I-perspective Limitations ........................................................ 138

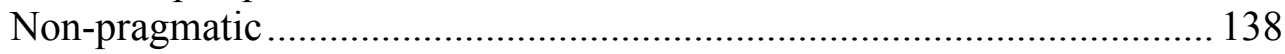

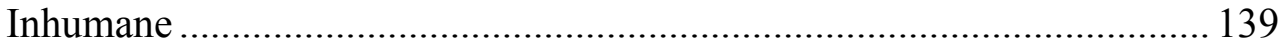

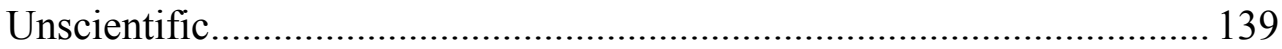

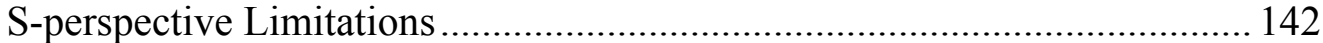

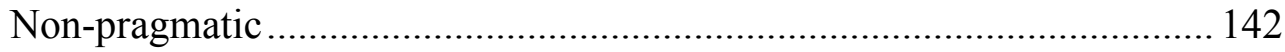

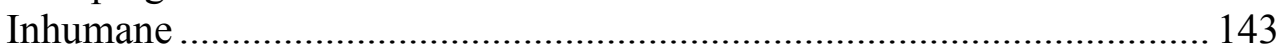

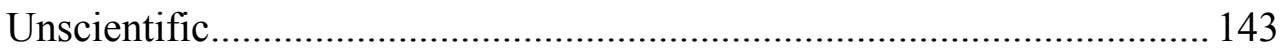

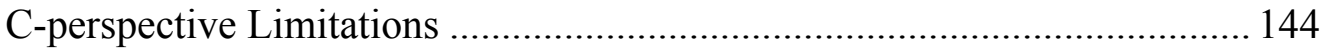

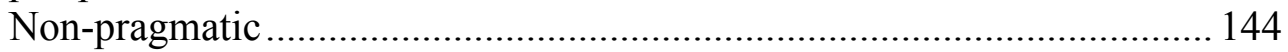

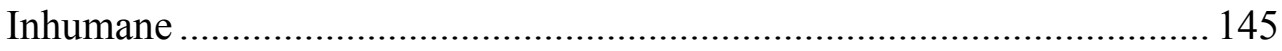

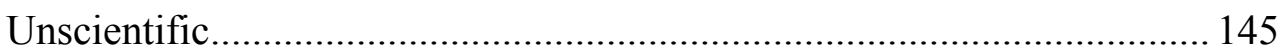

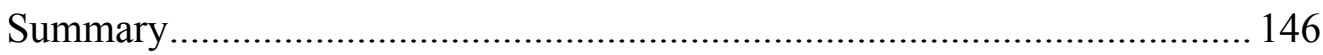

A Dynamic Perspective on Homelessness................................. 147

A Dynamic Pathway out of Homelessness................................................. 147

Survival Needs............................................................................... 149

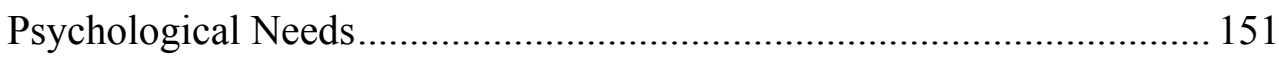

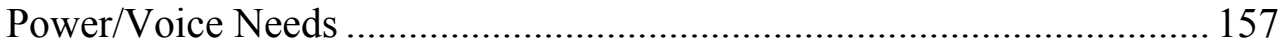

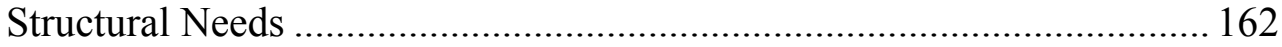

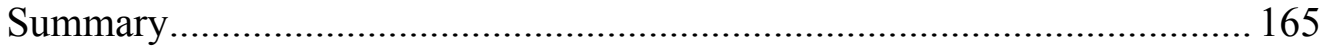

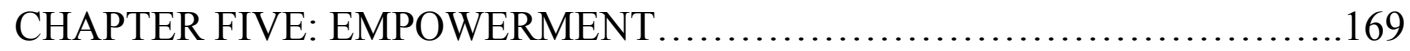

Improving Community Participation and Empowerment....................170

Collaborative Research - Participatory Action Research ........................... 172

Community Empowerment ............................................................... 175

Empowerment in the Research Setting: ................................................. 179

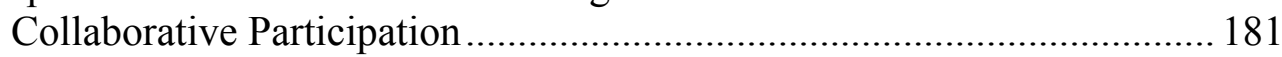

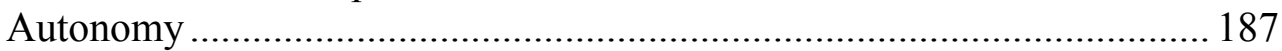

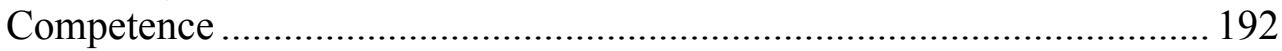

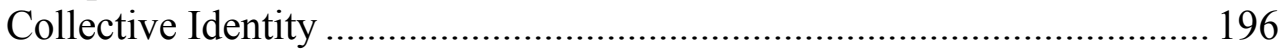




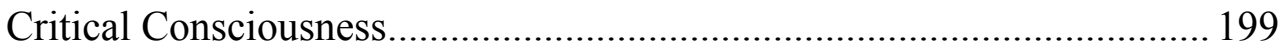

Dynamics among the components.......................................................... 202

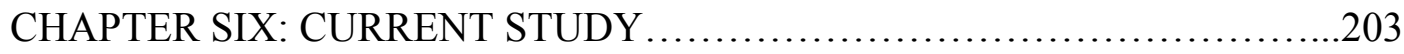

The Research Context and Goals.............................................204

Taking a Step along the Pathway Out of Homelessness ............................... 204

1 - Taking Steps toward Community Empowerment .................................2205

2 - Blockages in the Pathway .................................................................206

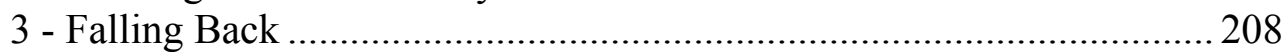

4 - Getting on the Path toward Community Empowerment .......................209

Current Research Focus and Goals.........................................2210

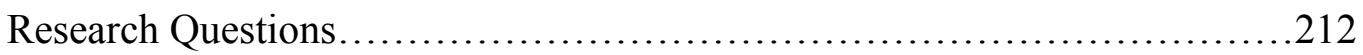

Final Objective: Accessibility of the Research Report.................................. 213

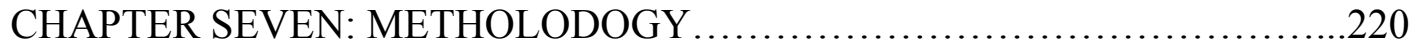

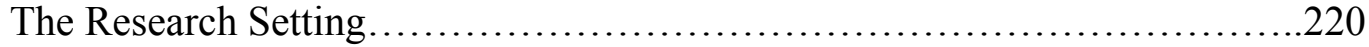

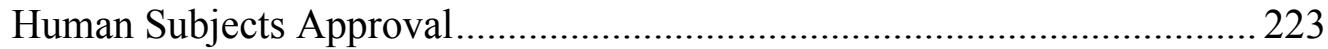

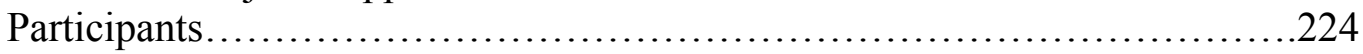

Recruitment - Number of Participants .................................................... 225

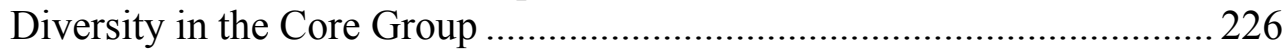

Sub-groups in the Core Group .............................................................. 226

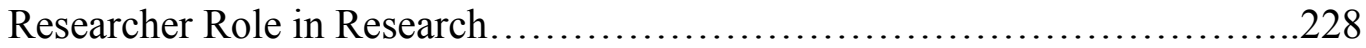

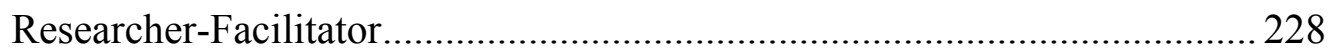

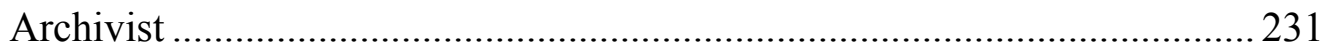

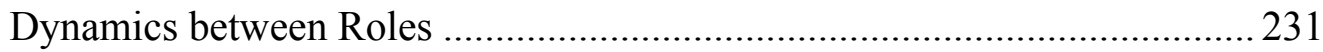

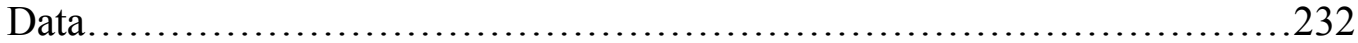

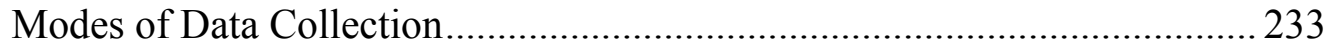

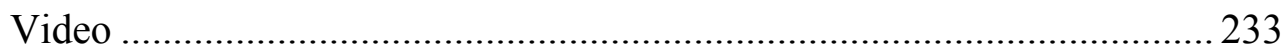

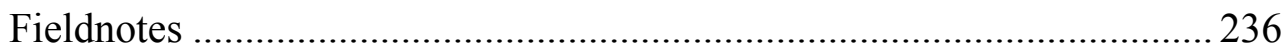

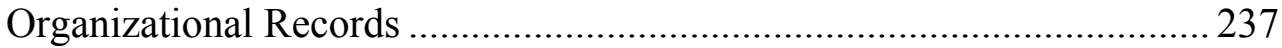

Research Design Features for Quality PAR .................................238

Evaluating the Quality of this Collaborative Research .................................2238

A Rubric of Questions for Reflection on the Quality of Inquiry................ 239

Including Diversity and Multiple Perspectives ......................................... 245

Termination / Sustainability ................................................................... 247

Trustworthiness in Qualitative Research.................................................249

Procedure: Timeline and Steps in the Research............................252

Before Creating the Action Tools: Documenting the Community.................2252

I. Initial Stage: Understanding the Research Context and Goals ............... 252

During: Documenting the Process while Making Action Tools .................... 255

IIa. Beginning the Co-creation of the Action Tool.....................................25

IIb. During the Co-creation of the Action Tools .......................................2.256

IIc. Creating Action Tool 5: Orientation Video ……………………….....259

After Creating the Action Tool: Documenting \& Analyzing ......................... 262

III. Documenting the Community ..................................................... 262 


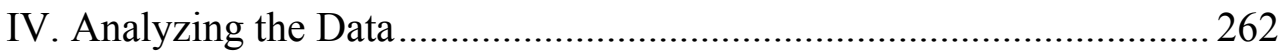

Procedure for Thematic Data Analysis................................................... 263

CHAPTER EIGHT: INTRODUCTION TO VISUAL RESULTS................271

CHAPTER NINE: VISUAL RESULTS .................................272

Committee Feedback on Visual Texts.....................................273

CHAPTER TEN: DISCUSSION...........................................275

Understanding the Power Shift: Implications for Empowerment Theory........276

Time and Change in Empowerment Theory .............................................. 277

A Tipping Point in Empowerment .........................................................283

Group Level in Empowerment Theory......................................................... 292

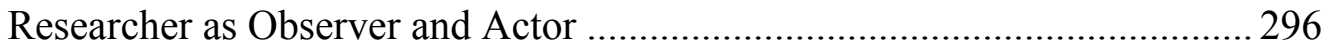

Implications for Practice................................................... 313

Openness to Learning from Others with Different Perspectives.................... 316

Critical Awareness of Self and Interactions with Others .............................. 319

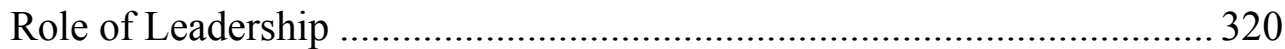

A Focus on Solutions Rather Than on Problems........................................... 320

The Process of Group Learning is as Important as Achieving the Goal ....... 322

Awareness of Participation and Cooperation as a Developmental Process .. 323

Use of Systems Thinking to Identify and Target Multiple Leverage Points. 325

Leadership Structure that Supports Participation and Equity..........................327

Credibility, Limitations, and the Final Report..................................328

Evaluating Credibility and Trustworthiness .................................................329

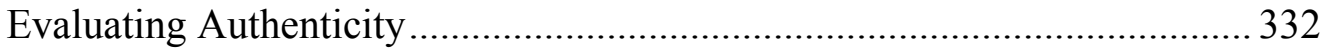

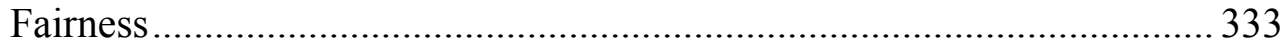

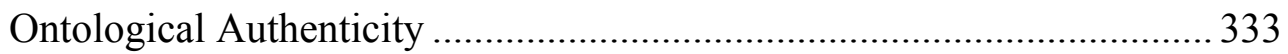

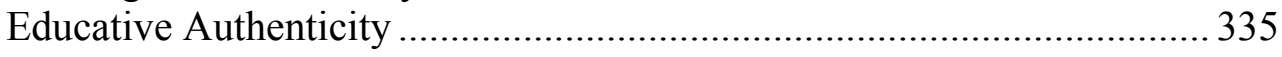

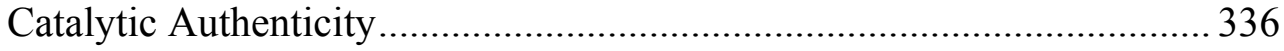

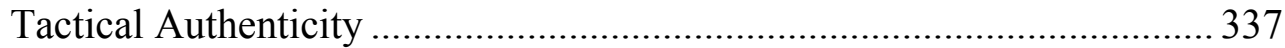

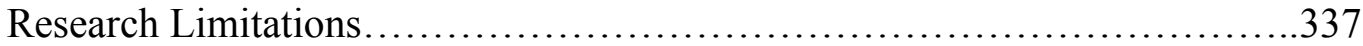

Limitations to Creating a Sustainable Process …………………….............. 338

Unexpected Outcomes of Increasing Core Group Cohesiveness .................... 341

Challenges to Creating a Visual Text Report for Multiple Audiences........... 343

Conclusions and Future Research.............................................347

The Developmental Pathway Model ............................................................ 349

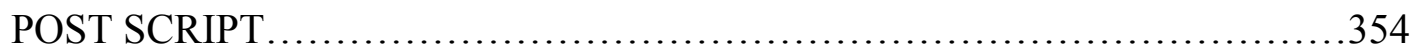

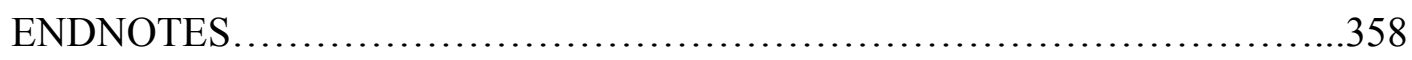

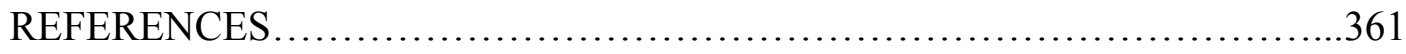

APPENDIX A: PREFACE: GETTING ORIENTED ............................395

APPENDIX B: PRESENTATION OUTLINE FOR RECRUITMENT …........410

APPENDIX C: CONSENT FORMS …..................................412 
APPENDIX D: DIGNITY VILLAGE P.A.R. WORKBOOK ..................417

APPENDIX E: INTERVIEW SCHEDULE .................................473

APPENDIX F: POST-RESEARCH INTERVIEW SCHEDULE ..............474

APPENDIX G: CODING INDEX (THEMES) FOR ANALYSIS ..............475

APPENDIX H: TECHNICAL INSTRUCTIONS FOR PLAYING DVD........480 


\section{LIST OF TABLES}

Table 1. Framework of three main perspectives on homelessness............. 100

Table 2. Sub-group terminology to understand intergroup dynamics..........228 


\section{LIST OF FIGURES}

Figure 1a. Structure of an integrated model of a developmental pathway out of homelessness that incorporates three perspectives. 148

Figure $1 b$. Survival as the first step on the developmental pathway out of homelessness .150

Figure 1c. Psychological crisis as a reaction to encountering obstacles to meeting psychological needs.

Figure 1d. Quality of life as the second step on the developmental pathway out of homelessness

Figure 1e. Power crisis as a reaction to encountering obstacles to meeting power needs 158

Figure 1f. Inclusion in the conversation on homelessness as the third step on the developmental pathway out of homelessness.

Figure 1 . Structural crisis as a reaction to encountering obstacles to meeting structural needs.

Figure $1 \mathrm{~h}$. Reducing power inequalities as the fourth step on the developmental pathway out of homelessness 164

Figure 1i. An integrated model of a developmental pathway out of homelessness 165

Figure 1j. Focus of current research: overcoming blockages in moving from a home-base to an empowered tent city community. 204

Figure 2. System research focus: Levels and attributes .214 
Figure 3. System research focus: Processes.............................215

Figure 4. Timeline and steps in research.............................253

Figure 5. Diagram of process involved in creating action tools...............257

Figure 6a. Screenshot of transcription window of "Shot Log Pro".............263

Figure 6b. Screenshot of coding window in "Shot Log Pro"...................264

Figure 6c. Analysis report sample of attributes over time for group meetings...265

Figure $6 d$. Analysis report sample of attributes over time for interviews........266

Figure 6e. Sample of thematic analysis report...........................267

Figure 7. Possible direction of change over time for empowerment..........280

Figure 8. Dynamic illustration of state of community empowerment..........280

Figure 9. Illustration of tipping point...............................283

Figure 10a. Levels and processes of research interest......................293

Figure 10b. Processes associated with multiple levels of empowerment........295

Figure 10c. Attributes associated with multiple levels of empowerment........296

Figure 10d. Perceiving role in empowerment theory........................298 


\section{PREFACE}

Due to formatting requirements, the preface is located at the end of the document as Appendix A. The preface provides a guide to the participatory action research with Dignity Village, including a fact sheet about Dignity Village, photos of coresearchers who participated in the research, and an historical timeline of major milestones for Dignity Village and the research project. The preface is particularly useful for getting oriented to the research and the co-researchers who are featured in the Visual Results section of this report. 


\section{CHAPTER ONE}

\section{INTRODUCTION: THE SHORTER STORY}

We see the world the way we do, not because that is the way it is, but because we have these ways of seeing.

- Ludwig Wittgenstein

Homelessness continues to rise in the United States, and only worsens with budget cuts for human services occurring across the country. Over the past two decades, the national socio-political response to homelessness has generally been characterized by short-term emergency programs that do not attempt to address the root causes of the problem. With the number of homeless persons increasing rather than decreasing, these short-term crisis shelters have become a permanent yet ineffective system of managing the problem. In many cities in the U.S., the existing shelter system has the capacity to help less than half the homeless population on any given night. In Portland, Oregon, for example, at least 1,500 people will not find space in the shelters and will sleep on the streets every night (U.S. Conference of Mayors [UCM], 2001; Multnomah County Citizen’s Commission on Homelessness Report [MCHR], 2004).

For those who are unable to find shelter space, the maze of legislation governing the use of public spaces results in an additional and often insurmountable burden. In many cities, it is a crime to sleep on the streets; police 
shuffle homeless people from one doorway to another, sometimes fining and arresting them for loitering, sleeping, and sitting in outdoor public places in urban centers. Many cities have rules against sleeping in vehicles or even against sitting in a public space with a blanket. Such legislation creates no alternatives for unhoused individuals to obtain a night's rest when shelter space is unavailable.

Furthermore, even when shelter beds are available, they are often not considered a viable or safe alternative for many people. The prevalent model of single-sex, warehouse-style mass shelters reinforces feelings of helplessness and a lack of dignity by regulating people's every behavior, from what they eat to when they sleep, providing no sense of personal freedom. Shelters cannot be used as a "home-base," either logistically or as a source of emotional support. Therefore, most shelters are merely a stopgap measure for fighting homelessness. Now more than ever, there is an urgent need for cost-efficient, transitional housing alternatives to the current shelter system.

As a result of this pressing need, there has been rising unrest among disenfranchised persons longing for safety, empowerment, and community. In the national tent city social movement, people experiencing homelessness have taken action to build their own affordable housing despite resistance by local governments and communities. Some of the resistance is rooted in a persistent dominant belief in society at large that people experience homelessness because they have done something "wrong" to deserve it. This belief is pervasive throughout educational 
institutions and the academic literature on homelessness. In most research on homelessness, particularly by psychologists, researchers have focused primarily on individual problems as causes of homelessness, and not on structural inequalities inherent in our socio-political system. However, since individuals continually define and redefine their identity based on their interactions with other members of their community (Berger \& Luckman, 1967), the physical stressors impacting homeless persons are compounded by feelings of stigma and alienation from a variety of communities. People experiencing homelessness often suffer a loss of self-worth, a loss of hope, and a sense of helplessness. The tent city social movement addresses these issues of discrimination and alienation as well as the lack of available housing by empowering individuals to form organized and supportive communities of alternative transitional housing.

\section{Research Setting}

It was in response to this social need in Portland that the first tents of Dignity Village were pitched. In the winter of 2000, police chased a small group of homeless people from place to place in downtown Portland as they searched for a haven in which to exist and to build their own housing, free of harassment. The tent city community of Dignity Village developed from these acts of resistance into a registered 501(c)(3) non-profit organization providing transitional housing for homeless people by homeless people themselves, with a mission to foster community and self-empowerment while helping themselves and others transition 
from the street to stable housing. Unlike typical shelters, couples and pets are welcome at Dignity Village, and community is fostered democratically through self-governance and Village participation, referred to as "sweat equity" by Villagers.

This tent-city model addresses an important social need and offers one component of a community-based solution to homelessness. With community support, contact information, hygiene facilities, and a full-night's sleep, people living in a tented community can apply for work, finish school, regain custody of their children, and kick their addictions. It also gives them a staging point and bargaining power to organize for real gains, such as changing the way homelessness is perceived and managed by social service industries, local governments, and communities. The intent of this research is aligned with the larger goal of Dignity Village to provide conditions and processes that allow unhoused people to organize for long-term social change. The current research will center on mobilizing the community of Dignity Village as a step toward obtaining more social power.

State of Dignity Village at Beginning of Research (late 2005)

Dignity Village demonstrates how a self-organized community can give people room to hope and room to organize for real change. However, effective social change requires more than just long-term planning; it calls for an empowered and well-organized community. As Dignity Village has developed and grown in its first five years, challenges typical to many volunteer organizations have arisen. A 
general state of disaffection and apathy has slowly settled in and replaced much of the common vision and intense energy that once existed and helped to sustain the struggle to build Dignity Village into its own powerful and legally legitimate entity. Participation in Village self-governance has dwindled to levels lower than ever before. It is not uncommon in organizations to find decreased participation in collective action once individuals find a solution to their most pressing problems (Casanova \& Blackburn, 1996; Lara \& Molina, 1997). For some people at Dignity Village, the struggle for shelter was a personal survival strategy and not necessarily an activity to achieve greater visions of democracy as an end in itself. Furthermore, the transitional nature of Dignity Village's members makes it even more challenging to maintain active participation, shared vision and goals.

Without fundamental change, many Villagers anticipated a gloomy fate for Dignity Village, that of short-lived success. In 2004, about a year prior to the beginning of the research, in an effort to boost participation, the organization began to more strictly enforce a mandatory rule for residents to participate and instituted a system to track the number of hours worked in Village operations by each of its residents. As a result, many residents worked their minimum hours but also withdrew even further from voluntary self-governance activities. Some residents noted that mandatory participation had the unfortunate effect of recreating the power dynamic commonly found in social service agencies serving homeless persons, in which the community becomes divided into rule-enforcers and rule- 
obeyers. Observing the complexities in solving this participation problem, Villagers began seeking alternative ways of promoting participation.

\section{Current Study}

Before the beginning of this study, I had nearly five years of experience working in partnership with Dignity Village on participatory filmmaking projects. As one of Dignity Village's supporters and a media partner, I was invited to participate in brainstorming sessions with Villagers around the issue of participation. An innovative idea emerged from these brainstorming sessions: to collaboratively develop a video-based, research-driven action tool to mobilize and re-energize participation of residents within the Dignity Village community. Villagers envisioned the action tool as an orientation video developed from their analysis of their own organizational archives, consisting of historical video footage, photographs, and print materials collected over the past five years in collaboration with us (their media partners through Kwamba Productions). Therefore, the goal of this research was to collaboratively develop a video-based "action tool" that would act as a catalyst for re-establishing a sense of community, engagement, and cooperation at Dignity Village.

This research was intended to address the state of disaffection within Dignity Village using community-based participatory action research. The federal Agency for Healthcare Research and Quality defines community-based participatory action research as "a collaborative research approach that is designed 
to ensure and establish structures for participation by communities affected by the issue being studied...to improve the health and well-being through taking action, including social change" (Viswanathan et al., 2004, p. 3). Community-based action research is a collaborative approach to investigation that seeks to engage participants as equal and full research partners in the research process (Stringer, 1999). This research approach is based on the recognition that participants are researchers themselves in pursuit of answers to the questions of their daily struggle and survival (Tandon, 1988). The research is seen not only as a process of creating knowledge, but also as a catalyst for developing consciousness and mobilizing people for action.

The study used an established process of participatory filmmaking that Village residents and the researcher had utilized in co-creating a documentary about Dignity Village. The dissertation was built upon this participatory process, taking a community-based action research approach that fostered empowerment, promoted democratic participation and a sense of community among Dignity Village residents. The research procedures focused on process with an end goal of a product, which I refer to as an "action tool." The action tool was developed through a democratic process by which a group of Dignity Village residents met and planned research activities together, with the goal of creating an effective and context-relevant tool for social change within Dignity Village. The Village planned to use the action tool for community organizing activities that included orienting 
new residents and members into the community, and motivating longer-term members to participate in the shared vision.

The goal of the research was for participants to learn new skills through engaging in action by developing a video-based action tool as a lever for organizational change in Dignity Village, and then to document whether these skills and aligned efforts transcended the research experience to enhance participation in other activities within the Village community. The research objectives followed a cyclical process by which change and understanding were pursued within a process of action and critical reflection (Dick, 2001). The data were collected by documenting observations through field notes and video-recording individuals' personal accounts, social dynamics and the quality of their engagement over time in both the research process and in the broader Dignity Village community. This video and written record of the research process were added to the Village archives to be used by Villagers in sustaining the action research process around future organizational issues with the hope of increasing participants' own competence and power to effectively solve future problems within Dignity Village.

This study was organized around four research questions that attempt to explore the quality and processes of the research as well as its impact on individual participants and on the community as a whole. 
The four research questions were as follows:

1. Before co-creating the action tool: What were the state and dynamics in the community that led to the concern that Villagers were becoming disaffected?

2. During the creation of the action tool: How did participants work together and include others in the process of creating an action tool?

2a. How did co-researchers participate and work together?

2b. How did co-researchers and community consultants work together?

3. During the creation of the action tool: How did this ongoing research process interact with the community?

3a. How did participating in the research processes impact coresearchers' quality of participation in other community activities?

3b. How did these research processes carry over into the community and impact the overall quality of participation and empowering processes at the community level?

4. After creating the action tool: What were the state and dynamics in the community, and how did people perceive them? 


\section{Style of Dissertation}

A founder of action research, Kurt Lewin (1951) operated with the view that social research is both scientific and socially engaged: "if you want truly to understand something, try to change it." In keeping with the underlying principles of the traditions and philosophy of community-based participatory action research (PAR) described above, I chose to present this research with Dignity Village in ways that emphasize the collaborative nature of this research. In constructing the research report, I deliberately chose the format, structure, voice, style, and orientation of this dissertation to keep in mind the accessibility and usefulness of the research to a broader range of audiences. The specific intended audiences for this report include both academics from multiple perspectives in understanding and researching homelessness, and the non-academic co-researchers and participants within the community of Dignity Village. In addition, the report addresses specific academic requirements relating to the fulfillment of a doctoral degree at Portland State University.

This dissertation takes a narrative form, typical of PAR, with detailed discussions of processes that the group utilized in generating the knowledge that is being communicated and acted on. The style of writing, or voice, is often an area of debate among qualitative researchers. How much should the researcher's voice dominate as the authority or expert in telling the story and interpreting the 
experiences of the participants? Should the researcher give up voice or authority to participants?

The voice, style, and orientation of this dissertation follow the collaborative nature of the research and the critique that researchers already have enough expert authority in generating knowledge. In the results section of this report, the voices of my co-researchers were pushed to the forefront, a place of authority they have often been denied. Many researchers using PAR argue that it is time for researchers to step down from the expert role and move to the margins in ways that may liberate others (Chase, 2005). With this goal of empowerment and liberation, I have positioned my voice in more of a supportive role that gives center stage to the community of voices (co-researchers), and at the same time, has allowed my voice to be present in a way that illustrates my active role as a participant in the research as well as editor and author in creating the texts. This has called for a delicate balance among multiple voices, illustrating the collaborative spirit of this research.

Within the field of PAR, many researchers are urging others to use forms of research reports that are more consistent with the philosophical underpinnings of the PAR research approach. An appropriate report style and format would be one that raises an awareness and provides a critique of the power dynamic between the researcher and the researched (Finley, 2005). Finley (2005) emphasizes that "... what is called for is expressive research that portrays the 
multidimensionality of human life as compared with truth finding, proofs, and conclusivity in traditional social science" (p. 683). It is in this context that the use of digital video in the form of "visual texts" as chapters is appropriate as an alternative report format for this PAR dissertation. Visual texts capture the variations in human experience in an effort to expand the range of understanding and voices heard by the reader, providing an emotional immediacy to the plurality of voices, permitting readers to hear the exact words of the participants and researcher, and their pauses, lapses, stops, and emotional tones (McCall, 2000). As Finley (2005) notes, "a [visual] text redirects attention to the process of doing research rather than looking for truth, answers, and expert knowledge in a final report of findings from the researcher" (p. 689).

\section{Structure of Dissertation}

This dissertation is divided into ten chapters, with eight chapters presented in written form (written text) and two chapters presented visually (visual text). The dissertation structure and chapters are organized using the systems idea of multiple perspectives. The idea of multiple perspectives is that each person interprets the world from their own unique perspective. Each perspective is valuable because "each perspective yields insights not attainable with the others," which together illuminate an alternative viewpoint, a multidimensional view, of the phenomena under investigation (Linstone, 1999, p. 33). A perspective can be understood as a way of seeing the world through the lens of assumptions, 
concepts, values, and practices. A perspective is not just unique to an individual; it can also be understood as a shared way of knowing through a common set of concerns and a common relationship to other actors, roles, and contexts. This dissertation presents the various shared perspectives on our understanding and response to homelessness as a nation and as individual citizens.

Because the organization of this report's narrative structure is different than traditional research reports, I have used traditional terms at the end of chapter titles for easier accessibility and readability for academic readers. Brief descriptions of the chapters, both written and visual texts, are presented in the next section.

\section{Written Text (manuscript)}

Chapter two frames the research from my perspective as researcherfacilitator and long-time supporter of Dignity Village. In this chapter, I describe the community setting and historical context of the problem to be addressed in this research. I also describe my own lens or perspective through which the research was framed, including a discussion of the values and philosophy inherent in this research approach.

Chapter three reviews and deconstructs the multiple perspectives in the literature on homelessness, illustrating the many sides of the story, and the sociopolitical context in which Dignity Village and the research was embedded. 
Chapter four synthesizes the multiple perspectives on homelessness in the literature from a systems perspective, discussing limitations of each in solving homelessness, and then describing a pathway out of homelessness that incorporates the best insights of multiple perspectives in the U.S. literature.

In chapter five, I describe the processes through which our goal of community empowerment, and ultimately of increased social power, might emerge. This section reviews the literature on empowerment and explores ways in which communities and community partners might promote empowerment in research processes, while at the same time fostering a critical awareness of issues of power and disempowering processes within collaborative research.

Chapter six provides a summary of the current study, defining the goals, objectives and questions of this collaborative research study.

Chapter seven provides a detailed description of the research methodology, data collection, data analysis plan, and specific design features for assessing the quality of the research.

Chapters eight and nine are visual texts (see below).

Chapter ten is the last section of written text. For chapter ten, I discuss the research findings within the context of the multiple perspectives in the literature and solutions for homelessness, the practical implications of the findings, the strengths and limitations of the research processes, and directions for future action. 
Visual Text (DVD)

The DVD portion of this dissertation includes two visual text chapters (Chapter eight "introduction to the results" and chapter nine "results") as well as the Dignity Village video-based action tool. The DVD can be viewed on a DVD player or on computers (Mac or Windows) with a DVD drive.

Chapter eight utilizes video to provide a more accessible overview of the research for my community partner in this research, Dignity Village. This chapter includes three sections: (1) a brief introduction to the research and its theoretical framework, (2) the research process and methodology used during the research and (3) a description of the research questions in relation to time period in the research (before, during and after the creation of the orientation video) and research level (community and core group levels).

In chapter nine, I present the "findings" of this research within the multiple perspectives and voices of the community that address my research questions. I narrate this visual text to describe my research process, my transformation and reflections during the research, and my interpretation of the findings in relation to the research questions. In this visual text, I use video recordings of (a) group research dynamics and dialogue, (b) individual interviews, and (c) out-takes of community life, social interactions, and community meetings to illustrate the processes and outcomes of this participatory research. This chapter presents a coherent and rich account of participants' experience and interpretation of events, 
Participatory Action Research

Chapter One: Introduction 16

and provides an empathetic understanding of participants' lived experiences of the issues investigated. 


\section{CHAPTER TWO}

\section{THE LONGER STORY: FRAMING THE RESEARCH}

The homeless who come before you in your role as a social service worker are subservient and shallow by design. In and out as fast as possible with as much mercy as we can get.

Back on the street we are fierce and independent.

$$
\text { Our sense razor sharp. }
$$

Our minds wide open for possibility.

Our wits refined. It takes enormous reserves of wherewithall to get through the day.

Tough. Fearless. Resourceful.

Cunning if need be, but wise.

Smart enough to run our own camp.

Wise enough to do it right.

We just need the chance.

It is within your power to offer us this:

the chance to control our own camp.

"T/S" written by Randy Dolinger

(street roots, February 1, 2005)

An important aspect of participatory action research is its emphasis on collaboration. The community is at the root of this collaborative research, and it is therefore crucial to begin with an understanding of the context of Dignity Village. With this in mind, this chapter provides a narrative-form introduction to Dignity Village to bring to the forefront the community context that gave birth to the research as well as to the state of disaffection within the community.

The first part of this chapter provides a rich description of a "typical" day in the community, describing the physical surroundings and interactions between 
Villagers and research partners. It also includes a brief description of the history and political context in which Dignity Village formed as a community, as well as the dynamics that may have led to the research context.

As collaborative research, many voices and perspectives worked together to generate this research process and action tool, but in this dissertation, it is my lens that selected and created the presentation of these voices to tell the story. Although my goal was to provide a lens that would illuminate the multidimensional views of the stories and voices in this research narrative, my lens should be considered only one way of seeing and telling this story. Therefore, the final section of this chapter provides a frame of reference for readers to better understand my voice and perspective, my relationship to Dignity Village, and how it may have shaped this research narrative.

\section{Entering the Research Setting}

\section{A Typical Research Day in December}

I park the badly-faded red Ford Escort on the side of the road across from the prison. I open the trunk while Wendy quickly grabs the long piece of bamboo in the trunk and jams it between the car body and trunk to hold up the door, a routine we've developed with this old car. We grab all of our bags of equipment, throwing them over our shoulders and strapping bags to our backs. Wendy carries a small backpack full of gloves, hats, scarves, a couple peanut butter and jelly sandwiches and a bottle of water, and a heavy large bag full of equipment and the 12 volt battery 
to charge our portable light set. I carry a backpack with the camera and throw the tripod bag over my shoulder.

It is an unusually cold, dry and sunny December morning in Oregon. We walk down the road and across the bridge over the slough toward the driveway of Dignity Village, planted in the middle of the City of Portland's leaf-composting yard, and snuggled up against the Columbia River Correctional Institute. Chain-linked fence surrounds the clusters of tents and wooden-framed communal areas huddled on the asphalt lot, with the smell of rotting leaves moldering in the air. The cold wind whips against me and I quickly zip my fleece up to the top of the zipper.

Ivan is sitting on a cement block at the end of the driveway near the road. He is wearing a pleasant smile and an Irish looking hat with small flaps folded up against the sides that form a point in the front of the hat. He is in full multi-colors, head to toe, sporting bright red and yellow leather shoes and an orange security vest with "Dignity Village security" handwritten on the back in faded black permanent marker. He sits with legs crossed and hands resting delicately on his knee. As he smokes a hand-rolled cigarette held with hemostats, he notices us. His only change in posture is a slight nod of his head and a wider smile. "How are you?" he says in his unusual accent, his words slippery in a song of deep-throated thick sounds overlaid with a Costa Rican accent. Wendy and I reply to Ivan, almost in unison, “Good, how are you?" "Good, good,” Ivan says. He cocks his head slightly and rolls his right wrist, waving his hand in a fluid and delicate circular motion as he talks. 
He says something like, "Men think they come from trees ... you see no woman as president. It is bad (shaking his head). Men forget that they have a mother and woman gave birth to them." It always takes me a few minutes of conversation to warm up to hearing where the words begin and end in his long and smooth sounding statements. Wendy and I listen and nod our heads in agreement. I hear something banging against the dumpster, and turn my head to see what I'm hearing.

Tami smiles and gives me a quick swipe of a wave. She is standing in front of a shopping cart with a large cardboard box full of loaves of bread. Bending over the cart, she picks up a couple of moldy loaves of bread by their plastic bags and throws them over her shoulder into the dumpster while remaining bent over the cart. I am half-watching while still listening to Ivan. I hear Wendy say something to Ivan, but I'm not paying attention, distracted by the activity. I turn to Tami and ask her if she needs any help. She smiles and says "No, just getting the commons area ready for Kwamba." I am a bit surprised that she remembers our company name, since she's lived at the Village for a shorter period of time. I say in a questioning and surprised tone, "Oh?" Tami grins even more and gives a short explosive laugh (her typical laugh regardless of the situation), and then says "Yeah."

Tim approaches us while we are finishing our conversations with Ivan and Tami. He slowly moves close to Wendy, and drapes his arm around her shoulders. "You cut your hair. Who did this? It's short." Wendy, shaking her head, "Yeah, I know. She cut it short. I didn't ask her to...but oh well." We begin to walk together 
down the driveway away from the Security Shack, an unpainted shack-like structure with two small windows and a short ramp up to the padlocked door. The building sits near the road at the end of the driveway, and is used by the entire community, as every person is required to work at least two hours per week on a security shift. The inside of the shack is plain and neat. A desk and two chairs sit on a plywood floor, and a calendar and clock hang on the walls.

"You know, it's even shorter than my hair," Tim smiles and continues to tease Wendy by lifting up his long gray ponytail and pulling it close to Wendy's head to compare. After a quick laugh, Tim, with his arm draped over Wendy's shoulders, says to both of us, "Well, they said they can't run any of the tests until the end of January." I respond, "Not till January? You're trying to get in to see a specialist, huh?" "Yeah... (he rolls his eyes)... they told me they're going to put the scope down my esophagus first and then the other end." We laugh. I am remembering Tim's story he told us last week about his last colonoscopy experience. Tim, “Yeah, I know (shaking his head). I told her, 'well that's better than what they did last time. They did the scope up the rear and then the esophagus and I was wondering whether it was the same scope.' She said they have different scopes, though. The one that goes down the throat is smaller." We all laugh as we walk together down the driveway toward the open gate. On the right side of the driveway, old and wet lumber and other pieces of wood are half-way stacked, with a short row of 3-4 cars parked in diagonals facing the chain link fence surrounding the 
village. There is a grassy area on the left of the driveway with a steep drop to the slough where they often spot urban wildlife like raccoons, beaver, nutria, and ducks. Right behind the open gate and near the fence are a row of three Port-o-lets, a green, an orange and a brown one.

I point to the Port-o-lets and we stop. I set the equipment on the ground and step into the brown one. I almost always pick the brown one since the door on the green one doesn't lock without serious force on the sliding plastic thing that latches the door from the inside (and then you get stuck getting out). The orange one is fine other than having a warped plastic door, bent outward on the lower half leaving a gaping inch or so where without any real effort I can watch the people as they walk by the toilet and in and out the gate of the Village. Wendy and Tim continue to chat while I do my routine pit stop after our hour or so ride from home. Sundays are probably the least desirable days to use the Port-o-lets since it is the day before they are cleaned, but I'm used to it and don't mind. It gives you a real and practical sense of the word "community" when you open the toilet lid and, inadvertently, I also get a sense of the health of the Village every Sunday morning.

Tim leaves us at the Port-o-lets to go back to his work in the office (he is the Treasurer and Outreach Coordinator). The Village officers each have a computer and workstation in a rusty single-wide trailer that was left there by the City of Portland. A tiny 6'x8' area in the front part of the trailer is general community space with two older computers hooked to the web and a cheap, beat-up phone on the 
wall. Villagers built a covered porch, stairs and a handicap-access ramp at the entrance to the office trailer. The ramp attaches to another set of ramps that lead to the showers and sink. Two large propane canisters that heat the showers are padlocked behind a wire mesh door and enclosure. A two-story, unused and colorfully painted chicken coop built and given to the Village by elementary school students is stored to the side of the trailer.

We walk toward the communal area and a short man with a baseball cap (Sue's partner Dex) walks by and says hello to us, "How are you gals today?" Wendy, "Fine, how are you?" "Alright," he says and smiles. Alan is walking behind him and slows his pace to talk. He has a tall, thin muscular build, and his nearly shoulder length strawberry blonde hair is blowing in his face with the gusts of wind. He looks like he's not feeling well. I ask him, “How are you? Are you feeling okay?" "Not well. About half of us in here caught this bug...Welcome! (throwing both arms up to exaggerate the welcome). Be careful not to catch it." He passes us as he walks toward the Port-o-lets.

The wind is gusting strongly and I hear the American flag snapping above, attached to the emblematic orange and green latticed three-legged tower that once held the yellow Dignity Village flag. Two years ago, during a record-breaking ice storm, the flag fell frozen to the ground from 25 feet above and shattered into pieces. The American flag was put up afterwards, and the Dignity Village flag never replaced. 
We head down the middle of the Village along the area known as the fire lane. We pass the bus which is parked near the office trailer. The front of the bus faces the gate, with the route destination sign above the front window that says "Dignity Village" in block letters. There is a For Sale sign on the dash with "make an offer" handwritten on the bottom part of the sign. The bus was donated to the Village by a supporter who runs an airport bus company. The bus has never left the Village, although it has been used in many creative ways. When it gets cold during winter, people would scrounge up money for fuel and start the engine and sit in the bus to get warm. Very few Villagers have clean driving records with a current license and the practicalities of who drives, where and when, along with the cost of insurance and gas led to their decision to use its comfortable space as a library and meeting area, and during the winter, a dormitory for guests needing to get off the streets and out of the weather for a few nights. Next to the bus are stacks of lumber for building, placed around a couple of old trailers and shacks that store donations and building materials during the rainy season.

“Hey, how are you guys?” Dog Dave with his gentle smile walks toward us from the office, looking as if he is heading toward the commons area too. When he gets closer, we walk side by side. "We're doing alright, how about you?" I say. He offers us a saltine cracker out of a newly opened package. "Oh, thanks, I'll take one." I take one cracker out of the full package and take a bite. Dog Dave, chewing the cracker that's in his mouth, says, "Nice stale crackers, huh?" I look at him and 
smile. "Yeah, I noticed." We walk beneath the orange leg of the tower to open the door to the commons area, past the life-size yellow fiberglass cow with crows perched on its back that has been at the Village since the national Kows for Kids fundraising campaign that ended a few years ago.

We enter the main part of the commons area, an open and round space punctuated by $2 \times 4$ posts and trusses holding up the raised dome ceiling with clear plastic tarp for the skylight. The octagonal structure arches over about 500 square feet with several sections of the walls made up of a patchwork of windows reaching from floor to ceiling. A row of faucets lines the back near the entrance; the water drains onto the asphalt ground, pools in the back and slowly drains out of the building. A shopping cart near the faucets overflows with expired Hostess Cupcakes, Twinkies, Hohos and Snowballs, a never-ending supply regularly donated to the Village. We have joked about using the boundless supply of the aged gooey preservative-full treats as one of their sustainable building materials, but we question whether it really fits within the Village's eco-friendly mission.

A row of beat-up old tables extends the length of the back wall, holding a coffeemaker and food donations of sandwiches, bread, fruit and other items depending on the day. Christmas decorations and orange and yellow extension cords line the posts and trusses throughout the center area. Eclectic styles of worn-out chairs and couches face a TV in rows that take up nearly all of the central space. End tables holding vases with artificial flowers and a few of the chairs cover large 
holes in the pressboard floor that were either chewed out by rats or broken through by past residents who fell through the floor as sections became soft from age and wet feet. The atmosphere is a bit messy and worn in its appearance, but also rather warm and cozy and full of community life with sounds of commercials and football announcers on the television, the ebb and flow of many conversations, the crackle and pop of the fire in the woodstove, and warm smells of toast and fried potatoes cooking on the top of the woodstove mixed with the acrid smell of cigarette smoke, as nearly everyone present is constantly rolling cigarettes and puffing out endless clouds of dense unfiltered smoke. The woodstove is spitting and crackling as Randy throws wood on the fire. In this relatively spacious building, people mostly congregate close to the woodstove. It has been cold, below freezing, and it's the only place that has heat in the Village (except for the small area in the office). The fire is blazing, yet if you walk only a couple of feet away from the stove, you feel drafts of cold air, just one of the reasons why the building is called the "white elephant." With its beautiful architectural arches, tall dome ceiling and many windows, the building has the character and mood of something earthy and organic. The designer and builder of the structure, an outside supporter and architect, put his heart and sweat into the work, focusing on his creation. He designed for community, but not for the community in the design, overlooking the importance of including (or failing to include) the Village as an equal partner in its design. 
We set our bags down behind the couch out of the way, and walk over to the woodstove where Dog Dave and Gaye are sitting. Travis is standing behind the stove holding his hands close to its surface. "Good morning, Hendy and Weather," Gaye says with a smile. I smile, remembering the day when Jack got tongue-tied and called us Hendy and Weather the whole day. Since then, it stuck as a community joke.

Someone stops Wendy and asks her a question about a cat (Wendy is a veterinarian). I stand close to the woodstove and stick my hands over the top to feel the warmth. "Man, it's cold and windy out there," I announce. "Yeah, it is," Gaye says matter-of-factly as she rubs her knees with the palms of her hands. After making my weather announcements, I always feel pretty silly about it. It often just slips out of mouth, probably because I'm not used to being exposed to the elements for more than five minutes at a time, jumping from building to building on campus or from car to warm building. I also bring it up to communicate that I recognize how much they are dealing with, just with weather alone. The Villagers typically shrug and say "it's not too bad," particularly the men at the Village. Is it that they live in the elements every day so it's not a focus but is instead just a backdrop in their lives? It's amazingly cold out there, but I always feel whiny and weak after bringing it up like it's a topic of conversation. I remember when Wendy and I stayed three nights at the Village about two years ago during a cold and wet December. We were filming the Village elections. I remember how challenging it was for me to stay 
focused on work. Simply picking up the camera became an immensely tiring task. Sleeping on someone's mattress in the rat-infested room off the commons area, we could only get warm and dry off a bit in front of the fire going in the woodstove. By the third day, I was exhausted and felt that it took enormous energy to pick up the camera when all I wanted to do was just sit by the fire. I was cold, wet, and miserable, and I realized how difficult it would be to do more than just survive under these circumstances.

It is a Sunday afternoon, and so many guys are sitting in the living room or standing near the woodstove, watching football on TV. Jon is half-laying on the couch in the back playing with Bones, an orange and white short-haired male cat adopted by Jon, his father Paul, and Ken when the cat was left by his owners about six months ago. Bones walks about 10 feet away from Jon and then stops and sits. Jon says sweetly, “Hey Bones...my little kitty.” As Jon calls for him, Bones doesn't turn around, but remains still with only his ears moving to a half-cocked position as if he is thinking "I hear you, but I'm not listening." "Bonesss....come back here. Sweet little kitty....come here." I hear snoring and look over to Bob who is sitting in a chair in the middle of the room, with his hoodie pulled over his head and almost over his eyes. Josh chants and screams at the TV, pointing out the poor plays of the football game.

Tim enters the room and walks over to us. "So are you gals going to do interviews this morning?" "We'd like to," I say. I stick my hands out near the stove 
again to warm them. Dog Dave looks up and holds up his package of saltines toward me. "Want some more?" slightly grinning. "No thanks." I smile. "They were actually better and less stale when I got to the middle of the package." Tim, "Who do you want to interview?" "I thought I'd ask Tami since she seemed interested in it last week," I say. "Let me go find her and see." Tim says, "She was out by the trailer earlier."

As I walk out the door, I hear a plane roaring overhead from the PDX airport, only a mile or so away. I turn right and walk past the cow to check for Tami at her tent. Unique shapes and colors of houses surround Tami's small tent covered by black tarp nailed to a wooden triangular shaped frame. The houses vary in style, much more so than in typical neighborhoods. Adorable warm and uniquely painted and adorned gingerbread-like houses are slowly replacing most of the older shanty-like structures that were themselves a step up from the Villagers' beginnings in tents. Textured with an adobe exterior, lapped siding or paint, the houses also vary in their configurations; some are tall with a sharply slanted roof and windows reaching to the top, another has a dormer with a sun-window over its roof, others have different styles of porches or decks and roof angles, but all are about 125 square feet and raised on platforms two feet high to protect them from pooling water and rat infestations.

I open the door to the office, and see Ken checking his email on the computer. “Hey Ken, have you seen Tami?" Ken, “No hon, I haven’t seen her.” I 
close the door and see her walking past the Port-o-lets by the garden. I call out, "Hey Tami!" She stops and waits for me. "I was wondering two things. The first thing is whether you'd like to be interviewed today (I notice her curl her lip slightly)...or we could also do it later." Tami, "How about in a week?" "Sure, okay.” Tami, “Yeah, in a week...this week isn't good for me. I'm working on staying positive." "Okay, no problem, we can do it next week, if you'd like. I also wanted to ask if I could use the key to the Chilipad (this is the name of one of the older shanty structures). Wendy and I think that we may have lost a small knob off our equipment and I wanted to look for it." Tami, "Oh yeah. Okay." Her hands are full but she still tries to get the key off her large set of key rings with other keys and dolls around her neck. She leans over to set things on a wet wooden bench near the garden, and I say, "Oh, let me help you. I can hold something." She hands me her Bible and pad of paper. Dog Dave walks out the commons area and looks at me kinda funny but smiles. I wonder what he's smiling about, and then become aware of my stiff posture as I hold the Bible in the air, flat in my palm as if I'm getting sworn in or something. I try to relax and wonder if I'm that uncomfortable holding the big Book. Tami untangles the mess of keys and unhooks the Chilipad key from one of the key rings. We trade key for Bible and smile.

We walk together silently down the center of the Village, passing the jungle of vegetables planted in long rectangular raised bed garden boxes sitting side by side on the asphalt lot. The garden is full of variations, diverse plants and 
veggies, all at various stages of growth. Some of the veggies thrive with new winter growth while others lean over tiredly on brown wiry stalks, dead, withered, some gone to seed. In a way, the garden as it is now in the winter season is like the Village. Some of its residents shine with energy, presence, and passion for Dignity Village, like the tall lush parts of the garden growing as if reaching to something beyond the square boxes that contain it. Other residents have grown tired, engaging less and less with the community, or altogether absent and withdrawn from community life and the vision of Dignity Village. This is what brings us here today. We are working together to pull out the weeds that choke the growth of some of the plants, working to find a way for this diversity of growth and engagement in the community to co-exist in a sustainable way. Consistent throughout the Village is a wish or hope for Dignity Village to exist, grow and maintain itself, but this desire sometimes competes with an even stronger and growing feeling of uncertainty about how this can be achieved, particularly together.

\section{Historical Context}

We came from nothing, with no hope and no help in sight, with nothing but a vision of community and a refuge, and we formed a tent city Village to help ourselves gain safety and dignity.

- Jack Tafari, Dignity Village 


\section{In the Beginning}

In the wet winter cold of the waning days of the millennium's first year, a change was in the air on the streets of Portland, Oregon. Jack Tafari, a poet and staff writer at street roots newspaper, roused action from the streets with a stirring editorial ${ }^{\mathrm{i}}$ decrying the indignity of society's treatment of the homeless and urging followers to join in solidarity to form a tent city in Portland. Joined by Bryan Pollard and his staff at street roots, ii the group's initial organizing efforts built strong momentum from the streets into a powerful and unified force, "fierce, strong, and determined, like a hungry dragon" (J.P. Cupp, raw video, June 23, 2002). These disenfranchised soldiers of a rising grassroots movement packed their shopping carts full of tents and supplies and set off to create a new tent city, risking what little they had for a larger vision of community and safety. A small window of opportunity had been opened by Multnomah County Judge Stephen Gallagher, who ruled that Portland's nineteen-year-old anti-camping ordinance was unconstitutional because "those without homes are punished for the status of being homeless" (Cowles, 2000). On December 16, 2000, the first six tents of Dignity Village were pitched by a small group of women and men on a forgotten, litter-strewn scrap of state land, a powerful act of civil disobedience to protest the violation of their basic human rights. Less than a week later, lacking specific directives, the police continued to enforce the anti-camping ordinance, forcing the group to move from place to place or risk being "swept" and sent to jail or fined. But despite the 
individual familiarity of this continuous flight from harassment, the solidarity and sheer numbers of the "Dignity soldiers" made a difference: they were no longer victims to verbal or physical attacks by police or other "street thugs," having found safety and power in numbers.

\section{The Socio-Political Context}

The struggle in creating Dignity Village reflects a larger national and international tent city movement of people experiencing homelessness who are taking action to build their own affordable housing despite resistance by local governments and communities. Some of the resistance is rooted in a persistent dominant narrative in society at large that people experience homelessness because they have done something "wrong" to deserve it. This prevalent belief has shaped our response to homelessness as a nation.

Homelessness was on the rise in the United States even before the effects of Hurricane Katrina or the Great Recession, with budget cuts for human services, a slowed economy and high rates of unemployment contributing to the growing problem. Over the past two decades, the national socio-political response to homelessness has generally been characterized by short-term emergency programs that do not attempt to address the root causes of the problem. With the number of homeless persons increasing rather than decreasing, these crisis-style shelters have become a permanent yet ineffective system of managing the problem. 
In many cities in the US, the existing shelter system has the capacity to help less than half the homeless population on any given night. In Portland, Oregon, for example, at least 1,500 people will not find space in the shelters and will sleep on the streets every night(UCM, 2001; MCHR, 2004). For those unable to find shelter space, the maze of legislation governing the use of public spaces results in an additional and often insurmountable burden. In many cities, it is a crime to sleep on the streets; police shuffle homeless people from one doorway to another, sometimes fining and arresting them for loitering, sleeping, and sitting in outdoor public places in urban centers. Many cities have rules against sleeping in vehicles or even against sitting in a public space with a blanket (National Coalition for the Homeless [NCH], 2006). Such legislation creates no alternatives for unhoused individuals to obtain a night's rest when shelter space is unavailable. Furthermore, even when shelter beds are available, they are often not a viable or safe alternative due to hidden crime and theft. The prevalent model of single-sex, warehouse-style mass shelters reinforces feelings of helplessness and a lack of dignity by regulating people's every behavior, from what they eat to when they sleep, providing no sense of personal freedom. Shelters cannot be used as a "home-base," either logistically or as a source of emotional support.

While mass shelters may function adequately in a crisis for immediate needs, the situation in emergency shelters in the aftermath of Hurricane Katrina pointed out the appalling conditions that many homeless persons face every day. 
Our shelter system was not designed for safety, empowerment, and community, and now functions merely as a stop-gap measure for fighting homelessness, particularly as many more Americans are now living on the margins. It is in this context that Dignity Village struggled to emerge as an alternative to sleeping in doorways and in shelters while waiting for affordable housing, creating for themselves an alternative to losing dignity and hope, creating a home, a place where you can have privacy and community, a sense of belonging and freedom to be.

\section{The Last Illegal Campsite - 17th and Saviour}

The "days under the Fremont bridge" is a story worth listening to at Dignity Village. The community narrative tells the story of their struggle to take part in a conversation with the politicians and broader community, and to regain control over their lives and their citizenship.

Five weeks from the day they first pitched tents, after being chased from four other sites, Dignity Villagers marched in a line, pushing their shopping carts along the sidewalks and streets for more than two hours to reach what would become their last "illegal" campsite at NW $17^{\text {th }}$ and Saviour. At this campsite, a colorful city of tents patterned a small scrap of unused land directly beneath the roaring traffic of a freeway bridge overpass. This is where I first met the heroic and ordinary people who form the backbone of Dignity Village.

An uneasy agreement with the City and negotiated protocols with the police allowed a respite from the constant movement from site to site. During their six 
month stay under the Fremont bridge, Dignity Village grew in size from the original six tents to 35 tents housing 83 people, and formed a system of democratic governance that gave rights and responsibilities to the safety of each participant/Villager. With a food preparation area, portable toilets, a storage tent, and a heated "security" tent, it became a relatively hospitable alternative where weary people could rest. Those six months gave them space to develop their infrastructure, creating leadership roles and protocols for intake, security, trash and sanitation, recycling, donations and cooking. All of this development took place under the booming thunder of traffic overhead, with the debris and pollution of a thousand vehicles floating down to stifle the senses and numb one's thinking. Communication required screaming into another person's ear or using a bullhorn at Village meetings. Despite the challenges, everyone seemed to understand and share the vision of a future Dignity Village. Part of building this future required strategic planning and countless meetings with city politicians, police, and attorneys as the Village worked to obtain legal status to exist as a tented village on public land and within urban land use codes.

Prompted by an anonymous complaint, the City of Portland requested that the Village disband by July 1, 2001. City officials explained that the Oregon Department of Transportation (ODOT) actually owned the small bit of land under the overpass, and it was the state who had ordered the deadline. The Village responded by organizing a public "teach-in" and the submission of a 40-page 
proposal to the City. This document, titled "Dignity Village: 2001 and Beyond" was a planning proposal and architectural blueprint for the creation of a permanent "green" sustainable urban village on a 5-acre parcel of vacant public land near the freeway in the downtown core (known by homeless people as the "field of dreams"). As intensive negotiations commenced, the City and ODOT granted a twomonth extension to the deadline, to September 1, 2001. The City agreed to pay ODOT's fine for every day that Dignity Village stayed at the site under the Fremont bridge. A City Commissioner of Portland, a far-thinking supporter of the Village concept, attempted to bridge the division between the city council and the homeless villagers by forming a resolution to adopt Dignity Village as Portland's pilot project. At the public City Council hearing to vote on this resolution, dozens of villagers and supporters spoke movingly for their cause, and with only one detractor raising a voice of dissent, the Council voted 4 to 1 to approve the resolution to work with Dignity Village as a city pilot project. But the devil was in the details, as the specifics of the resolution noted several near-impossible requirements to be met by the Village.

An even more extreme barrier to any remote hope of success for Dignity Village was the city's choice of location for the pilot project. City officials organized this pilot project to begin at the city-owned leaf composting yard under the roaring jets of the Portland International Airport, next to the Columbia River Correctional Institute and at least 40 minutes away by bus from any social services 
in the city's urban core. The Village would pay rent to the city for the privilege of pitching tents on the asphalt lot at Sunderland Yard, surrounded by a chain-link and barbed-wire fence and mountainous piles of compost. The Villagers saw the site as more of a concentration camp or forced relocation to a remote reservation than a dignified next step in their good faith negotiations with the city. The group struggled to decide together the future of Dignity Village. Some Villagers wanted to protest the forced move, and use the media to illuminate their lack of choice in existing legally as a tent city or as individuals experiencing homelessness. Villager JP Cupp asserted, "Homeless people rise up and unite! You have tents to gain and nothing to lose but your shopping carts!" Some Villagers saw this protest as the only dignified option. If they were to get arrested, as threatened by the police, and Dignity Village fell apart, well then, they went out in a blaze of glory, making a powerful social statement. Other Villagers didn't agree with this direction. They didn't want to be arrested and to break the law. They were not criminals. They wanted to keep their homes, their place and community together as a village. They didn't see any real "legal" choice but to go to Sunderland Yard or wherever the City required, despite their fear that it might be a death trap for the Village's long-term survival.

As the deadline approached, the tension built and the community seemed on the verge of splitting apart entirely under the tremendous pressures. A few weeks before the deadline, the Village voted to stay and protest the move and announced their intentions at a press conference. In the days before the deadline, they called 
meeting after meeting to discuss new information from supporters, from the City, from neighbors, and from themselves, desperately trying to settle on a strategy in the face of a constant blizzard of advice and mounting pressure. Each meeting seemed to conclude with a different set of plans, flip-flopping between moving to Sunderland and taking a stand at Fremont.

Late in the night, just hours before the deadline, half the tents remained standing under the bridge along with a large Penske moving truck packed with belongings parked nearby on the street. A small group of people begged to split off from the larger Village core, in terror for their lives, of going to jail, fearful for the safety of their pets and their meager belongings. Unable to bear the tension and harrowing choices faced by the group, Wendy spoke up and offered a temporary refuge at our farm for the animals and for those people who could not risk jail sentences. She hoped that providing more choice for the differing needs of Villagers would free up the stronger "soldiers" who wanted to take a stand at the site. After an intense discussion among themselves, Villagers came to a consensus to accept our offer, but to keep the location of the refuge a secret from the press. In the wee hours of the morning, we drove the Penske truck along with a caravan of Villagers and pets out to our farm to set up camp in our backyard. This was, for Wendy and me, the ultimate test of our stance against NIMBY-ism and prejudice, an unintentional chance to put words into action, and a gesture of trust and belief in the community of Dignity Village. 
As a third of the Village departed for the farm, the Village core met yet again under the bridge to make a final decision on whether to stand or move. By the merest of margins, the group voted to take a stand and stay where they were, hoping to exploit the political capital and support they had received for their struggle to affect larger social change. A brief period of quiet descended over the remaining tents as the exhausted Villagers tried to grab a short rest before the upcoming challenges of the approaching deadline. In the darkest hour just before dawn on September 4, deadline day, two individuals (one of them an outside supporter, the other a Village member) quietly splintered off from the group and from the democratic nature of Dignity Village, and as the first rays of the sun pierced the horizon, pitched their tents at Sunderland Yard, posting a sign on the gate that read “a deal's a deal." Mayor Vera Katz seized the moment and drove immediately out to Sunderland Yard, shook hands with the two individuals and thanked them as representatives of Dignity Village for keeping their word. In shock and in anger, the remaining Villagers, still under the bridge, lost their united voice and their hope, and the community disintegrated into individuals struggling to survive and flee from police. Over the next few days, disheartened Villagers slowly regrouped in ones and twos to the new legal city-owned site to try to reforge their community bonds, democracy and vision. 
Barely two weeks later, the Twin Towers in New York City crumbled to the ground, and the struggles of Dignity Village faded to the background of local and national consciousness.

\section{The Leaf Composting Yard}

Dignity Village began to slowly rebuild at Sunderland Yard, out of sight and all but forgotten by both friends and foes. With attention shifted away from them, left to rot next to the leaves, their attitude became one of slowly hardening determination to overcome both the inertia and the obstacles in front of them, to create a garden and a community out of a bitter asphalt desert. They formalized their legal status as an organization, writing organizational by-laws and receiving nonprofit 501(c)(3) status from the IRS. They continued to pursue their goal of buying their own land and moving off the city's site. For two years, a site selection committee consisting of Villagers, supporters, politicians, and other community members met weekly to discuss land options for Dignity Village. A supporter committed to donate a million dollars to purchase a piece of property for Dignity Village. The committee researched over 200 pieces of property, and found no available public or private land, either because of its designated land code or because the owner refused to sell to a homeless camp. As a result, Dignity Village has now existed on the city-owned compost island since 2001, with their site selection committee disbanded and no immediate prospects of moving onto their own land. iii 
As the Villagers build their community, they have also built a physical Village. Over the years, the tents have given way to weatherproof shanty structures built out of recycled building materials and tarps, and then from shanty homes to code-compliant and eco-friendly one-room houses, with many made of straw and cobb. Nearly a decade after the Village's inception, in accordance with their original ten-year plan, almost 50 one-room houses have replaced all of the tents and shacks. The Village has made huge strides in achieving their goal to link ecologically sustainable development with affordable housing. Using natural building techniques and recycled materials for their housing, the Village has also installed a wind turbine and built rainwater harvesting systems in efforts to move forward with their plans for renewable energy production to reduce dependence on city utilities. All funding for the Village comes entirely from private donors, grants and foundations, and their community continues to provide services at miniscule cost to taxpayers.

\section{Vision of Dignity Village}

Dignity Village strives to foster community and self-empowerment while providing transitional housing for its members. One of their main goals is to provide a safe, drug-and-alcohol-free alternative to the streets for 60 homeless adults every night. To that end, they implement a variety of operational activities needed to maintain a safe, diverse, and empowering community that provides support for members to pursue their own goals while working interdependently toward a vision of Dignity Village. In addition to private dwellings, the Village provides basic 
services including toilets, showers, cooking facilities, telephone, mail, computer and Internet access, and access to health care and other social services. The Village operates a website (www.dignityvillage.org) which displays media coverage and historical narrative as well as a job hotline and a resume database. Their longer-term goal is self-sufficiency though the creation of micro-industries, which will develop the Village economy and provide skills and training for people in need.

Dignity Village is much more than a service provider. The Village creates systemic change by empowering homeless people to assume leadership, educational and activist roles in the Village. The Village functions as a dynamic self-help environment that provides a participatory framework for supporting each other, while simultaneously encouraging individual residents to more effectively help themselves at a personal level. Unlike typical shelters, couples and pets are welcome at Dignity Village, and community is fostered democratically through selfgovernance and Village participation, termed "sweat equity" by Villagers. Their participation and common work builds community and relationships that provide mutual support as they share stories, experiences and skills in a battle against the harsh experiences of homelessness. With community support, contact information, hygiene facilities, and a full-night's sleep, people living at Dignity Village community have the opportunity to regain control over their lives again and to take steps toward achieving their own personal goals (e.g., finishing school, finding 
permanent housing, regaining custody of their children, climbing out of debt, or kicking an addiction).

Dignity Village also gives this disenfranchised group a staging point and bargaining power to organize for real gains, such as changing the way homelessness is perceived and managed by social service industries, local governments, and communities. Individuals and families who have lost their homes have lost much more than a roof over their heads; they have lost their histories, their stability, their privacy, those intangibles that underlie our assumptions of basic human rights. With control over their lives stripped away from them, their voices discredited and left unheard, they have in essence lost their citizenship (see Arnold, 2004; Feldman, 2004; Stoner, 1995).

The political roots of Dignity Village grew out of necessity to fulfill basic human needs and a desire to be treated with respect and dignity by allowing individuals experiencing homelessness to regain control over their lives. It also grew out of an awareness of their rights as human beings and citizens, and a critique of their position within this context. Self-blame within a society that reinforces this message gave way to a broader analysis of the system in which they were embedded. Why are those affected by homelessness kept out of the conversation and away from the decisions that affect their lives? This group of unhoused activists decided to "sit at the table" despite societal resistance. It wasn't about adding one token homeless person to the political table to represent the diverse voices and 
experiences of many; rather, it was about the voices of an entire Village with diverse perspectives, about bringing long-term social change to the accepted practices of managing homelessness. The idea was to turn the system on its topheavy head, creating innovative solutions to homelessness from the bottom up. Changing the power dynamics in our continuum of care system is at the heart of Dignity Village. However, social change requires more than just long-term planning; it calls for an empowered and cohesive community.

\section{Research Context and Focus}

We must indeed all hang together, or, most assuredly, we shall all hang separately.

\section{- Benjamin Franklin}

Within the first five years of their development, Dignity Village faced challenges typical to many volunteer-based organizations. In the absence of obvious external causes or enemies to unite against, a general state of disaffection and apathy slowly settled in and replaced much of the common vision and intense energy that once existed and helped to sustain the struggle to build Dignity Village into its own powerful and legally legitimate entity. In late 2005, at the beginning of the research, participation in Village self-governance had dwindled to its lowest levels ever. It is not uncommon in grassroots organizations to find such decreased participation in collective action once individuals find a solution to their most pressing problems (Casanova \& Blackburn, 1996; Lara \& Molina, 1997). For some 
people at Dignity Village, the struggle for shelter was a personal survival strategy and not necessarily an activity to achieve greater visions of democracy as an end in itself. Furthermore, the transitional nature of Dignity Village's membership made it even more challenging to maintain active participation, shared vision and goals.

Within the community, the state of Dignity Village at the beginning of the research was described as generally negative in mood, with low morale, and in some cases, frustration and withdrawal of individuals from the community. A small group of active participants saw themselves as carrying most of the weight and responsibilities of running the organization, while the majority of members and residents ${ }^{\text {iv }}$ fulfilled only their minimum required work of ten hours per week, avoiding or withdrawing from the self-governance activities of the Village such as participating on committees and on the Village council. Long-termers (Villagers who had resided in the community for more than two years) also described a change in the quality of interpersonal relationships, collective action, and an overall disinterest in political critiques or action. In response to these developments, the leadership of the Village created more protocols, committees and rules to monitor participation, orientation, and enforcement. To some at the Village, this response seemed rigid and controlling, similar to the shelter system. Other Villagers saw these changes as a natural way of bringing stability to the community through adapting to changing circumstances. 
The goal of this research was to explore the state and internal dynamics of participation at a deeper level. In this section, I present my own understanding of the history and dynamics leading to this growing state of disaffection in the community. This discussion is organized into four main areas of influence: (a) political activism, (b) collective identity and external social networks, (c) transitional nature of the system with regard to its participants, and (d) perceived power and inequality.

\section{Political Activism}

As a highly politically active and energized community in its early days, Dignity Village mobilized large numbers of local housed and unhoused people to take action for justice and dignified treatment within the homeless helping industry. Those seen as leaders within the Village (who were also co-founders of the initial political campaign) articulated their vision of a future democratic Dignity Village in ways that empowered others, not only to reflect on their own position in the system, but also to take action toward improving their condition. Under the bridge, Dignity Village was empowered.

Gaining social power and political clout through a growing web of support networks and media coverage, Dignity Village was a force to be reckoned with. Strategic planning made each step and action effective and powerful in mobilizing and empowering citizens to do something. For example, from their very beginnings, Villagers did not move quietly in the night to another hidden location 
every time the police gave a 24 -hour trespassing notice before sweeping the camp. Rather, they moved during daylight hours, walking strategically in a long line and pushing their "Burnside Cadillacs" (shopping carts) with signs attached to them that read "I love Vera Katz," "Homeless Liberation Front," "Dignity,” and "Call 281xxxx for info." Each move attracted major television news media, bringing the issue out from under the bushes and the doorways to housed people's living rooms where they could hear, maybe for the first time, interviews and voices of homeless people who did not accept the status quo.

The collective action and participation of the community in political events was initially reflected in their internal politics as well. As a community, they shared the responsibilities of keeping each other safe. Every time individuals were threatened, by thugs, by bigots, and even by undercover cops, the community would come together to create plans for protecting the individual from harm and for maintaining the power of the group. Through this, they developed security protocols and participated in self-governance to maintain order and safety in the Village, reducing theft, violence and drug-use on the premises. Some security issues focused on internal order (e.g., residents fighting or stealing from each other), but given the harsh realities of their downtown location, many security issues focused on justifiable concerns about external threats to their safety. The community remained a target for hate crimes, but because of their solidarity and numbers, this occurred at a somewhat reduced or at least less damaging level than most individual homeless 
people experience. ${ }^{\mathrm{v}}$ For example, an anonymous person (or persons) dropped a firecracker or a small explosive from the bridge overpass directly into the community of tents below. Fortunately, no one was hurt in the incident.

Some early founders of the Village concept felt that the premise of "love and respect" within the community would obviate the need for any internal regulation, but it was agreed that four simple "non-negotiable" rules were essential to maintaining order and safety as well as the longevity of the Village. These basic rules were, and continue to be: (a) no drugs and alcohol or paraphernalia on site, (b) no violence to yourself or others, (c) no stealing, and (d) everyone contributes to the upkeep of the Village. The first three rules were enforced by the Village during weekly community meetings. Each case would be presented along with evidence and the community would discuss and decide on how to resolve the issue. Every Villager at the meeting had a voice and a vote, and was thus empowered to democratically participate in the self-regulation of the community. Enforcement of the last rule about contributing was from the beginning more complicated, given a lack of clear consensus and articulated expectations on the specific requirements of participation. At first, the Village was fairly open and flexible to differing interpretations and variations in participation, although the issue continued to stir debate within the community.

At one meeting that I attended under the bridge, a few people suggested that they adopt a rule making attendance at Village meetings mandatory, with the 
rationale that it was healthy for individuals to participate in making decisions that affected them, as well as critically important for the Village as a whole to "keep the troops together." One Villager made the point that she and several other people worked during the evenings when meetings were held. The majority of Villagers felt that this rule would restrict freedom to participate and that enforcing a participation rule too closely paralleled the coerciveness of shelters that require shelter users to attend a Christian service in the morning before leaving. The discussion illustrated the concerns about participation, even at a time when three-quarters of the community were actively participating in meetings and in other Village activities. A noticeable decline took place in Village political activism and collective action after their move out to Sunderland Yard. Some people thought this decline occurred because the Village no longer had a seat at the table of conversation with local political leaders when they accepted what they saw as the unjust and unhealthy conditions instead of taking a stand against the city. This same group believed they had missed a critical opportunity to make change and had lost the momentum necessary for real systemic change to occur. In the words of a Villager arguing against moving to the site, "Sunderland is a leaf composting yard, where things rot and decompose. Well, we are not rotting. We are not refuse. We are dignity...ever living!" (J. Tafari, raw video, September 5, 2001). The move to Sunderland began to take a toll on the Village. The community feelings of loss and self-blame seemed to surface as discontent, in-fighting and a slow erosion of vision and collective action 
beyond their community borders. The initial focus on political action and efforts toward broader social change shifted to a focus on developing internal order, toward the creation of a more stable organizational structure as well as improving the physical aspects of the Village. At the time, this shift in focus didn't result in loss of shared vision, only a changed emphasis. With the stability of place settled for at least their first year, the Village had some control over their destinies. They had space, a temporary piece of land, and a strong determination to show the world that they could turn a dumping ground into a sustainable and green urban Village. And they have indeed accomplished a great deal on this front since their move to Sunderland Yard.

As usual, though, there are other perspectives to consider in view of progress. A part of the Village, small in number but powerful in voice and leadership, held strong views that the internal focus was extreme, leading them down a path that would steer them away from achieving real long-term social gains. Conflicts ensued, resulting in a deeper divide between the two main perspectives: (a) political activism, with social change on the forefront of concerns (an external focus), and (b) an organizational focus on improving the health and well-being of the individuals within and transitioning through the Village community (an internal focus).

While dissimilar, there were shared values on both sides. Both perspectives valued social change as well as community well-being and organizational order, and 
both understood that one side couldn't live without the other. The point of conflict lay in where to take action and in which area to grow first. The P-perspective (political) preached a greater vision beyond the immediate community of $60+$ people, and criticized the O-perspective (organizational) as losing momentum with its focus on internal order and stability. The P-perspective valued a strong connection to the streets and to helping other homeless people, retaining of sense of history and identity as street-fighters or soldiers in a war on homelessness and social injustice. The O-perspective shared the vision of social change and helping other homeless on the streets, but not at the expense of maintaining itself as a coherent and stable community. In a Villager's words, "I think that Dignity Village is a place for people to come and get back on their feet and try to get back into the real world...I know it's also a movement, but I also think we need to think about the homeless that are in this village right now. I know we have other people out there that are homeless that are in need as well, but if we can't take care of our own damn selves, how are we gonna take care of everybody else? This is something we all have to start working on...trying to take care of ourselves, so that we can build ourselves up to the point where we can start helping other people come in off the street...” (Mike, raw video, October 10, 2001).

The debate between the two perspectives often became intense, and what would seem like minor practical issues, such as the use of the few parking spaces in the driveway, resulted in heated conflict over vision and goals (raw video, February 
26, 2004). On the one hand, people with the O-perspective felt parking spaces were a limited resource, and necessary mainly for community members to get back on their feet. On the other hand, Villagers holding to the P-perspective viewed a decision to restrict the use of parking spaces to Village community members as chauvinistic and unjust to other homeless people who were also trying to survive and get their lives in order.

“...I don't give a fuck if the vehicles are unsightly. Up until they are selling drugs or they are violent or they are a problem, if people need to move so we make spaces, we should work with them in a creative way..." JP relaxes his voice and slows his speech as he pulls his chair back and sits down again. “... and remember who we are and that these people are just barely trying to survive, just barely better than we are. Just barely. They have a little vehicle. We have a tent..."

Gaye interrupts JP, who had been speaking without a break for more minutes than officially allotted per person. "Shut up, JP, it's my turn!"

There are 15-20 people sitting around a large round and colorfully painted green and yellow table in the center of the council room. This circular dome-shaped building off the side of the main commons area, wall to wall with windows and clear 
plastic skylights, is called the Dome of Democracy. Some of the individuals participating in this particular meeting hold council positions, while others do not, yet they actively participate at the meeting even knowing that they will not be allowed to vote when the elected council decides on a mode of action. The council meetings are a place for dialogue, a place to voice concerns and views, and a means to practice democratic citizenship at the Village. It is important to be aware of the issues because each month, some of the issues also come before the full membership meeting, where every member of the community has a vote.

"If John's parking his vehicle, which runs, he parks out on the street because there's nowhere to park. If Watchdawg were here, he'd be parking on the street because there's no place to park." Gaye is referring to a couple of Villagers who have valid licenses and vehicles. Gaye's O-perspective on parking echoes the view of many individuals in the room. "Exactly!" JP says, as if he caught Gaye in a trap.

"But, instead, we have a bunch of crap cars in here that nobody's using! And nobody can drive, and screw them!" Gaye says angrily. 
JP jumps in angrily, "So what if their vehicle is ugly and it doesn't run! They don't have insurance cuz they don't have money. They don't have the plates changed cuz they don't have money. They're not using it to drive. They're using it as their home. They're being survivalists. That's what we're doing. They're being utilitarian. In other words, they're creating and utilizing the resources at hand and building resources in order to survive. Remember who we are when we decide on how to handle this. We need to handle this in a spirit of love...I think we're being chauvinistic to other homeless people when they come in....People that don't drink, that don't sell drugs, that don't prostitute, they curse us because of chauvinism because when they come in, we don't offer them a cup of coffee, we run them off and we give them bureaucracy because we think because we're a corporation that we're something special. We've lost the essence of necessity. We have lost our vision!” JP suddenly stops talking and his last words linger in the quiet full room. His cheeks are flushed and his posture frozen as if momentarily caught between giving up and insistence. He folds his arms and sits quietly...until Gaye fills the silence.

"No, we haven't!" she asserts. 
These two dominant perspectives, once clearly present in the Village, now no longer co-exist in the same way. Most of the co-founders have transitioned out (who held the more political perspective) as well as most of the individuals that were present in the beginning during the Village's most politically active times as a community.

At the beginning of this research, the O-perspective had become the dominant perspective at the Village. As a result, the Village had made enormous developments in their physical space, internal structure and organizational process, but at the expense of developing politically active strategies and activities for social change in areas of homelessness. Tied to the city as their tenants while at Sunderland Yard, Dignity Village must maintain an amicable relationship to the powers-that-be, balancing their organizational stability with political activism, just as all social systems must find a balance between openness and adaptation to the environment on the one hand, and closedness and rigidity on the other in order to protect itself (and its identity) from being swallowed by a more powerful system in which it is embedded (Zwick, 2002). The balance between self-sufficiency and interdependence will constantly challenge Dignity Village; that is, unless they begin to forget where they came from, their sense of community, their uniqueness, and their vision, which will only weaken them to possible "predation" or takeover by other larger systems (Zwick, 2002). In the initial stages of this participatory research, there was an ominous sense among Villagers that they were currently 
heading down this latter path, and that they wanted to remember and perhaps return to their roots, their struggle, their state of empowerment and collective action. This required rebuilding their sense of community through dialogue, vision and critical awareness, a supportive context that was empowering and mobilizing, and a sense of competence in working together as a community. In other words, they wanted to work towards reaffirming their collective identity and a shared vision.

\section{Collective Identity and External Social Networks}

Over time, Dignity Village had noticed a change in individual's participation and in collective action as a community. Numerous scholars studying social movements note that collective identity is considered central for collective action and participation (see Robnett, 2002). Collective action cannot occur in the absence of 'we,' characterized by common traits and specific solidarity. It is a collective identity that enables individuals to see themselves as people linked by interests, values, and common histories (Della Porta \& Diani, 1999). Collective identity is a process of creating a sense of togetherness and direction, which shifts and changes depending on how a community defines itself relative to its environment (Melucci, 1995).

Constructing a more unified or coherent collective identity in the Dignity Village community depends just as much on their interactions with people external to their community as on their relationships with each other. Individuals act collectively because they are able to define themselves and their relationship with 
the environment through interaction and negotiation (Melucci, 1995). As a community, Dignity Village developed an understanding and awareness of what made them unique from other communities, and whether their vision of who they wanted to be (their possible selves) as a community was consistent with their actions. It would be impossible to talk of collective identity without referring to its relation to its environment, which forms the basis of its individuality (Melucci, 1995). The community needs interactions with the outside community and other organizations to understand how they are different as a collective and what ties them together as a community.

In the beginning, the foundation of Dignity Village as a political movement emerged out of a strong sense of community and a coherent and action-oriented collective identity. As members of Dignity Village took action together and interacted more and more with their external environment (institutions, local churches, schools), they grew more mindful of and able to articulate their values, practices, and boundaries that defined them and their vision as a group. One crucial aspect of Dignity Village was their definition of themselves as a community working towards self-sufficiency, setting them apart from other organizations and communities that serve the homeless population based on a charity model. As the Village developed this self-sufficient identity, the group encountered and struggled with the disparity between these two approaches: the charity model provided fish for hungry people, the self-sufficiency model provided a fishing pole and bait. 
While both approaches have the best of intentions, the dominant practice of helping within the homeless industry has been based on the charity model, which has created disempowerment as well as unequal power between helpers and those helped. As a nation, this approach has reinforced a cycle of dependency, rather than providing real help toward solving homelessness. The Village community learned that support and assistance came in various styles, and they struggled with how to teach others what was helpful to them. Helping others may take on a form outside of what feels familiar to us, a form that challenges our traditions and assumptions, requires us to reflect on our own position of power, and entails giving up the traditional position of helper as knower, guide, and advisor. An e-mail correspondence on July 29, 2005 between an outsider and Villager Jack Tafari provides an illustration of teaching others how to help the Village:

To the Dignity list-serve:

"Hello, I'm not homeless but I've wanted to do something to help homeless people and, just so you know, it has nothing to do with pity (for some reason that word springs to peoples mind when help is offered). I'm human and so are the homeless and I want to help my fellow humans. Make sense?

Okay then, here's my question. Is there anything, anything at all I can do to help with the village or the people there or . . something??? From the photos you all look like you had a lot of fun just building..."

Reply from Dignity Village:

"Good morning, and thanks for your questions and offer to get involved with our project. To paraphrase McLuhan who said that "there are no passengers on spaceship Earth, we're all crew," that's kind of the way it is here at Dignity. We're all in this together and although our "do for self" ethic is strong, we appreciate good company and volunteers from the wider community. It makes perfect sense what you are saying. 
There's a lot of building going on which is more fun in the early part of the day than in the noonday sun when the tarmac's hot. We have a lot of recycled building materials that we're denailing and we're building decks and houses. If you brought a lawnmower and a gas can so we could mow the strip behind the security shack, that would be appreciated.

Glad you found http://outofthedoorways.org and hope you find your way here. One way we fund our operations is through book sales so be sure to tell all your friends to $B U Y O U R B O O K$ !

Blessed love.

Jack"

[Italics replace hyperlinks in the text.]

As Dignity Village formed and articulated their boundaries and collective identity, the Village decided to accept donations of material resources, and not donations in the form of labor that could be done by Villagers themselves. Rather, people were invited to work with Villagers on specific projects, but only if it was understood clearly as equal partnership or that the Village had ultimate control over the project aims.

Because of the challenging nature of this context, relationships with supporters have always been delicate and somewhat unstable. In general, I think it is fair to say that even supporters who have since withdrawn from active participation believed strongly in Dignity Village, had positive relationships with many Villagers, and were drawn and inspired by the Village's sense of community, vision and work. Difficulties seemed to arise in just how supporters were supposed to help; Dignity Village's self-sufficiency approach was confusing and uncomfortable for many people. It required a type of patience with "not knowing," and with building relationships where there were clear boundaries separating supporter from Villager. 
Some supporters who tried to help found it too difficult at times to watch the Village seem to fall apart or go down the wrong path, or they were bewildered that the Village did not take more help (or a certain type of help) from people who had expertise or skills that could be useful, but instead insisted on doing things themselves, succeeding or failing on their own. This barrier or boundary between Villager and supporter was viewed by some supporters and Villagers as an exclusive "us" versus "them" mentality that did not bring people together, while others saw it as a healthy boundary that raised consciousness of the power dynamics inherent in helping relationships to create new ways of working together as equals in light of these differences.

Over time, the relationships between the Village and its supporters have changed from regular active involvement to sporadic involvement as part of specific activities or events. For the most part, many of the supporters that were once actively involved in the beginning stages of forming Dignity Village are gone, and with this absence, another point of continuity and history is also gone. A poor fit between the style and approach of some supporters and that of the Village may have partly led to this change. Some supporters struggled with constant self-awareness and critique of the ways in which they were helping the community, often feeling misunderstood and unappreciated. Another reason for the change in the support network structure of Dignity Village may have been a simple change in Village needs. As Dignity Village became more sophisticated, competent, and self- 
sufficient, their needs for external relationships have changed, and some supporters no longer found their "help" helpful.

In 2005, at the beginning of this research, Dignity Village had a social network in which it interacted (e.g., outreach, tours, volunteers, events, donations), but active involvement from consistent supporters occurred less regularly than before. Some of the long-term Villagers spoke about this change in the number of active supporters, and questioned whether this was healthy for the Village. Could it be that the decrease in regular interactions with external individuals and organizations had contributed to a decline in their collective identity and sense of community over time? A sense of community refers to "a feeling that members have belonging, a feeling that members matter to one another and to the group, and a shared faith that members' needs will be met through their commitment to be together" (McMillan \& Chavis, 1986). With fewer interactions with a consistent external community, the Village may have lost a sense of their identity and the meaning to their own experiences and to their development over time (Della Porta \& Diani, 1999). Maintaining a coherent collective identity during the research was a necessary part of re-energizing the participation and collective action that once existed in Dignity Village.

\section{Transitional Nature of System}

One mission of Dignity Village is to provide transitional housing in an empowering, safe, drug-free, and democratic community environment. Unlike other 
organizations in the helping industry, Dignity has refused to take a "one size fits all" approach. In line with this philosophy, they treat each individual as unique, with their own set of factors for their condition of homelessness as well as their own goals and path to improving their condition. Dignity Village has held to a philosophy that the time needed for growth is different for each person, and so there is no time limit to how long a person can live at Dignity Village, as long as the basic rules are not broken. Some people need only a short time at the Village before moving on to achieve their goals, while others who face obstacles such as accrued debt, parole, depression or drug/alcohol addictions require more time, perseverance and support from the community before they are ready to leave Dignity's gate.

While this trailblazing philosophy is logical and empowering in theory, it raises tough questions about the realities of such an open and flexible structure. Do residents simply never leave the safety of the Village? Or is the opposite true, so that the population is in constant transition and nothing is ever the same at the Village? To be frank, the answer lies somewhere between these two extreme and likely unstable states. In October 2005, the longest residency was approximately five and a half years, for just two individuals, both actively involved in leadership positions at the Village. Nearly half of the resident members had been living at Dignity Village one year or less, with the remaining half spread fairly evenly between 2, 3, and 4 year residency lengths. On average, during the Village's first five years, roughly $2 / 3$ of the people who transitioned through Dignity Village were 
short-timers, staying at the Village for less than a year. There was a waiting list for entry, but space constraints and number of houses as well as the city's enforced 60person limit restricted the inflow of newcomers. ${ }^{\mathrm{vi}}$

With regard to individuals exiting the Village, Villagers estimated that over 850 people had transitioned through between 2001 and 2005. In Dignity Village's 2004-05 fiscal year, 71\% of people who left moved into more permanent housing, while $39 \%$ went back to the streets or to an unknown location (T. McCarthy, personal communication, February 28, 2006). While many residents of the Village transitioned through voluntarily, a number of residents were forced to leave due to lack of compliance with the basic rules. In the case of noncompliance, individuals typically were removed for committing a violent act or repeatedly breaking one of the basic rules. Often, in the nonviolent cases, the community responded with significant flexibility, providing a second, and sometimes a third, chance for individuals to learn and change their behaviors.

Because a goal of Dignity Village was (and continues to be) to empower residents within a transitional housing context, one might expect a relationship to exist between empowerment and transition, with empowered individuals exiting the community at a faster rate. In this case, there could be a paradox between two goals within the Village; empowering individuals to transition through the Village could counteract the higher-level goal of increasing collective action and community empowerment. In reality, however, there seemed to be no linear path between 
empowered individuals and exiting the Village. In fact, for many individuals, empowerment was related to an emerging emotional connection to Dignity's vision. Many of these individuals decided to take leadership roles within the Village until they were ready to pursue other personal goals outside of the Village or until they trained another Villager to take on their position in the community. Therefore, the Village goals of individual empowerment and community empowerment did not seem to contribute as significantly to the state of disaffection as one might have expected within this semi-transitional community (somewhere between transitional and intentional).

However, there was another part of the Village system that might have had more influence on disorder and disaffection within the community: that of intake or orientation of newcomers. The arrival of newcomers to the Village seemed to heighten emotions and conflicts within the community. Group dynamics changed constantly with new personalities, different values, and an unfamiliarity with Dignity Village, its history and its vision. A long-term member of the Village, Gaye Reyes, explained that part of the problem was that "we have become the 'out of the trailer park' movement instead of the 'out of the doorways' movement. Most of the people in here don't know what it's like to live on the street. They don't understand where we came from and how we had to fight to make this happen and that there were no alternatives. Those who come off the street feel that Dignity is a step up, but those who come out of houses and land here without experiencing the streets 
think that they have hit rock bottom." Maintaining a coherent collective identity and active participation with a constant influx of newcomers who bring their own agendas was challenging but not impossible for Dignity Village. Moderate to longer-term residencies and a core group of committed leaders provided the Village with some continuity and stability. Although the influx of newcomers brought stress to the system, some Villagers did not necessarily consider this a negative feature. With newcomers comes energy and possibilities for change as an organization and community. Instability is a source of possible change in a system (Zwick, 2002). There is a tendency for communities to develop toward a more ambiguous definition of identity as a more heterogeneous group of individuals come to associate with a community over time (Friedman \& McAdam, 1992).

While newcomers brought the potential for positive change in the system, there was also the potential for a polarization in views as two populations coalesced around differing viewpoints and visions. As more and more of the Villagers who were present at the Fremont bridge site transitioned out of the Village, there remained smaller and smaller numbers of "long-termer" Villagers, those who remembered the pressures and events of the days under the bridge and the difficult community decisions regarding the move. As Dignity Village became a more comfortable place physically and more accepted as a small part of the city's overall plan to resolve homelessness, newcomers experienced a very different environment than longer-term members of the community. Conflicts emerged between the "old 
guard" and the "newcomers," resulting in decreased participation. Newer members

of the community felt discouraged that nothing would ever change because the same leaders remained in power. Longer-term members felt frustrated that they were carrying the full weight of participation at the Village. These power dynamics seemed to be a significant source of the expressed decrease in morale and increased disaffection at Dignity Village.

\section{Perceived Power and Inequality}

Over time, the Village developed ways to manage and cope with the stress on the community from the constant inflow (and outflow) of newcomers and the semi-transitional nature of the community. Dignity Village aspires to create an environment where people can learn and grow, and become empowered through participating in democratic decision-making. The foundation of the organization is based on the idea that democracy is a mechanism that allows it to be constantly learning and improving itself. However, questions that constantly seemed to arise were "how much democracy should we have...how many rules should govern us?" As the organization became more efficient and stable by developing an infrastructure with more protocols and positions for officers, council, departments and committees, the community also became more rule-bound, hierarchical, and rigid, moving towards a system opposite to what it had initially envisioned. Dignity Village developed out of a basic need for housing and a critique of the bureaucratic and hierarchical shelter system, where the individuals served were managed and not 
heard. Despite Dignity's developing stratification, there was still a significant difference between these two systems in terms of democratic citizenship. At Dignity, every member had a vote. The general membership voted for the main organizational positions (e.g., council member, officer, etc), who then made routine decisions over finances and rule enforcement for the membership. During their monthly membership meeting, members continued to make decisions on some of the most pressing issues for the Village.

Just months before the beginning of this research, in an effort to boost participation and to more evenly distribute the work load among residents, the membership defined the rule "contribute to the upkeep of the Village" as a mandatory ten hours per week for those individuals not working outside of the Village and six hours per week for those working at least part-time jobs. They also developed a system of enforcement and a way to track the number of hours worked in Village operations by each of its residents. As a result, participation increased as residents complied with the minimum hours. However, the quality of participation and engagement, in terms of Villagers' emotional commitment and enthusiasm toward the community (as demonstrated in leadership and voluntary selfgovernance activities) seemed to ebb and flow, practically unchanged from the time before the implementation of this protocol.

Some residents expressed the opinion that mandatory participation had the unfortunate effect of recreating the power dynamic commonly found in social 
service agencies serving homeless persons, in which the community became divided into rule-enforcers and rule-obeyers. However, even if there was discontent with this protocol, most Villagers acknowledged that the rule helped to reduce the community conflicts and rumors over the level of contribution in the community. Gaye Reyes, in the position of Village "bean-counter" responsible for monitoring mandatory hours, explained that in the past, “... whatever work you are doing, if it's not visible, you haven't done it. That's why the bean-counter is important. Each month, I report the hours of each person and how they are contributing" (G. Reyes, personal communication, October 10, 2005).

The rules, protocols and hierarchy seemed to help to create order, but they also seemed to lead to power and status differences between members and nonmembers, resulting in more conflicts between newcomers and long-timers. Newcomers were required to follow rules and to fulfill the mandatory hours of work, but they were not allowed to vote until they become members themselves by a majority vote of the current membership, after a three-month "trial period" or orientation. The Village established this process to provide space and time for newcomers to learn about the Village and to socialize them from a "street survivalist" mentality to a "community-oriented" frame of mind. Without this waiting period, the Village's identity was at stake. At one time, as soon as an individual resided at the Village, she or he could vote. As a result, the Village overall felt their sense of community and collective identity shifting rapidly and 
incoherently as groups of newcomers, some with unhealthy or individual-centered agendas, voted on important issues that affected the Village as a whole. The Village developed new protocols to protect the community from significant changes due to the arrival of large blocks of newcomers (also known as guests or residents) with their own agendas. However, within this context, issues of power and difference between newcomers and members were emphasized, leading to tensions in the community between these two groups.

As newcomers entered the community for the first time, they typically didn't know much about Dignity Village and its history. Their first impression was that it was a place to live without as many rules and with more privacy than a shelter, a place that allowed freedom and control for individuals through democracy, but as they began to get more comfortable with the community, sometimes their sense that "this was a good idea" started to wear off and they chafed under the established rules and order. Many of these newcomers complained of feeling powerless, like an outsider being observed rather than a real participant in the grassroots democracy that characterized Dignity Village. From these newcomers' point of view, they were, once again, in a situation where they were treated as second-class citizens with no voice or vote. Sometimes, the more a newcomer felt "left out," the more the newcomer strived for control and to be "let in" to the community. Other newcomers who arrived without having first experienced the constraints of the shelter system were often overwhelmed and ashamed of their changed status to homelessness, 
resulting in a divide between those coming from the "doorways" and those coming from "trailer parks."

All of these dynamics often led both groups down a path of tension, mistrust and impatience with each other. When newcomers brought their critique of the established system as well as their own ideas for change at Dignity Village, members in the community often complained that newcomers only wanted to give advice and critique, and did not want to listen and learn about the community first. Newcomers felt judged and misunderstood, and perceived some of the members as "power-tripping." Newcomers felt that many of the long-term members had lost their compassion for what it was like to be scared, and to be an outsider in an established community. Most of all, they wanted to be heard and to feel a connection with others in the community, as fellow human beings who had shared similar painful experiences with homelessness. The negativity between newcomers and members spiraled into feelings of frustration, disconnection and minimal participation, creating barriers for newcomers, and for the entire Village, to develop feelings of passion, commitment and solidarity.

\section{Summary}

In summary, the state of disaffection in the community in October of 2005 (at the beginning of the research) emerged from a five-year history of dynamics operating within a system of both opportunities and constraints. I described the history of the state (and research context) within four main areas: political activism, 
collective identity and external social networks, the transitional nature of the system, and perceived power and inequality.

Aware of the complexities in solving this issue of low morale and participation, Villagers sought alternative avenues to re-invigorate community participation and a collective identity. The Village had a desire to restore the emotional engagement, participation, and empowerment that had been slowly deteriorating. Most everyone at the Village had heard one story or another about being "under the bridge." One main element emerged as a common thread through the various community stories about this period of Village history: a loss of the perspective that they were connected to something greater than themselves and beyond the individual-focused task of finding a home. The vision of Dignity Village was that all people in their community were participants and community members in a long-term action plan for social change. Under the bridge, external conflict and necessity strengthened their ties. Now, at the five-year juncture point, what would be the tie that bound them together? This question guided both our exploration and action in this research, in which the community turned to storytelling as a vehicle to re-invigorate a sense of community with emotional connection, history and continuity, identity, and meaning (Rappaport, 1998).

Several community members at Dignity Village pointed to the transformative power of video in this regard. They explained their intense feelings of pride and ownership when they had the opportunity to see themselves, their 
history, and their story pulled from their own Village archives, in videos created for outreach or portions of the documentary. The videos elicited strong feelings in both longer-term residents who were reinvigorated by remembering their early efforts, and inspiring to those who had not been part of the original group. As Villager Laura noted, "The video made me see that at Dignity Village, I am part of something that is much bigger than myself" (L. Brown, personal communication, November 13, 2005).

Given their experiences with the impact of video, the community wanted to develop a video-based action tool that would tell the community narrative, which would act as a catalyst for re-establishing a sense of community and identity, and community participation and empowerment in Dignity Village. The intent of this research was aligned with Dignity's long-term goal of providing supportive conditions and empowering processes that allowed individuals to obtain more social power and to organize for long-term social change.

\section{The Lens through Which This Story Unfolds}

As collaborative research, many voices and perspectives worked together to generate this research process and action tool. Each voice and perspective was unique and valuable because "each perspective yielded insights about the system not attainable with the others," which together, illuminated an alternative viewpoint, a multidimensional view, of the participation problem at Dignity Village (Linstone, 1999, p. 33). Even so, it is through my "perceptual filters," my lens of assumptions, 
concepts, values, and practices in which this alternative viewpoint was constructed (Lendaris, 1986, p. 604). It should be considered just one way of seeing and telling this story. Therefore, this last section in this chapter provides a frame of reference for readers to better understand my voice and perspective, my relationship to Dignity Village, and how it may have shaped this research narrative.

\section{My Relationship to Dignity Village}

This research draws on my experience working with Dignity Village since 2001 as a documentary filmmaker, researcher, videographer and archivist. This participatory action research project was situated in the context of my role within the community as supporter and frequent visitor, with a shift in role from participant and observer to facilitator-researcher within this research project. This shift was made in part to better serve the community and in part as fulfillment of my own research and educational goals.

I have been a participant at Dignity Village since its inception, assisting them in recording and analyzing their own history. As part of a broader social change initiative, Dignity Village began working with Kwamba Productions, of which I am Creative Director, to document the experience of organizing the Village and to produce a feature-length documentary on their efforts. During this time, my relationship with the Village has been one of many: documentary filmmaker, legal media partner, archivist, supporter and friend. From the start, my graduate training 
at Portland State University influenced the way I approached my relationship with Dignity Village, within the values and ethics of community psychology.

Dignity Village and Kwamba Productions formalized their relationship in 2002 with the goal of collaboratively developing a comprehensive educational media package on Dignity Village in addition to the documentary. Taken together, these various media products form what we call the Tent Cities Toolkit, which, in brief, is a DVD toolkit with interactive video-based media that provides information and resources on issues of homelessness and the role of tent cities in fighting the injustices and stereotypes that perpetuate homelessness.

My dissertation research focused on producing one of these tools, crucial to the vitality of Dignity Village. The research addressed a key issue facing all tent city communities - that of sustainability of vision in a transitory population. My dissertation took on this issue in a collaborative action research project with Dignity Village. The goal was to develop a video-based action tool that would act as a means for sustaining residents' active participation and sense of community in Dignity Village. Villagers envisioned the action tool as an orientation video that would tell the story of the community's history and political roots, their vision and their identity as a community.

\section{Development of my Role and Agenda}

Well before the research started, in a casual conversation, Sue, a newcomer at the Village, asked me why I was so involved with Dignity Village on various 
projects. Surprisingly, I found myself floundering in my answer, when just a couple years prior, I answered it with ease. I tried to explain to Sue that "I am involved in issues of homelessness and social justice because I feel outraged when people are excluded from making important decisions that affect them. It is simply not right that people in bureaucratic positions, disconnected from the lives they are affecting, make decisions and manage other people's lives. The people who are affected have no voice in these decisions, so when I see a group stand up to those in power and say 'this is not right,' when I see a community like this courageously persevere in a struggle to create change ...it just does something to you."

Through this experience of attempting to articulate reasons for my involvement, I discovered that something had changed for me over the years. I lacked not only the words, but also the self-awareness to answer this question in a way that fully captured my reasons. It no longer felt cognitive (e.g., "I am involved because it is important that the world hear Dignity Village's story"). What I discovered was that my role in Dignity Village somehow slowly seeped into my very identity, values, view of the world, and actions. I was as dumbfounded by the question as if the question were "Why are you the way you are?" Nevertheless, the question was indeed relevant, as it concerned my agenda and the importance of making it explicit to those I work with as well as to the readers of this dissertation so that they become aware of my perspective. 
To answer this question, I should start at the beginning, when I first met the folks at Dignity Village. I first heard about Dignity Village when I bought a newspaper from a street roots vendor standing outside of Cramer Hall on the Portland State University campus, and the feature story centered on the beginning struggle for a group of unhoused persons to exist together and to create a tent city they called "Dignity Village." The article awakened me. All of a sudden, I was selfaware of my lack of action, inexperience, and ignorance of politics and social issues. The next few weeks after reading the article, the story of Dignity Village lingered with me as I sat in my classes inside the safe and thick walls of the academic institution, discussing in my classes applied research in social and community psychology. It seemed that the more I learned about community in the classroom, the more I felt disconnected from it. The community of Dignity Village existed out there beyond my comfortable borders of privilege and the ivory towers of the academic institution. I wanted to learn more about what they were doing, and to learn what it was like for them to experience this newly formed community. But I didn't want to show up uninvited, to study and observe the Village like a zoo; I wanted to interact with the people in the community who stirred in me a newlyformed desire to learn about politics and to do something that was real, something that mattered.

I showed the Street Roots article to Wendy, my partner at Kwamba Productions, and we talked about how inspiring their story was. One of our friends 
knew some people who lived in a small trailer on the fringes of Dignity Village, and she offered to introduce us to them. The three of us visited her friends, who encouraged us to walk over and introduce ourselves to Dignity Village. As we stepped out of their trailer and walked toward the camp under the Fremont bridge, I became increasingly self-conscious: would they be offended or reject me because of the differences between us? Would they think we had some sort of agenda? How exactly should I act, and what if I said something stupid? In retrospect of course, these are some of the same fears that many people have on walking into any situation with an unknown group of people, regardless of their specific circumstances; it has been interesting to note over the years the same recurrent concerns among new people interested in visiting the Village for the first time. I noticed a few people staring at us as we walked on the sidewalk that marked the border of the tented camp. As we passed a line of Port-o-lets, heading toward a large orange and white tent, I felt like turning back, but before I could, a tall young man dressed in camo pants with a bandana on his head and a scraggly brown beard quickly walked out of the tent toward us, smiling and reaching out his hand to us. He shook hands with each of us and introduced himself. His name was JP. We explained that we were visiting some friends who lived nearby in the trailer, and we wanted to come over and learn more about what they were doing. Without hesitation, he invited us into the camp whenever we wanted, to hang out, listen and talk with people in the community. We accepted and thanked him, and spent the 
next few hours learning more about Dignity Village, introducing ourselves to other Villagers, asking a few questions about their community, but mainly just listening and observing. Sitting in small groups clustered between the tents, eating or smoking or talking together, the Villagers were guarded but friendly, welcoming us to the table, offering coffee, and answering our quiet questions.

When I first stepped foot in Dignity Village, I didn't know much about homelessness. I was exposed to homelessness through hurried experiences walking in downtown Portland or in my car on the highway on-ramps as I observed individuals at a distance holding a sign asking for help. These experiences were few, as I had lived most of my life in a middle class, predominantly white, rural area about 40 miles northwest of Portland, and there, I don't remember ever seeing anyone who was homeless.

I was initially exposed to the complexities of homelessness and poverty when I traveled abroad for the first time to Kenya. While on a street in the town of Nakuru, a small group of young children surrounded me, tugging at my hands and pants and begging me for money. Without much thought other than a desire to help, I reached into my pockets and handed them some change. The children smiled and ran off together, and I felt good about myself. As I was smiling, a Kenyan woman who had been watching began to walk toward me with a friendly but stern look on her face. Politely, she requested that I stop giving money to the children, explaining that many of the street children had run away from home and that they used the 
money that tourists give them to buy glue which they sniffed to get high. She explained further that this was a huge problem that they face as a nation, as many children leave their poverty-stricken homes to work in the city. Many of the children never return to school or their families and develop serious and deadly addictions to glue. Stunned, I could only nod my understanding. The conversation had a powerful and immediate impact on the way I understood myself and the impact I have on the environment and society, even as a short-term visitor. On an almost daily basis while in Kenya, I was confronted with this issue of helping. I had to decide what to do and how to act, as I was now suddenly aware of myself as an actor in the world, connected to others, either contributing to or alleviating problems. Similarly, reading about Dignity Village heightened my awareness of my role and potential for impact in my own country, in my own city and community. And when Wendy and I decided to return again to Dignity Village, I brought with me an openness to learn and understand.

As Wendy and I spent more time at the Village, we began to feel a passion for telling their story. Our company, Kwamba Productions, was founded in 1995 with a mission to create innovative media products that affect social change worldwide. We have created a number of advocacy and educational videos, and at the time that we met the Villagers, we had just completed our first social change documentary. We began to see a possibility of acting as a vehicle for the community's story through media, and we decided that we needed to talk with the 
community about it. We discussed this with Ibrahim, a Village leader, and he encouraged us to present our idea at their weekly community meeting. Most of the Villagers at the meeting responded positively to the idea. However, one active supporter of the Village who was at the meeting did not trust the media in general, and our agenda specifically, and she voiced her concerns to us and to the community. We understood her apprehension, having encountered this distrust of the stereotyped "media person" before, and we responded to her and to the Village by taking great care in being sensitive, flexible, honest and clear about our intentions. We started out by visiting the Village once a week, interviewing individuals as a way to build rapport and trust. Our initial experiences with the Village occurred right around the time that they were beginning intense negotiations with the City, in the summer of 2001. Six weeks after we first came to the Village, they asked us to help them prepare a video for an important meeting at City Hall, where the city would decide whether to support Dignity Village as a pilot project. A student had promised to create a video for them to use in the meeting, but never followed through with delivery. They were in a bind, and decided to ask us to help out.

Honored that we were asked to do this work, we approached it seriously, inviting them to get involved and to direct the process. As it was their tool for the meeting, it was important for us to understand how they wanted to tell their story. We knew that the City Hall meeting was an historical moment and that the decision 
would impact many people as well as the system itself. We arranged several meetings with supporters and Villagers, where they gave feedback on the rough cuts and storyline, co-creating the tool for the maximum impact for their goals. The shared collaborative process of creating the video gave us a way to understand each other and how we work together, our assumptions, agendas, and values. And we seemed to fit.

Since we first met in 2001, my role in the Village has shifted along a continuum of observer to participant. Initially, I was much more of an observer, watching quietly in the background, listening, maybe filming a little, and interacting only when approached. With more interactions and with the development of trust over a period of months, my role shifted to a more active role, culminating in our complete participation and immersion in the Village when twenty of them moved up to our farm for a couple of weeks in September of 2001 as part of the intense experiences surrounding the move to Sunderland. Since then, my role has been much more fluid, shifting dynamically between personal friend, supporter, documentarian, and co-researcher even in the course of a single conversation. Our relationship has not lacked for complexity and drama at times, but through all this, we seemed to stay on the same page and on the same path.

At the heart of my answer to the question of my agenda and involvement with Dignity Village was their empowering influence on me. Dignity Village lit a fire under my feet to take action and to become an active citizen. My understanding 
of homelessness developed through my experiences with Dignity Village. They were my life-teachers. And their situation inspired me to read extensively in the literature on homelessness and community, searching for answers and ideas. More than ever before, I felt connected to people and to a vision of an improved situation for individuals in poverty, and I grew critically aware of myself as being embedded in an interrelated and complex system. The classroom was about my individual quest for knowledge and information; Dignity Village was about relationships and a shared understanding, and most of all, a hope for something better and more just. It did not depend on me and my performance; it depended on us.

As I became part of Dignity Village, it became a part of me. I now understand that I am an activist, as this part of me surfaced and took shape through my experiences as a participant in Dignity Village. Like a religious awakening, I began to believe in something greater and beyond myself, to see myself connected to a larger whole, and then to understand my responsibilities as a citizen and community member to take action for social justice. Now, as a nascent activist and community psychologist, the intent of my work is to awaken others into seeing possibilities for social change, and then acting on these visions. As this is my agenda, I continue to be involved because I am involved; I am committed to the vision of Dignity Village and to the relationships within the community, and this bond gets to the heart of why I chose to facilitate and participate in this research and in Dignity Village. 
Telling the story of my relationship to the community of Dignity Village is one avenue to understanding and making my lens more visible. However, sometimes a story, which can be powerful at conveying meaning about aspects of life and relationships, can also distract readers from an author's voice, and in so doing, mask the point of view of the storyteller. For that reason, I attempt below to illuminate my lens even further by positioning my work in a values context within science, community psychology, and participatory action research.

\section{My Perspective and Value-orientation}

My approach to working within the community of Dignity Village was positioned within my values and worldview as a scientist-practitioner, community psychologist, and participatory action researcher. For me, all of the views within these philosophies integrate and form a larger lens that embodies a systems perspective. The point here is not to describe the details of a systems perspective, but rather to highlight how it may have shaped my way of seeing and telling this story.

A systems perspective is a means to organizing complexity into a coherent story that illuminates the underlying structures, interactions, and processes (Senge, 1990). It also recognizes that problems are embedded within a continuously changing context, and that ignoring ties with the context will not lead to a better understanding of the causes or the possible solutions within a system of actors, or in this case, the context of a community. The problem emerges bottom-up from the 
interactions and processes within the community; therefore, studying these processes within the context is a necessary part of understanding and changing it. Within this perspective of wholes and interactions over time emerges a profound shift in awareness to seeing ourselves within the system, with a unique way of seeing our own reality that not only affects the way we understand the problems but also creates the problems we experience (Senge, 1990). Systems thinker Peter Senge suggests that this may be the "antidote to our sense of helplessness and passivity" as citizens and scientists; rather than helplessly reacting and exacerbating our problems, we can become aware of our actions and role as active participants in shaping our future (Senge, 1990). If we begin to see ourselves as part of the problems, we then understand that we are also part of the solutions. Thus, a systems perspective shows me that everyone (including scientists) shares responsibility for the problems, and for action.

In the remaining part of this section, I position myself and my views within the context of three areas of controversy within science: scientists' active participation in research, their control over the research, and representation of the research and of the participants. The purpose of this discussion is not to debate the range of philosophical positions within the multiple contexts in science, but rather, the intent is to present my values within the context of working relationships in communities, as my values and beliefs are tied to this context. 


\section{Action}

Action in inquiry is a point of controversy among various paradigms. Some paradigms view action as a form of contamination of research results and processes, a form of advocacy or subjectivity, while others view action as a meaningful and important outcome of inquiry processes (Greenwood \& Levin, 1998) as well as a political and ethical commitment (Guba \& Lincoln, 2005). The difference in these views lies in philosophical claims about forms of knowledge that are considered "legitimate" (Gaventa \& Cornwall, 2001). Positivists believe that there is an objective reality that exists apart from our flawed perception of it and that reality can be approached only through the utilization of the scientific method. This suggests that knowledge that affects people's lives falls largely in the hands of a monopoly of privileged experts, who exercise power over others in their expertise through the exclusion of other forms of knowing as well as through excluding the voices of the knowers (Gaventa \& Cornwall, 2001; Selener, 1997).

Fundamental to my approach to research with communities is a shared belief that science is not just about accumulating knowledge for knowledge's sake, but instead, that science is an inherently political process that serves a particular purpose, and that purpose is to improve and change the world (Rappaport, 1977; Reason \& Bradbury, 2001). "Knowledge, as much as any resource, determines definitions of what is conceived as important, as possible, for and by whom" (Gaventa \& Cornwall, 2001, p. 72). Through access to knowledge, and participation 
in its production, use and dissemination, participants can directly affect their futures of what is possible and equitable (Gaventa \& Cornwall, 2001).

There are multiple ways of knowing that start with acting and interacting with the immediate context, by socially constructing knowledge. With this view, the most appropriate research approach allows for social, group or collective knowledge-making as a means to democratizing knowledge production in order to expand the boundaries of human action (Hall, 1992; Gaventa \& Cornwall, 2001). Knowledge is not something to be discovered or accumulated in expert-based journals, but rather emerges in the continually changing processes and contexts of everyday living, and ordinary people who routinely act upon reality in order to both change and to understand it (Gaventa \& Cornwall, 2001; Reason \& Bradbury, 2001). Participatory action research attempts to put forth this form of knowledge, one which includes those who are directly affected by the problem as participants in the research process, thus democratizing control over knowledge-making as a means to disrupt existing power relationships and to create active citizenship (Boog, 2003; Gaventa \& Cornwall, 2001). This research and my values are positioned within participatory action research.

What is meant by "action" in participatory action research is not blind action; it is "intentional action" that is political, critical, and informed by selfconscious awareness and analysis of one's own reality in a process of learning (Gaventa \& Cornwall, 2001). A vital part of action in the research involves the 
process of reflection in learning and in the development of a new critical awareness of the status quo and of the capacity of ordinary citizens to act for themselves (Selener, 1997). This worldview and value-orientation reopens possibilities for human agency as the centerpiece of social change that aims to empower and strengthen the capabilities of those who are relatively powerless to create their own future (Greenwood \& Levin, 1998).

\section{Control}

Another controversial topic among the different scientific paradigms centers on questions of control between researchers and participants in the research process (e.g., who determines the salient questions, data collection methods, research findings, report style, and representation). For more conventional inquirers, the issue of control does not raise debate around action, voice, reflexivity, and issues of representation because each of those issues in some way threatens claims to rigor and objectivity (Polkinghorne, 1989). For inquirers with a participatory worldview, the issue of control is inherently coupled with power, authority, and scientists' values. Within this context, control is only problematic as inquirers seek to obtain participants' genuine participation (Guba \& Lincoln, 2005). Within the context of participatory action research and my own value-orientation, this inquiry was treated holistically as context-bound, embedded in a community's values and practices, and the inquirer was always considered a participant in the processes of acquiring new knowledge (Guba \& Lincoln, 2005). This is a shift in perspective toward conducting 
research with communities rather than on them, a shift from lone researcher or objective outsider to an ongoing collaboration with community partners throughout the research process (Greenwood \& Levin, 1998). This shift to collaboration redirects our attention to questions of what is practical, worthwhile, and relevant to solving the problem in accord with the values and culture of the community and the relevant environment (Reason \& Bradbury, 2001; van Beinum, 1998). The issue of control no longer begs the question of "whether or not we get involved, but how" (Balcazar, Garate-Serafini, \& Keys, 2004, p. 251).

Inquirers as community partners aim to address power imbalances in research in a way that fosters empowerment and democracy, allowing those whose voices were previously marginalized and silent to now be heard (Guba \& Lincoln, 2005). However, it is misleading to suggest that power dynamics do not exist in participatory action research or in research that comes from the community (see Maguire, 1987; Gaventa \& Cornwall, 2001). No human relationship is exempt from a power component, although power is not necessarily always negative and delimiting on others; it may have a synergistic element, such that action by some energizes more action by others (Hayward, 1998). So how we approach and practice research in communities, the relationship between researcher and participants, the source and scope of the research, can all be traced to both negative and positive aspects of control and power. Variations in the application of participatory action research and the amount of inquirer and participant control depend on the 
underlying assumptions, world views and values of both the inquirer and the participants (Grundy, 1982). In this research, I valued and sought equality and democracy between researchers and co-researchers. Since power is inherent in relationships and in research, I intended to critically examine and reflect on my actions within the research context, identifying how and where equality and democracy fall short in practice.

Although many researchers may have a different notion of democracy and its value, I view the value of democracy in research by its nature in creating an arena for lively debate among multiple viewpoints and for decision-making that respects and values each perspective and the diversity of viewpoints within groups. A systems perspective has shown me that when dealing with complexity within communities, there is simply no one "right" perspective (Senge, 1990). In fact, we often may unintentionally take on dominant perspectives that influence the way we perceive the world and decide what things are worthy of pursuit. Therefore, in this research, I valued openness to other perspectives as a way to hold a mirror up and become aware of how our own assumptions and values shape our work.

As research begins to point out to us that most of our "mental models" are systematically flawed, missing important relationships, dynamics and variables, it becomes more critical as scientists to be aware of our own mental models, and to understand that the way to change these mental models is to bring them into the open (Senge, 1990). Through dialogue and openness to diverse viewpoints, 
individuals become susceptible to having their thinking influenced by one another. In this state of openness, we can gain access to depths of understanding not accessible otherwise; we can be more insightful and intelligent than we can possibly be individually (Senge, 1990). And through this, I believe we can begin to realize the value and power in participating as a member of a collective community through participating in processes of knowledge production that strengthen voice, power, and action, all necessary steps in social change toward a more open, equitable, and democratic society.

\section{Representation and Authority}

Issues of control are closely associated with questions of representation and authority, such as who takes on the authority to represent the research and who represents whom (Denzin \& Lincoln, 1994). The questions that arise from these crises include the following noted by Finley (2005): "How should research be reported? Are the traditional approaches to dissemination adequate for an expanding audience that includes a local community? How do researchers 'write up' their understandings without 'othering' their research partners, exploiting them, or leaving them voiceless in telling their own stories? What forms should research take? How can researchers make their own work available and useful to participants rather than produce reports in the tradition of academics writing for other academics or policymakers?" (p. 682-3). 
The value of an inquiry's relevance and usefulness to the community opens a range of complex issues about voice, representation, and interpretive authority. Writing or expressing community research is not simply a process of reporting truths or creating an outlet for 'findings' to be accumulated and stored up in journals for the scientific community alone; reporting is part of constructing a reality as one sees it within the context of a researcher's position and condition within society and culture (Finely, 2005; Reason \& Bradbury, 2001). There is no single truth, only knowledge that is the product of a social process in which people come together to share experiences, investigate and learn or construct knowledge through acting and interacting in their environment (Gaventa \& Cornwall, 2001). "We are not just mirrors, passively reflecting a situation we find ourselves in. We are writers, not just readers, we are actors acting with other actors...we traverse an epigenetic landscape. A landscape we discover as well as create" (van Beinum, 1998, p. 77). In the context of this new position of researchers as community partners, it is important to recognize that all stages of the research process, including the reporting phase, are embedded in this partnership. Thus, the way we represent our collaborative research in the community should portray the "multidimensionality of human life as compared with truth finding, proofs, and conclusivity in traditional social science" (Finley, 2005, p. 683).

In collaborative research, there is a need for alternative forms of reporting in accordance with this value-orientation, one which represents the diversity and 
complexity of the worlds and perspectives of participants and expands the limited boundaries of scientists as the only intended audience for our communication/reports (Finley, 2005). The style of communication will thus depend on the context of the research and the values of the community, as well as the intended audience. Many inquirers in this context have become storytellers, experimenting with narratives that expand the range of voices, perspectives, and the multiple dimensions of human experience (Finley, 2005).

In accordance with this approach, the written portion of this dissertation takes a narrative form with direct quotes and rich descriptions of the community context as well as multiple perspectives within the literature on understanding and responding to homelessness. The research report includes "visual texts" in an effort to capture the variations in human experience and the range of understanding and voices heard by the reader, presenting visual examples of the social interactions, mood, dialogue, and outcomes of the research in narrative form. Collaborative research speaks not only to process, but also to how we represent "our research" and create our reports in a way that is accessible to a wide range of communities.

\section{Summary}

Unlike conventional science, inquiry within community psychology and a systems perspective intends to expose our values as scientists and critically examine our roles as agents of change and as constructors of knowledge. Community psychology is considered a field of practice with explicit goals and values of 
fostering "critical consciousness" (Freire, 1996, 1998). As psychologists, we should listen and use our "resources as servants" to facilitate new discoveries and solutions to problems (Rappaport, 1998). Contrary to what our scientific training tells us, psychologists are also participants and actors in this world, connected to and part of societal problems. A systems perspective has shown me that I cannot detach myself from problems to which I have a systemic relationship and moral responsibility (Flood, 2001). I believe that my role as a community psychologist is as both researcher and participant, engaging in research as a change process where my voice is just one in a collective narrative integral to social change toward fair and democratized societies. The values and worldview I have described have shaped not only the way I have approached my work with Dignity Village, but also my view of research as a process of engagement, learning, and empowerment important for everyone and to society as a whole.

To gain a more complete multi-dimensional understanding of the context in which this research with Dignity Village is situated, the next chapter of this dissertation deconstructs the multiple perspectives that frame our understanding and response to homelessness as a nation. 


\title{
CHAPTER THREE
}

\section{MANY SIDES TO THE STORY: PERSPECTIVES IN THE LITERATURE}

\author{
We don't see things as they are, we see them as we are.
}

Anaïs Nin

There are many sides to every story, yet most of the time we are unaware of the various versions. We commonly retell the stories that we hear most often and that fit consistently within the dominant viewpoint that is often communicated through our social institutions (e.g., art, song, mass media, laws) (Mankowski \& Rappaport, 1995). We learn who we are, and who we are not, through these "dominant cultural narratives" (Rappaport, 1998, p. 229). We learn how to act and interact with others, finding our place in this world. These ways of seeing the world guide our ways of acting, and through this, we learn what is important, valuable, and possible.

When we think about homelessness, we share ways of thinking, filtered through a lens of shared assumptions, concepts, and values that guide our practices and responses to the problem. And because our views are shared, we become less aware of them as viewpoints — one of many — and instead assume they represent reality by itself. We see only a part of the multi-dimensional, complex social problem of homelessness, yet we take action (or inaction) according to our partial views. Therefore, capturing a greater number of perspectives and differences should lead to a greater number of possibilities for relevant and effective action (Linstone, 1999; Senge, Kleiner, Roberts, Ross, \& Smith, 1994). A more accurate, well-defined and 
multi-dimensional understanding of homelessness may likely emerge from listening to and for different versions and voices.

In this chapter, I present my review of several main perspectives within the academic literature on homelessness. I provide a delineated description of three perspectives, emphasizing and contrasting specific aspects of each for the purpose of clarity. In reality, these perspectives likely exist along a continuum rather than in such distinct categories. However, in an effort to encourage dialogue, I present this specific framework of the main perspectives on homelessness that have shaped our understanding of and response to homelessness. This framework is also relevant to understanding the socio-political context of the research community setting, and the factors that may both support and undermine the emergence of an empowered Dignity Village.

Multiple Perspectives in the Literature

"Multiple perspectives" is a systems concept developed by Harold Linstone (1984, 1999) within the context of real world socio-technical systems in the areas of corporate planning and academia. Linstone (1999) argues that decision makers cannot rely solely on a single dominant perspective and analysis when dealing with complex real-life systems. Each person interprets the world from her/his own unique perspective, valuable yet limited in its view. Thus, the act of shedding light on multiple perspectives illuminates an alternative viewpoint, a multidimensional view, of understanding any phenomenon, in this case, homelessness. 
In contemporary American research on homelessness, there are three main perspectives in the discourse. The first is the Individual-Personal perspective (Iperspective) which often dominates the discussion (and our views) of individuals experiencing homelessness. The I-perspective typically focuses on the deficits and deviant characteristics of homeless people, including categorical differences between various subgroups of the homeless as well as the differences between unhoused and housed people. In this view, the primary causes of homelessness are the micro-level individual factors that affect a person on a deeply personal or intimate level, such as mental illness, substance abuse and addiction, and family estrangement (Shlay \& Rossi, 1992; Snow \& Anderson, 1993; Sommer, 2000). The I-perspective has predominated in the literature, media, and policy response to homelessness over the past 30 years (Buck, Toro, \& Ramos, 2004; DeOllos, 1997; Sommer, 2000).

A second perspective, less influential in guiding our response to homelessness, has been a Societal-Structural perspective (S-perspective), which views homeless people not in terms of their deficits but instead as 'unlucky victims' who show healthy, normal behaviors considering their situation within an ill-structured and inequitable socio-political system (Burt \& Cohen, 1990, as cited in Shlay \& Rossi, 1992; Rossi, 1989; Sommer, 2000). From this view, the primary causes of homelessness are unequal structural factors within macro-level economic or societal conditions, such as the changing job market, increasing poverty, and changes in the 
housing market, to name a few (Shlay \& Rossi, 1992; Wright, Rubin, \& Devine, 1998).

A third and newly emerging perspective is the Community-Contextual perspective (C-perspective), which centers on a critique of our traditional top-down approach to resolving homelessness. It views homeless persons as diverse and the causes of their homelessness to be within the context of their specific situation, both locally and nationally. From this perspective, all homeless persons deserve more than charity; they deserve respect and assistance that comes from the bottom-up and from a "peer" community of people experiencing homelessness rather than guided and managed by bureaucrats and service providers (Blau, 1992; Hopper, 2003; Rossi, 1989; Snow \& Anderson, 1993; Wagner, 1993; Wright, 1997).

Bringing these different viewpoints and values to the surface can illuminate how they shape our understanding of and guide our responses to homelessness. Depending on the perspective, specific weaknesses or strengths of homeless persons are emphasized and recommendations for future actions and solutions emerge from the dialogue between specific voices and stakeholders involved in the area of homelessness. In the past decade, the most prominent groups participating in the policy debates on homelessness have included government officials, advocates, and social scientists (Toro \& Warren, 1999), all of whom are seen as sharing similar perspectives, ideology, and approaches to the problem (Toro \& Warren, 1999). What is needed is to bring the multiple diverse perspectives to light, and hence, to the public 
discourse and policy debates on poverty and homelessness. Without this dialogue, we restrict the possibilities of opening more avenues for responses that get to the heart of homelessness. In the remainder of this chapter, I will outline and discuss the three main perspectives within the systems concept of multiple perspectives to illustrate both their strengths and limits. Table 1 summarizes the distinctive characteristics of the three perspectives.

\section{Individual-Personal Perspective on Homelessness}

From the I-perspective, the story of homelessness is a tale about difference. Within the story, the main characters are differentiated between housed and unhoused, between the deserving and undeserving poor (Wright, 1997). The narrative weaves through the plot of homelessness to create an identity of "good" Americans and "good" people only some of whom are worthy of respect and assistance. These are the protagonists in our story. They are the elderly, families, children, the mentally ill, physically disabled, abused, rejected, and anyone innocent of social responsibility and societal norms. The antagonists in our story include those who "choose homelessness as a lifestyle." They represent their own personal failures due to a poor work ethic, rebellious attitude, and lack of social ties. They are considered able-bodied but unemployed, and viewed as either "parasites" sucking off the public welfare or as "dangerous" individuals who reject public assistance outright by refusing to sleep in shelters, thereby continuously breaking local laws that ban sleeping in public. 


\begin{tabular}{|c|c|c|c|}
\hline & Individual-Personal & Societal-Structural & Community-Contextual \\
\hline Worldview & scientific, clinical, medical model & structural, historical & contextual, process-oriented \\
\hline Definition of homeless & $\begin{array}{l}\text { includes those who are living } \\
\text { outside, in shelters, abandoned } \\
\text { buildings, etc. }\end{array}$ & $\begin{array}{l}\text { expands definition to include those in } \\
\text { poverty, at risk of homelessness }\end{array}$ & $\begin{array}{l}\text { those marginalized/oppressed } \\
\text { with no voice or power and } \\
\text { who are without a place to live }\end{array}$ \\
\hline $\begin{array}{l}\text { System level of } \\
\text { analysis and response }\end{array}$ & $\begin{array}{l}\text { individual (mental and physical } \\
\text { deficits) }\end{array}$ & $\begin{array}{l}\text { society (economic, political, social } \\
\text { institutions) }\end{array}$ & community \\
\hline $\begin{array}{l}\text { View and portrayal of } \\
\text { homeless }\end{array}$ & $\begin{array}{l}\text { 1. undeserving for charity or } \\
\text { autonomy (able-bodied; } \\
\text { incompetent; irresponsible) } \\
\text { 2. deserving for charity but do not } \\
\text { deserve autonomy (children, } \\
\text { mentally/physically ill) }\end{array}$ & $\begin{array}{l}\text { all deserving; no differences between } \\
\text { poor and rich }\end{array}$ & $\begin{array}{l}\text { all deserving aid and autonomy } \\
\text { and equal respect }\end{array}$ \\
\hline Ethical basis & logic, rationality, charity model & morality, economic equity & $\begin{array}{l}\text { social justice, democracy, } \\
\text { empowerment, self-help }\end{array}$ \\
\hline Approach/orientation & $\begin{array}{l}\text { top-down } \\
\text { disengaged observer } \\
\text { conceptualization focus }\end{array}$ & $\begin{array}{l}\text { top-down } \\
\text { disengaged observer } \\
\text { conceptualization focus }\end{array}$ & $\begin{array}{l}\text { bottom-up } \\
\text { engaged participant observer } \\
\text { practical/action-oriented focus }\end{array}$ \\
\hline Mode of Inquiry & $\begin{array}{l}\text { observation of personal: surveys; } \\
\text { interviews; ethnographic methods }\end{array}$ & $\begin{array}{l}\text { analysis of societal response: } \\
\text { historical analysis; content analysis; } \\
\text { interviews; telephone polls; } \\
\text { ethnographic methods; longitudinal } \\
\text { studies }\end{array}$ & $\begin{array}{l}\text { participatory research with } \\
\text { critical awareness of power: } \\
\text { action research; participatory } \\
\text { research }\end{array}$ \\
\hline Research topics & $\begin{array}{l}\text { health status (chronic and acute } \\
\text { disorders, infections and } \\
\text { communicable disease, physical } \\
\text { trauma); basic demographics; } \\
\text { personal disabilities and deficits } \\
\text { (mental illness, substance abuse, } \\
\text { family estrangement); dislocations } \\
\text { and disaffiliation; length of } \\
\text { homelessness, places of shelter }\end{array}$ & $\begin{array}{l}\text { longitudinal predictors of exits from } \\
\text { homelessness; public attitudes toward } \\
\text { homeless; self-identity; evaluation of } \\
\text { service providers; family structure; } \\
\text { single-resident occupation units; } \\
\text { affordable housing; public benefits; } \\
\text { changing job opportunities; physical } \\
\text { conditions/daily stress; capitalist } \\
\text { economies; economic dislocation }\end{array}$ & $\begin{array}{l}\text { identity work to retain dignity; } \\
\text { tent cities; protests; social } \\
\text { movements; community } \\
\text { development; empowerment, } \\
\text { social power; resourcefulness } \\
\text { of discarded waste products } \\
\text { into survival goods; resilience; } \\
\text { encampments; ethics of } \\
\text { survival; informal economies }\end{array}$ \\
\hline
\end{tabular}




\begin{tabular}{|c|c|c|c|}
\hline & Individual-Personal & Societal-Structural & Community-Contextual \\
\hline Objective & $\begin{array}{l}\text { experts to solve problem; } \\
\text { respond to "crisis" }\end{array}$ & $\begin{array}{l}\text { advocates to pressure government to } \\
\text { solve problem; long-term economic } \\
\text { reform }\end{array}$ & $\begin{array}{l}\text { learn through taking action for } \\
\text { social change; participation by } \\
\text { those affected by problem }\end{array}$ \\
\hline Planning horizon & short & far & intermediate \\
\hline Response/actions & $\begin{array}{l}\text { - dominant response: crisis, short- } \\
\text { term fixes for deserving poor; } \\
\text { community safety - punitive } \\
\text { practices to monitor and regulate } \\
\text { undeserving poor } \\
\text { perceive current response as } \\
\text { adequate; incremental change } \\
\text { appropriate } \\
\text { - future actions: increase transitional } \\
\text { housing and services focused on } \\
\text { helping deserved poor }\end{array}$ & $\begin{array}{l}\text { perceive that response is inadequate } \\
\text { with reduction in affordable housing, } \\
\text { SROs, employment opportunities, } \\
\text { public benefits } \\
\text { - future actions: increase affordable } \\
\text { housing, job opportunities, public } \\
\text { benefits, decrease economic disparity }\end{array}$ & $\begin{array}{l}\text { perceive that current system } \\
\text { has oppressive structure, over- } \\
\text { reliance on experts, and leaves } \\
\text { homeless out of decision, } \\
\text { making it more difficult to exit } \\
\text { homelessness } \\
\text { - future actions: grassroots } \\
\text { organizing, raise critical } \\
\text { awareness of power } \\
\text { dynamics/oppression; more } \\
\text { democracy and inclusion of } \\
\text { those affected by problem in } \\
\text { decision-making; community } \\
\text { coalitions to plan for } \\
\text { intermediate steps toward } \\
\text { increased affordable housing }\end{array}$ \\
\hline Communications & $\begin{array}{l}\text { technical reports; ethnographic } \\
\text { personal accounts (descriptive); } \\
\text { professional journals, journalism }\end{array}$ & $\begin{array}{l}\text { professional journals and books; } \\
\text { historical analyses; descriptive; } \\
\text { journalism }\end{array}$ & $\begin{array}{l}\text { resistance-art: documentaries; } \\
\text { poetry; art; political protests; } \\
\text { community reports/action plans }\end{array}$ \\
\hline Audience focus & $\begin{array}{l}\text { professionals involved in treating } \\
\text { homeless \& solving problem }\end{array}$ & $\begin{array}{l}\text { professionals involved in changing } \\
\text { economic and social policies }\end{array}$ & $\begin{array}{l}\text { those affected by problem; } \\
\text { individuals who support } \\
\text { bottom-up approach }\end{array}$ \\
\hline
\end{tabular}


The moral of this story is that as "good" Americans, we are morally obligated to solve homelessness, and that we can do so by providing treatment and basic needs to the disabled and deserving "good" homeless people, and by controlling the ablebodied, undeserving, "lazy" homeless people through "tough-love" policies. Historically, from the I-perspective, the story of homelessness is a story about compassion on the one hand, and discipline on the other; it tells the story of salvation and rehabilitation for some and exclusion and punishment for others.

\section{Academic Literature from the I-perspective}

Over the past three decades, the story of homelessness has been told most often from the I-perspective. Prevailing cultural images portray "the homeless" as dispossessed and disaffiliated from "proper roles of adulthood and citizenry," waste products or diseased and deviant outsiders following a different set of cultural norms, and generally an unpleasant reminder of "all that is sick and disordered about the present society" (Hopper, 2003, p. 62-63). A popular and pervasive explanation of homelessness suggests that homelessness occurs to adults who have personal deficits and pathologies that render many of them unable to afford and maintain housing in the long-term (Sommer, 2000; Sosin, 2003). Personal deficits include limited educational and work histories, mental health issues, substance abuse problems, and lack of ability to maintain a social network (Sosin, 2003).

In the U.S., individual-level explanations of homelessness are the most widely accepted, particularly in the professional literature (Buck, Toro \& Ramos, 2004). 
Many social scientists have focused their attention on defining, counting, and analyzing different subgroups of the homeless, particularly the proportion of the homeless that are mentally ill, in poor physical health, substance abusers, veterans, criminals and so forth (Fischer \& Breakey, 1986; Rossi, 1989; Roth, Bean, \& Johnson, 1986; Shinn \& Weitzman, 1990; Struening, 1987, as cited in Wagner, 1993; Snow \& Anderson, 1993; Snow, Anderson, \& Koegel, 1994, as cited in Sommer, 2000). Measuring personal vulnerabilities (Shlay \& Rossi, 1992) and defining causes of homelessness guided much of the research in both the U.S. and Europe in the 1980s and 1990s (Burrows, Pleace, \& Quilgars, 1997; Fitzpatrick, Kemp, \& Klinker, 2000; Hutson \& Clapham, 1999, as cited in Christian, 2003). Within this perspective, the erosion of family support networks and the presence of mental and physical deficits are regarded as particularly critical in the determination of homelessness (Snow \& Anderson, 1993; Sommer, 2000).

\section{Dominant Responses to Homelessness from the I-Perspective}

Prior to the 1980s, homelessness was considered a problem within communities, and therefore to be solved by specific localities, with religious organizations and other nonprofits providing the primary response (Sommer, 2000). The daily needs of homeless people, primarily food and housing, were met by private charities through soup kitchens, food banks, and shelters (Cohen \& Burt, 1990 as cited in Shlay \& Rossi, 1992; Cooper, 1987; Hoch \& Slayton, 1989). At the time, private organizations were better able to respond quickly and to provide emergency relief in 
the form of meals and emergency housing (Cohen \& Burt, 1990, as cited in Shlay \& Rossi, 1992; Cooper, 1987, as cited in DeOllos, 1997; Hoch \& Slayton, 1989).

Homelessness did not receive national attention (or a federal response) until the early 1980s, when the rate of homelessness steadily increased and began to deplete the resources provided by local private charities. The first dramatic increase in homelessness and poverty since the Great Depression occurred during the Reagan and the first Bush administrations, an era of conservative political administrations who denied that the problem needed a federal response (Blasi, 1994). The rise in numbers was dramatic, but what particularly attracted the attention of advocates, researchers, and the media was the emergence of women and families with children as the "new homeless" (Shlay \& Rossi, 1992; Sommer, 2000). As the problem worsened, many advocates, mainly researchers, professionals, and charities, fought to secure government recognition and public support by organizing a campaign that pushed the "politics of compassion" to the forefront (Wagner, 1993).

Advocates painted a picture of contemporary homelessness as a different problem than the "hobo era" of the 1930's. In this new picture, homeless families were front and center, as they made up a third of all homeless people across the nation (Interagency Council on the Homeless [ICH], 1999; Shlay \& Ross, 1992). Advocates utilized the image of homeless families and children, vulnerable and helpless victims, to evoke national sympathy (Wagner, 1993). The campaign made notable gains, winning major lawsuits that required local municipalities to dramatically increase the number of shelter beds, food programs, civil rights policies, and eligibility for social 
benefits. In 1983, the government made the first national effort to respond to homelessness, enabling the Federal Emergency Management Agency (FEMA) to provide emergency short-term funding to meet the basic needs of people experiencing homelessness (Blau, 1992, Solarz, 1992). With pressure on the federal government mounting over four years from the growing media coverage of human interest stories, increased advocacy and public sympathy, and the additional financial burden on local governments, the federal government was compelled to respond. In 1987, the Stewart B. McKinney Homeless Assistance Act was enacted, along with a host of local and state plans, to increase affordable housing, transitional housing, and aid to the mentally ill. Funds were to be dispersed among private agencies and programs designed to provide emergency food and shelter programs (Blau, 1992, Rossi, 1989, Solarz, 1992). The 1987 McKinney Act continues to be the major legislative response in which current homeless policy is rooted, with several amendments in the ' 80 s and '90s that slightly increased the scope of the Act, but with no other comprehensive legislation on homelessness since then (O’Connell, 2003).

The American response to homelessness over many decades seems to cycle between sympathy and animosity, charity and penalty (Hopper, 2003). The twopronged approach that differentiates between the "deserving" and "undeserving" poor has remained fairly consistent from colonial times to today (Wagner, 1993). How we have dealt with, and continue to deal with, homelessness often follows our views about who is deserving and undeserving of aid, with public benefits provided mainly to those viewed as deserving — generally women with children and people with 
disabilities — and punitive methods utilized for managing the "undeserving" homeless. The coexistence of two such contrasting responses to homelessness suggests the operation of two sets of causal factors and images of "the homeless" (Sommer, 2000).

Most of the federal funds for homelessness are designed for the deserving poor, with the majority of federal funding passing through nonprofit organizations that provide at least $85 \%$ of homeless emergency housing and services (ICH, 1999). Funding and services are designed for homeless people who are challenged by mental illness, physical disability, substance abuse or HIV/AIDS (Fuchs \& McAllister, 1996, as cited in Sommer, 2000). This assistance has primarily taken the form of emergency shelters, food (food stamp programs, food pantries, and soup kitchens), general health and mental health treatment, substance abuse programs, and general assistance to help clients obtain federal benefits (Jahiel, 1992). Unfortunately, these services are still insufficient to meet the overall demand, even among those considered deserving (Morse, 1992). Furthermore, single homeless people are often not eligible for many of these benefits (O'Connell, 2003), leaving a large segment of the homeless population without recourse to assistance.

In dealing with the "undeserving" poor, we have responded primarily with a combination of repressive measures that penalize those who are perceived as unwilling to take advantage of emergency assistance, forcing individuals to receive treatment or to engage in programs that could result in housing or economic stability. Across the U.S., many cities have passed, and currently enforce, a growing body of laws that criminalize activities such as sleeping or sitting in public places, loitering, panhandling 
or begging, that are necessary for survival on the streets (NCH, 2004). If individuals are found sleeping in public, they have two options: to stay in a local shelter or be incarcerated (Sommer, 2000). Street sweeps of homeless people are common, as is the provision of bus tickets to send the homeless elsewhere (Schmalz, 1988, Uzelac, 1990, as cited in Wagner, 1993).

From the I-perspective, the public often views individuals' non-use of services as rebellion, which leads to the "tough love" response as a necessary part of policies for social control and public safety (Wagner, 1993). As street people become more visible and routinely cross paths with housed individuals, the public wants to know why nothing is being done by authorities to solve this obvious problem. Because this question is framed by the I-perspective, the societal response is to blame the poor for their long-term poverty, deviancy, and laziness and to praise the generosity of the welfare state (Wagner, 1993). Through this perspective, business owners, neighborhoods, and the fearful public see the homeless crisis as a failure in social controls of homeless individuals by authorities. With public pressure, authorities tend to respond by taking short-term reactive measures, using police repression, arrests, or street sweeps to reduce the public outcry and solve the problem, at least temporarily.

Within this perspective, the policies and programs providing emergency shelter and short-term assistance that emerged during the 1980s are considered a logical response to what was viewed initially as a temporary crisis, brought on by an economic recession and primarily caused by mental and physical disabilities. Establishing shelters, soup kitchens, mobile health services, education and job training 
programs and other emergency services are morally necessary to help people in dire and evident need. Our responses within the charity and medical models of saving and rehabilitating individual homeless persons have been reasonable given the context of the individual-centered explanation of homelessness, although the response is limited to providing nothing more than temporary relief (Toro \& Warren, 1999).

Over the past few decades, we have not seen the hoped-for decline in homelessness, and if anything, we have seen new patterns and problems emerging as a result of our policies. For example, increasing numbers of cities have enacted legislation criminalizing the homeless, and increasing numbers of requests for emergency shelter continue to be unmet across the country (NCH, 2006). The lack of shelter space nationwide has been cruelly illuminated by the additional thousands of people made homeless by Hurricanes Katrina and Rita. It is clear that the dominant Iperspective alone does not get to the root of the problem of homelessness, and we are in need of new perspectives on homelessness that open us to exploring alternatives that may be effective in reducing homelessness. In the past decade, with the growth of other perspectives on homelessness, many local services have increasingly moved from emergency-based services to transitional and longer-term programs for the homeless (Sommer, 2000), although the emergency aid and punitive policies have remained the "backbone of the service delivery system" (Bassuk \& Lauriat, 1986, p. 125, as cited in Johnson \& Cnaan, 1995). 


\section{Societal-Structural Perspective on Homelessness}

From the S-perspective, homelessness is not a story about difference, but rather it is a tale about commonality. The main characters depicted in this story are not "the homeless;" they are instead "the very poor," like you and me, fallen through the cracks of a disparate capitalist economy. The tale moves away from "individuals as cause" to a plot deeply rooted in our inequitable social structures that gave birth to the growing housing problem (Bahr, 1973, Bahr \& Garrett, 1976 as cited in Shlay \& Rossi, 1992).

The antagonists in this story are the current policies and institutions that have failed for the lower classes and perpetuated homelessness and a growing rate of poverty. Stories place the very poor (disabled, nondisabled, and unemployed) within a wider context and view so that we can see the link between their condition and our economic and social trends, which affect the ability of many very poor individuals to compete for and retain housing. Within this context of the harsh conditions of the street, individual deficits can be understood as due to daily stress that individuals have to endure for survival.

From the S-perspective, the depiction of homelessness is uncomfortable and brash, because at the heart of the story, we begin to realize that we are at fault for homelessness, not them. Solving homelessness means getting dirty by going to the root of the problem that lies deep within our capitalist economy and social structures. It means battling poverty by improving the labor market, increasing affordable housing, and enhanced public benefits (Burt \& Cohen, 1990, as cited in Sommer, 2000; Rossi, 1989). This story of homelessness is a story about humanity and taking 
steps toward long-term social change, rather than quick fixes aimed at treating the symptoms of the problem. It is a utopic story of what could be possible if we changed our direction toward economic and social equality.

View of Academic Literature from the S-perspective

Since the 1980s, the S-perspective has been vocal in challenging the dominant ideology by redefining, analyzing, and portraying homelessness at the societal level. Defining causes of homelessness guided much of the research for both the individual and societal perspectives throughout the 1980s and 1990s; however, researchers viewing homelessness through the S-perspective dispute the causal theories of individual disability as the defining characteristic of homelessness as an overrepresentation of individual explanations. Researchers raised concerns over numbers, variations in definitions and methods used to measure characteristics that support the traditional view of homelessness (Shlay \& Rossi, 1992). Studies have shown that point-prevalence surveys based on direct counts of homeless or bed utilization in shelters frequently result in an overrepresentation of the disabled chronically homeless (Snow et al., 1994; Toro \& Warren, 1999).

Much of the research on homelessness over the past few decades has focused on mental illness as a causal agent, with significant funding available for this type of research. Recent findings, however, consistently show that only about a third of all homeless persons nationwide are mentally ill (Institute of Medicine, 1988; Koegel \& Burnham 1987; Tessler \& Dennis, 1989; Wright et al., 1998; Wright \& Weber, 1987). 
These findings suggest that mental illness cannot be the defining characteristic to explain homelessness. Phelan and Link (1999) argue that most of those who experience homelessness are unlikely to have high levels of severe deficits, and that homelessness more readily occurs to adults who have low incomes and other personal crises (Link et al., 1995).

Furthermore, when researchers compare these characteristics between the unhoused very poor and domiciled very poor, we see fewer differences that are solely characteristic of homelessness, but are instead more characteristic of poverty and high levels of stress (see Sosin, 2003). For example, some findings show a high percentage of domiciled, low-income young adults with substantial substance abuse problems (Kessler, McGonagle, Zhao, \& Nelson, 1994), indicating that substance abuse is more related to low-income status, and not housing status.

Most comprehensive small sample comparative studies suggest that many of the measured symptoms of mental illness can be considered relatively transient reactions to being homeless (Toro et al., 1995, as cited in Sosin, 2003). The physical conditions and daily stress under which persons experiencing homelessness live render them extremely vulnerable to both acute and chronic health problems (Wright et al., 1998; Sommer, 2000). Unlike the dominant view, the S-perspective frames personal disabilities within the context of homelessness, which speaks to the survival strategies for dealing with the terror of homelessness (Shlay \& Ross, 1992; Snow et al., 1994). Homelessness excessively defined in terms of the "medical model" distracts attention 
from more fundamental and controversial questions pointing to economic and social factors (Snow, Baker, Anderson, \& Martin, 1986).

Researchers generally agree that both personal disabilities and economic marginality disproportionately affect homeless individuals and that these characteristics pose significant challenges to exiting homelessness (Sommer, 2000), but those researchers who are examining structural theories emphasize that economic and social trends, combined with governmental policies, are more than an environmental backdrop to the problem, and instead are critical factors that drive levels of homelessness. Within this perspective, a number of causal factors are considered to play a role in the rise of homelessness: the transformations in the labor market, changes in family structure, capitalist economies, transition to a postindustrial society, economic dislocation, deinstitutionalization of the mentally ill, the growing rate of poverty (Adams, 1986, Belcher \& DiBlasio, 1990, Dear \& Wolch, 1987, Jencks, 1994, Lang, 1989, as cited in Shlay \& Rossi, 1992; Koegel, Burnham, \& Baumohl, 1996, Marcuse, 1988, as cited in Sommer, 2000; Wright et al., 1998), the deterioration of public benefits (Shlay and Ross, 1992), and the decline of singleresident occupancy (SRO) units and a shortage of affordable housing (see Shlay \& Rossi, 1992). The two major causes of homelessness are noted by a number of researchers as unemployment and long-term joblessness (Burt \& Cohen, 1990, as cited in Shlay \& Rossi, 1992; Rossi, 1989; Sommer, 2000) and the decline in low-income housing options (Wright et al., 1998). All of these factors have led to an increasing number of poor Americans with limited financial resources to spend on housing. 
In addition to research on the causes of homelessness, researchers taking the S-perspective explore a central question on the condition of homelessness, not as a trait, but as a temporary state. Is homelessness a transitional or episodic condition lasting a relatively short period of time, or is it a more permanent and chronic condition (Burt \& Cohen, 1990, Freeman \& Hall, 1987, as cited in Shlay \& Rossi, 1992; Rossi, 1989)? One to two yearlong longitudinal studies show that there is considerable variation in duration (Burt \& Cohen, 1990, as cited in Shlay \& Rossi, 1992; Rossi, 1989), but that a large proportion of people experience homelessness episodically, finding places to live from time to time (Rossi, Fisher, \& Willis, 1986, as cited in Shlay \& Rossi, 1992; Wong, Piliavin, \& Wright, 1998). In fact, large national telephone surveys show that only a small proportion of the population is continuously or chronically homeless (see Toro \& Janisse, 2004). Consistently, the strongest predictors of transitioning out of homelessness include receipt of income maintenance benefits and subsidized housing (Wong, 1997 as cited in Sosin, 2003), with family relationships also a predictor of locating and remaining in housing (Metraux \& Culhane, 1999). From the S-perspective, understanding the multiple pathways into and out of homelessness is key to developing policies and structural supports that help to end homelessness and alleviate poverty. This perspective reflects recognition of the dynamics of homeless situations, and the influence of changes in social values over what constitutes adequate housing (Shlay \& Rossi, 1992). 


\section{Societal Responses to Homelessness from the S-Perspective}

Those who work with or study homeless people agree that more low-cost housing, with a long-term approach, is the only permanent way to resolve homelessness (Johnson \& Cnaan, 1995), yet most of the programs and policies in place deal with homelessness in the short-term, as emergency situations (Buss, 1990, Redburn \& Buss, 1986, as cited in Sommer, 2000). Since the 1800s, our primary response as a society to homelessness has been quick fixes through emergency interventions (Buss, 1990, Redburn \& Buss, 1986, as cited in Sommer, 2000; Hopper, 2003). Emergency shelters provide temporary relief at best, not solutions (Toro \& Warren, 1999), and they are often viewed as poor quality, unsafe environments which are avoided by many unhoused persons (Huttman, 1988, Rossi, 1989; USDHUD, 1989). In fact, during the 1980s, the large and impersonal National Guard Armories functioned as emergency housing to handle the rising increase in the very poor, much like many shelters today, with lines of cots in large open areas leading to the revival of the term "warehousing the poor" (Wright, 1997, p. 214). Within this historical view, it becomes clear that our way of thinking and responding to homelessness has not changed significantly, and we continue to avoid allocating funds to get at the root of the problem (Hopper, 2003).

Some researchers see a contradiction between research and policy: our current knowledge of homelessness is not consistent with our actions to resolve the problem (Jahiel, 1992). In the literature, the most cited explanation for increased homelessness has been the decline in affordable housing (Burt, 1997, as cited in Sommer, 2000), 
although the I-perspective of individual causality continues to pervade much of our research and response over the decades. Professionals consistently suggest enhanced public assistance as a viable approach to reducing homelessness, yet the political will for such an approach appears entirely absent (Rossi, 1989).

Contrary to this suggestion, various state and federal welfare reforms continue to move in the opposite direction by making it increasingly difficult to obtain public income assistance (Toro \& Warren, 1999). The diminishing amount of low income housing (Housing Shortage, 1998 as cited in Toro \& Warren, 1999; Shinn, 1992) and the ongoing cuts in public welfare benefits (see DeOllos, 1997) show that the Sperspective approach of long-term solutions to homelessness remains a theoretical approach with minimal implementation at present. With the continued rise in requests for shelter and a lack of shelter space nationwide, it is apparent that emergency measures aimed at addressing the immediate needs of homeless persons are inadequate. Nevertheless, most of the money currently spent on homelessness is still used to provide emergency services (Toro \& Warren, 1999), rather than being used on S-perspective-based programs with a longer-term focus.

Researchers and practitioners have sought to explain the perceived failure within the U.S. to develop more preventive policies that would address the root or structural causes of homelessness. One explanation thought to be influential in shaping the federal response was the political and ideological environment of the 1980s. Many saw the Reagan and Bush administrations as dominated by conservative ideology and economic principles that promoted capitalism and individual responsibility for 
economic success (Jahiel, 1992). In commenting on the rising problem of homelessness in the 1980s, President Reagan expressed his viewpoint, shared by the administration, "They make it their own choice for staying out there. There are shelters in virtually every city, and shelters here, and those people still prefer out there on the grates or the lawn to going into one of those shelters" (Miller, 1991, p. 161).

Some professionals comment that another explanation for the federal government's inaction since the McKinney Act of 1987 may be that homelessness has faded as a political issue and has simply become routine and expected, ceasing to elicit sympathy or public demands for action (Hopper, 1998). The public has become numb to the situation; “the difference between past [the 1980's] and present is the public acceptance of homelessness as part of our society" (M. Stoops, NCH, personal communication, August 12, 2005, p. 2). Others speculate that the increased visibility of shelters and other programs may serve to contain, and therefore hide, the problem, leading the public to perceive the problem as resolved (The Economist, 2000 as cited in Sommer, 2000).

However, public opinion polls between 1987 and 1993, as well as more recent surveys, have found little or no evidence for "compassion fatigue" (Link, Phelan, Bresnahan, Steuve, Moore, \& Susser, 1995, p. 535, as cited in Buck, Toro \& Ramos, 2004). Surveys in 1994 and again in 2001 reveals that the public continues to demonstrate generally compassionate attitudes toward the homeless (see Tompsett \& Toro, 2004), even acknowledging that there are multiple causes for homelessness mostly rooted in structural factors and not lack of individual effort (Buck, Toro \& 
Ramos, 2004). Over the years, the stereotypical views of homelessness have appeared to lessen, while a willingness to support additional housing and services have increased. When asked in the most recent 1994 national poll, 65\% of Americans nation-wide expressed willingness to pay $\$ 25$ more per year in taxes to help homeless persons (Manrique \& Toro, 1994 as cited in Toro \& Warren, 1999). It must be noted, however, that this poll was taken at the height of the 1990s high-tech boom, and before the more recent economic downturn at the turn of the century. Nevertheless, we find a change in perspective in the public realm that is shifting away from the individual-centered approach (Buck, Toro, \& Ramos, 2004). The S-perspective may have gained some foothold in our perceptions, but has yet to have an influence on changes in governmental policies.

Some advocates critique their own advocacy strategies for gaining federal support and funding in the 1980 s as a contributor to the current inadequate governmental response to homelessness (Blasi, 1994; Hoch \& Slayton, 1989; Rosenthal, 2000). Most consider the advocacy efforts to have been successful in moving the issue of homelessness to the policy arena, gaining support and funding for basic needs and services (Marcuse, 1988, as cited in Wright \& Vermund, 1996; Blau, 1992). However, in doing so, advocates may have portrayed homelessness in a way that relieved the homeless of any moral responsibility for their condition, and reinforced the view of the unhoused as dependent, isolated, and different.

Advocates often emphasized certain segments of the population (mainly the disabled and families) to evoke maximum sympathy and response (Burt, 1992; 
Wright, 1988), presenting them as helpless victims of circumstance. As a result, the response was constrained by political and ideological factors within the dominant Iperspective, resulting in consensus to provide emergency shelter and services to contain and treat the poor (consistent with the view of the very poor as helpless) rather than to address the more structural causes of homelessness (Jahiel, 1992), as expressed in the S-perspective. Wright (1997) suggests that advocates may have captured public sympathy at the cost of relieving public pressure for action, allowing the avoidance of adopting more costly long-term solutions and policies that address root inequalities in power, property, and privilege (Wright, 1997).

Advocates may have won the battle, but not the war, as they have come to realize that the current crisis-based response to homelessness avoids the opposition of those advantaged by the status quo (Jahiel, 1992). From this perspective, many argue that short-term emergency based services (e.g., shelters, soup kitchens, food and clothing) are the least expensive interventions and ones that provide the appearance of concern and action. They are our "patchwork remedies" that will help to resolve our guilt and responsibilities, but never help to resolve homelessness. Long-term changes are considered essential for the eradication of homelessness, and these include politically and economically difficult policies such as revising the US social welfare policy, expanding the availability of job training programs, enlarging public and private support for increasing availability of low-income housing and SROs, increasing minimum wage, and guaranteeing health and education to all (Hoch \& Slayton, 1989; Johnson \& Cnaan, 1995; Shlay \& Rossi, 1992). 


\section{Community-Contextual Perspective on Homelessness}

From the C-perspective, homelessness is not a story about difference or commonality since it accepts that both co-exist. Rather, it is a tale about citizenship and power. The plot parallels the story told by the S-perspective in that it acknowledges structural social inequities, although in the C-perspective, it is a backdrop instead of a main focus. Unlike the S-perspective, this story highlights who instead of what: who is left out and how, and who is denied rights and control over their own lives. The story zooms in and focuses on the lives of individuals within the harsh and disparate condition of homelessness, highlighting another layer of complexity through their varied stories, their intentions, experiences, and interactions with authority and the homeless helping system. The protagonists in this story are those who are excluded and marginalized, without a home or place to exist without harassment from authorities. However, in this story, the main characters are not portrayed conventionally as disabled and helpless. As individuals, they may be oppressed and lack power, but they are by no means helpless. This narrative tells the story of strength and humanity that is absent in our dominant cultural narratives. The strength and power of community is realized when people come together as a collective to improve their own condition.

Through both individual and collective stories, the C-perspective utilizes the concept and meaning of home as a critique of political freedom. The home signifies the autonomy to have control over our own lives and the ability to pursue our longterm goals. Losing home signifies losing your place in society and finding yourself in 
a "contested landscape" (Wright, 1997). The C-perspective is a story about a class of Americans who not only lose their homes and possessions, but lose their most fundamental rights as citizens: their right to have a voice and be included in decisions that affect their lives, to have the choices and freedoms granted to all other citizens. It is a story that critiques, but does not wallow in, the disempowering processes and effects on those who are marginalized. Mostly, it tells a story of empowerment and collective action to change the status quo, to create places and spaces where voices can be heard and where actions have an impact on improving the conditions for communities marginalized by homelessness. This is a story about taking collective action to reclaim democracy.

View of Academic Literature from the C-perspective

While the I-perspective focuses on the individual and the S-perspective centers on societal structures as causes to homelessness, the C-perspective points to processes and power dynamics at the community level. It views the power dynamics between individuals and their immediate environments as critical factors in producing homelessness, structural inequities, and the marginalization of the poor. Unlike other perspectives with a more static conceptualization and response to homelessness, this perspective contextualizes the issue by examining the linkages and processes between the differing perspectives on homelessness. The intention is to raise critical awareness of our role in exacerbating the problem by illuminating the consequences of our responses on those directly affected by homelessness. 
The C-perspective critiques the dominant view of individual characteristics as a factor in causing homelessness as misleading. These researchers argue that current research findings remain valid, but the issue is more a matter of framing and interpretation of the data and research (Shlay \& Rossi, 1992). From the C-perspective, interpretation and meaning arises from understanding the immediate context within which unhoused persons negotiate. For example, when asking unhoused persons themselves, Snow and Anderson (1993) found little support for the commonly-held belief that many individuals choose voluntarily to be homeless. These researchers suggest a differing view that "homelessness may indeed be a matter of so-called choice for some people, but perhaps only when the few available alternatives are no more palatable than life on the streets. To the extent that this is true, the choice is of the lesser of evils and takes on a rather different meaning than if it were made in the face of more attractive options" (p. 254-255). What is choice without understanding the context in which that choice is made? Understanding individuals' experiences on the street and their struggles to improve their condition is critical in providing useful services that assist rather than impede individuals' pursuit of goals and assist exit from homelessness.

Research over the past two decades has focused on the causes of homelessness, and has raised important concerns in developing a response. However, few studies have attempted to understand the daily lives and struggles of homeless people in order to develop a response that will help people without taking away their autonomy, dignity, and power (Hill, 2003). A recent study by Morrell-Bellai, Goering, and 
Boydell (2000) asks homeless individuals about their experiences entering and exiting homelessness. They found that in the early stages of homelessness, feelings of helplessness and powerlessness are not typical and do not contribute to causing their homelessness. In fact, their research shows that when people initially find themselves homeless, they are highly motivated to find work, to find decent housing, and to obtain supportive counseling for the emotional issues that contributed to their homelessness. However, over time, individuals experience a number of barriers to accessing appropriate employment, housing, and supportive counseling and gradually lose hope in their ability to resolve their homeless situation.

Morrell-Bellai et al. (2000) suggests that exiting homelessness is delayed, not because of choice or individual deficits, but rather as a result of limitations of shelters and other programs to provide services beyond those that meet basic survival needs. This study, along with many not specifically cited here, illustrates the importance and value of unhoused individuals' perspective in understanding homelessness and the impact of policies and programs. Shifting from an almost exclusive focus on individual characteristics to an emphasis on the ecology and context of homelessness will take us closer to resolving homelessness and reducing poverty (Koegel, 1992).

Currently, only a relatively small proportion of studies within the social sciences views homelessness through the lens of the C-perspective (Wagner, 1993). A radical departure from conventional perspectives and from other accounts of homelessness, the C-perspective challenges the dominant portrayal of homeless individuals as vulnerable and dependent people worthy of sympathy. Rather, they are 
viewed as people worthy of respect and equality. In spite of the positive accomplishments by advocates in the 1980s for homeless people, there continues to be an unrelenting view of pathology on the streets that obscures the strengths of the homeless and portrays them as lacking political and social awareness of their conditions (Wagner, 1993). The common view of homeless persons as passive victims of society is reflected in our treatment and exclusion of their voices and perspectives in our research (Wagner, 1993).

Within public debates about poverty and in the social science literature, the voices of the poor are noticeably absent in issues that directly impact their lives (Wagner, 1993). Wagner (1993) argues that "only a small ethnographic tradition within the social sciences and an occasional militant protest by the poor serve to give voice to their views" (p. 3; e.g., William Whyte, 1966; Herbert Gans, 1962; Elliot Liebow, 1967; Carol Stack, 1974 as cited in Wagner, 1993). Homeless people are not disaffiliated, dependent, or socially disorganized as portrayed by many researchers. The C-perspective illuminates how street people develop their own self-consciousness, culture and alternative communities that challenge the status quo (Bahr, 1973, as cited in Shlay \& Rossi, 1992; Blau, 1992; Rossi, 1989; Wagner, 1993).

Far from being isolated, some studies have shown that many homeless individuals develop intricate and cohesive social networks of friends and companions (Wagner, 1993), and describe themselves as serious, loyal, and trustworthy friends to others (Snow \& Anderson, 1987). Strong ties within the street community suggest that collective approaches that build on existing social networks may provide a more 
natural and empowering process for assisting poor people in obtaining housing and other benefits (Wagner, 1993). Within the literature, only a few studies explore the development of communities and encampments on the street (Fishman, 1993; Phillips \& Hamilton, 1996; Rivlin \& Imbimbo, 1989; Wagner \& Cohen, 1991; Wright, 1995), or mention the existence of social protest among the homeless (Cohen \& Wagner, 1992; Fabricant \& Kelley, 1986; Ropers, 1988), or describe the emergence of a social movement (Blau, 1992). The persistent focus in the literature and media on homeless persons' vulnerability tends to deny as well as nurture resistance to their potential social consciousness, political power, and humanity both as individuals and as a collective (Wagner, 1993).

Research from the C-perspective explores not only the disempowering processes of homelessness in the socio-political power structure, but also the empowering processes created by many individuals on the street through the formation of democratically governed communities. While often depicted in the literature as politically disempowered and disabled, a small body of work reveals the strengths of homeless people (Cohen, Teresi, Holmes, \& Roth, 1988; Grigsby et al., 1990, La Gory, Ritchey, \& Mullis, 1989, Rosenthal, 1989, as cited in Wagner \& Cohen, 1991; Snow \& Anderson, 1987). Much of the research from this perspective explores the experience of homelessness from the perspective of persons on the street, focusing on relevant topics such as dignity and self-worth (Finley, 2003a; Miller \& Keys, 2001; Osborne, 2002; Seltzer \& Miller, 1993; Snow \& Anderson, 1987), well-being (Biswas-Diener, 2002; Riggs \& Coyle, 2002), and empowerment (Cohen \& Wagner, 
1992; Rocha, 1994), as well as descriptions of the resistance tactics of the homeless that include squatting in abandoned buildings (Wright, 1997), public theatrical performances and poetry readings (Burnham, 1987 as cited in Wright, 1997), the organization of homeless unions and cultural productions (Paschke \& Volpendesta, 1991; Wallis, 1991 as cited in Wright, 1997), and the occupation of boarded-up houses and public squares (Wright, 1997).

It asks those who are involved in homeless research and policies to critically examine our positions and agendas, and the ways in which we have helped to maintain the status quo and resisted possibilities for change and improvement by not listening to the voices that have been pushed to the margins. In contrast to the other perspectives, the $\mathrm{C}$-perspective opens these lines of communication to other voices and perspectives excluded from debates on poverty and homelessness.

In line with the values of social justice, democracy, and empowerment within the C-perspective, researchers often approach their work as engaged participants rather than disengaged observers. Hopper (2003) critiques anthropology and traditional research on homelessness as "mute guides to its eradication. Though they go to the heart of what it means to be homeless, none of them has a thing to do with resolving it" (p. 207). How much longer shall we focus our attention on analyzing the causes of homelessness? Hopper (2003) argues that "like Dante's underworld visitor, we have wandered through this fresh hell, taking note of familiar faces, ruined lives, and dashed hopes, leaving little trace behind. Writing well may be a kind of revenge — but against whom, exactly?" (p. 205). 
Within this context, Hopper (2003) considers these observational writings "parasitic texts" because they describe and provide commentary but lack any form of engagement and consideration for the "well-being of those whose lives and cultures they study" (p. 205). He supports Liebow's (1993) moral argument by asserting, "Forget about how they got here, no one deserves to be treated like this" (Hopper, 2003, p. 206). From this perspective, researchers are urged to "take up their pens and their cameras, paintbrushes, bodies, and voices" (Finley, 2003a, p. 689) and to take action, not as experts or as treatment professionals, but as participants in a movement for social justice against the "oppressive structures of our everyday lives" (Denzin, 1999, p. 572, as cited in Finley, 2003a, p. 689).

Since the 1980s, an abundance of surveys has been conducted by professionals and service providers to detail the characteristics (e.g., Rossi, Wright, Fisher, \& Willis, 1987), needs (e.g., Cohen et al., 1988), and disabilities (Fischer \& Breakey, 1991) of homeless people. However, with the exception of a small number of studies, very few researchers have taken a participatory or collaborative approach to their research by involving homeless individuals as equal partners in the research process. Participatory research can create empowering processes for participants as they engage in and gain control over their learning as well as their futures. Literature on homeless encampments and on self-help programs demonstrates that homeless individuals can be helped and can help each other without the guidance of professionals (Cohen \& Wagner, 1992; Rivlin \& Imbimbo, 1989; Wright, 1997). The critique of power dynamics, even in the arena of science between the researcher and the researched, are 
reflected in the participatory research approach of the C-perspective. Some researchers call for a C-perspective research approach that moves from interpretation and theory to empowerment and social change (Denzin, 2003; Finley, 2003a).

Traditionally, researchers communicate their views to professionals through technical reports, papers, and ethnographic accounts. In accordance with the Cperspective orientation, researchers and other professionals use a variety of reporting formats to communicate and empower those affected by homelessness, creating reports based on the differing requirements and goals of their audiences. Some of the reporting formats include performance art, poetry, documentaries, political protests, community action plans, and creative writing. "The stories that impact us most deeply are often communicated in social settings through art, song, mass media and dramatic performance" (Mankowski \& Rappaport, 1995, p. 212). Research within this ideology uses storytelling to communicate a different perspective, often excluded in society, as a way to make research accessible and available to all persons, and not just those of privilege and power.

View of Societal Responses to Homelessness from the C-Perspective

While the I-perspective response to homelessness focuses on short-term crisis interventions, the S-perspective sets its sights on more far-ranging, long-term solutions involving broad social and political change. The approach of the C-perspective aims for more practical, middle-range responses, attempting to provide necessary steps along the path to long-term social change. The C-perspective critiques the current 
response to the social problem of homelessness as being conceptualized in ways that do not threaten established institutions and that avoids any threats to assumptions within the I-perspective. This response to homelessness has been considered by many advocates to be "an inevitable consequence of the detachment of homelessness from the problems of poverty and growing inequality, and the further oversimplification of homelessness itself" (Blasi, 1994, p. 568). More serious and socially responsible efforts to resolve homelessness, by contrast, would entail a re-examination of existing power inequalities in economic and social institutions, in order to challenge the status quo and make real change happen (Edelman, 1987 as cited in Toro \& Warren, 1999). So far, our response has mainly been piece-meal and reactive, with little forethought and overall planning for broad solutions aimed at ending homelessness.

Every response and action has consequences for the system as a whole, both intended and unintended, regardless of initial intentions. The C-perspective is critical of the consequences of short-term shelters and the strict enforcement of existing local ordinances that criminalize or severely restrict the activities deemed necessary by those living in public spaces, such as sleeping, panhandling, and even sitting (NLCHP, 1999; NCH, 2006).

The intent of emergency shelters is to fulfill the basic needs of people experiencing homelessness on any given night (e.g., a warm bed, hot food, and a shower). Within their scope and specific purpose, shelters have established a set of rigid rules, regulations, and procedures designed to promote the smooth operation of the institution in order to provide basic services to the maximum number of people 
every night, within the limits of their funding and resources. However, despite the multitude of rules and regulations, shelters are often perceived to be unsafe and a place where crimes against persons and their property commonly occur (Hopper, 2003; Rivlin \& Imbimbo, 1989; Snow \& Anderson, 1993; Wright, 1997). There are a number of other troubling problems with many of the shelters within the existing system. Many shelters do not provide facilities for families or couples, who may be forced to break up, abandon their children, or turn children over to foster care (Kozol, 1988, Waxman \& Reyes, 1987, as cited in Rivlin \& Imbimbo, 1989). The number of hours that a person is allowed to spend in a shelter is constrained and often at odds with finding employment or maintaining employment at atypical hours such as graveyard shifts. People are required to leave the shelter during the morning as early as 5:30 am and begin standing in line as early as 4:00 in the afternoon to ensure getting a bed (Rivlin \& Imbimbo, 1989). Even more troubling is the view by many shelter users that the majority of shelters are unsanitary and degrading (Hopper, 2003; Snow \& Anderson, 1987, 1993; Wagner, 1993; Wright, 1997).

In order to use shelter services, individuals cope with various types of “degradation ceremonies" that are perceived to impinge on one's sense of dignity, respect and freedom (Garfinkel, 1956 as cited in Wright, 1997). The excessive rules within a shelter dictate when and where residents stay, eat, bathe, and sleep, limiting the autonomy of residents to make even simple choices that affect their lives (Gounis, 1992; Seltser \& Miller, 1993; Stark, 1994). Wright (1997) explains that "every attempt to satisfy a human need — whether securing clothes or finding a bed for the night — is 
met, from the squatter's perspective, with degrading procedures and extended waits that communicate the homeless individual's worthlessness" (p. 220). "Clients are processed in an impersonal, highly structured, assembly-line fashion," waiting in long lines to receive services (Snow \& Anderson, 1987, p. 1352), then crammed in a warehouse-like facility with rows of beds side by side, communal showers, and unsanitary conditions, often with little privacy or choice, and in some cases people are required to attend Christian religious services in order to receive services (Golden, 1992; Grunberg \& Eagle, 1990; Huttman \& Redmond, 1992; Rivlin \& Imbimbo, 1989; Seltser \& Miller, 1993; Snow \& Anderson, 1987, 1993). Many individuals who have used shelters mention the rampant lice infestations (Wright, 1997), and tell stories of intimidation and harassment from shelter employees (Hopper, 2003; Wright, 1997). Shelters with treatment-oriented ideologies seem to have reproduced external networks of domination and power through excessive rules where the homeless are treated as either "a soul to be saved or a body to be repaired" (Wright, 1997, p. 216). While it is not the case that every shelter conforms to these descriptions and practices, the commonality of these negative perceptions indicates a valid and troubling perspective that should clearly be brought to light.

To many homeless adults, using a shelter means submission to a rigid discipline and overbearing authority that many find intolerable and dangerous for one's body and self-respect (Wright, 1997). Shelters are often perceived as places of last resort, avoided whenever possible (Wright, 1997). When a task force in California interviewed 182 homeless people on the street and in shelters, they found that only a 
small proportion of individuals slept at a mission or in shelters $(11 \%)$, while the majority chose to hide in bushes, streets or alleyways, in abandoned buildings, on roofs, and in other makeshift places (Dowell \& Farmer, 1992).

According to interviews of homeless men by Hopper (2003), individuals commented that "sure, the streets were rough...but [at least] you could keep your 'dignity' there” (p. 93). It was considered an insult to one's autonomy, dignity, and self-respect as an adult to be ordered about and treated in this fashion. Living on the streets instead of in the shelter meant preserving one's "spirit and sense of identity," dignity, and self-respect (Hopper, 2003, p. 98; Miller \& Keys, 2001; Seltser \& Miller, 1993; Snow \& Anderson, 1993; Wright, 1997) as well as “personal control over one’s surroundings" (Wright, 1997, p. 219). Those who chose not to use shelters viewed themselves as more independent and resourceful, while those who used shelters coped with their experiences by preserving a critical awareness of shelters as "greedy corporation[s] run by inhumane personnel more interested in lining their own pockets than in serving the needy" (Snow \& Anderson, 1987, p. 1352). A number of researchers suggest that most homeless shelters currently function in ways that perpetuate homelessness by fostering social disaffiliation, learned helplessness, and a loss of power, self-worth and hope (Cohen \& Sokolovsky, 1989; Goodman, Saxe, \& Harvey, 1991; Hopper, 2003; Osborne, 2002; Rosenberg, Solarz, \& Bailey, 1991; Snow \& Anderson, 1993; Wright, 1997).

Despite the continued use of shelters as the primary response for housing homeless individuals, most professionals and service providers agree that it is a poor 
substitute for adequate low-income housing and a home. Resources that meet basic needs of homeless persons can also be socially responsible and respectful in ways that offer opportunities to participate in the community and promote dignity, selfsufficiency, and self-worth (Miller \& Keys, 2001; Snow \& Anderson, 1993). When shelters no longer "contain" the poor, either because of the limited number of available beds or because of unacceptable conditions that lead to individuals' refusal to use them, street persons become more visible in the public eye (Wright, 1997). Some number of persistent and vocal groups of local businesses, property owners and shoppers routinely complain of homeless persons disrupting their commerce, their safety, and peace of mind (e.g., panhandling) and pressure local politicians and authorities to become more vigilant in enforcing/maintaining proper social boundaries (Snow \& Anderson, 1993; Wright, 1997). Neighborhoods, businesses, housed citizens, and authoritative decision makers decide which place is considered "proper" for homeless persons to meet the public gaze (Wright, 1997). Examples of this response of NIMBY-ism (Not-In-My-Back-Yard) can be seen in organized protests against locating facilities, treatment centers, and other services for the poor in certain areas, particularly in middle- or upper-class communities or near a particular business (Beggs, 1993, Dear, 1992, as cited in Sommer, 2000; NLCHP, 1997; Takahashi, 1997).

A further example of the NIMBY-ism response can be seen under the guise of policies linked to urban revitalization and "quality of life" efforts (Maggs, 1999, Nieves, 1999, as cited in Sommer, 2000) which pass restrictive ordinances to exclude 
homeless persons from downtown areas (Stoner, 1995; Wright, 1997). According to two different surveys, $85 \%$ of major cities nationwide had laws prohibiting or restricting begging, sleeping or camping in public space (National Law Center on Homelessness and Poverty [NLCHP], 1999; NCH, 2003). Meanwhile, all of the communities surveyed lacked enough shelter beds to meet demand (NCH, 2003), with one study by the US Conference of Mayors (2005) revealing that $16 \%$ of those people actively requesting shelter are unable to access it, and an even larger percentage (32\%) of homeless families are unable to access shelter.

As people sleep outside with nowhere else to go, they are awakened by police who either arrest them or fine them for camping or sleeping outside, or if they are lucky, they are only ordered to "move along" (NCH, 2003). One police officer explained, "The problem with the homeless... is not necessarily how criminal they are, but how the public perceives them to be criminal. What is actually true and what the public feels or is afraid of may be two different things" (Snow \& Anderson, 1993, p. 99). Neighborhoods pressure police and authorities to be more vigilant toward the homeless, and therefore their role as police, according to one police officer, is to "keep the homeless out of the face of other citizens" (Snow \& Anderson, 1993, p. 100). Unfortunately, these policies tend to criminalize the homeless by preventing the very activities necessary for their survival while homeless (NCH, 2004). Criminalizing these basic activities makes daily survival and exiting homelessness even more "difficult, depressing, demoralizing, and frightening" (NCH, 2004, p. 7). The result of these ordinances is that it simply perpetuates the problems of 
homelessness and creates a public environment of intolerance. It appears that our social responses may have unintentionally led to policies that focus on "eradicating the homeless" rather than on "eradicating homelessness" (Amster, 2002). Our current policies created to "help" homeless individuals through guidance and coercion raises questions about acceptable social practices, freedom, equality, and citizenship entitlements of homeless people (Stoner, 1995). "Citizenship in itself represents many things: exclusion and inclusion, a norm of political identity, and territorial belonging" (Stoner, 1995, p. 135). Rights to occupy public space and to make decisions that affect one's future are tied to citizenship and to homeless individuals' worth as human beings (Stoner, 1995). Redirecting our response within the path of interdependence, humanity and social responsibility seems a more honorable route, even though historically a road less taken (Arnold, 2004).

\section{Summary and Synthesis of I-S-C Perspectives}

I have described the three I-S-C perspectives in an attempt to clearly delineate the aspects that make them both different and similar in their conceptualization, approach, and response to homelessness. I must, however, reiterate that my described framework provides more clearly differentiated boundaries and polarity than may actually exist. The I-S-C multiple perspectives are a framework for gaining a deeper understanding of homelessness and a tool for nurturing a critical awareness of our shared beliefs, mental models, and assumptions that guide and shape our research focus and interpretations as well as our response to homelessness. 
Many researchers and practitioners share perspectives that bridge these prototype perspectives described in this chapter, emphasizing different elements within each. It would be far too simple for individuals to fit completely into one perspective or ideology or to take only one view at all times. More recent research illustrates this point in its synthesis of perspectives. Sosin (2003) calls these "pioneering individual-level explanations" that integrate the I- and S-perspectives. From this perspective, homelessness occurs in an environment with limited resources and structural inequities, where individuals with disadvantages of limited human capital or other personal problems compete in a highly competitive market in search of and in maintaining housing and employment (Sosin, 2003). This view places the individual in context and refuses to place blame on individuals for their condition while acknowledging their disadvantages (Sosin, 2003). A number of researchers agree that the search for housing, just like other limited resources, is an active competition in de-industrialized cities, and that those with serious disadvantages fare the worst in obtaining income from employment, shared living space, subsidized or low cost housing, welfare supports, help from social programs, and assistance from relatives (Baxter \& Hopper, 1981, as cited in Shlay \& Rossi, 1992; Hopper \& Baumohl, 1994; Hopper, Susser, \& Conover, 1985; McChesney, 1990; Sosin, 2003). It seems clear that a synthesis of a variety of viewpoints will have the greatest impact for social change. 


\section{CHAPTER FOUR}

\section{A SYSTEMS LENS:}

\section{A DYNAMIC PERSPECTIVE ON HOMELESSNESS}

From a systems perspective, the story of homelessness is a tale of multiple perspectives. Characters are not depicted as one-sided, as good versus evil, but instead multi-dimensional and complex. The main characters are the stakeholders involved in analyzing and solving homelessness. They are numerous and cannot be distinguished as either protagonists or antagonists in the story. All play a part, helping to maintain and/or end homelessness. Each character is valued equally for his or her partial truths and insights into the homeless situation. As the story develops, the situation of homelessness worsens and unintended effects emerge. We begin to see how each character in the story acts independently, focusing on one perspective of the situation. Over time, as we observe the story, we begin to notice patterns. We begin to see how characters' actions sometimes resonate with and facilitate one another, but most of the time how they impede or limit one another, causing either no change or unexpected consequences to occur. The linkages and interrelationships of these actions are not quickly or easily apparent; the consequences of the actions only emerge over time.

The moral of the story is that the system responds to each of our actions in ways that may not necessarily be good for the whole_-in this case, for ending homelessness. It becomes clear that everyone is part of the system, tied together and interdependent, and therefore also responsible for the problem. From the systems 
perspective, the story suggests that the next steps toward a solution reside in taking multiple stances so as to see the problem from each perspective and, at each level of analysis, to understand how the perspectives interact, converge, limit and drive the problem of homelessness. Only then might we find the points of leverage to make real long-term change happen, as intended.

This chapter attempts to synthesize, from a systems standpoint, the multiple perspectives on homelessness in the literature. I first discuss the limitations of each perspective in solving homelessness, and then describe a pathway out of homelessness that incorporates features of each perspective. From this dynamic perspective, I discuss how empowered homeless communities such as Dignity Village are a vital and necessary step along the multi-perspective pathway to dealing more effectively with homelessness.

\section{Limitations of Perspectives and Their Suggested Solutions}

Over the years, the magnitude of homelessness has failed to decrease, leading many people to question the effectiveness of our response to the problem (Sommer, 2000). My review of the literature demonstrates that we have painted too simple and incomplete a picture of the problem of homelessness, and over the past decade, responded in ways that reflect the limitations of our thinking. An effective response to solving homelessness in the U.S. would be: (a) pragmatic in implementing the necessary steps to either supporting pathways out of homelessness or preventing those from entering it in the first place, (b) humane in its response, and (c) based on 
scientific evidence. The dominant response in this country, implemented from the Iperspective, has not followed these principles. The following section reviews our limitations as a nation, from all three perspectives, in implementing a pragmatic, humane, and scientifically-based response to homelessness.

\section{Dominant I-perspective Limitations}

\section{Non-pragmatic}

The consequences that have emerged from America's response to homelessness demonstrate the limitations of our dominant way of thinking from the Iperspective. Our response has been driven by emotions and a sense of urgency rather than a pragmatic and realistic implementation of efforts to address homelessness. A large proportion $(85 \%)$ of federally funded programs provides emergency housing and services designed for a sub-population of homeless persons who are mentally ill, physically disabled, or addicted to drugs (Fuchs \& McAllister, 1996, as cited in Sommer, 2000; ICH, 1999). Other short-term "tough-love" measures, such as legislation to limit the public view of homeless persons, may temporarily reduce public outcry, but do nothing to improve conditions for homeless persons and to reduce or prevent homelessness for the many more individuals who will fall into it.

With the I-perspective response, we have seen no decline in homelessness, only new patterns and problems that have emerged over time, such as increases in the amount of legislation in cities across the nation to discipline individuals on the street who refuse to use shelters, as well as increases in the number of requests for 
emergency shelters due to a lack of adequate shelter space. Undoubtedly, many of the emergency services play an important part in supporting some number of homeless individuals. However, the overall approach remains limited in implementing a realistic plan for solving homelessness long-term. We lack clear and practical steps toward achieving our long-term solutions (e.g., affordable housing) and specific goals to ending homelessness.

\section{Inhumane}

America's response to homelessness has not only been impractical, but the Cperspective literature clearly demonstrates how the response has also been inhumane. Interviews of homeless people highlight the undignified aspects of our response. Shelters impose rigid and unthinking controls on everyday aspects of homeless persons' lives, and public ordinances criminalize individuals who sleep outdoors in public spaces, either to avoid shelters, or because of a lack of shelter beds. From our response, it appears as if we are attempting to block every autonomous effort by an individual to establish a home base and to get out of homelessness. This response is consistent with a view of homeless individuals as "damaged" people unable to help themselves, and thus can easily overlook the basic humanity in every individual.

\section{Unscientific}

Our dominant view of homeless people as damaged has guided not only our approach to providing services, but also our research focus, methodology, and interpretation of data on homelessness (Shlay \& Rossi, 1992). Most research focuses 
on the deficits and pathologies of individuals, often suggesting a causal link between personal pathologies and homelessness (Sommer, 2000; Sosin, 2003). There is no scientific basis for this causal claim. First, very few research studies are longitudinal, and certainly not experimental in design. Causal explanations can thus only be speculative, and alternative explanations and pathways are just as likely to be found as a cause of homelessness. For example, one third of the homeless population may be mentally ill, but that does not necessarily mean that mental illness caused their homelessness, and in fact the stressful conditions of poverty and lack of resources and health care may exacerbate mental and physical conditions (Link et al., 1995; Phelan \& Link, 1999; Sommer, 2000; Sosin, 2003; Wright et al., 1998). Furthermore, comparative studies show substance abuse, a characteristic thought to be proportionally high in the homeless population, as similar in proportion to those housed individuals who live in poverty (Kessler, McGonagle, Zhao, \& Nelson, 1994).

Second, many characteristics of the homeless population may be overrepresented or misrepresented due to biased research sampling and limited access to a diverse population. The majority of research from this perspective collects data from homeless individuals directly, or through service workers, in easily accessible and visible areas, such as emergency shelters and services. The concern is that data from a specific subpopulation is being generalized, and guiding the development of services. It is possible that individuals who use shelters and these services are in disproportionately poorer physical or mental condition, and have fewer options and personal resources to survive the pressures on the street. 
Another common interpretation of research on homelessness from the Iperspective is that homelessness is a chronic condition, yet the few longitudinal studies available have shown that homelessness is actually more episodic, and that very few individuals remain homeless chronically (Rossi, Fisher, \& Willis, 1986, as cited in Shlay \& Rossi, 1992; Wong, Piliavin, \& Wright, 1998). Research also suggests that successful pathways out of homelessness depend largely on available affordable housing, public benefits, and social support (Metraux \& Culhane, 1999; Wong, 1997 as cited in Sosin, 2003). Thus, there is no scientific basis for the claim that homeless individuals are a different type of people who are unable or unwilling to exit homelessness. Research from the S- and C-perspectives challenge these claims, demonstrating the political awareness of communities of homeless people, the experiences of homeless people utilizing the service industry, motivations to exit homelessness, community ties, and other strengths, which illustrate the humanity, diversity, and highly stressful and inhumane contexts in which they negotiate every day, not just to survive but also to attempt to climb out of homelessness. A look at the literature illustrates that our response is not based on scientific evidence, but rather on different interpretations of data and limitations in our view of the problem of homelessness. 


\section{S-perspective Limitations}

\section{Non-pragmatic}

The S-perspective adds another dimension to understanding and responding to homelessness, by reducing blame on individuals for their homeless situation and focusing on macro-economic factors which generate homelessness. Although this perspective promotes long-term structural changes that get at the root of the problem (e.g., affordable housing, public assistance, higher wages, and employment opportunities), its focus is fairly static and stops short of a realistic plan and clear processes to achieve these long-term goals. The S-perspective implies a solution to homelessness coming almost entirely from the top-down, believing that the only real and socially responsible solution resides in changing the socio-economic structure that will reduce poverty, not just homelessness. Although this view is clearly needed, if offers no steps toward this broader social change, and instead implies that homeless people, and others living in similar poor conditions, should wait for those in power to wake up and make these changes for the betterment of society. To some, this view takes on utopic, and therefore less pragmatic, qualities, particularly in light of the realities of the fluctuating demands and political interests in the U.S., and the capitalist foundations of our economic system. How much change can we expect from the topdown, without pressure and action from the bottom-up? 


\section{Inhumane}

Although the S-perspective views homeless individuals as "just like you and me" who are worthy of housing, its top-down approach can have unintentional heartless effects. Its long-term, macro-structural focus neglects the immediate needs of the homeless, with no steps in place to resolve suffering in the interim. The voices of poor people are noticeably absent from this perspective, reducing the dialogue that challenges existing practices and inequalities. Without action or pressure on the system to change from all sides, homelessness may only worsen, and many poor Americans will unfairly pay the price of this top-down focus.

\section{Unscientific}

Scientific evidence suggests that causes of homelessness include both microand macro-factors. The S-perspective alone does not incorporate these micro-factors, disregarding the commonality of pressures that might create a need for additional societal support for individuals within the homeless population. People experiencing homelessness are not "just the same" as everyone else, but may indeed have specific needs to assist in getting themselves out of homelessness (e.g., coping with specific stressors, traumatic experiences, etc). More recently, there have been a few longitudinal studies within the S-perspective on predictors for successful exit out of homelessness. More research is needed to integrate individual-centered findings with the larger structuralist concerns of politics, culture, and the economy (Blasi, 1994; Hopper, 1998; Wright, 1997). 


\section{C-perspective Limitations}

\section{Non-pragmatic}

Because the C-perspective focuses on processes and power dynamics in the local context, it offers more sensible solutions and processes for homeless individuals to exit homelessness and improve their situation. This perspective occurs mostly within the philosophy of self-help, and adds a dimension to understanding and responding to homelessness through establishing the importance of a home-base for individuals to improve their own situation, and for the potential empowerment of the homeless as a class. This view offers processes for homeless people to improve their immediate situation, but it is limited in its scope. Because it focuses on the immediate context, the C-perspective reduces the view of the processes and pathways for broader, more long-term changes in the inequitable economic structures that continue to generate homelessness. Although it offers hope for individuals living in the margins, it does not offer a broader perspective for society to 'solve homelessness' and to improve conditions in the long-term.

The predominantly grassroots and self-help philosophy of the C-perspective may unintentionally reduce pressure on the power structure and inhibit the conversation needed for social change. The view's emphasis on empowerment as a solution may be misleading by suggesting that simply empowering those who are marginalized to take action and make change can alone be effective in changing the power dynamics that maintain homelessness. Without considering the relationships 
among other parts of the system, social change efforts that threaten the existing power dynamics in the system will likely be resisted.

\section{Inhumane}

The C-perspective primarily focuses on improving the immediate conditions for individuals experiencing homelessness, and challenging the current inhumane practices in the emergency-based system. However, a rigid adherence to strict selfhelp concepts may result in unintentional consequences where homeless individuals must "go it alone" to a large extent, with minimal system support. It is not realistic or humane to expect homeless people, already encumbered by stress and circumstances, to carry the bulk of the burden for solving their problems without social support. The extreme version of this perspective runs the risk of focusing blame solely on individuals for not succeeding in their efforts to exit homelessness, rather than recognizing the array of additional factors and top-down processes involved in ending homelessness.

\section{Unscientific}

The C-perspective is an emerging viewpoint, and as such, its concepts are yet to be explored in broadly diverse samples and in longitudinal studies. Nevertheless, there have been a small number of studies that have investigated the strengths of homeless individuals and their political and social awareness of their conditions (Wagner, 1993). We must be careful in generalizing results at this stage, because these studies focus primarily on people who do not use homeless services, or who may have 
different coping skills or physical conditions than some other homeless individuals or sub-populations. These studies are often conducted locally to provide communities with information on resolving homelessness in their city specifically, rather than addressing any national approach. Future studies are needed to clarify the implementation of the C-perspective in our response to homelessness.

\section{Summary}

Traditionally, our understanding of homelessness is based on static perspectives with very few longitudinal studies that examine the pathways into and out of homelessness over time. The behavior of people experiencing homelessness has been looked at almost exclusively from an outsider's perspective and out of any context (Koegel, 1992). It is time to shift our thinking to a broader perspective that explores multiple levels and diverse perspectives in understanding homelessness. No single perspective holds the Truth about homelessness; all perspectives are limited in scope, conceptualization, and level of analysis and response. Thus, overemphasizing the value of one perspective or approach over the other will lead to ineffective policies and solutions to ending homelessness. Once the problem is defined by a dominant view, such as is currently the case in our focus on individuals' pathological characteristics, the range of effective solutions naturally becomes restricted to interventions that change those individuals (Levine \& Perkins, 1997).

In the end, it appears that our response to homelessness has been guided by our interpretations, self-interests, and ideological preconceptions, rather than by concerns 
for what is scientific, pragmatic, and humane. It is time to reflect on our filters of bias and begin a dialogue between multiple perspectives if we are to find an effective solution to ending homelessness in this country.

\section{A Dynamic Perspective on Homelessness}

A necessary step in reducing the impediments to ending homelessness is to carefully examine the main perspectives and responses to homelessness and the varying contextual processes that affect this response. A dynamic perspective on homelessness is needed to conceptualize and implement a pathway that will support homeless individuals in exiting homelessness, and promote enduring and effective change in reducing homelessness and the socio-economic inequities that drive it.

\section{A Dynamic Pathway out of Homelessness}

Systems thinking tells us that a multi-dimensional view of the problem comes with stepping back far enough to see the forest rather than just the trees, as it were, which will open new possibilities for seeing how the multiple levels, processes, and dynamics drive the emergence of homelessness (Senge, 1990). A systems perspective takes the best insights of multiple perspectives, in this case, the I-, S-, and Cperspectives, and creates a dynamic perspective of the larger picture of homelessness. By looking at multiple levels and perspectives, and by illuminating the underlying structures and processes that interact with and give rise to homelessness, we can begin to identify critical steps along a pathway out of homelessness - not only for individuals, but for society as a whole. 
In the remainder of this section, I describe my conceptualization of how the I-, S-, and C-perspectives can be framed as components along a developmental pathway out of homelessness. Figure 1a illustrates the foundations of the model upon which I build the dynamic pathway. Each perspective is reflected at points of "need" for homeless people, individually and as a class, that lead to new developmental stages toward a solution to homelessness. The micro-level and macro-level pathways spanning across

Figure 1a. Structure of an integrated model of a developmental pathway out of homelessness that incorporates three perspectives (Individual, Community, and Structural) on the causes and remedies of homelessness by depicting four stages, each corresponding to a set of individual/group needs and societal responses.
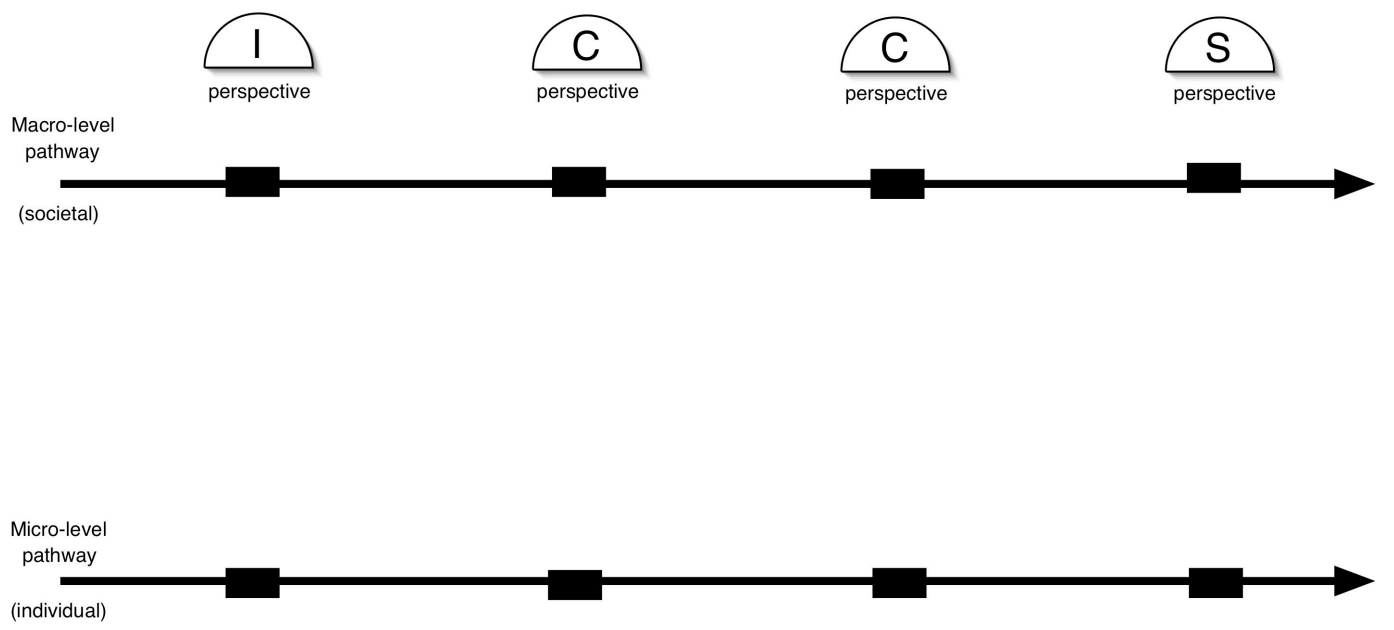
the perspectives illustrate how both individuals and society as a whole meet these needs in a parallel and interrelated manner. The micro-level pathway describes how individuals may gain housing, increased social welfare, and an improved economic condition. The macro-level societal pathway interacts with the individual pathway toward changes that may lead to effective social structural improvements and reduced homelessness. The discussion below follows the pathway from a first step emergencybased response to homelessness through social change with an exit out of homelessness, and describes four main areas of need and "crisis" points when facing some of the impediments that occur along the way.

\section{Survival Needs}

When individuals become homeless, their immediate concern is to find the basic needs to survive, mainly shelter, food, and clothing. This effort is represented in Figure $1 b$ by the vertical arrow pointing up from the individual pathway to the societal pathway. At a societal level, we have responded to this pressure (after much advocacy in the 1980s) by focusing our efforts toward meeting these basic survival needs. This response is depicted by the vertical down arrow from the societal pathway to the individual pathway.

The I-perspective tells us that individuals experiencing homelessness have special needs, although these are most likely related to coping with and surviving the stressful and complex conditions of poverty and homelessness, rather than pathologies specific to homeless people. Personal crises and mental or physical disabilities both 
make people more vulnerable and are likely exacerbated by poverty and homelessness (Link et al., 1995; Phelan \& Link, 1999; Sommer, 2000; Sosin, 2003; Wright et al., 1998). Thus, over many years, the I-

perspective response has been to develop emergency services for a large and diverse homeless population that attempt to provide basic survival and health needs, such as shelter, food, clothing, health care, welfare benefits, housing, and welfare subsidies, as well as special services for mental health, alcohol and substance abuse, and domestic violence (see Shlay \& Rossi, 1992).

\section{Emergency shelter and basic needs:}

Step one along the pathway. As a group, homeless people are able to survive through the interaction between societal supports and individual efforts to meet basic needs. In Figure $1 b$, the group-level state of survival is depicted as an emergent state from the interactions and negotiations between the individual and societal pathways.

Emergency services are an important initial step in a developmental pathway out of homelessness for any individual, as well as for society. From the other perspectives, the critique is not whether these services are important, but instead,
Figure 1 . Survival as the first step on the developmental pathway out of homelessness

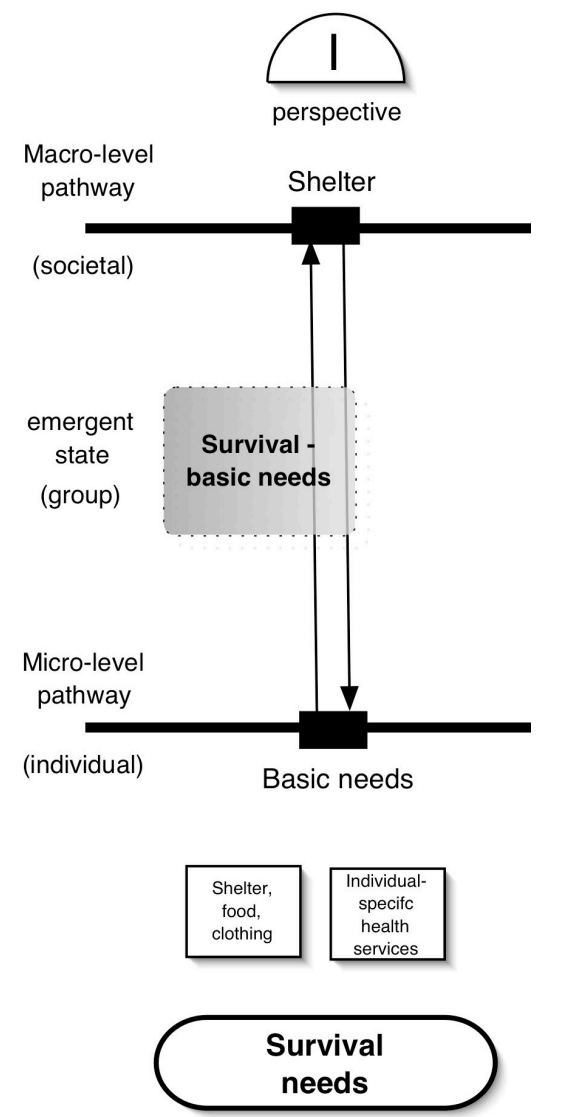


whether our scope of response considers a developmental and dynamic view beyond that of basic survival needs. Although we have made progress in implementing this step, there is a need for improvement in the delivery of services and for increasing the numbers of emergency shelters and services (Morse, 1992; NCH, 2003; UCM, 2005). It is important that we are effective at meeting basic needs of individuals experiencing homelessness, in order to build a solid foundation for advancement to development stages further along the pathway.

\section{Psychological Needs}

\section{Encountering a}

psychological crisis. The

literature (generally from the

C-perspective) on the

experiences of homeless

groups and individuals has

consistently described

significant impediments in

the system to getting housing and ending one's

homelessness. In Figure 1c, vertical dashed line

represents the blockages
Figure 1c. Psychological crisis as a reaction to encountering obstacles to meeting psychological needs

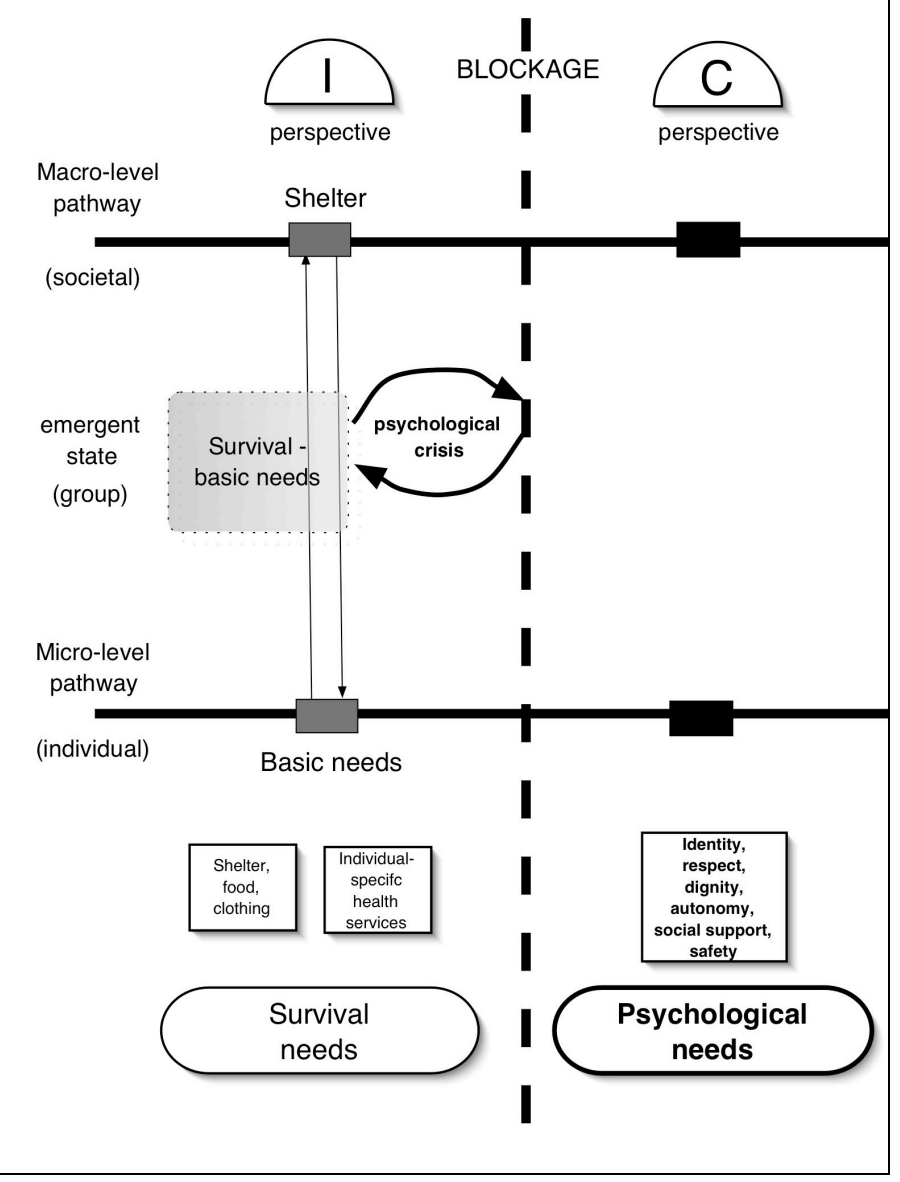


between stages that prevent progress and lead to regression to previous stages. The Cperspective describes a "psychological crisis" in which homeless individuals' psychological needs are undermined, resulting in a lack of autonomy, respect, and identity, a loss of hope, feelings of powerlessness and alienation, a sense of frustration, and lack of safety, among others. This experience of a psychological crisis is depicted in Figure 1c. A feedback loop represents a cycle, in which homeless people who have successfully met their basic needs are faced with blockages when making efforts to meet their psychological needs. When facing these blockages, many people are delayed in taking the next step toward exiting homelessness as they get stuck in the cycle and slip back to survival mode.

Research on homeless individuals' experiences with our current emergencybased homeless-helping industry describes some of the blockages that people experiencing homelessness face as they take efforts to resolve their homelessness. Research shows that emergency shelters and services are often delivered in ways that undermine the ability for individuals to meet their basic psychological needs (Hopper, 2003, p. 98; Miller \& Keys, 2001; Seltser \& Miller, 1993; Snow \& Anderson, 1993; Wright, 1997). For many homeless individuals, their situation means standing in countless lines to receive basic needs, sometimes being sent away empty-handed after a long wait, without a bed, a meal, or even a blanket to keep from freezing on cold winter nights.

Many homeless individuals who have slept in shelters report their experiences in shelters as degrading. Shelters are reported as impersonal, rigid and excessive in 
rules and insensitive staff, and often unsanitary and unsafe (Golden, 1992; Gounis, 1992; Grunberg \& Eagle, 1990; Hopper, 2003; Huttman, 1988; Huttman \& Redmond, 1992; Rivlin \& Imbimbo, 1989; Rossi, 1989; Seltser \& Miller, 1993; Snow \& Anderson, 1987, 1993; Stark, 1994; Wagner, 1993; Wright, 1997; USDHUD, 1989). Most adult shelters do not allow couples to stay together, making it even more difficult to maintain relationships and social ties (Kozol, 1988, Waxman \& Reyes, 1987, as cited in Rivlin \& Imbimbo, 1989). When asked by researchers, homeless individuals commonly report their experience of homelessness as associated with a lack of permanent housing or a secure place for physical possessions, a feeling of isolation, rejection or alienation, a lack of emotional attachment to or identification with a place and a lack of a safe space (Chawla, 1992, Rubenstein \& Parmelee, 1992, TwiggerRoss \& Uzzell, 1996, as cited in Riggs \& Coyle, 2002).

As a society, we impose numerous barriers, intentional or not, to advancement along the pathway out of homelessness. To manage the growing numbers of homeless people, we have developed legislation in cities that criminalize basic human acts of survival when homeless. With the lack of shelter beds or transitional housing, many individuals are left with no choice but to survive on the streets, finding or creating a safe place to sleep outside. Nevertheless, many of these autonomous efforts are discouraged and often punished. Policies and services that erase or limit individuals' autonomy not only hinder progress toward exiting homelessness but also reduce the potential for discovering the necessary conditions for ending homelessness. 
My review of the literature illustrates the limitations of our primary response to homelessness in America over the past 30 years. If no substantial structural changes are implemented, many individuals may be "stuck" with barely surviving homelessness, and society as whole will have no concrete plan or appropriate responses to support the necessary steps toward resolving homelessness overall. Individuals who become homeless receive a level of support that allows them to survive, but additional supports are missing from the system to assist in taking steps toward housing and meeting other needs (e.g., social support, respect, autonomy, etc).

A study on entering and exiting homelessness found that individuals lose hope and motivation over time as they continuously meet obstacles while attempting to get back on their feet (Morrell-Bellai et al., 2000). This obstructed path and the recurrent relapse to survival mode has been referred to as "the cycle of homelessness," and both micro-level and macro-level attributes affect its persistence. With the prevailing individual-centered response to homelessness, which implies that homeless persons are to blame for their own plight, many unhoused individuals experience a loss of selfworth, a sense of powerlessness, and a loss of hope in attempting to move along this pathway to improve their condition. It is important that we reduce the obstacles that delay homeless individuals from exiting homelessness, and at the same time, encourage the social change necessary for solving homelessness.

Home-base and tent cities: Step two along the pathway. Figure 1d illustrates an opening in the barrier to the next step along the pathway, indicating the notion that 
overcoming these blockages allows individual/group and societal progress to be made.

Breaking through these barriers demands significant pressures from the bottom up.

Thus, the figure depicts a successful "break-

through" stemming from the emergent group or community level to the next developmental step.

For individuals, a linear path exists from basic needs to this step of establishing a homebase. However, individuals alone are less likely to successfully exit this step given the significant impediments
Figure 1d. Quality of life as the second step on the developmental pathway out of homelessness

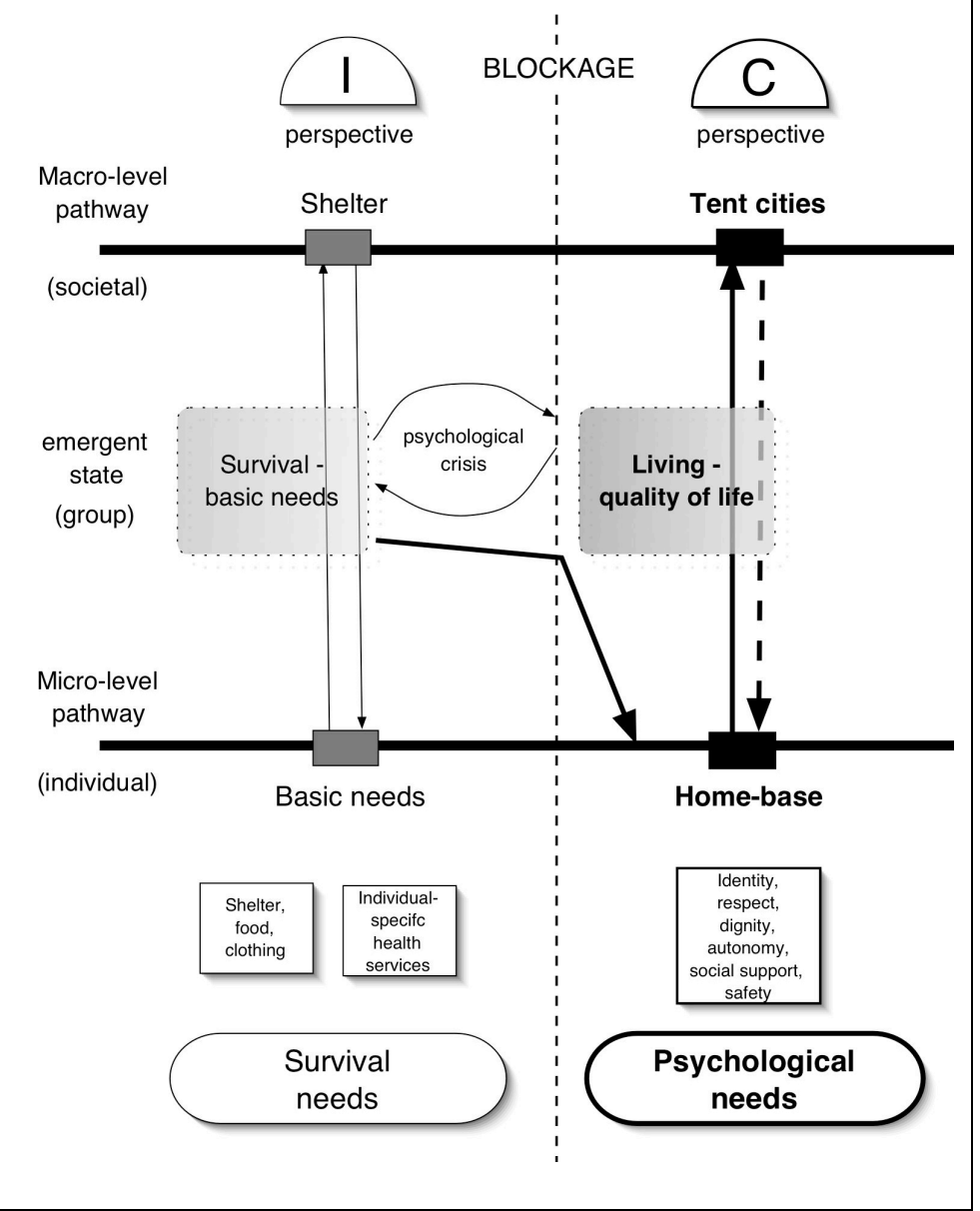

to meeting basic psychological needs.

In recent years, despite official resistance and numerous obstacles, some alternative responses have emerged almost entirely from the bottom-up in the form of placemaking activities in which homeless persons themselves create safe places to live (Wright, 1997). In Figure 1d, the dotted vertical line from the societal pathway down 
to the individual pathway portrays the lack of substantial supports for individuals to create a home-base. The solid vertical line from the individual pathway up to the societal pathway illustrates the grassroots efforts in placemaking activities, which include establishing safe havens, squatting in abandoned buildings, constructing makeshift "shanties" out of scavenged building material or cardboard, or selforganized encampments formed by homeless persons themselves (Wright, 1997). Hopper (2003) describes this form of self-help as that of "people with no property except what they scavenge, [turning] these outlaw spaces into places of habitation, respite, and even hope. They do so even in the face of the constant threats of eviction, fire, and filth" (p. 191).

Studies from the C-perspective have found that the experience and skills gained from these democratic encampments outlast even the physical benefits of the tent city after it is gone (Cohen \& Wagner, 1992; Wagner \& Cohen, 1991; Wright, 1995, 1997). Residents of encampments consistently speak of the key benefits as including: gaining a sense of place and privacy, dignity, autonomy, safety, mutual support, and most importantly, a hope for change (Casanova \& Blackburn, 1996; Cohen \& Wagner, 1992; Rivlin \& Imbimbo, 1989; Wright, 1995, 1997).

Over time, through the process of placemaking and the interactions and negotiations with societal structures (supports and impediments), many homeless groups are able to meet their basic psychological and social needs, gaining an improved quality of life and experience of living, and not just surviving (Savage, raw video, July 2001). This emergent state is depicted in Figure 1d. Tent cities such as 
Dignity Village demonstrate a C-perspective approach that focuses on the psychological and social needs of individuals in creating a strong and self-aware community. These communities are not just an alternative and more liberating response to homelessness, nor are they simply an interim solution to the housing crisis. Tent cities are a crucial and necessary step along the pathway out of homelessness.

\section{Power/Voice Needs}

Encountering a power/voice crisis. Research on homeless encampments suggests that once individuals fulfill their basic social and psychological needs with a home-base, they also desire to have a voice in their community, to exercise their power and competencies, and to gain control over their lives (Hopper, 2003; Rivlin \& Imbimbo, 1989; Wright, 1997; Wright \& Vermund, 1996). Figure le illustrates a "power crisis" that homeless people experience as they face blockages to meeting these needs. Progress toward the next developmental stage is delayed as people face these barriers and slip back to simply maintaining their home-base.

Tent cities are often fertile grounds within which people can develop a critical awareness of the power dynamics of their condition. Research shows that residents of tent cities participate more actively in political advocacy to gain social supports for homeless people as a group and as a community (Rivlin \& Imbimbo, 1989; Wright, 1997; Wright \& Vermund, 1996). Typically, the mere presence of a tent city is political, attracting some support from community activists, but generally opposition 
from the current socio-political system (Hellegers \& Mercier, 2003). Nearly every encampment or tent city has faced powerful resistance from city authorities, often leading to police sweeps and disbanding of the camp (Amster, 2002).

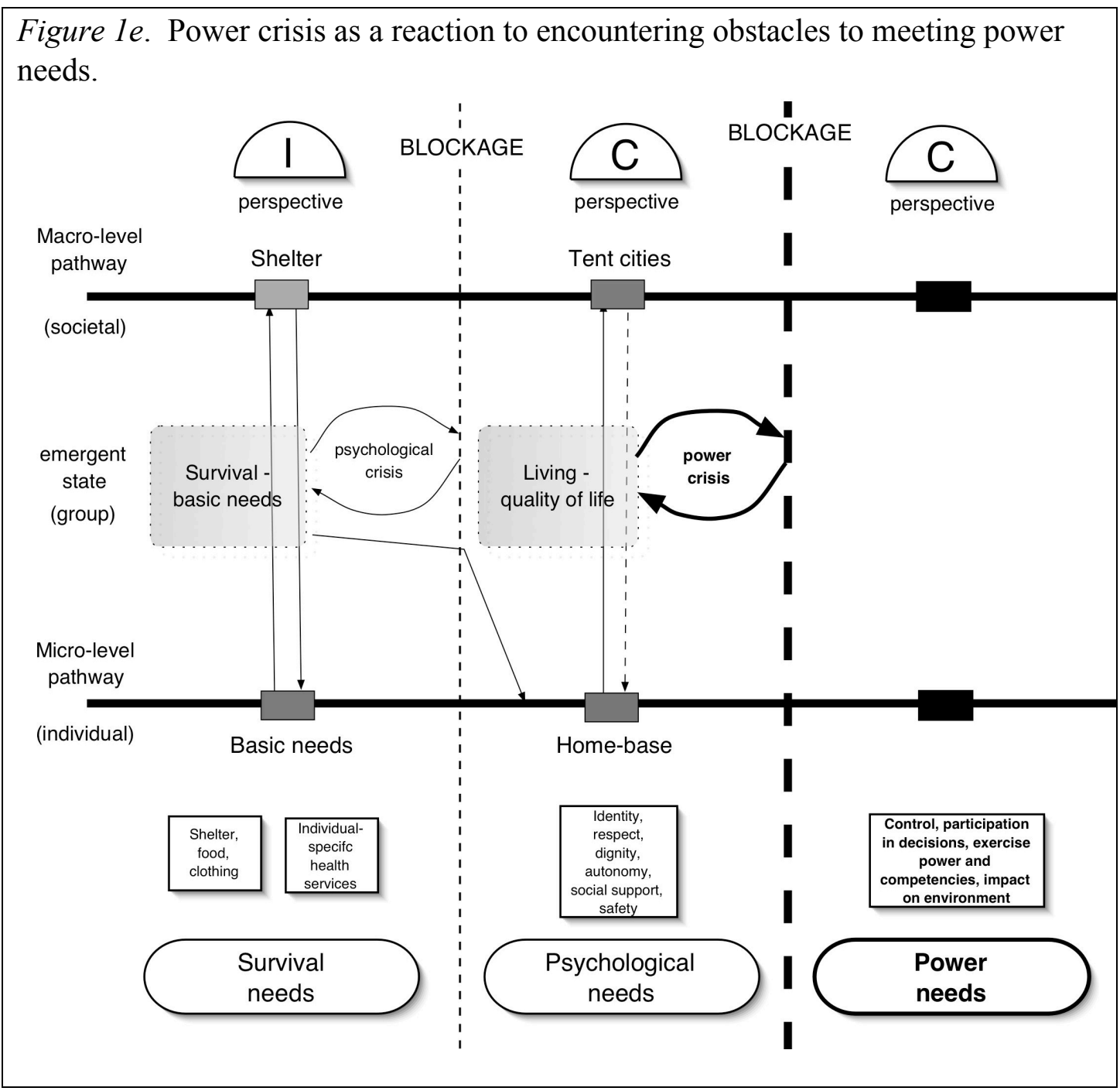

Because the I- and S-perspectives do not provide support for autonomous efforts from the bottom-up, individuals attempting place-making activities may find it hard to maintain their momentum, and many slip back toward simply maintaining a home-base to meet their basic psychological needs, focusing less on political action. It 
is difficult to maintain even a home-base with few resources and external opposition to a community's existence. Moreover, individuals and communities do not have the psychological and physical resources to begin reflecting and discussing issues of power as they struggle to meet basic needs. These experiences, combined with the lack of control over one's own time, space, and options and the inability to be included in conversation and social action toward solutions that directly affects one's life, undermine power individually (Andrus \& Ruhlin, 1998) as well as social power of homeless communities relative to other classes in society.

Empowerment and building a power base: Step three along the pathway. Homeless encampments that are founded on democratic principles provide support for higher-order individual needs such as empowerment, and having a voice and vote in decisions that directly affect them. Mutual support in a democratic community where they have a place and a voice allows residents to construct a collective identity and collective action centered on issues of social justice for other homeless people in acquiring housing and needed services (Wright, 1997). Many individuals living in tent cities have become politically active, and desire to have a voice in creating policies that affect them. Figure If illustrates this interaction between societal structures (building a power base that includes other grassroots organizations and advocates) and empowered homeless communities that pressure the system to listen to voices and views that have been historically excluded and left unheard.

Clearly, social change does not come from waiting, and the C-perspective argues this point by drawing on our emotions, humanity and pragmatism, attempting 
to stimulate action in challenging the existing structures and perspectives. If we are to take socially responsible steps toward solving homelessness, it will involve a change in our perspectives and practices. Challenging our own ways of thinking involves conversation among diverse perspectives. Multiple perspectives and democracy is a process that will bring all the key players to the table where we can begin to work together in making these changes.

Figure 1f. Inclusion in the conversation on homelessness as the third step on the developmental pathway out of homelessness.

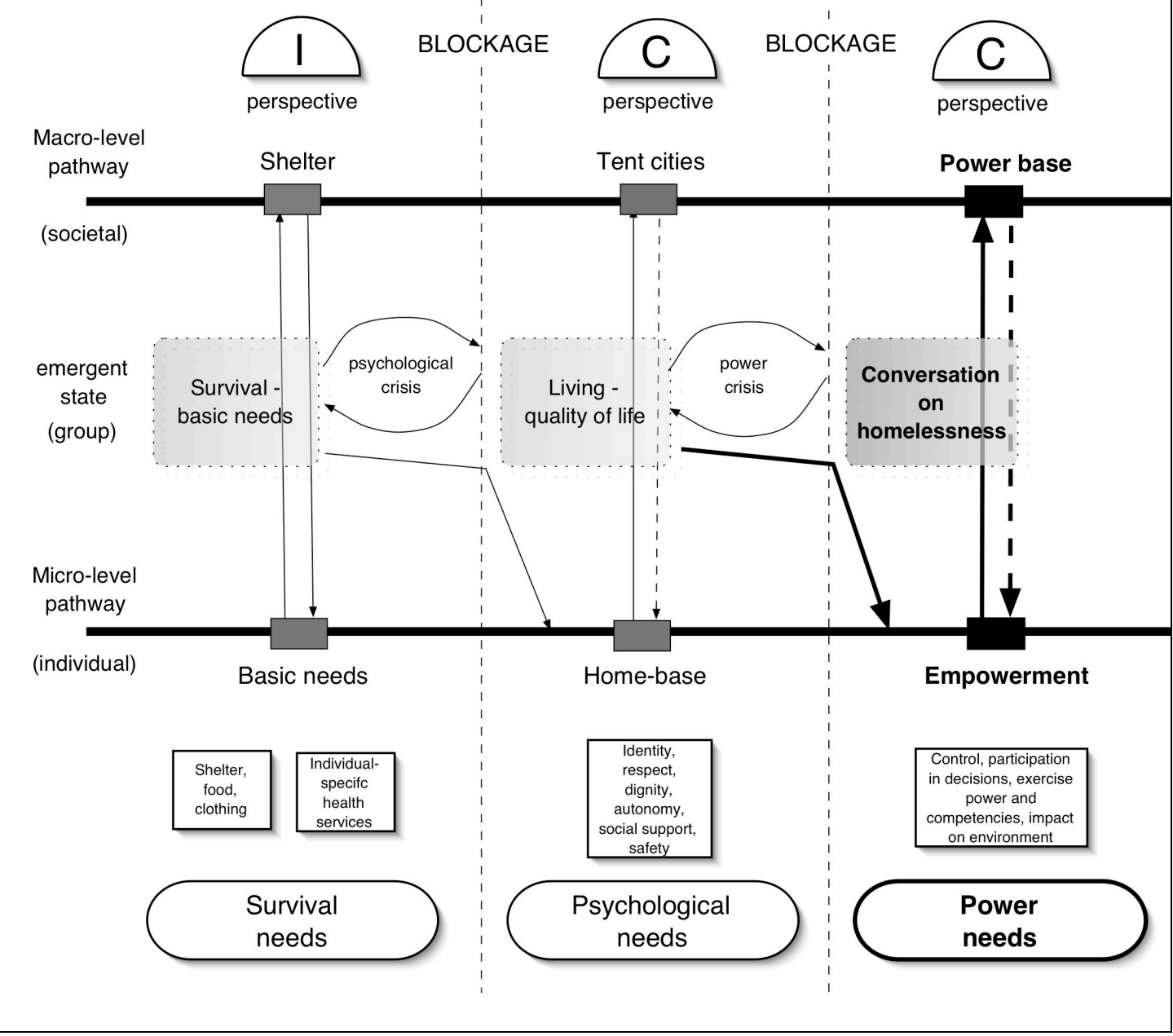


Empowered communities of formerly homeless people are a necessary step for such social change because it is this increase in social power as a class that will provide the conditions necessary for the inclusion and participation of those experiencing homelessness in public discourse about their future and America's future (Wright, 1997). It is time that the varied voices and perspectives of homeless persons are brought from the margins to the forefront of our dialogue and decision-making on homelessness. Without this conversation, the power dynamics that give rise to structural inequities will remain unchanged.

Some might argue that moving all homeless individuals directly into affordable housing would resolve the problem, but even if we ignore the practicalities of this solution, it misses a crucial developmental step that requires the involvement of homeless people in challenging the status quo. Without this dialogue, we risk implementing additional "band-aids" for the problem that do not address the underlying inequitable social structures giving rise to homelessness. A public discourse involving multiple perspectives will allow us to improve the supports along the pathway out of homelessness for the majority of individuals, and help us in creating long-term social improvements that reduce homelessness altogether as a society. A home-base and empowerment are important steps in this pathway, and the only way to make progress toward a long-term solution. "What holds people together long enough to discover their power as citizens is their common inhabiting of a single place" (Kemmis, 1990, p. 117). Hence, placemaking is a key element in creating social processes that reinforce, shape, and support individual and collective identities 
(Stokowski, 2002) and establish foundations for collective action for ending homelessness (Wright, 1997).

\section{Structural Needs}

Encountering a structural crisis. The S-perspective brings to the conversation a view of the structural socio-economic inequities that maintain and give rise to homelessness, addressing issues of economic disparity, class, and poverty. This perspective focuses on long-term change through mechanisms that will increase lowincome housing, job opportunities, wages, public benefits, and overall democratic decision-making. Social change means getting to the root of problem and significantly reducing poverty and homelessness in America on a large scale. However, to reduce structural inequities, there must be pressure from the bottom-up on the power structure that forces policy-makers to include multiple perspectives and the homeless community in the conversation on solutions for homelessness. Professionals have consistently suggested enhanced public assistance and an increase in affordable housing to reduce homelessness, yet politicians seem unwilling to take such steps (Rossi, 1989). Figure $1 g$ illustrates the blockage that results in a "structural crisis" in a pathway out of homelessness. A strong and empowered community is crucial to deal with the vested interests within the power structure, and the resistance to change in the system. Building a power base of advocates for collective action will help to increase and maintain pressure to shift the power dynamics toward increased equality and democracy. 


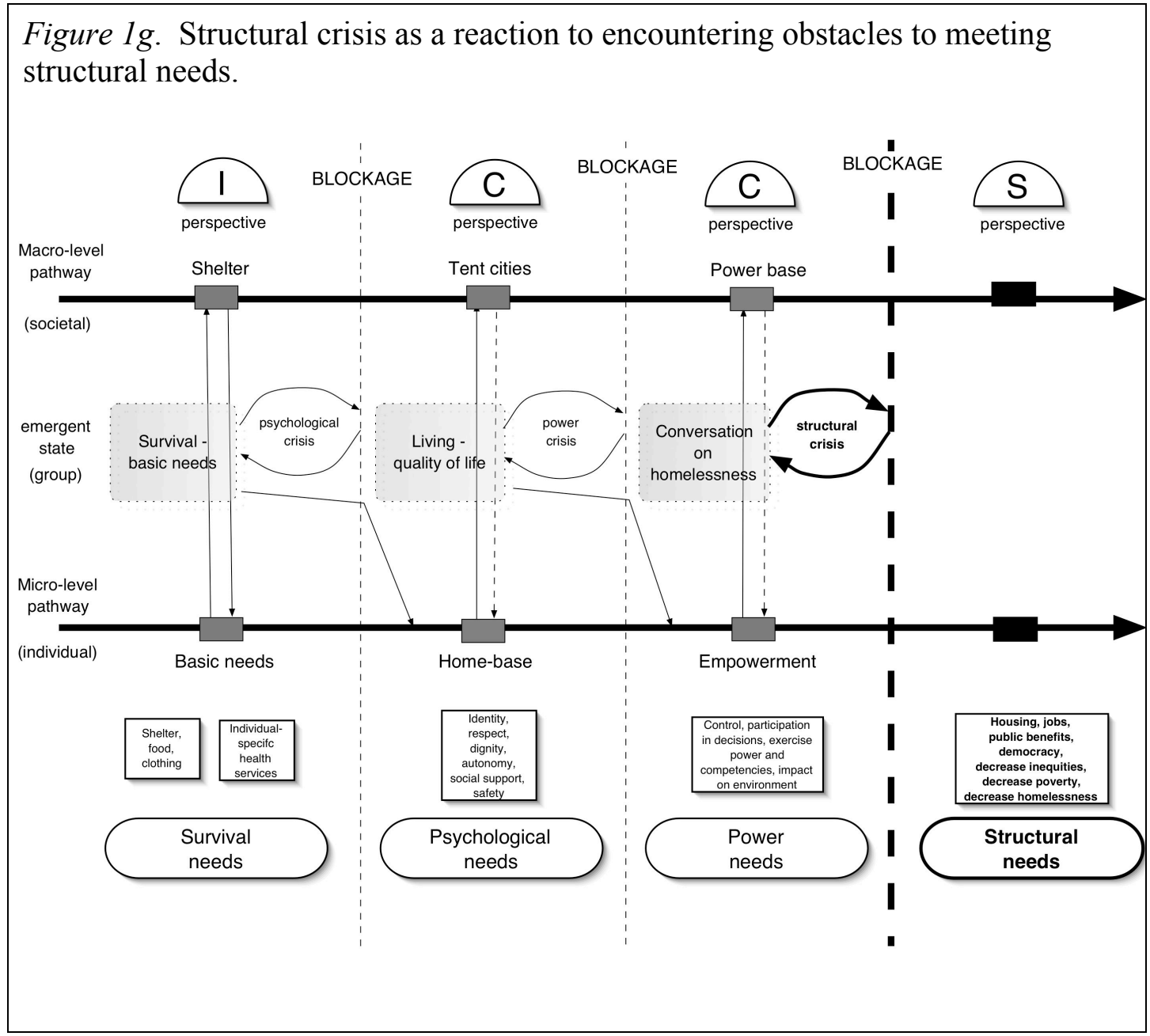

Reducing power and structural inequities: Step four along the pathway. Tent

cities provide more than services and hope for their residents. Tent cities are political by their very existence, challenging the nation's core assumptions about homelessness through their emphasis on self-determination and democracy (Hellegers \& Mercier, 2003). Harris, the Director of Real Change, emphasizes that "...there is a distinction to be made between organizing that empowers homeless people as individuals, and that empowers them as a class" (as cited in Rosenthal, 2000, p. 123). Systems thinking tells us that long-term, enduring improvements do not occur without changing the 
underlying structure that generates the problem. These structural changes will only emerge from a more complete and holistic view of homelessness and the dynamics at play, as well as from taking steps for social change down the pathway out of homelessness. Figure $1 \mathrm{~h}$ illustrates the emergent state and structural changes necessary in reducing power and societal inequities to get to the root of homelessness. The dashed line represents an inadequate top-down (societal) response, while the solid line depicts the pressure from below by grassroots/individual efforts.

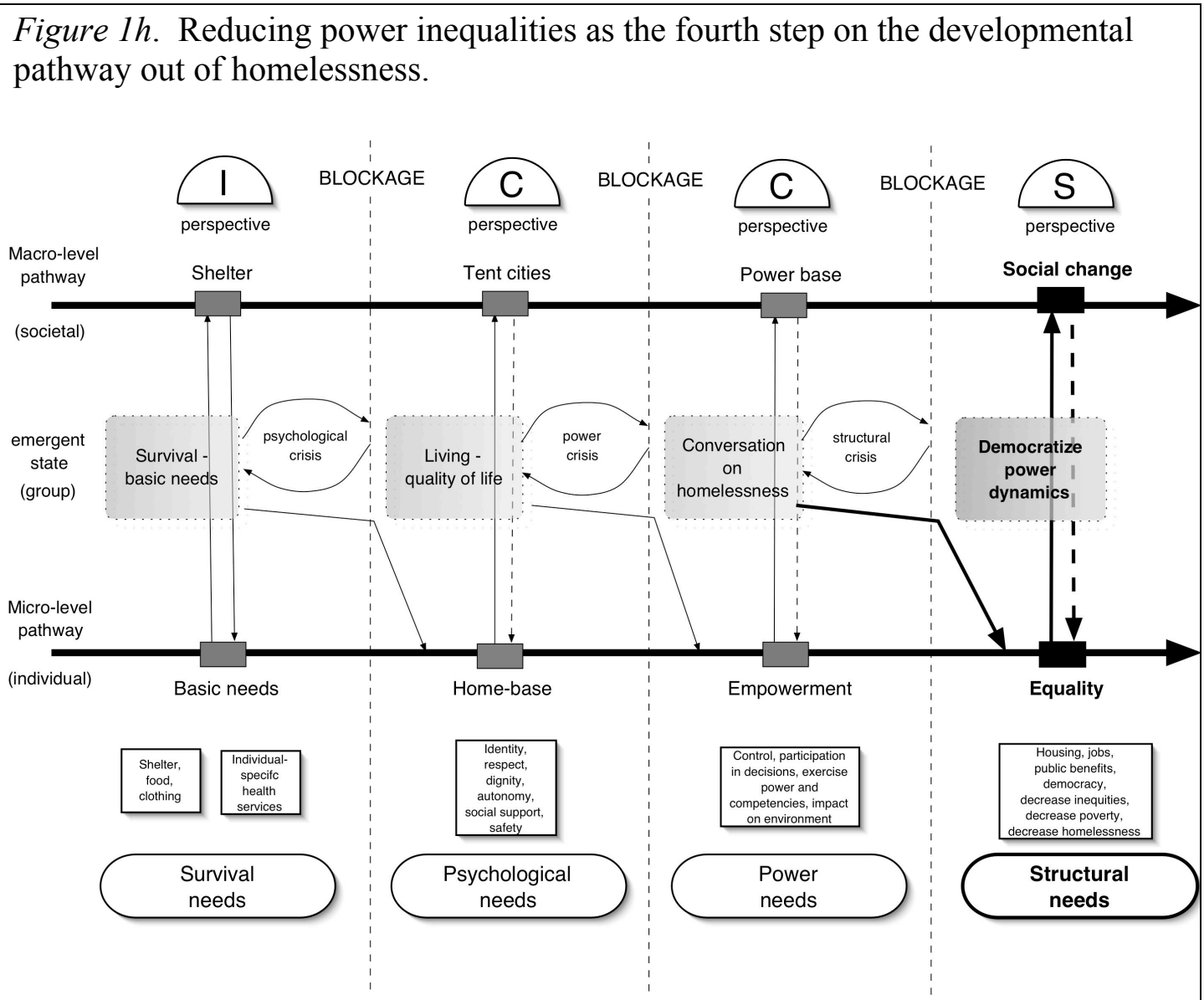




\section{Summary}

In order to begin to understand the dynamics that both support and fail people experiencing homelessness, it is crucial to elaborate a broader view of homelessness within the U.S. socio-political context and along a developmental pathway (see Figure $1 i$ for the entire figure). To end homelessness, it will take seeing our response for what

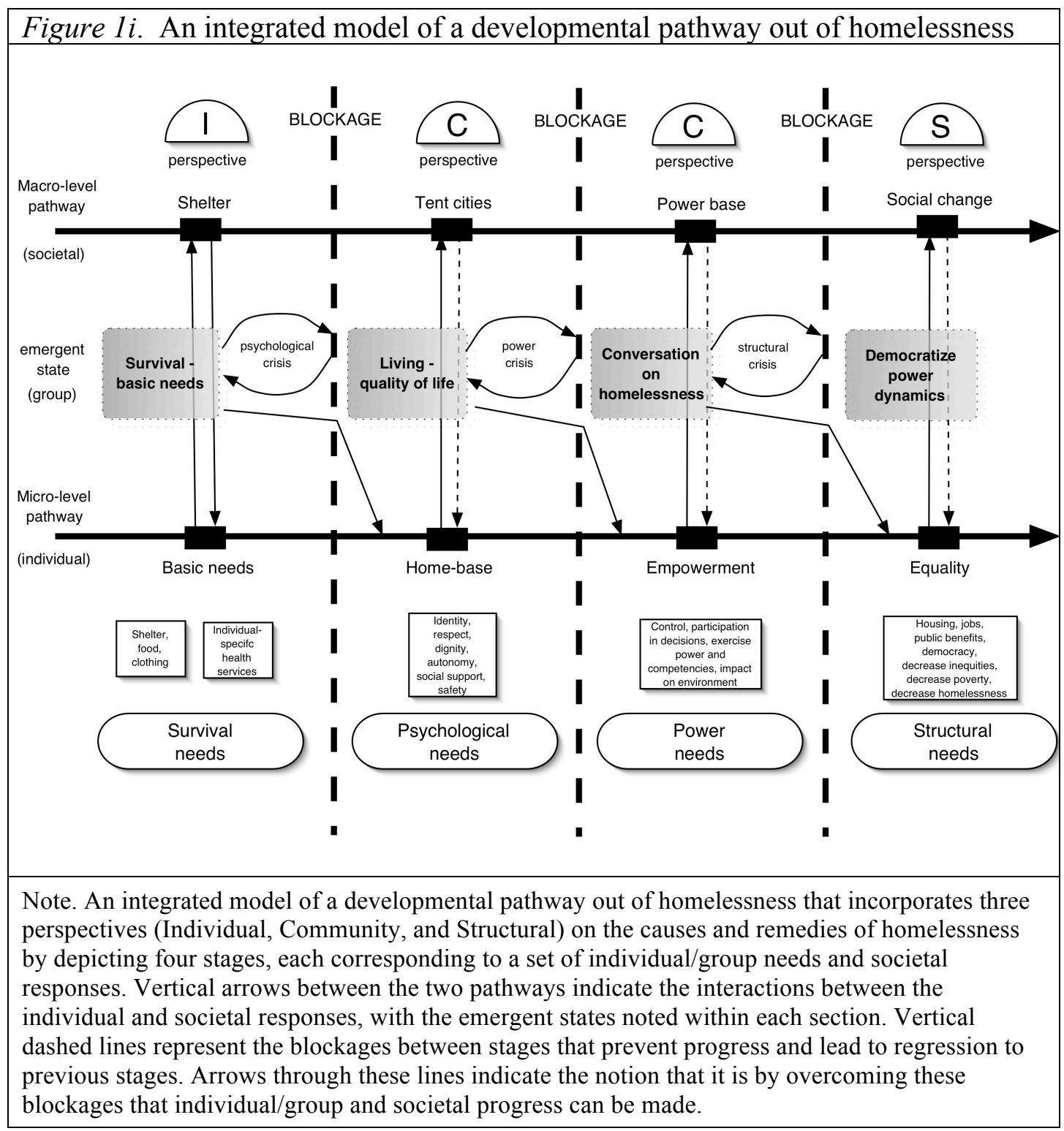


it is - the intended and unintended consequences of our reactions to homelessness. Individuals on the street are not a product of amoral character or disabilities, but rather they emerge from "the complex negotiations over the meanings of urban space within which homeless persons find themselves" (Wright, 1997, p. 7). Homelessness does not occur in a vacuum; it is constructed and maintained by people through social interactions, and through the consequences of our decisions on how to respond to the issue.

This integrated model of a developmental pathway out of homelessness identifies steps in supporting both homeless individuals and society in ending homelessness. For the sake of clarity, the model is limited in its representation of the dynamics along the pathway. The model depicts two linear unidirectional pathways (individual and society) to illustrate the intended direction of movement toward a goal of ending homelessness. However, a linear directional pathway may convey a model that is far too simplified. This representation does not intend to suggest that an individual must experience one need, or crisis, before experiencing another need or crisis along the pathway. Individuals may look for a home-base that will satisfy shelter, psychological, and social needs at the same time, as can be seen by the many individuals who reside in tent cities because they offer just that.

Within the current socio-political context of homelessness in the U.S., it is society who has limited its focus on shelters and on individuals, consequently resulting in a blockage that artificially separates the importance of shelter from the importance of meeting psychological needs necessary for surviving and exiting 
homelessness. Although the individual pathway is important in the model, the model does not intend to focus on the individual and on providing supports specific to individuals exiting homelessness. Rather, the focal point is on the grassroots movement necessary to drive developments in societal progress which break through barriers toward social change.

A key notion of the model is that multiple perspectives and developmental steps give rise to much of the dynamic complexity and feedback cycles that affect the momentum and sustainability of grassroots movements and tent cities, including Dignity Village. The movement along the pathway should not be conceptualized as one large unified grassroots social movement of homeless individuals, groups, and tent cities taking one step at a time, together. At any one time, there are multiple individuals, perspectives, groups and tent cities at different steps, sometimes stuck, and sometimes successfully taking the next step toward ending homelessness as a society. As tent cities and other groups move along the pathway at different stages, a broad social network may emerge from the loose connections between various groups, slowly building a more organized power-base necessary for social change.

Even within the small community of Dignity Village, there is much diversity in perspectives and needs at any one time. Newcomers just arriving at the gate of Dignity Village naturally focus on meeting their basic needs. As many newcomers first listen to long-termers discussing politics and power (their "power crisis"), newcomers often describe these conversations as "too much political talk," “overwhelming,” or “irrelevant.” Similar to Maslow’s (1943) hierarchy of needs for 
individuals, basic needs take priority for some period of time as newcomers gain the energy and perspective to expand their focus to additional needs. To end homelessness as a society, it is necessary that we begin to expand our homes and perspectives outward to encompass our communities, our environment, and our society. The integrated model demonstrates a pathway out of homelessness for society and the necessity of tent cities in a grassroots movement toward democracy that integrates the I, S, and C-perspectives in the dialogue on homelessness.

Within the tent city model, residents collectively gain voice and the social power necessary to sit at the "policy table" and participate in the dialogue and decision-making that affects them. Dignity Village has demonstrated how a selforganized community can give people room to hope and room to organize for real change. The challenge now lies in sustaining the energy and collective action required for its survival and continued effectiveness for social and political change. The intent of this participatory action research is to provide conditions and processes that support Dignity Village in obtaining more social power, in participating in and shaping public discourse on homelessness, and in organizing for long-term social change. This research therefore seeks to understand both the bottom-up processes within the community, and the contextual processes that may constrain or support the empowerment of Dignity Village. 


\title{
CHAPTER FIVE
}

\section{THE HEART OF THE STORY:}

\section{PROCESSES FOR EMPOWERMENT AND SOCIAL CHANGE}

\author{
I sing for my Village, \\ Dignity Village. \\ Dignity, a word so commonly \\ patronized, but a word \\ which one will gladly \\ lay their life down for \\ when it touches their heart \\ and moves them
}

as much as my village moves me.

I believe in self-determination, the human right of individuals, communities, tribes, and nations to control their own livelihood.

I know the path of self-determination for my village, the home of Portland's tented poor will be a rough path. I know that it is a struggle, a struggle worth fighting for.

from "A Song for My Village" written by J. P. Cupp (street roots, special edition on Dignity Village, 2001, p. 3)

Issues of power and lack of power are at the heart of any movement for social change, whether they represent an explicitly stated focus or simply an unseen current beneath other stated goals. An empowered community is crucial for effective mobilization toward a collective vision. The purpose of this chapter is to explore ways in which communities and community partners may promote empowerment in 
research processes, while at the same time fostering a critical awareness of issues of power and disempowerment within collaborative research. Without an understanding of the processes of empowerment, we risk an unexpected turn in the road that leads us to disempowerment. Therefore, through a review of the literature across related fields, this chapter explores the importance of five basic components, as well as contextual supports, that may give rise to either an empowered or disempowered community at Dignity Village. For each of these components, I discuss a) the relationship between the component and empowerment, b) the specific contextual supports to promote that component in empowerment, and c) practical, concrete activities and processes to support each component within this research setting.

\section{Improving Community Participation and Empowerment}

Communities grow from common purpose, shared values and a mutual understanding of their situation and possibilities for their future (Senge \& Scharmer, 2001). As a democratic self-help community, Dignity Village aims to re-energize participation and community empowerment through their shared philosophy of collaborative learning and action. Given my long relationship with Dignity Village, we quickly became partners in this collaborative action research project with a goal of increasing participation and community empowerment.

Currently just over five years old, Dignity Village faces the challenge of sustaining a shared vision and the active participation of its members, a problem commonly faced by most volunteer organizations (Prestby et al., 1990), tent city 
encampments (Wright, 1997) and social movements for housing (Casanova \& Blackburn, 1996; Lara \& Molina, 1997). At Dignity Village, participation and a sense of community waxes and wanes, but more recently, it has dwindled to levels lower than ever before, becoming problematic for the community as a whole. The common vision and intense collective energy that once existed and helped to sustain the struggle to build Dignity Village into its own powerful and legally legitimate entity has slowly degenerated into disparate visions, overall negativity, rocky relationships, and for some, a deadly apathy.

The community has taken efforts to boost participation, but they have not seen any significant changes in residents' emotional investment and actions. If they do not get to the root of the problem, many Villagers foresee a gloomy fate for Dignity Village, that of short-lived success. I have heard several Villagers explain that the loss would impact more than the members of Dignity Village. It would be a serious step backward for social change. As Dignity Village is considered one of the longest surviving, entirely grassroots, and democratically self-governed tent cities currently in the US, it is a model and inspiration for many newly emerging tent cities and homeless activists. A core group at Dignity Village, aware of the significance of this community problem, is determined to understand the complex dynamics that have given rise to this state of disaffection. The purpose of this chapter is to describe the processes through which community empowerment at Dignity Village may re-emerge. 


\section{Collaborative Research - Participatory Action Research}

The current research project is rooted in the philosophy and practice of participatory action research. This form of research is not just a means of acquiring knowledge for knowledge's sake, but rather is a process of collaborative learning through taking action towards reaching a goal or solving a problem significant to the well-being of the community, and is therefore particularly suited to the situation at Dignity Village. Communities learn from a process of taking action, studying the processes and consequences of these actions, constantly striving to improve and develop effective solutions. The research follows a cyclical process by which change and understanding can be pursued within a process of action and critical reflection (Dick, 2001).

Participatory action research (PAR) is considered to be an orientation and approach more than a research methodology. Although definitions and approaches to PAR vary, the paradigm shares a set of core principles: it aims to be empowering and collaborative with a goal of acquiring practical knowledge and achieving social change (Masters, 1995; Nelson, Ochocka, Griffin, \& Lord, 1998). It is founded on the recognition that participants are researchers themselves in pursuit of answers to the questions of their daily struggle and survival (Tandon, 1988). As a community-based research approach, it is embedded in the values and practical concerns of communities (Reason \& Bradbury, 2001). It assumes a strengths-based approach consistent with principles embraced by community psychology in which participants are encouraged to recognize, use, and build on their own strengths and existing resources to 
accomplish their goals, as well as the strengths and power of their collective communities (Taylor et al., 2004).

The term “action” in PAR represents Kurt Lewin's (1946) concept of action research and social action (Prillentsky \& Nelson, 2002 as cited in Taylor et al., 2004) which involves increasing citizen voice and power, building sociopolitical awareness, and facilitating social or systemic change (Nelson et al., 1998). Lewin viewed social research as both scientific and socially engaged, and that "the best way to understand something is to try to change it" (as cited in Greenwood \& Levine, 1998). Action represents the idea that there are different ways of learning, and one way is through "knowledge-in-action" (Reason \& Bradbury, 2001). Taking "action" means working toward practical outcomes, and creating new forms of understanding. "Action without reflection and understanding is blind, just as theory without action is meaningless" (Reason \& Bradbury, 2001, p. 2). A major goal of PAR is to provide a means for marginalized communities to re-establish power and control in their own lives (Balcazar, Keys, Kaplan, \& Suarez-Balcazar, 1998), helping people to understand themselves as agents of change (Kemmis, 1993).

As part of the process of re-establishing power and control, there must be a shift in the role of the researcher from "expert" to "researcher-facilitator" and from "participants" to "co-researchers." This change in terminology represents a shift both in researchers' working relationship with participants and in their assumptions about knowledge production and who is the "expert." Researchers engage "participants" as equal and full research partners in the entire research process (Stringer, 1999) from 
defining the problem based on what is useful and worthwhile to formulating mutually acceptable solutions to the stated problems (Greenwood \& Levin, 1998). Participants are seen as competent social actors and co-researchers who are the experts on the topic and its direction, while the researcher-facilitator is an expert in the sense of consultant, facilitator, and protector of process.

The role of a researcher-facilitator is to help create and facilitate a process that amplifies diverse voices in the dialogue (Greenwood \& Levin, 1998; Reason \& Bradbury, 2001), expands choices (Nelson et al., 1998), and provides space for individuals to reflect and realize their power as a member of a collective community within a broader social change agenda (Charlton, 1998, Freire, 1993, Minkler, 1985, as cited in Greenwood \& Levin, 1998). Researcher-facilitators help to create and maintain a context and process that stimulates people to change, supports positive working conditions that are empowering and productive for participants, enables people to develop their own analysis of their issues, assists people to analyze their own situation, and assists in planning and implementing their plan by raising issues and helping to locate resources (Stringer, 1999). A researcher-facilitator's main focus is to facilitate human development and learning. The research is a collective learning process in which the community co-researchers engage actively in dialogue and action to understand their situation and take steps toward improving their community and exercising their power. 


\section{Community Empowerment}

Since the goal of this research is to facilitate the empowerment of the Dignity Village community, I focus on empowerment at the community level and the interactions among individuals that give rise to it. The concept of empowerment has roots as a more individual-level concept, connected to raising self-consciousness, learning to stand up for oneself (self-advocacy), and self-improvement (e.g., competencies, perceived control, etc). However, in the past few decades, empowerment has also been conceptualized at the community level in the sense of collective and group empowerment (Boog, 2003). The distinction between individual psychological and community empowerment remains unclear in the literature (Saegert \& Winkel, 1996), and no single definition has been adopted.

Zimmerman (2000) provides the following: "An empowered community is one that initiates efforts to improve the community, responds to threats to quality of life, and provides opportunities for citizen participation. ... The structure and relationships among community organizations and agencies also helps to define the extent to which a community is empowered" (p. 54). Zimmerman (2000) further describes empowered communities as providing resource accessibility for all members of the community and equal opportunities for involvement. A definition by Wright (1997) describes collective empowerment as the "advancement of a group or class of individuals through collective action, in which collective identities are established, if only for a short time based upon a project that challenges established relationships of power" (p. 319). Central to most definitions is an understanding that community empowerment is 
not simply the aggregate of many empowered individuals, but is instead a process and outcome emerging from how well individuals work together in an effective and interdependent manner (Cottrell, 1983; Saegert \& Winkel, 1996; Zimmerman, 2000).

Theoretical assumptions. The ideological foundation of empowerment theory is based on the concept that society is founded upon structured inequalities, and that a shift in power is necessary in order to begin to address them (Taylor, 1999). Thus, empowerment is centrally concerned with gaining social power for those "who are excluded by the majority society on the basis of their demographic characteristics or of their physical or emotional difficulties, experienced either in the past or the present" (Rappaport, 1990, p. 52). Empowerment implies an unjust lack of power or exclusion from democracy for particular groups within our social, political, and economic structures. Empowerment further implies a process of gaining control and power based on basic rights of equality and democracy. Gaining power does not necessarily mean it comes from "that of conflict rather than cooperation among groups and individuals, of control rather than communion" (Riger, 2002, p. 401). Power is not always repressive. It may have a synergistic element that results in power as an expanding commodity (Foucault, 1979, Miller, 1976 as cited in Swift \& Levin, 1987), meaning that action by some enables more action by others (Hayward, 1998; Swift \& Levin, 1987).

Like power, empowerment is complex, with varieties of possible conflictual and synergistic qualities, pointing to the possible states and outcomes of empowerment. For example, empowered communities may not necessarily also be empowering to their members, which over time may lead the community down the 
path of disempowerment. Because the intent of this collaborative research is to increase the collective empowerment of the community in order to increase strengths, competencies, and interdependence as a collective, it is important to understand how empowering and disempowering processes as well as contextual supports in the research may facilitate or limit community empowerment.

Limitations of empowerment theory at the community level. Theories of community empowerment are developing, but remain limited in providing a framework of basic components and processes that may facilitate or hinder the emergence of empowerment. Rappaport (1984) explains that "we do not know what empowerment is [exactly], but like obscenity, we know it when we see it" (p. 2). As empowerment involves an "infinite variety" of actors and settings, it follows that an infinite variety of processes and outcomes may exist (Maton \& Salem, 1995; Rappaport, 1984; Zimmerman, 1995, 2000). Thus, a particular framework may overgeneralize certain components or processes that are bound to specific contexts, decreasing researchers' cognitive flexibility and openness to other potential factors contributing to empowerment or to solving the problem at hand. While there are benefits to illustrating empowerment theory as a framework free of details on processes and outcomes, there are also real disadvantages, especially in providing practical and ethical guidance for communities and community partners who are working together in an attempt to facilitate empowerment in practice.

In community-based research, we commonly assume that whatever emerges from the community through collaboration represents what 'the people' really want, 
leading to an "illusion of inclusion" and "moral authority" that becomes hard to question (Gaventa \& Cornwall, 2001). Hall (2001) argues that, even though, participatory research has been framed in a liberating and democratic context, researchers and communities may utilize practices that reinforce existing power relations and perpetuate the problems being addressed. This may not happen intentionally, but simply through a lack of critical reflection and dialogue that challenges both researchers' and the community's practices. Marginalized communities may speak "in a way that 'echoes' the voices of the powerful, either as a conscious way of appearing to comply with the more powerful parties' wishes, or as a result of the internalization of dominant views and values" (Gaventa \& Cornwall, 2001, p. 75).

Another issue centers on the power dynamics between researchers and communities. This becomes particularly problematic when researchers are unaware of the power differentials felt by marginalized communities. Collaborative research can address these power dynamics, but not erase them. Power differentials will always exist between researchers and communities; however, it is important to take responsibility for this power. Power should be acknowledged and valued, rather than ignored or viewed as a barrier to empowerment (Pease, 2002). Every person involved in collaborative work should be valued for the unique skills and perspectives that they bring to the group. This will allow for a process of continual critique and analysis of the power dynamics, in an attempt to minimize the disempowering processes. 
Developing a critical understanding of the power dynamics within the setting and between "researchers" and "researched" is vital to facilitating empowerment in collaborative research. Unfortunately, it can be an extremely ambiguous and challenging task in the absence of clear understanding of which elements are important to the process, and how to facilitate these processes in practice. Van Beinum (1998) emphasizes that “one walks on a narrow path. One can easily 'do' too much and cause dependence, or, on the other hand, one does not give the other the opportunity to learn from one's experience" (p. 73). Identifying basic processes that can lead not only to empowerment, but also to disempowerment, will be important in understanding empowerment and improving our abilities as community partners to provide research contexts that facilitate its emergence.

\section{Empowerment in the Research Setting: Processes and Contextual Supports}

Under what conditions do historically silent and marginalized communities achieve empowerment and control over their own lives? As an applied researcher and community partner, our goal is "...to enhance the possibilities for people to control their own lives..." (Rappaport, 1981, p. 15). The literature clearly articulates the role of the researcher as facilitator of the process, and that this role involves creating and sustaining a climate that builds positive working relationships, cultivates dialogue, learning, and democracy, and promotes inclusion of diversity and multiple 
perspectives (Sohng, 1998; Stringer, 1999). However, the ways in which a researcherfacilitator actually employs this in practice on a day-to-day basis are less obvious.

As a guide for this collaborative work, I have developed a preliminary framework for understanding the processes of community empowerment. The framework identifies possible basic components in the empowerment processes found in various related areas of literature, which include PAR, motivation (i.e., selfdetermination theory), social movement theory, social work, volunteer organizations, and self-help groups. The purpose of this framework is not to advance empowerment theory, but rather to provide a guide for practicing collaborative and reflective research within my specific research context. While these guidelines may be useful for other researchers in similar settings, it is not my intention for this guide to be used as a blueprint for implementing PAR or empowerment research broadly. PAR and empowerment are context-bound, and as such, the research processes should remain flexible and relevant, based on the values, philosophy, and vision of the community. The framework will be used to reflect on questions of quality and ethics in the practice of collaborative research, and to locate blockages of empowerment in an attempt to facilitate rather than limit empowering processes in the research. The framework will also serve as a tool to define the boundaries of the research, identify and describe the processes utilized and the dynamics that emerge over time. As the collaborative research goal of this study is to re-energize community participation and to increase community empowerment at Dignity Village, it is particularly important to have a 
guide for navigating within the complex terrain of empowerment and disempowerment within the research process.

Research and practice on empowerment have identified a specific process that contributes to changes in empowerment at the individual level (see Parsons, Gutiérrez, \& Cox, 1998), but much is left to be explored and developed at the community level. Integrating the literatures mentioned above, five common themes emerge as potentially significant components in the process of community empowerment. These components include: a) collaborative participation, b) autonomy, c) competence, d) collective identity, and e) critical consciousness. These components were also selected because of their relevance to the historical dynamics that have led to the current state of disaffection at Dignity Village. I believe that ignoring these basic components may risk creating disempowering experiences for our community partners. With that in mind, the purpose of the remaining sections in this chapter is to describe each of these components and their relationship to empowerment, as well as to provide practical suggestions from the various literatures to facilitating empowerment in the research context.

\section{Collaborative Participation}

Many speak of empowerment in terms of 'involving' people or of allowing them to participate in decisions affecting their well-being. However, empowerment requires that the disempowered not only participate in decision-making but actually make the decisions. "To be empowered is not only to be 'involved in,' but to do" 
(Swift \& Levin, 1987, p. 84). Collaborative participation is a process in which individuals are responsible for their actions, including learning and respecting the abilities and contributions of their peers in a cooperative and democratic structure of interaction designed to facilitate the accomplishment of a specific end product or goal through people working together in groups.

Empowerment through participation in knowledge-making means expanding who participates in the knowledge production process, thus democratizing the relationship between researcher and citizens (Gaventa \& Cornwall, 2001; Greenwood \& Levin, 1998). "When the process is opened to include new voices, and new perspectives, the assumption is that policy deliberations will be more democratic, and less skewed by the resources and knowledge of the more powerful"' (Gaventa \& Cornwall, 2001, p.71). Gaventa and Cornwall (2001) point to the democratic relationship in participatory research as a challenge to power relations because it includes those directly affected by the problem in the production of knowledge, not just as participants who make decisions or have input at different phases of the research process, but as co-researchers directing the entire research process. PAR is an 'inclusive' rather than 'exclusive' approach that emphasizes collaboration and shared ownership of the research process, and the outcomes of the research (Taylor, 1999). Active and collaborative participation can lead to feelings of ownership that motivate people to learn and to make a difference for the collective (Stringer, 1999).

Another advantage of collaborative participation in empowerment research is that, collectively, we can be more insightful and more intelligent than we can possibly 
be individually (Senge, 1990). Empowerment and the birth of creative solutions develop through participating in dialogue with diverse people (Gaventa \& Cornwall, 2001; Greenwood \& Levin, 1998). Frank (2000) stated “Taking the other's perspective is a necessary step in constructive social change" (p. 94, as cited in Chase, 2005, p. 668). When we realize that our thinking is active and constructed, we begin to take a more creative, less reactive, stance toward our thoughts (Senge, 1990), and we begin to see the importance of collaboration and participation in empowerment and social justice.

The literature consistently shows a strong relationship between participation with others (in community activities and organizations) and empowerment (Chavis \& Wandersman, 1990; Zimmerman \& Rappaport, 1988; Zimmerman, 1990, 2000). Participation is considered a proximal variable because it is through participation that empowerment and actual changes can occur (Chavis \& Wandersman, 1990). The very process of participation produces a sense of empowerment (Wandersman \& Florin, 2000). Participation provides a means by which individuals and communities can develop skills, resources, knowledge, competence, and control, and provides a way to exercise their empowerment most effectively (Prestby, Wandersman, Florin, Rich, \& Chavis, 1990). Particularly relevant for Dignity Village, Prestby and colleagues' (1990) study on grassroots voluntary organizations shows participation to be critically important to organizational viability. A study on tenants of an SRO hotel for formerly homeless women with psychiatric disabilities found that active group work brought more unity among them (Cohen, 1988). A longitudinal study by Chavis and 
Wandersman (1990) found a bi-directional process in which participation contributed significantly to a sense of community, and a sense of community contributed almost as powerfully to participation.

As a key component of empowerment, collaborative participation has become one of the core activities of PAR. Whether communities achieve their goals through the empowering processes in PAR is highly dependent on the quality of interaction between researchers and communities (Keune, 1998). This relationship forms a foundation for empowerment and the quality of produced knowledge and change (Keune, 1993 as cited in Boog, 2003). It is a relationship that is based on the value of collective action, and the diverse insights and competencies of all parties involved (Heron \& Reason, 2001). Features of collaborative relationships include: symmetry, communication, openness, mutual trust and respect, and mutually-developed ethics of care (Finley, 2005; Keune, 1998). Research is not collaborative if it does little to alter the power dynamics between researchers and researched. Clearly, there are specific professional and interpersonal skills that are needed for researchers to understand the power dynamics in research settings and to be successful at creating a context for facilitating empowerment and change (Heron \& Reason, 2001).

Contextual supports and impediments to collaborative participation. Typically, the initial reason for setting up PAR is to address a problematic social situation. There may already be impediments to collaboration and participation in the community. Thus, it is important to identify these impediments and supports in order to create a fertile ground in the research setting where collaborative participation is 
valued and strengthened rather than discouraged and resisted. Community empowerment depends largely on whether important stakeholders allow others to be empowered. PAR studies in Latin America and the Netherlands show situations where stakeholders resist changes and disempower primary research participants (Keune, 1993 as cited in Boog, 2003).

Characteristics that affect participation in volunteer organizations, either positively or negatively, include: interpersonal conflict; social support; others' participation or interest in the organization; perception of organizational progress; alignment with organizational goals/activities; characteristics of leaders (Lamb, 1975, as cited in Wandersman \& Florin, 2000); internal organizational adequacy (Checkoway \& Zimmerman, 1992; Knoke \& Wood, 1981); participatory decisionmaking (Knoke \& Wood, 1981, as cited in Wandersman \& Florin, 2000; Prestby \& Wandersman, 1985); delegation of responsibilities to greater proportion of the membership (Florin, Chavis, Wandersman, \& Rich, 1992); formalization of organizational structure and tasks (Milburn \& Barbarin, 1987, as cited in Wandersman \& Florin, 2000; Prestby \& Wandersman, 1985) and effective communication (see Prestby, Wandersman, Florin, Rich, \& Chavis, 1990). The Block Booster Project (Chavis, Florin, Rich, \& Wandersman, 1987, as cited in Wandersman \& Florin, 2000; Florin et al., 1992) shows how structure, decision-making style, and the social climate of volunteer organizations are related to members' involvement, satisfaction, and commitment. These structural supports are not only important for viability and effectiveness of volunteer organizations, but also for the success of PAR 
settings, which are only microcosms of the larger structure. Recognizing these factors can be useful in creating conditions that promote participation and enable coresearchers to build relationships based on equality, respect, and collaboration. A practical guide for facilitating collaborative participation. In collaborative research, the research process is co-managed by all participants. There are no specific techniques applied by a professional researcher to manage the process. PAR researchers are both participants and facilitators in maintaining an agreed-upon structure, direction, and process to keep the research moving in useful directions without imposing or controlling the process (Greenwood \& Levin, 1998). I plan to facilitate collaborative participation in this research by using the following guide:

- Create and maintain a research environment that is structured to enable relationship building, collaborative projects, and the sharing of insights across the entire community and beyond (Senge \& Scharmer, 2001).

- Create ground rules for structure and to monitor and provide equal amounts of time for speaking to reduce the disempowering influence of those who dominate the dialogue and open space for those who are quieter in the research group.

- Use socially appropriate language (avoid jargon) to aid in effective communication (Stringer, 1999). Positive change originates from "the capacity for people to work through disagreements to achieve effective solutions to problems" (Stringer, 1999, p. 32).

- Listen and provide feedback to members by clarifying and directing the discussion so as to remain focused on purpose. This helps to provide structure so that participants are able to see their progress. 
- Open new channels and forms of communication (Stringer, 1999) through art, media, role play, storytelling, and group exercises that build trust and dialogue. Use a broad range of communicative methods, learning methods and techniques (Boog, 2003).

- Promote the inclusion of all relevant stakeholders in the process of investigation (Stringer, 1999) by providing opportunities to participate in decision-making (see Foster-Fishman \& Keys, 1997) and by inviting and valuing diverse views. Inclusion promotes a sense of community (Bond \& Keys, 1993) which is important in collaboration, and which creates change rather than resistance.

- Analyze the specific situation and purpose of the research in order to identify existing inequities in the power structure and network of community members and research participants (Boog, 2003; Gaventa \& Cornwall, 2001).

- Decide and agree on the methodology, activities, schedule, and goals of the research early in the process.

- Spend time together outside of goal-oriented research to establish informal relationships and build trust.

\section{Autonomy}

Autonomy refers to the freedom to express one's true self and to follow one's own vision and life path (Gaventa \& Cornwall, 2001). “Autonomy concerns the experience of integration and freedom, and it is an essential aspect of healthy human functioning" (Deci \& Ryan, 2000, p. 231). Autonomy is related to having greater access to resources and choice (Kanter, 1977, Pacanowsky, 1988, as cited in FosterFishman \& Keys, 1997; Rappaport, 1981; Spreitzer, 1995), more opportunities (Foster-Fishman \& Keys, 1997), control of knowledge (Greenwood \& Levin, 1998), 
and privacy or control over "home" (Ridgway, Simpson, Wittman, \& Wheeler, 1994). Autonomy appears to be critical to the exercise of power (Gaventa \& Cornwall, 2001), self-determination (Deci \& Ryan, 2000), and to the process of empowerment and countering power in a way that affects our mindset, assumptions, and consciousness of the issues which affect our lives (Friere, 1981 as cited in Gaventa \& Cornwall, 2001). “This 'power within' is shaped by one's identity and selfconception of agency, as well as by outside forces held by 'the Other"' (Gaventa \& Cornwall, 2001, p. 72).

Particularly within the area of homelessness, recovering "home" means recovering the privacy and freedom of self-expression, a sense of security, improved social status, a sense of having a stakehold in the community, and a renewed sense of competence. Empowerment emerges naturally from these experiences supporting autonomy (Ridgway et al., 1994). A research study investigating the personal impact on homeless persons of being involved in the co-creation of their homes shows that this freedom to have control and self-expressed preferences demonstrates respect, that "you are valued. You are a unique person whose ideas and needs we hold in esteem" (Ridgway et al., 1994). Making decisions where there are genuine choices is synonymous with exercising personal power. At Dignity Village, empowerment comes from controlling access to personal space, from being able to alter one's environment and select one's daily routine, and from having personal space that reflects and upholds one's identity and interests (Ridgway et al., 1994). It suggests that there is a vast difference between participating in a community based on 
expressed and shared values as opposed to one dictated by externally imposed rules for conduct.

In the self-help literature, autonomy is considered the defining characteristic of self-help groups (Roberts, Luke, Rappaport, Seidman, Toro, \& Reischl, 1991). Their origin, purpose, and mode of operation rest entirely with the members of the group themselves. According to Roberts et al. (1991), this freedom allows groups to take a more pragmatic approach to dealing with their members' problems. The result is greater control and responsibility upon the shoulders of members for both the successes and failures of their groups, which can be therapeutically beneficial (Roberts et al., 1991). Autonomy is also considered one of the psychological needs essential for motivating people's self-determination (Deci \& Ryan, 2000).

In the context of organizations, decision-making autonomy facilitates selfdetermination (Koberg, Boss, Senjem \& Goodman, 1999; Spreitzer, 1995). In the context of classrooms, research shows that higher levels of perceived autonomy are related to increased participation in class and school performance (Connell \& Wellborn, 1991). These studies also point to the importance of social contexts in supporting and hindering autonomy. Research by Crichlow (1989) suggests that many urban high schools communicate (implicitly and explicitly) low expectations and disinterest, as well as suppress opportunities that inhibit African American children's experiences of autonomy in the school setting (as cited in Connell \& Wellborn, 1991). 
Clearly, these findings are not specific to school settings. Social contexts have an impact on individuals' sense of autonomy, well-being, and power. A study of adults in a nursing home facility reveals that perceived support for autonomy was one of the strongest predictors of psychological and physical health (Grow \& Ryan, 1994 as cited in Ryan \& Solky, 1996). In the literature on homelessness, it is clear that the social context provides limited choice and autonomy for individuals, often resulting in a sense of powerlessness and an increased length of time in homelessness. Residents of tent cities and encampments stress freedom and autonomy as a highly important to their well-being and sense of power (Rivlin \& Imbimbo, 1989; Wright, 1995, 1997). Paying attention to social context is also important for self-help communities like Dignity Village, even though they are democratically governed. Communities develop structure and organization to balance growth and efficiency, but sometimes at the cost of individual loss of autonomy. If the community is aware of these issues, there may be ways to design social contexts, as well as community research contexts, that facilitate autonomy and participation (Connell \& Wellborn, 1991).

Contextual supports and impediments to autonomy. Autonomy support refers to the amount of choice provided by communities for members to express and follow their own personal goals and values (Connell \& Wellborn, 1991). The literature shows that providing choice and acknowledging people's inner experience enhances individuals' motivation and sense of competence (Koestner, Ryan, Bernieri, \& Holt, 1984, Tafarodi, Milne, \& Smith, 1999, Zuckerman, Porac, Lathin, Smith \& Deci, 
1978, as cited in Deci \& Ryan, 2000). Providing opportunities and choice also has positive effects on creativity, complex problem solving and learning, while rewards and evaluations seem to have a negative effect (Amabile, 1982, Grolnick \& Ryan, 1987; McGraw \& McCullers, 1979, as cited in Deci \& Ryan, 2000). Other events that may lead to an undermining of motivation and autonomy include: coercion, threats, surveillance, evaluation, and deadlines (Amabile, DeJong, \& Lepper, 1976, Deci \& Cascio, 1972, Harackiewicz, Manderlink, \& Sansone, 1984, Lepper \& Greene, 1975, as cited in Deci \& Ryan, 2000). In reviewing the literature on autonomy-supportive contexts, it becomes apparent that specific activities in varying contexts can differ in the extent to which they support or limit autonomy. In general, an ideal state for promoting autonomy appears to be situations where the structure is: clear, consistent, predictable, relevant, respectful, and supportive of genuine preferences and selfexpression (Connell \& Wellborn, 1991).

A practical guide to facilitating autonomy. Factors to consider when promoting autonomy in community research include:

- Provide opportunity at the start (induction meeting) for participants to collaboratively define the inquiry topic (Heron \& Reason, 2001; Parsons, Gutiérrez, \& Cox, 1998), the criteria for joining the inquiry, and the arrangements for the meeting structure and related matters (Heron \& Reason, 2001).

- Decide together how meetings should be arranged for sufficient time to reflect and take action (Heron \& Reason, 2001). 
- Decide collaboratively how roles are to be distributed (possibly rotating the facilitator role) (Heron \& Reason, 2001).

- Co-create ground rules to provide clear expectations and predictable structure (Heron \& Reason, 2001).

- Provide a range of opportunities for individuals to participate in ways that are relevant to them and that encourage self-learning and growth.

- Open space and time for reflection on direction, and provide choice-points where the community discusses possible new shifts in direction for keeping the research relevant and useful to the changing needs of the community.

- Create "action plans" with specific dates in mind for implementation, but do not treat the action plan as a deadline (which is perceived as coercive).

- Do not monitor other's tasks; provide individuals with the space to do things their own way.

\section{Competence}

Competence is defined as "experiencing oneself as capable of producing desired outcomes and avoiding negative outcomes" (Deci \& Ryan, 1985, White, 1959, as cited in Connell \& Wellborn, 1991, p. 51). Participatory action research aims to provide support and structure for individuals and communities to learn how to work interdependently and effectively in problem-solving and achieving their goals. According to Rappaport (1981), "Empowerment implies that many competencies are already present or at least possible ... [and] what you see as poor functioning is a result of social structure and lack of resources which make it impossible for the existing competencies to operate" (p. 16). This assumption is in line with the philosophy of PAR that builds on a long ideological tradition of acknowledging the 
strengths and value of every individual's skills, competence, and knowing. As people accumulate, organize, and use complex knowledge constantly in everyday life, they have much of the information and analytic skills needed to solve the issues that affect them (Greenwood \& Levin, 1998). PAR is based on the belief that human beings have useful knowledge that can and should guide the creation of their communities (Martin, 2001).

Skills develop and emerge through iterative cycles of learning, action, and reflection. Reflecting on the action process is a way to assess consequences for constant improvement and development of competence and knowledge (Greenwood \& Levin, 1998). The community context directly affects how participants perceive their position of power, the possibilities and limits of change, and the dilemmas they face (Robnett, 2002). The motivation literature demonstrates how competence is needed for responsible autonomy and for effective action, similar to how sense of competence is needed for motivation. For example, perceived competence is considered a critical component for self-determination, undermining or promoting students' engagement and actions in school (Skinner, Wellborn, \& Connell, 1990 cited in Connell \& Wellborn, 1991). Another study by Fischer (1978) suggests that individuals become more motivated when they see and feel responsible for their actions that result in positive consequences (as cited in Deci \& Ryan, 2000). Competence may be a path to empowerment in affecting how we perceive our future possibilities for personal and social change. 


\section{Contextual supports and impediments to competence. Connell \& Wellborn} (1991) highlight "positive structure" as important in promoting competence and motivation. Positive structure refers to an environment that communicates clear expectations to individuals, provides positive feedback (Boggiano \& Ruble, 1979, Deci, 1971, as cited in Deci \& Ryan, 2000), and responds consistently and predictably (Connell \& Wellborn, 1991). Research consistently shows that children's experience of structure in their homes and elementary school classrooms are positively associated with their feelings of competency (i.e., knowing strategies for achieving success and avoiding failure in school; Connell \& Ryan, 1987, Ryan \& Grolnick, 1986, Skinner et al., 1990, as cited in Connell \& Wellborn, 1991).

A study on block associations shows that social climates with higher levels of cohesiveness, structure, task focus, member commitment and satisfaction, and leader support and control are related to competencies in accomplishing their goals and maintaining their operations (Prestby \& Wandersman, 1985). Research on empowering community settings and volunteer organizations suggests that empowering community settings have an opportunity role structure that provides many options for participation that are highly accessible to diverse skill sets and selfconfidence, and contain many opportunities for skill development and exercise of responsibility (Maton \& Salem, 1995; Prestby \& Wandersman, 1985; Florin et al., 1992). Providing a higher degree of structure and formalization in task-oriented activities within self-help group work and volunteer organizations has been shown to promote involvement, satisfaction, clarify boundaries, facilitate trust and sharing and 
enhance group viability over time (Moos, 1974, Silverman, 1980, as cited in Maton, 1988; Florin et al., 1992; Prestby \& Wandersman, 1985; Giamartino \& Wandersman, 1983; Milburn \& Barbarin, 1987, Pate, McPherson, \& Silloway, 1987, Smith, 1966, as cited in Wandersman \& Florin, 2000; Wandersman, Jakubs, \& Giamartino, 1981). A practical guide to facilitating competence. I plan to facilitate competence in this research by using the following guide:

- Make the acquisition of knowledge, skills, and resources as explicit objectives and the role of reflection as an explicit component of the event (Martin, 2001).

- Collectively plan and implement specific tasks.

- Provide a structure that encourages involvement, but at the same time, limits off-task activities and discussions.

- Provide a range of opportunities for individuals to participate and help to maintain structure and direction of research (e.g., time keeper, facilitator, process keeper, note-taker or record-keeper, data collector, etc).

- Initiate group members into the methodology of the inquiry so that they can make it their own (Heron \& Reason, 2001).

- Ensure that the problem is analyzed and solved by the community (Hall, 2001).

- Teach techniques and appropriate social science strategies that will enable and empower people to carry on with their work (Martin, 2001).

- Hand over responsibility as soon as required skills are in place (Martin, 2001).

- Identify and build on strengths and capabilities, rather than focusing on correcting deficits and weaknesses (Dunst, Trivette, \& Deal, 1988; Parsons, Gutiérrez, \& Cox, 1998).

- Collectively mobilize resources (Parsons, Gutiérrez, \& Cox, 1998). 


\section{Collective Identity}

Collective identity is "an interactive and shared definition produced by several individuals (or groups at a more complex level)... that must be conceived as a process because it is constructed and negotiated by repeated activation of the relationships that link individuals (or groups) [to the community]" (Melucci, 1995, p. 44). Collective identity activates relationships in order to give a sense of togetherness and unified direction to the goals they pursue (Melucci, 1995). It is connected to a sense of community, which is a feeling of belonging and interdependence, a commitment to helping one another, and shared emotional ties and support (McMillan \& Chavis, 1986; Sarason, 1974). Collective identity involves emotional investment, enabling individuals to feel a part of a common entity (Melucci, 1995). It implies unity, mutual recognition of connectedness and belonging, shared beliefs and values (Maton \& Salem, 1995), and continuity of shared meaning over time, connecting past and future action to effects (Melucci, 1995).

The literature suggests that collective identity or sense of community is an essential component in empowerment (Chavis \& Wandersman, 1990; McMillan, Florin, Stevenson, Kerman, \& Mitchell, 1995; Della Porta \& Diani, 1999), and to the strengthening of self (Della Porta \& Diani, 1999). Collective identity also has a strong relationship to collective action and participation (Chavis \& Wandersman, 1990; Della Porta \& Diani, 1999; Friedman \& McAdam, 1992; Maton \& Salem, 1995; Melucci, 1995; Wandersman \& Giamartino, 1980; Zimmerman, 1995, 2000). 
Collective action is not just participation of individuals. It is purposive action created in social relationships through a sense of togetherness and direction (Melucci, 1995). In the context of self-help groups, collective identity can provide members with new ways of viewing their problem or the world, and with a sense of purpose and direction (Levy, 2000). Social power emerges from the strength of interpersonal relationships (Speer \& Hughey, 1995). Collective action and empowerment cannot occur in the absence of a 'we' characterized by common traits, interests, values, and common histories (Della Porta \& Diani, 1999). Communities may form and take action together toward a common goal, but they will dissolve after the issue is addressed if not built on strong interpersonal relationships (Speer \& Hughey, 1995). Systems thinker Peter Senge (1990) suggests that visions dissolve when people forget or lose their connection to one another.

Contextual supports and impediments to collective identity. PAR involves relationship building and may foster a connectedness not only to the topic area, but to the people involved (Nelson et al., 1998). Emotional connection, membership, use of shared symbols and common identity can be used to characterize and promote productive relationships in some community contexts (Speer \& Hughey, 1995). Selfdetermination theory hypothesizes that motivation will be more likely to flourish in contexts characterized by a sense of secure relatedness (Ryan \& La Guardia, in press, as cited in Deci \& Ryan, 2000). Giamartino and Wandersman (1983) note that group cohesion is found in social climates with a lower tolerance for independent action uncoordinated with the group, higher encouragement for sharing personal feelings and 
information, and higher tolerance for negative feelings or disagreements. These contextual supports enhance collective identity through increasing connectedness.

Another facilitator of collective identity is storytelling or community narratives, which communicate to its members what it means to be a member of the community. Communities usually establish themselves through storytelling (Mankowski \& Rappaport, 1995) in social interaction, texts, and other forms of communication which include pictures, performances, and rituals (Rappaport, 1998). Community narratives help to create memory, emotion, meaning, and collective identity (Harper et al., 2004; Rappaport, 1998; Schank, 1990 as cited in Rappaport, 2000). Stories can also function as motivators (Harper et al., 2004). People are motivated by a story, an understanding of what they are working for, and who they can become-now, and in the future. Collaborative research can help in co-creating new narratives of power and empowerment that resist and challenge the dominant cultural story of who they are (Harper et al., 2004; Mankowski \& Rappaport, 1995; Rappaport, 1998). Keeping the oral transmission of a community culture alive is vital to the survival of a community (Mankowski \& Rappaport, 1995). A practical guide to facilitating collective identity. I plan to facilitate collective identity in this research by using the following guide:

- Build and maintain positive cooperative relationships (Stringer, 1999).

- Emphasize leadership roles that facilitate and support people rather than direct and control them (Stringer, 1999). 
- Maintain harmony by resolving conflicts that arise, openly and dialogically (Stringer, 1999).

- Be open to and encourage multiple perspectives, share different narratives, challenge old narratives that may be damaging and create new ones together (Harper et al., 2004; Stringer, 1999).

- Build collectivity by harnessing the strengths of mutual aid and self help, and established social networks (Dunst, Trivette, \& Deal, 1988; Parsons, 1998; Parsons, Gutiérrez, \& Cox, 1998).

- Produce and maintain community rituals as a way to develop and sustain identity (Della Porta \& Diani, 1999).

- Include the entire community in constructing their story, their history and vision (books or visual documents; video). Utilize stories of community heroes which demonstrate aspirations and achievements, making available to its members new possibilities (Rappaport, 2000).

\section{Critical Consciousness}

Critical consciousness refers to the capacity to analyze and understand one's social and political situation and to develop a critical awareness of the causes of undesirable social conditions, the possibilities for change, and the importance of acting to transform the world (Friere, 1973; Kieffer, 1984). The work of Paolo Friere (1973) has had significant impact in shifting ideas of PAR away from individualistic models and to the embeddedness of individuals in political contexts which directly affect people's lives. Friere (1973) asserts that when marginalized people have opportunities to develop a dynamic understanding of their condition within the larger contexts of power in society, they will begin to become empowered to think and act on the 
conditions around them (Shor, 1993, p. 32, as cited in Humphries, Mertens, \& Truman, 2000).

In PAR, empowerment is grounded in critical consciousness through a cyclical process of action and reflection (Speer \& Hughey, 1995). As we learn to listen and hear each other in new ways, we begin to understand how the privileged and more powerful influence the way we perceive the world (Hall, 2001). The development of critical consciousness stirs individuals to action in challenging deep-rooted power inequities (Hall, 2001; Humphries et al., 2000). Action without reflection is blind and ineffective at addressing power and making real social change. However, action which is informed by critical consciousness mobilizes and provides direction for purposive and effective action for the transformation of power relationships in the direction of greater democracy (Greenwood \& Levin, 1998).

Contextual supports and impediments to critical consciousness. The literature is limited on research that explores contextual supports and impediments to developing critical consciousness. However, I believe that ideas from PAR and systems thinking can provide some insight. PAR aims to create conditions for collective reflection that provide structure and support for autonomy and relationshipbuilding in order to develop a foundation for dialogue that enables diverse people to "see themselves in one another" (Senge \& Scharmer, 2001, p. 238). Collective reflection involves dialogue among multiple perspectives which provides fertile grounds for individuals to change their own views and to develop critical 
consciousness. A context encouraging systems thinking may also help to facilitate critical reflection.

Systems thinking involves interpreting individuals' lives and community issues as emergent wholes (Jackson, 1991 as cited in Flood, 2001). It focuses on what emerges at system levels larger than the specific community or individual, thereby bringing awareness to the interrelatedness between individuals and a larger context, and the dynamics that create and maintain problems as well as the dynamics that resist change (Flood, 2001). Systems thinking provides us with a lens for seeing ourselves as part of the whole, our role in the problem and as agents of change. Through dialogue and reflection, we achieve alignment of our ideals, and negotiate a clear value set that binds individuals together toward achieving empowerment (Flood, 2001).

A practical guide to facilitating critical consciousness. I plan to facilitate critical consciousness in this research by using the following guide:

- Education or discussion regarding social, political, or economic forces contributing to the problem in order to raise consciousness (Andrus \& Ruhlin, 1998; Parsons, Gutiérrez, \& Cox, 1998). Such insights can reduce self-blame and impediments to empowerment by promoting an understanding of the difference between individual and societal responsibilities (Andrus \& Ruhlin, 1998).

- Exposure to how other cultures and countries respond to homelessness.

- Actively promote dialogue and inclusion of diversity in the change process (Parsons, Gutiérrez, \& Cox, 1998).

- Use facilitation tools to collectively define the problem, identify and analyze the critical factors, processes and dynamics that maintain the problem. 
- Map out powerful stakeholders and processes that may impede change, and include important stakeholders in research and change.

Dynamics among the components

Reflection on community empowerment as a whole may help us begin to see the interactive relations among the components that give rise to an empowered community. These relationships are complex, and if we focus too much on any one component, we may unintentionally impede empowerment, or even enhance disempowerment. For example, too much emphasis on autonomy may undermine the development of collective identity and the interdependence necessary in aligning individuals' visions and actions in the direction of community gains, rather than individuals' competing interests. Increasing one component affects the others, risking unintended consequences. Collaborative research and PAR are empowering based on the extent to which co-researchers are able to facilitate and connect all the components in the research process. This requires collaborative participation of everyone involved, the freedom and control of autonomy to explore what is meaningful and relevant, the exercise of competency and skills as an interdependently working group taking action, a collective identity the promotes a positive sense of "we-ness" and aligned vision, and a continuous critical reflection that directs us in reaching our goals and understanding the larger context. For collaborative researchers, guidance may come from a systems perspective in allowing one to see and value the contributions of each part and each perspective, while remaining mindful of the whole and the contexts that limit and promote community empowerment. 


\section{CHAPTER SIX}

\section{THE CURRENT STUDY}

There is a pressing need for change in the role of social scientists to become more active in implementing research at all levels, working with stakeholders from diverse backgrounds to facilitate inter-group relations in ongoing efforts to reduce the impediments to social change (Toro \& Warren, 1999). As the dynamics become clearer to stakeholders, they may begin to see how every individual is part of the system, tied together and interdependent. This is especially crucial in resolving complicated social concerns such as ending homelessness.

While affordable housing and reducing economic disparities are important aspects in the long-term solution to ending homelessness, tent cities are also necessary components. Within the tent city model, residents collectively gain voice and the social power necessary to sit at the "policy table" and participate in the dialogue and decision-making that affects them. Dignity Village has demonstrated how a selforganized community can give people room to hope and room to organize for real change. The challenge lies in sustaining the energy and collective action required for its survival and continued effectiveness for social and political change. The intent of this participatory action research was to facilitate conditions and processes that support Dignity Village in obtaining more social power, in participating in and shaping public discourse on homelessness, and in organizing for long-term social change. 
The Research Context and Goals

\section{Taking a Step along the Pathway Out of Homelessness}

Over the years, Dignity Village has demonstrated how a self-organized and empowering community can give people more than a home-base: it can provide hope and the necessary supports to organize for social change, crucial steps down a pathway out of homelessness. Figure $1 j$ illustrates the area along this pathway on which this research project focuses. In the next sections, I describe the processes and dynamics highlighted in the figure that were explored and addressed in this participatory action research.

Figure $1 j$. Focus of current research: overcoming blockages in moving from a home-base to an empowered tent city community.

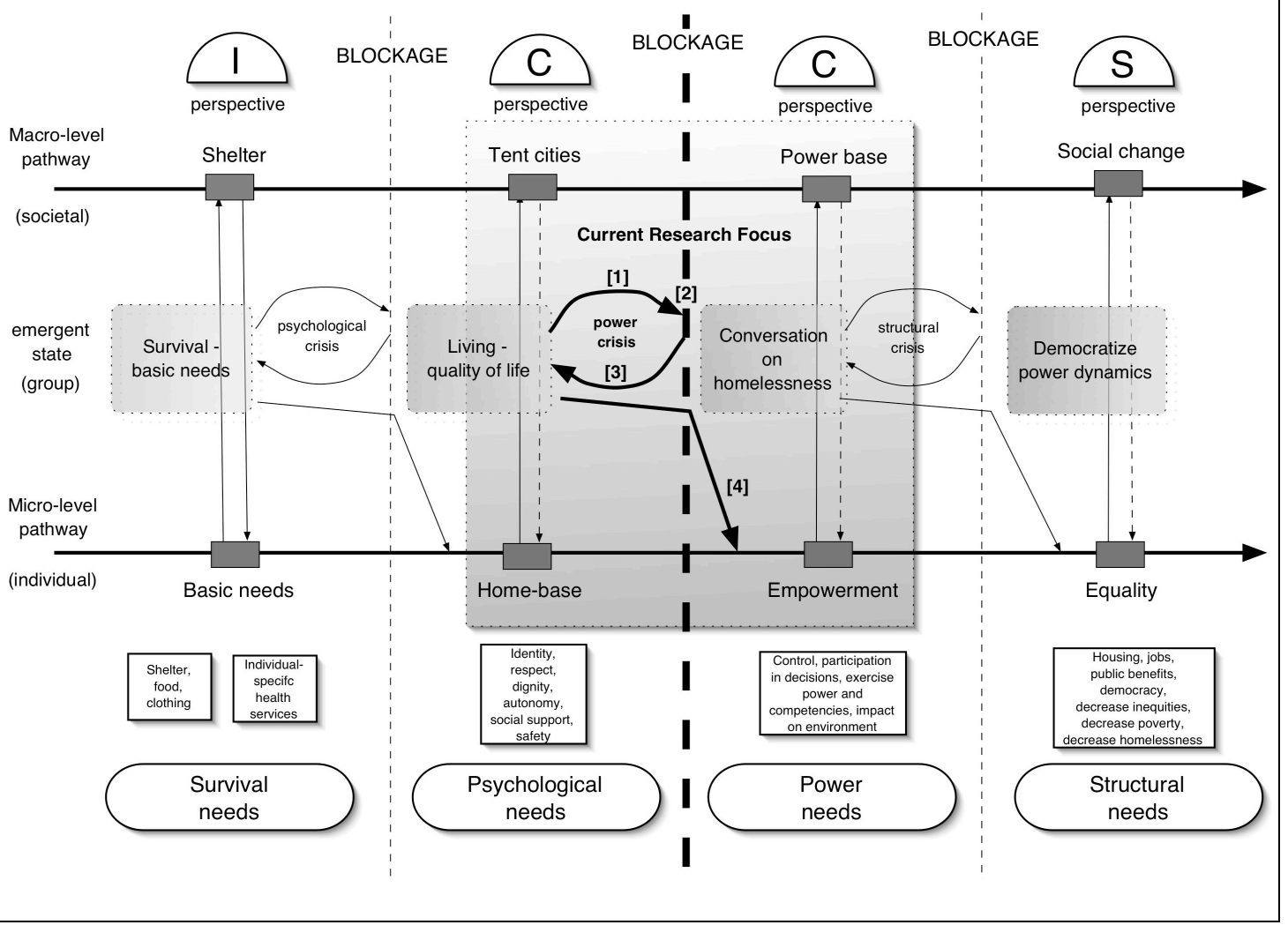




\section{1 - Taking Steps toward Community Empowerment}

At the time this research project began, Dignity Village faced a challenge in sustaining the energy and collective action required for its survival and continued effectiveness for social and political change. With many of its newer members just beginning to meet their psychological needs by acquiring a home-base and a community, long-term members struggled to maintain their commitment and participation in political and broader community-based issues, the next step along the pathway. Many of the long-term members had actively participated in the Out of the Doorways campaign that sparked the movement and formed Dignity Village. At that time, external pressures were so strongly aligned against them that members of the community could not reside at the Village without participating at some level in the community conversation on homelessness. Most all residents of the newly-forming Village developed a critical awareness of their lack of voice in the broader conversation, as well as an understanding of the societal barriers to getting out of homelessness. But by the time of the research, five years after the Village began, this critical awareness remained generally confined to a small group of long-termers and “original Dignity soldiers” who continued to live and work at Dignity Village. Many of these long-termers were still actively involved in Dignity Village, participating in leadership positions and on committees.

Long-termers differed in their visions of the future of Dignity Village, but one of their shared beliefs was that it was important and necessary that Dignity Village exists and grows into a self-sufficient and empowered community. Long-termers 
thought of Dignity Village as more than a home-base where individuals reside in their homes and act independently from the community. They envisioned Dignity Village as a community and culture that promotes a collective and interdependent "we" instead of a survival and independent "I" mentality. This vision wasn't necessarily unique to this long-termer group of Villagers, because many other Villagers had expressed a similar desire: mainly to get along and work well together, to live together interdependently rather than in conflict and in negativity. This participatory action research grew out of a desire by the long-termers to improve their community, and to take steps toward building a community with a higher quality of participation where people are willing and committed to doing their part, where Villagers work together in cooperative, democratic, and supportive ways, where Villagers participate in a community conversation on homelessness and on the history and future of Dignity Village, and develop a political awareness and a commitment to its future.

\section{2 - Blockages in the Pathway}

Unfortunately, taking these steps toward improving their community was exceptionally challenging in practice. Since their move to Sunderland Yard, Dignity Village had faced numerous barriers head-on, with the community beginning to take steps toward community empowerment, but then falling back to a more disaffected and disorganized state. Collective identity and the quality of participation in the community were constantly perturbed by the very nature of having a transitional membership. While many new members had become part of Dignity Village, the 
majority of the longer-term members who were part of the original political movement had transitioned out of the community in the year prior to the research beginning. As a result, there were fewer people to carry on community traditions and maintain organizational memory, as well as fewer long-term commitments and a higher turnover in leadership positions.

Because of the stressful nature of homelessness, those who enter and live at Dignity Village face many challenges in meeting their own basic needs, such as a lack of resources, histories of poor coping with stress and trauma, increased debt, loss of ID and driver's license, high unemployment, and in some cases, a loss of family ties. These challenges are not necessarily unique for Villagers or homeless people, but are associated with the conditions of poverty in general.

Another barrier to quality participation and building a sense of community at Dignity Village is illegal drug use. At the beginning of the participatory research, a higher than usual proportion of the community were actively using methamphetamines. Much like the problem nationally and in the larger Portland area, the Village struggled with the challenges of enforcing their anti-drug rule, while at the same time respecting each others' homes and privacy.

A lack of resources at Dignity Village also acted as a barrier toward community living. For example, in the year or so prior to the research, the community worked to move members out of tents and into more solid structures at the Village that meet local building codes. With only meager building supplies, the community had set up a system where they would put resources into one house at a time as materials 
became available, based on the length of time an individual was a member of the Village. Despite the community system, the lack of resources created a competitive environment, and individuals would undermine each other, or steal donations, to build and finish their own houses.

Another barrier came from a lack of outside support. At the start of the research, many Villagers spoke about the tenuous fate of the community because of their uncertainty and lack of control over how long the City would allow them to remain in their current location, as well as the lack of funding. Initially, the Village was in negotiations with the City to sign a ten-year lease at Sunderland Yard; however, city officials would consistently exclude the Village from communications and then provide only partial information. For example, the Village was told that the City would be altering the property boundaries, thus forcing the community to move some of their houses. However, the City did not provide additional information or a schedule so that the Village could plan where and when to re-build and move their houses. In addition, the lack of funding from supporters or private donors for basic operational expenses was a serious barrier to growth, in that it is difficult for a community to even begin to see a broader political vision when they are consistently faced with insufficient funds to pay basic utilities.

\section{3 - Falling Back}

As Dignity Village faced substantial barriers to progress along the pathway, the community experienced the repercussions of falling back to a previous 
developmental step in the face of these obstacles. In the year prior to the research, the community showed divisions between community members who were focused on building a home and members who saw the power of the collective and the importance of activism for social justice. This difference did nothing to unite the community toward taking steps together down a pathway out of homelessness. Instead, Dignity Village moved toward conflicts between groups ("I" vs. "we"; drug users vs. nonusers; newcomers vs. long-termers; non-political vs. activists), more stringent enforcement of rules to deal with the drug problem indirectly (e.g., throwing out drug users for disruptive behaviors or theft when such evidence was more readily available), increased accusations about transparency, low morale and participation, more withdrawal by members, more stress and negativity in the community, a lack of motivation to work together, a lack of commitment to Dignity Village, and a rampant "I" survival mentality where people grew more focused on meeting their own needs rather than working together toward higher-order community needs. The community felt stuck in a cycle that was leading them backwards along the path to a state of general disaffection.

\section{4 - Getting out of the Cycle and on the Path toward Community Empowerment}

Many Villagers had lost hope in Dignity Village and had begun to see it as a failure, although there were diverse explanations for why it was considered a failure. Despite this low morale, a small group of Villagers had not lost hope, holding on to their understanding of the importance of Dignity Village in the struggle for social 
justice. And it was this small group who were struggling to get out of the cycle and back on the path toward a vision of Dignity Village as an empowered and empowering community with political consciousness, and once again, a force to be reckoned with.

\section{Current Research Focus and Goals}

This participatory action research grew out of a desire to address community issues that were undermining the quality of participation, a sense of collective identity, and community empowerment, and that gave rise to the state of disaffection within Dignity Village. This collaborative research attempted to understand and change the dynamic processes that were blocking the development of Dignity Village into an empowered and empowering community, and attempted also to facilitate the empowering processes with which Dignity Village could take the next step on the pathway out of homelessness.

The research focus at the A-level was the emergence of an empowering community which: (a) supports quality of participation, emotional connection, shared vision and collective identity, and commitment from members; (b) supports and practices democratic action, collective critical consciousness, inclusion and respect of diverse views, values, and skills; and (c) facilitates collective action in supportive and cooperative relationships. This research sought to understand dynamics and processes at the B-level, within the community and within the research context, that worked together to give rise to the state of disaffection and that undermined processes toward an empowered and empowering community. The research also sought to take action 
toward shifting these dynamics out of the cycle and state of disaffection and toward an empowered and empowering community.

The research was carried out within a collaborative approach of participatory action research, which involved democratically creating and maintaining research processes that facilitated the five possible components of community empowerment identified previously in chapter five. These include: collaborative participation, autonomy, competence, collective identity, and critical consciousness. The research procedures focused on process with the goals of implementing action steps and creating a product, namely, the orientation video, which I refer to as an "action tool." The action tool was developed through a democratic process in which a group of Dignity Village residents met and planned activities together, with a focus on creating an effective and context-relevant tool. The process provided the opportunity for every resident to be involved at some level, in an open manner that allowed for changes in co-researchers' level of involvement. Individuals could participate at any level: from active weekly involvement in the core research group (co-researchers) to periodic involvement as community consultants who provided information and feedback to the core research group at specific milestones throughout the project.

The action tool was envisioned as an orientation video that portrays the community narrative, including where residents came from, who they are, and future visions of possibilities for their community and for social change. Village members would use the action tool in their orientation process for "newcomers" as well as "long-termers" in the community, with the hope that the tool would help to re- 
establish a sense of community and identity, participation, and cooperation that could make Dignity Village, once again, an empowered community with a shared vision for social change. A secondary goal of this research was to document whether the empowering processes and aligned actions co-created within the research would transcend the research context to enhance community empowerment.

\section{Research Questions}

This study was organized around four research questions that attempted to explore the quality and processes of the research as well as its impact on individual participants and on the community as a whole.

The four research questions are as follows:

Before co-creating an action tool:

1. What are the state and dynamics in the community that have led to the concern that Villagers are becoming disaffected?

During its co-creation:

2. How do participants work together and include others in the process of creating an action tool?

2a. How do co-researchers participate and work together?

2b. How do co-researchers and community consultants work together?

3. How does this ongoing research process interact with the community?

3a. How does participating in the research processes impact coresearchers' quality of participation in other community activities? 
3b. How do these research processes carry over into the community and impact the overall quality of participation and empowering processes at the community level?

After creating an action tool:

4. What are the state and dynamics in the community, and how do people currently perceive them?

Figures 2 and 3 illustrate the levels and dynamics of the research focus relative to each research question.

\section{Final Objective: Accessibility of the Research Report}

Collaborative research speaks not only to the process of doing research, but also to the accessibility of our research reports to a wide range of communities. Greater accessibility of the report breaks down academic barriers and enables the inclusion of more voices and perspectives in public discourse. Thus, in keeping with the principles of participatory action research, a final objective is to report the research in ways that emphasize its collaborative nature. The inclusion of marginalized communities in knowledge-making is central within the philosophy of PAR, and the usefulness and accessibility of the research report to the community is a vital part of this knowledge-making process.

In my research report, I have deliberately chosen the format, structure, voice, style, and orientation of this dissertation to keep in mind the accessibility and usefulness of the research to a broader range of audiences. PAR seeks to enhance an 
Figure 2. System research focus: Levels and attributes

\section{A-level focal unit: Community}

Attributes: An empowering community which: (a) supports quality of participation, emotional connection, shared vision and collective identity, and commitment from members; (b) supports and practices democratic action, collective critical consciousness, inclusion and caring of diverse views, values, and skills; (c) facilitates collective action in supportive and cooperative relationships

B-level sub-units: Social dynamics in research

Attributes: Social dynamics and processes that support or undermine the development of an empowering community, with a specific focus on five potentially key components in the process of community empowerment: collaborative participation, autonomy, competence, collective identity, and critical consciousness.

A-level
focal unit-
community processes

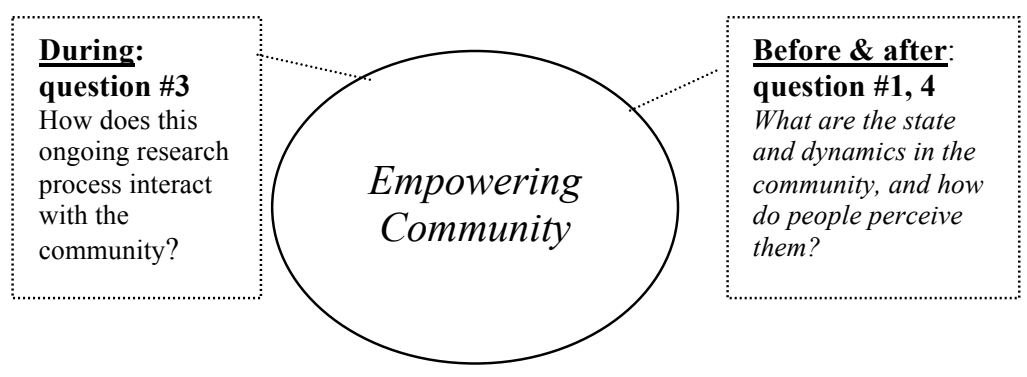

\section{B-level}

sub-units group social dynamics

During: question \#2

How do participants work together and include others in the process of creating an action tool?

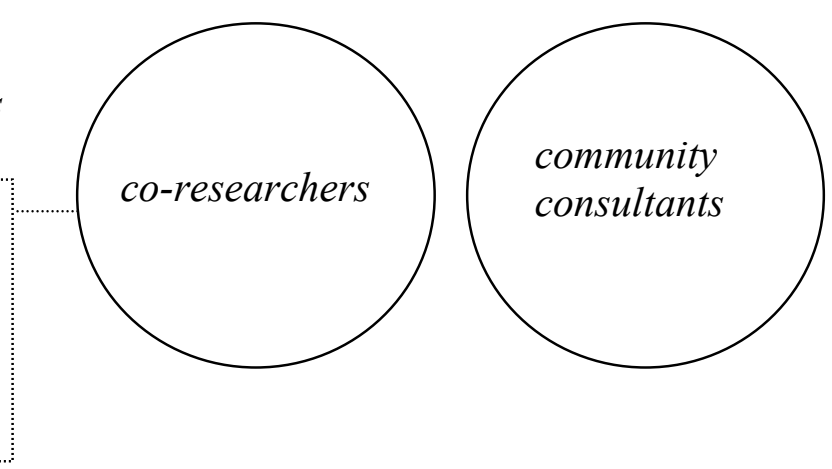




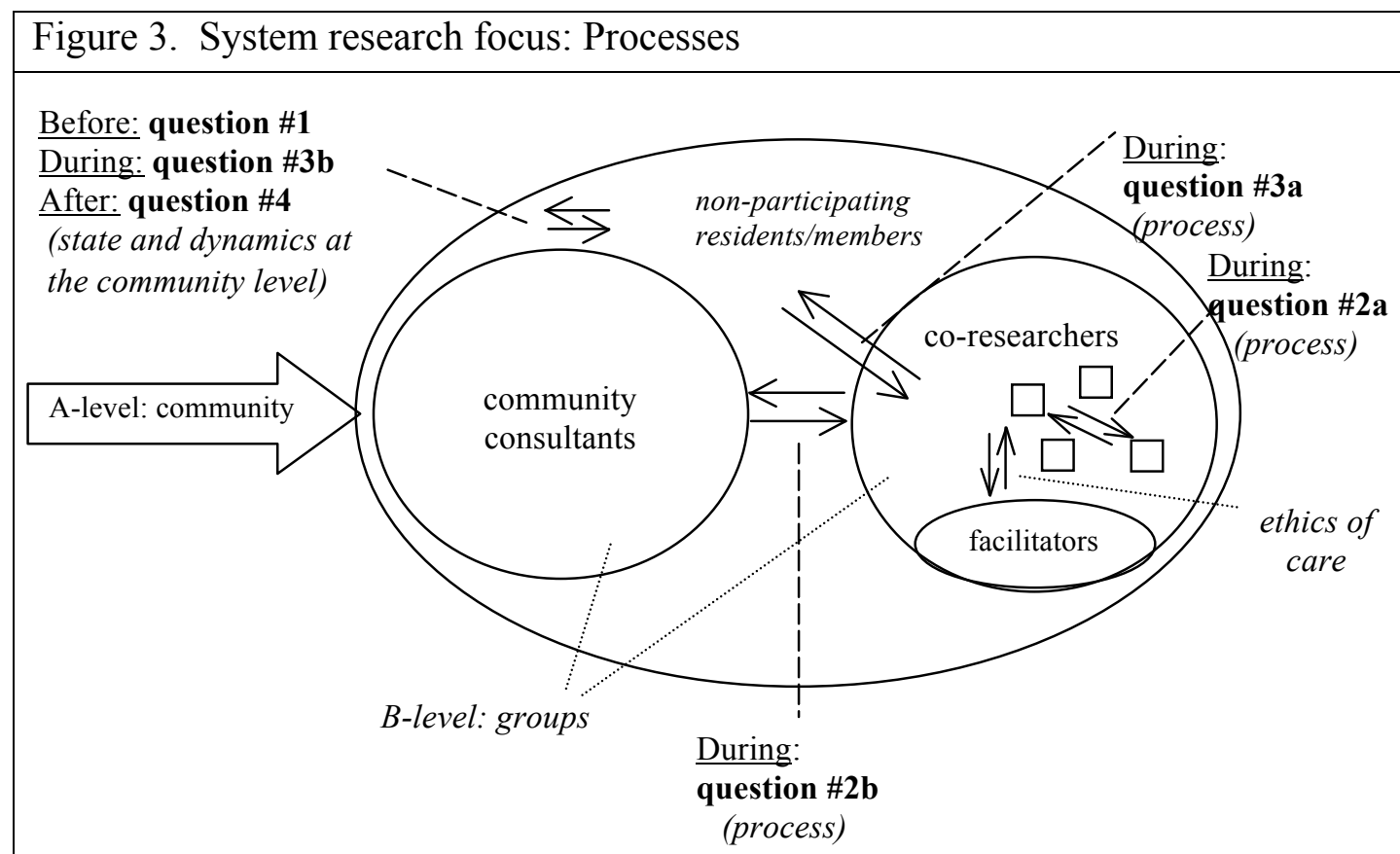

Research questions:

1. Before: What are the state and dynamics in the community that have led to the concern that Villagers are becoming disaffected?

2. During: How do participants work together and include others in the process of creating an action tool?

2a. How do co-researchers participate and work together?

2b. How do co-researchers and community consultants work together?

3. During: How does this ongoing research process interact with the community?

$3 \mathrm{c}$. How does participating in the research processes impact co-researchers' quality of participation in other community activities?

$3 \mathrm{~d}$. How do these research processes carry over into the community and impact the overall quality of participation and empowering processes at the community level?

4. After: What are the state and dynamics in the community, and how do people currently perceive them? 
empathic understanding of participants' experiences, and video is a more suitable tool for conveying these kinds of data than text. Text-based report structures can inhibit clear and adequate representation of people's experiences and perspectives, as some of the richness of the data is lost in translation to text. With video, viewers can see the setting, hear participants and the inflection in their words, and observe their body language. Directly experiencing and observing these subtleties in participants' expressions are important in developing empathy and understanding of another's point of view. Using video records of participants' own voices can also reduce the amount of technical or academic terminology that might hinder understanding across multiple audiences. This also provides the audience ("reader") with more raw data and the freedom to develop their own understanding and critique of the author's participation, interpretation, and analysis. In visual texts, researchers can also add commentary that is as analytical or theoretical as any in text (Eisner, 1998). In some cases, visual texts can offer richer resources for helping others understand a situation than a written narrative would provide (Eisner, 1998).

My intention was to create a research report in a format that will accomplish the following goals: a) to make my lens explicit (e.g., my relationship to the Dignity Village community, my values and beliefs that shape the telling of this story and the research processes itself), and to describe how my participation in the research not only impacted others, but also how participating in the research was transformative for me; b) to provide context for the research relevant to the dynamics leading up to the disaffected state of Dignity Village and the research focus; c) to raise awareness of the 
multiple perspectives in the U.S. academic literature on homelessness; d) to provide a conceptual framework for the significance of the current participatory action research within a broader systems perspective on a pathway out of homelessness; e) to provoke questions and encourage a certain critical reflexiveness in audiences as they read/view the document; f) to stimulate open dialogue within the Dignity Village community and beyond the margins of Dignity Village to public discourse on homelessness that includes multiple I-, S-, and C-perspectives, as well as marginalized voices of unhoused people who are often excluded from these conversations; and g) to act as a useful tool for Dignity Village to carry on participatory action research for improving their lives and community living.

Many of these goals overlap with the goals of specific intended audiences for this report, which include both academics from multiple perspectives who are attempting to understand and conduct research on homelessness, and the nonacademic co-researchers and participants within the community of Dignity Village. In addition, the report must address specific academic requirements relating to the fulfillment of a doctoral degree at PSU. Broadening the accessibility of the research to reach diverse audiences with one report has clear benefits. However, with this broadening, there are trade-offs. First, I risk sacrificing depth in order to traverse a more expansive terrain necessary to connect diverse audiences. Second, different audiences may "read" this report for different purposes. For example, one reason the dissertation committee members read the report is to evaluate the quality of the research. This agenda is quite different from readers who participated in the research 
and are community members of Dignity Village, who will more likely read for practical purposes such as continuing to adapt and use PAR as part of ongoing collective efforts to improve their community.

Given the differing priorities for each audience, it may not be possible to address them all in one report as if they are singular and independent. Priorities can contradict and compete, making it more difficult to address them fully when reporting to multiple audiences. One example of a competing priority involves focusing on care for the community (protecting the community from potential harm), at the same time as maintaining transparency in an academic report (revealing potentially harmful incidents relevant to the research questions). Clearly, there is no simple guide for how to resolve these dilemmas, only that they must be kept in mind and constantly negotiated during the creation of a report.

As I created the visual results section, I took special care to address these competing priorities. For example, in an effort to protect the community, I decided to exclude certain video clips of individuals or situations that might incite harm to the individual or to the community as a result of its inclusion in my analysis. Decisions such as these were documented in a text-based journal, which served two purposes: 1) to improve the quality of the research through self-critique and reflection process, and 2) to increase transparency in my decision-making and in acknowledging the limitations of addressing competing priorities that are inherent in communicating to diverse audiences. In this journal, I also documented the strategies I used in dealing with these challenges as well as the effects of those decisions on Dignity Village. I 
utilized the journal to write a summary in this report's discussion section to communicate some of the main challenges, decisions, and limitations in the process of making the visual results section video. This discussion section should provide transparency for the academic audience, using a written text format to provide general examples that will be informative for learning, but still protect individuals within the Dignity Village community from potential harm.

Finally, as the narrator of this story, I framed the results and discussion sections to bring continuity to the story, as well as to make my perspective in the research process explicit. An important part of the process in PAR is self-reflection. In practicing this philosophy in the process of constructing the report, I turned the lens on myself, and used my experiences as both an insider and outsider to the Dignity Village community, not only to describe the research processes and its impact on the community, but also to describe how my participation impacted the quality of the research and how the research affected my own development.

Please see the "Getting Oriented" preface at the beginning of this document to review terminology and definitions used in this study. 


\section{CHAPTER SEVEN \\ RESEARCH METHODOLOGY}

\section{The Research Setting}

The concept of this research emerged from informal dialogue between Wendy and me and a small group of Dignity Village community members in the summer of 2004. One individual, a member of the intake committee, brought up the need for an orientation video that would capture and tell their story in a way that would emotionally connect others to Dignity Village. She felt that the low morale and decreased participation in the community were rooted in a general lack of emotional engagement to Dignity Village, its history, and vision. The group debated the various issues that bound the community together at Sunderland Yard, and whether they could re-invigorate a sense of community through storytelling. Given their experiences with the impact of video and our collaborations in creating other media outreach tools, they believed that a video would be an effective tool to address this issue. At the time of this original discussion, we decided to postpone the project until we had completed or made significant progress on some other collaborative projects (i.e., documentary and Tent Cities Toolkit).

Months later, I spoke with a professor at Portland State University about the possibility of using this collaborative project as part of my dissertation. She encouraged me to pursue this community-based project as dissertation research. I asked several Villagers from the original discussion group about whether it would 
be acceptable for me to collaboratively work on the orientation video for the purposes of my dissertation research. Individuals from this group supported this request, although they also brought up potential issues to address within the broader Dignity Village community, such as issues of researcher exploitation and equal partnership in research.

Many members of Dignity Village share a common concern regarding "poverty pimps," a term they coined to refer to people who earn a good living by providing services to those in poverty; some Villagers see the hypocrisy in this system, and mistrust those people who have a vested interest in maintaining their "customer base" of poor people. This general community wariness regarding possible exploitation extends as well to research activities. Throughout its existence, Dignity Village has received many requests from academic institutions about research, and the Village (or individuals at the Village) has often participated in research activities. Some Villagers describe these experiences as positive and rewarding, but a few individuals have expressed concern about other experiences with community partners, in which the partners received the notoriety and grant monies to work with the Village on specific projects, creating a kind of exclusion, or unequal partnership between them.

In my discussions with Villagers, some individuals have complained about specific experiences where others received "a feather in their cap" for things that Dignity Village had itself achieved. These Villagers perceive others (community partners, academics) as gaining expertise and recognition through Dignity Village, 
often opening doors for the expert to be included in critical dialogue about homelessness, while Dignity Village remains the passive subject or hidden partner, no closer to being included in the broader political dialogue. I want to emphasize that not all individuals in the community feel this way; however, some of the individuals who pronounced these views and concerns were long-term members of the community. To address these concerns, I spoke with several of the more hesitant individuals about the possibility of collaborating on the project for my dissertation research, and found that the overwhelming majority of Villagers that I spoke with did not have these concerns for this specific project. Only one Villager remained hesitant, stating that he worried whether others would disapprove; however, he encouraged me to approach the Village membership about it.

I signed up to speak at the membership meeting in October 2005. At the meeting, I proposed the research project as a continuation of our collaboration, utilizing similar processes (see Appendix B for recruitment presentation outline). After I spoke, one Villager felt that it was necessary to provide more context to some of the newer Villagers regarding our long collaborative relationship. At the end of the dialogue, the community showed their support of the project and we scheduled our first research meeting. At the end of the meeting, the cautious Villager leaned over and asked, 'Is this for your Masters?' I replied, 'No, for a PhD.' When he did not say anything for a moment, I worried that he was not supportive. Then, he looked at me and said quietly, "We're proud of you." 
I did not seek an official written letter of support from the community, but used consent forms for individuals who wished to participate directly in the research.

\section{Human Subjects Approval}

After receiving support from the Village about developing the orientation video as part of my dissertation research, I postponed moving forward with the project until I had taken the necessary steps toward obtaining approval from my committee, preparing for my research proposal, and obtaining human subjects approval. However, these preparatory steps with the university took time, and the problems appeared to worsen at Dignity Village. Individuals at the Village would often gently ask how soon we would be able to begin, pointing to the importance of the video at this critical time for the community. I felt an ethical dilemma emerge while waiting for these understandably important approval stages by the research institution.

Within this context, as a community-based researcher and partner to the Village, I felt a sense of responsibility to respond to the urgency expressed by Dignity Village. I met with my dissertation chair and two other committee members to discuss this issue, and they supported the process of applying for HSRRC approval prior to the acceptance of my dissertation proposal. I obtained first approval by HRSCC on June 6, 2005, and an approval of continuation from HRSCC throughout the research and analysis phase. 


\section{Participants}

When the research began, there were approximately 35 individuals who resided at Dignity Village; however, this number constantly fluctuates between 3060 individuals who reside there at any one time. The Village does not discriminate by religion, race, gender, sexual orientation, mental health, handicap, age, lifestyle choice, previous record or economic status. The characteristics and demographics of individuals in the Village community change continuously, as residents transition through to affordable housing or to other destinations. Nevertheless, it is possible to very broadly characterize the community as predominately male, heterosexual, European-American, and over the age of $18^{1}$.

This participatory research project provided the opportunity for every resident to be involved in the research process at some level. There were two levels of possible participation for individuals: (1) to participate as part of the core research group and (2) as community consultants, providing information and feedback to the research group at specific milestones throughout the project. These groups were established, but remained flexible and open to allow for individuals to become more or less involved in the research over time as their circumstances or interests changed.

\footnotetext{
${ }^{1}$ Due to City of Portland restrictions, the Village may not admit any members under 18 years of age.
} 


\section{Recruitment - Number of Participants}

At the membership meeting on October $6^{\text {th }}, 2005$, I proposed the research to the community and asked individuals to sign up as either core group members or as community consultants. At the time, nine individuals signed up to be part of the core group and ten signed up as community consultants (total 19). Since the first sign-up, however, at least 28 individuals participated in the research at some level (i.e., including both core group and community consultants). At one point in the research (at the end), almost every individual in the community, except those few who could not make the meeting, participated in providing feedback on the orientation video.

Since the research process was inclusive and the duration of the research about one year, participation in the core group fluctuated but remained fairly consistent over time. In the course of the yearlong research, seven of the individuals participating in the "core group" left the village. One person officially withdrew from the research in order to focus on transitioning out of the community. On average, there were nine (9) core researchers who attended the meetings regularly, and 15 individuals who participated periodically in the research. A total of 24 individuals participated at least twice in the core group research meetings and activities.

At the first core research meeting (and subsequently with involvement of new individuals), I gave each person a consent form to read. I also described the main points of the research purpose and process, potential benefits and risks of participating, and how their participation was voluntary and could be withdrawn at 
any time. All co-researchers signed a consent form (see Appendix C for a copy of consent forms).

\section{Diversity in the Core Group}

Since the community was too large to involve everyone in the working group for developing the action tool, it was important to discuss whether we had enough diversity in our group to represent the various perspectives within the Village regarding community participation. During our first couple of meetings, we spent some of the time discussing whether we needed to recruit additional coresearchers for the core group. The idea was that change could not occur if there was resistance from others, particularly from key individuals or groups with differing perspectives within the community. Understandably frustrated with the low participation in general at the Village, the core group decided that it was not necessary, or that it would be ineffective, to try to recruit additional individuals to participate in the core group. Throughout the initial stages of the research, I personally invited and encouraged several Villagers to participate in the group in an effort to encourage inclusion and tolerance of diverse perspectives on the community issue. No one was excluded from participating in the research throughout the research process.

\section{Sub-groups in the Core Group}

For the purposes of this research, I defined three main groups (e.g., newcomers, mid-termers, and long-termers) in the Village that differed in their 
perspectives on the participation problem in the community. Some villagers had used this terminology, but they more commonly used the terms "waves" to describe when individuals had first arrived at Dignity Village. During the research, I identified these three main groups as ones that appeared to be distinctive from one another, with each group seeming to hold similar perspectives on the participation problem and other issues in the Village, as compared to the many "waves" or generations of Villagers that enter the community as residents.

Newcomers. Throughout the duration of the research, there were seven (7) newcomers who participated at least twice in the core group. I defined newcomers as individuals who had resided at Dignity Village for less than six months. Of these newcomers, one (1) participated consistently until the end of the research.

Long-termers. There were eight (8) long-termers who participated in the core group. I defined long-termers as individuals who were members of Dignity Village for more than two years or were individuals who were considered "founders" of Dignity Village who had left and returned after a couple of years. Of these, four (4) participated consistently until the end of the research.

Mid-termers. There were nine (9) mid-termers that participated in the core group. I defined mid-termers as individuals who were members for approximately 6 months to 2 years. Of these, four (4) participated consistently until the end of the research. Table 2 provides a summary of this information. 


\begin{tabular}{|l|l|c|c|}
\hline \multicolumn{4}{|c|}{ Table 2. Sub-group Terminology to Understand Inter-Group Dynamics } \\
\hline Group & Definition & \# Regulars & \# Occasional \\
\hline $\begin{array}{l}\text { Newcomers } \\
(<6 \text { mos })\end{array}$ & $\begin{array}{l}\text { Individuals residing at Dignity Village } \\
\text { (DV) for less than six months }\end{array}$ & 1 & 6 \\
\hline $\begin{array}{l}\text { Mid-termers } \\
(6 \text { mos }-2 \text { yrs })\end{array}$ & $\begin{array}{l}\text { Individuals residing at DV for approx. } \\
\text { 6 months to 2 years }\end{array}$ & 4 & 5 \\
\hline $\begin{array}{l}\text { Long-termers } \\
(>2 \text { yrs })\end{array}$ & $\begin{array}{l}\text { Individuals residing at DV for more } \\
\text { than two years or individuals who were } \\
\text { considered "founders" of DV who had } \\
\text { left and returned after some time }\end{array}$ & 4 & 4 \\
\hline & \multicolumn{1}{|c|}{ TOTAL } & 9 & 15 \\
\hline
\end{tabular}

Researcher Role in Research

Although this dissertation work and research approach is a continuation of an established process with Dignity Village, it involved a "change of hats" from supporter and documentarian/archivist through Kwamba Productions to researcherfacilitator and archivist through Portland State University.

\section{Researcher-Facilitator}

My primary role in the research process was as researcher-facilitator in promoting empowerment through achieving the group's common goals. However, in order to facilitate empowerment, it was critical for participants to obtain control over the direction and substance of the research, by directing and participating in the process of defining a focus, collecting data, analyzing and interpreting data, reflecting, and taking action with the aim of improving their own lives, competence, and well-being. As part of empowerment, it was also important that there was a shift in the role of the researcher from "expert" to "researcher-facilitator." Participants were seen as competent social actors and "co-researchers" in the research; they were 
the experts on the topic and its relevance, while the researcher was an expert only in the sense of teaching, facilitating, and protecting process.

In the case of community-based collaborative research, facilitation does not mean acting as an external agent offering technical guidance to members of a group. Rather, my role as facilitator was to establish and support a collaborative endeavor in which people could learn and achieve their goals together (Kemmis \& McTaggart, 2005). It is not necessarily the case that collaboration means that the facilitator is an entirely equal co-participant along with others. There is a difference in roles and expertise, whereby co-researchers are topic experts and facilitators have some special expertise in process or skills that may be helpful to the group in its endeavors (Kemmis \& McTaggart, 2005). I brought to the research process skills and knowledge in media development, filmmaking, archiving, research, and community psychology for the purpose of guiding co-researchers in the process of developing their own action tool. My role was not to teach individuals some specialized skills for them to become a filmmaker or archivist, but instead, to enable and assist individuals in utilizing archives and media as "researchers" and as citizens who wanted to act toward making a difference in their community. As researcher-facilitator, my role was to develop and guide a process that made the archives and research process accessible and practical to the Dignity Village community, and to facilitate the development of the action tool by teaching general technology and media communication skills required to carry out its development. 
Because I am partly an "insider" at the Village, I also brought my own experiences and memory of the Village's history and growth to the group dialogue.

Facilitating in this research context involved: (1) assisting in creating and maintaining a positive group environment for learning and empowerment; (2) facilitating group direction (determined democratically at the beginning of the research process) and assisting the group in staying on track toward achieving planned goals as the group developed their own analysis of and solutions to their issues; (3) utilizing numerous methods and techniques to facilitate experiential learning and self-reflection by individuals involved in the research project in a way that was experienced as supportive rather than critical or domineering. For example, I encouraged individuals to realize their strengths and capacities as a community/group and discouraged specific modes of thinking that shut down possibilities for effective change and resolving issues; (4) assisting in planning and implementing the group's plan by raising issues and helping to locate resources; and (5) stimulating people to change by opening lines of communication and dialogue among diverse perspectives. A good facilitator should articulate the value and appreciation of the skills of others, emphasizing the importance of group work (Greenwood \& Levin, 1998). A researcher-facilitator's main focus is to facilitate human development and learning. And, in essence, this was my role.

The specific tasks carried out by the researcher-facilitator and co-researchers are explicated later in this chapter on research process. 


\section{Archivist}

In this research, I had an additional role as archivist of the process. In this case, my role was to create a record (i.e., field note observations, interviews, and video) of the research process and its impact on individuals' quality of participation in the community during and immediately following the creation of the action tool. A record of the research process served the following purposes: (1) sustaining the process for future problem-solving activities at Dignity Village, (2) exporting the process to other similar social contexts, and (3) improving and changing environmental contexts and processes that appeared to hinder empowerment during and after the research process. The specific tasks involved in documenting the process are described in the section on data collection.

\section{Dynamics between Roles}

These two roles as researcher-facilitator and archivist were separate, yet complementary in the research process. The dynamics between the two roles helped to shape each other in a feedback loop. In PAR, learning and change come from the cyclical process of action and reflection. The role of archivist involved observation, documentation, and reflection, and this reflection provided feedback for direction and improvement in facilitating the research process and providing contextual supports for empowerment. This cyclical process of facilitation and reflection through documentation provided a process whereby I could assess the group status with respect to the five basic components of empowerment described in Chapter 
Five. These reflections were brought to the group during facilitation, and the group in turn reflected on and discussed these issues and how to improve our group learning process.

\section{Data}

Data were collected on research processes and individuals' experiences, perspectives, and participation in the community for the purposes of (a) guiding and improving research processes and action during the research, (b) archiving and sustaining process in the community, and (c) understanding the impact of participating in the research on empowerment and participation of individuals within the broader community.

Data recording modes vary in the degree of their fidelity, which refers to the ability of the investigator to later reproduce the data exactly as they become evident to him or her in the field (Lincoln \& Guba, 1985). Audio or video recordings have the greatest fidelity, although not in an objective sense as such recordings still depend on what investigators choose to record. Field notes have less fidelity, but have advantages in that (a) taking notes may not be as threatening to participants as videotaping, (b) the process of taking notes helps to keep the facilitator engaged, alert, and responsive to the situation, (c) field notes provide quick access for the facilitator to refresh his or her memory rather than searching through tapes, and (d) they are an easier way to record a facilitators' own thoughts, reflections, and insights (Lincoln \& Guba, 1985). 
The current research employed both video-recording and field notes of observations as modes of data collection. Individual interviews, group research processes, and community gatherings and activities were recorded on video, with field notes taken about specific events or highlights that sparked thoughts, reflection, or insights after the event. Social interactions and daily living in the community were not captured entirely on tape; therefore, field notes were utilized as a way to document mood, participation, and social dynamics throughout the research. Data relevant to changes in participation and empowerment were also collected from Dignity Village's organizational records (e.g., calendars, outreach events, list-serve, meeting agendas and minutes). I describe the procedures used and the types of data collected from the three different modes of data collection (video record, field notes, and organizational documents) below.

\section{Modes of Data Collection}

\section{Video}

I used a Sony PD-150 digital video camera with a professional shotgun microphone attached to a microphone stand to record the research processes (group work), individual interviews, and community activities and gatherings. I videotaped every group meeting and co-facilitated the meeting along with Wendy Kohn, who is co-owner of Kwamba Productions and also has a long relationship with Dignity 
Village. ${ }^{2}$ Half way through the research, I used an additional camcorder to record visuals of our facilitation. During the first half of the research, I chose not to use two cameras to record both viewpoints (co-researchers and co-facilitators) because it was technically challenging to operate that much equipment at the same time as facilitating the research group. Towards the end, when facilitation became easier and some individuals in the core group began to assist in facilitation and notetaking, I added the second camera to record and demonstrate my role in the research, how I may have impacted the research dynamics and to have a record for later use in reflection on group dynamics in the research.

In the case of individual interviews, Wendy operated the camera and kept a written field log of the main points of the interview, while I conducted the interview. I asked the majority of the questions; however, the floor was open for Wendy to ask questions as well as for the interviewee to ask questions of us.

While we did record every group meeting, I did not intend to interview every individual in the community or in the research group, as this would be an enormous task given the continuously changing membership of the community. I used qualitative case study methodology (see Stake, 2005) to track changes in levels and

\footnotetext{
${ }^{2}$ Wendy assisted in facilitation in addition to taking notes on the white board. I took the role of camera operator for the practical reason of my illegible handwriting. During the initial stages of research, the group preferred not to rotate facilitators among the group or to co-facilitate, so Wendy assisted me while we set up processes as a group and the group became more comfortable with the research setting and processes. It was also the case that, for the first couple of months of meetings, there was significant variability in group members, which made it more challenging to establish and maintain a supportive environment for group work as well as for other members to feel comfortable with taking on different, more formal roles in the group work. The plan was for Wendy to slowly reduce her role (and then I would do the same) as members of the group increased in the cofacilitation and note-taking roles.
} 
quality of participation in the research group. With this methodology, a case may be an individual, subject, context, or event. In this research, I focused only on cases that manifested a common characteristic of movement or change in participation in the research (movement can be inwards or outwards, engagement or disengagement, empowered or disempowered, empowering or disempowering in the research). Clearly, these cases were not known in advance. Throughout the research period, I interviewed individuals participating in the research who showed such movement (e.g., quiet to more vocal, supportive to unsupportive, etc). When there did not seem to be a case of movement, but rather resistance to change, I interviewed these individuals in an effort to open dialogue and promote critical reflection of their role in the research and in community dynamics.

During the research, I interviewed 11 individuals to understand the multiple perspectives on the community problem of participation, the history of the situation, the people involved and affected, interactions and relationships among people, and goals or vision of community. Sometimes individuals were interviewed more than once, but this was not a goal of the research process. The goal was to understand what processes and dynamics supported or hindered participation and empowerment in the research and in the community.

The interviews were semi-structured, and explored: (a) the individual's state of mind in relation to participation in the community and research, (b) his/her sense of connection and belonging in the community and the research group, (c) his/her understanding of the participation issue, and (d) the impact of the research on him or 
her personally, as well as on the community as a whole. Please see Appendix E for a copy of the general interview questions. At the end of the research (more specifically, within the month after the creation of the orientation video), I interviewed the seven remaining and longest committed co-researchers participating in the core group. Please see Appendix F for a copy of the post-research interview questions.

Video data collected. Over the course of the yearlong research, I collected a total of 205 hours of video footage (excluding the hours of video obtained with the extra camera angle). Fifty-three hours were interviews, 117 hours were records of the research meetings, and 35 hours were b-roll (visuals of community activities, community meetings, impromptu interactions with individuals, and the general environment).

\section{Fieldnotes}

I wrote field notes of my observations and experiences with the community before, during, and after the group meetings. In my observations and field notes, I paid particular attention to social interactions among community members, interactions between myself and Villagers, and the general mood of the Village in order to gain insight into the level of participation and empowerment within the community. After leaving the Village, Wendy and I discussed interactions and jotted down notes together. I then wrote the field notes from my perspective, and Wendy checked consistency by reviewing my field notes. As she reviewed the 
notes, she made comments or additions based on her own experiences or perspective of the situation. In cases where we held quite different perspectives on a situation/observation, we discussed our differences and either changed the field notes based on our discussion or left the field notes with two differing perspectives, as I considered each perspective of a situation as valid and did not necessarily feel the need to reconcile the differences, since the goal was not standardization. It was the aim that in reviewing one another's field notes and interpretations, the field notes would be more consistent and provide more details and richness than with one perspective.

The process of creating field notes also provided time for reflection on what was necessary to guide facilitation and group process toward more empowering processes. During this process, Wendy and I coordinated our roles, gave each other feedback, and shared insights that helped to improve our facilitation skills in the research.

Fieldnotes data collected. I wrote field notes of my observations and reflections after each research meeting. At the end of the research, I had created a total of 50 documents of field notes.

\section{Organizational Records}

I asked permission to access and review the Dignity Village calendar of past outreach events and activities, council meeting notes, and membership meeting notes. I sifted through and identified data that were relevant as an indicator of 
changes in the level of community empowerment at Dignity Village throughout the period of the research.

Organizational records collected. At the end of the research, I obtained and made copies of all of Dignity Village's organization meeting minutes from 2005, 2006, and the beginning of 2007.

\section{Research Design Features for Quality PAR}

In PAR, the process of the inquiry is just as important as the specific outcomes. Because the process evolves through collaborative action, it cannot be defined in terms of a specific standard methodology. Consequently, there are no hard and fast rules to evaluate the validity or quality of research practices. This leads to questions about how communities and community partners evaluate whether they are doing good quality research.

\section{Evaluating the Quality of this Collaborative Research}

A question commonly debated in qualitative inquiry, particularly in participatory action research, is "What are features of good quality research?" There has been a "movement in qualitative research away from validity criteria that mimic or parallel those of empiricist research toward a greater variety of validity considerations that include the practical, the political, and the moral...toward a concern for validity as asking questions, stimulating dialogue, making us think about just what our research practices are grounded in, and thus what are the significant claims concerning quality we wish to make" (Reason, 2006, p. 191). As 
Reason (2006) argues, we are not pursuing validity to "get it right," but rather, we are pursuing quality inquiry that stimulates open dialogue.

In response to this debate on validity and quality of qualitative inquiry, Finley (2003) developed a rubric as a guideline for assessing research, which has stimulated much dialogue and use in qualitative inquiry. Finley's rubric emphasizes a commitment to research practice that is ethical, political, and culturally responsive (p. 293). These qualities explicitly exclude craftsmanship, artistry, and expertism in research (e.g., video editing style, cinematography, etc.), because, as Finley argues, these qualities are less fundamental to social justice research. Good quality research is grounded in experiences of ethical care, passion, communion, and social responsibility (Finley, 2003b).

\section{A Rubric of Questions for Reflection on the Quality of Inquiry}

Finley (2003b, p. 293-294) proposes questions within three interconnected commitments, which include commitments to:

1. Community - to dialogical, nurturing, caring, and democratic relationships between researchers and participants who share their commitment to understanding social life. These questions focus on deep participant and researcher interactions and involvements.

2. Action within community - to engage research work that is locally useable and responsive to cultural and political issues that takes a stand against social injustice (Denzin, 2000 as cited in Finley, 2003b). These questions 
focus on professional, personal, and political actions that might improve participants' lives.

3. Visionary critical discourse - to research efforts that examine how things are but also imagine how they could be otherwise. These questions focus on future-oriented work that is based on visionary perspective that encompasses social justice, community, diversity, civic discourse, and caring.

Finley (2003) poses questions within these three commitments as a guide for assessing the quality of the inquiry. As these questions are appropriate to the purpose and approach of this participatory action research, I created a tailored list of reflection questions within the three commitments proposed by Finley (2003), adding questions and reflections from the literature, for use in continuously evaluating and improving the quality of this dissertation research as I carried out the research process.

\section{Community}

Ethics of care.

- Is there evidence of an ethics of care among the co-researchers and the researcher-facilitators (Finley, 2003b)?

- Is the researcher-facilitator performing a useful, local, community service by conducting the research (Finley, 2003b)?

- Could the research be harmful in any way to the community of participants (Finley, 2003b)? 
- Is the research an emergent process (Reason \& Bradbury, 1999)? Good quality PAR does not arrive fully in a clear research design before the research begins, but evolves over time and develops within communities (Reason, 2006).

- How has the community sustained the research processes after the project has ended? How has the researcher-facilitator prepared the community for the end of the research?

- How have community members been involved in reviewing the material with researcher-facilitator and interpreted, dissented, challenged her interpretations and representations of them (Fine, 2000)? How does the researcher-facilitator report these departures and agreements in perspective (Fine, 2000)?

Voice, authority, and reflexivity in representation.

- Are we giving voice to participants and marginalized communities, and how (Lincoln \& Guba, 1986)?

- Whose voices are represented most clearly, those of the researchers or those of the participants (Finley, 2003b)?

- Where has the researcher-facilitator backed into the passive voice and decoupled responsibility for her interpretations (Fine, 2000)? Where has she hidden her own authority behind participants' narrations or interpretations (Fine, 2000)? 
- Is there adequate self-awareness and self-exposure of the researchers' positionality (in relation to politics, intentions, etc.) for the audience to make judgments about her point of view (Alexander, 2005)?

- Is there evidence of a blurring of roles, of researcher being researched and of participants as researchers (Finley, 2003b)?

- Does the text represent and honor all viewpoints and their underlying values in the context (Lincoln \& Guba, 1986)?

\section{Action within Community}

Open space for dialogue.

- How does the form of representation (written and visual texts) create an open space for dialogue between community members, readers/perceivers and between co-researchers and researcherfacilitators (Finley, 2003b)?

- Does the research (practice and representation) allow an "open" text in which there are spaces for multiple meanings to be constructed? Does the research provoke questions, rather than draw conclusions (Finley, 2003b)?

- Has the research (practice and representation) helped people to understand and appreciate other diverse views in the setting (Lincoln \& Guba, 1986)?

Open opportunities for empathy and communion. 
- Is the practice and the representation of the research passionate and visceral (Finley, 2003b)? Does it create opportunities for communion among participants, researchers, and the various discourse communities who might be audiences of (and participants with) the research text (Finley, 2003b)?

Change or the potential for change.

- How does participation in the research have a transformative potential?

- Were participants in the research aware of themselves as agents and change-makers (Lincoln \& Guba, 1986)?

- Does participation result in more active and informed citizens with greater moral authority (Anderson, 1998)?

- How has the research or dissertation text acted as an impetus for participants to change things (Lincoln \& Guba, 1986)?

- How does the dissertation text and research process affect the coresearchers and other members in the community (emotionally, intellectually, and politically) (Lincoln \& Guba, 1986)? Did it create a space where unjust systems and processes are identified and interrogated (Lincoln \& Guba, 1986)? What has been expressed through the illumination of voice (Lincoln \& Guba, 1986)? Did the experience motivate individuals to take some level of informed and strategic action (Lincoln \& Guba, 1986)? 


\section{Visionary Critical Discourse}

- Have researchers been willing to experiment with form, both in their practice of research and in their representation (Finley, 2003b)?

- Does the representation, both through its form and its content, have the capacity to connect its local, community service purpose with purpose of its audiences (Finley, 2003b)?

- How open and accessible is the text to different audiences?

- Does the research representation/text encourage a certain critical reflexiveness in the audience as they engage in the moment of reading/viewing/experiencing (Alexander, 2005)? The dissertation/research text should push the audience to learn and engage previously unspoken and unknown things about the culture of the community and the experience of their engagement in the research in ways that can be extrapolated to broader issues of social and cultural interaction (Alexander, 2005).

- Is the reader likely to be moved to some kind of action (Finley, 2003b)?

- Has the text incited political movement, emotional response, or engaged temperament (Alexander, 2005)?

- How does the research representation spark further research in other substantive areas (Charmaz, 2005)? 
- How does the work contribute to the making of a better society (Charmaz, 2005)?

\section{Including Diversity and Multiple Perspectives}

Inclusion of diverse perspectives is critical to the quality and effectiveness of community-based participatory action research (Stringer, 1999). Dialogue with others who have diverse perspectives on the issue is important to learning and enduring change (Greenwood \& Levin, 1998). In PAR, diversity of experiences and perspectives (skills, ethnicities, gender, politics, etc) of co-researchers is seen as an opportunity for developing creative and effective solutions (Greenwood \& Levin, 1998).

According to Greenwood and Levin (1998), groups commonly suffer from feeling stuck in a particular view of the situation, which in turn limits their ability to develop alternative courses of action that may be effective. Communities and groups may have become hardened into positions or have become pessimistic about the possibilities for change (Greenwood \& Levin, 1998). Sometimes the lack of diverse perspectives on the issue reduces the dialogue and productive tension necessary for exploring other dimensions of a problem and for opening up more options for addressing the problem. The co-researchers' history together may lead them to overlook some important resources for change, including specific individuals who might be included in the process, or opposing factions or viewpoints that might be included in the dialogue (Greenwood \& Levin, 1998). PAR involves taking a deeper 
collective analysis of reality in order to change it, not simply to reflect on the reality of the moment (Gaventa \& Cornwall, 2001). The more homogenous the group, the more difficult it is to challenge the status quo and to force to the surface hidden assumptions and shared thinking in the group that limit a more multi-dimensional and accurate view of the problem (Gaventa \& Cornwall, 2001). Without challenging these status quo modes of thinking, there is danger that the existing power relations or social dynamics in the situation may simply be reinforced, without leading to substantive change in the community, and only perpetuating the problems being addressed (Gaventa \& Cornwall, 2001).

Procedures for capturing and including multiple perspectives. Particularly in the initial stages of research, I encouraged diversity and inclusion within the group process. This involved challenging the group to identify and take the perspective of those in the community who held opposing views or different experiences of a situation. Sometimes, even when the group was open to these diverse viewpoints, those in opposition were not comfortable with joining the group. A fairly homogenous group was perceived as intimidating, exclusive or defensive of other perspectives on the issue, particularly since these social dynamics seemed to be driving the situation they were trying to solve. Under these circumstances at Dignity Village, I utilized several techniques to encourage diversity.

One technique was to assist the group in opening up and being tolerant of diversity. In the current study, this involved collaboratively setting up ground rules and a group process that supported dialogue and diverse perspectives and that 
managed emotional tension in productive ways. It also involved setting the local situation in a broader context with opposing perspectives and experiences (anonymously) as a way to assist the group in expanding its sense of the situation and some options for the future.

Another technique was to encourage others to join the group and participate in the dialogue. This involved interviewing and having informal conversations with other community members, who were not part of the core group, to identify opposing views and experiences on the issue. We found that these conversations helped to validate these other perspectives as important, build trust with the individuals and reassure them that their perspective was valued, respected, and important to making change in the community. If the individual did not feel comfortable participating in the group process, I brought his/her perspective (as anonymously as possible) to the group to encourage dialogue and other ways of thinking. A number of times, individuals joined the group after being interviewed about the community issues.

\section{Termination / Sustainability}

An important part of PAR and empowerment-based research is sustaining the learning processes in the community for a significant period of time. Change takes time, and the reflective learning processes in PAR can be an important way of managing enduring change and long-lasting improvements. Another important part of PAR is empowerment of the community to continue processes and research 
without the assistance of the "outside" researcher-facilitator (keeping the role of facilitator in the group process, but with community members as facilitators). Planning for sustainability and empowerment involves handing over responsibility of group processes as soon as possible (Martin, 2001). It also means giving coresearchers control over the direction, processes and action plans. The more the research is rooted in a community's values and practices, the more useful and valuable the research experience may be to their day-to-day problem solving. In the current research, planning for sustainability involved co-researchers participating, gaining skills and exercising their power in various group roles in the research process. The more roles that were available, the more options each individual had to participate at various levels. Some of the roles that emerged during this research process included, but were not limited to, the following: (a) facilitator (kept group on-task); (b) note taker; (c) time keeper (assisted in keeping an agreedupon schedule/agenda); (d) "stack" monitor (kept track of the list of individuals who would like to speak on a topic); and (e) "mood" monitor (assisted in monitoring ground rules and process to maintain structure and promote communication and positive working relationships). As the research progressed, I encouraged, but never required, co-researchers to participate in these various roles.

Another way I planned for the sustainability of process was by creating a Dignity Village Participatory Action Research Booklet that included: (a) an introduction to participatory action research and the situation at Dignity Village, (b) creators' (co-researchers') statements about the research, (c) ground rules that 
provided structure and supports for the collaborative group work, (d) the specific goals of the research defined by co-researchers in the core group, (e) steps involved in creating the action plan and action tools, and (f) the action tools themselves (see Appendix D). Each member of the core research group received a booklet in a threering binder so that they could easily update the materials in the future; a few copies of the booklet were also placed in the Village office.

\section{Trustworthiness in Qualitative Research}

Lincoln and Guba (1985) have developed alternative criteria appropriate to qualitative designs to ensure rigor without sacrificing the relevance of qualitative research. Planning for trustworthiness of qualitative findings involves four criteria: (1) establishing credibility, which refers to establishing that the results of qualitative research are credible or believable from the perspective of the participant in the research; (2) transferability, which refers to the degree to which the results of qualitative research can be generalized or transferred to other contexts or settings; (3) dependability, which refers to the need for the researcher to account for the everchanging context within which research occurs; and (4) confirmability, which refers to the degree to which the results could be confirmed or corroborated by others. 
In this research, I established the credibility of the findings through the following:

a) disclosing my research orientation in the research report and research process through exercising reflexivity in field notes and debriefings with coresearchers

b) intensive and prolonged engagement in the community setting

c) persistent observation (research was carried out each week for approximately 14 months)

d) data triangulation by collecting data at different time periods and from different sources (different individuals with varying experiences and perspectives on the participation issue at Dignity Village)

e) methodological triangulation which involved using more than one method (observational field notes, video record of the group research process, individual interviews and organizational documents. These are described in more detail in the data collection section). It also involved using more than one observer or investigator. As a co-facilitator of the research, Wendy reviewed my fieldnotes and added her own perspective, observations and experiences, providing me with another perspective and a sense of consistency in the observations.

f) referential adequacy, which refers to the ability to support my claims using data and notes 
g) checking my interpretation of the participation problem and of the collected data with co-researchers and others in the community

To enhance transferability, I provided rich descriptions of the research context and the assumptions that were central to the research, as well as video recordings of the actual research meetings. A full description allows other individuals (e.g., tent cities, social workers, researchers) to make an informed judgment on how sensible and appropriate the research processes were for transfer to a different context.

To increase the dependability of the findings, I described the changes that occurred in the setting and how these changes affected the way we approached the research. This required a detailed description of the specific processes that we undertook.

I enhanced confirmability by: a) keeping a reflexive journal of my procedures for checking and rechecking the data throughout the study; (b) keeping written and visual records of the process, including my reflections, decisions and insights, to provide an audit trail for the possibility of an external data audit that examines the data collection and analysis procedures and makes judgments about the potential for bias or distortion; and c) actively searching for and describing negative instances that contradict prior observations. This is referred to as negative case analysis, which is a process of identifying instances in the data that violate working theory and interpretations of the data. 


\section{Evaluating Authenticity in Research}

In a later work on evaluating the quality of qualitative research, Lincoln and Guba (1986) developed criteria of authenticity, which they consider more consistent with the constructivist philosophy. They describe five dimensions of authenticity, which include: a) fairness, b) ontological authenticity, c) educative authenticity, d) catalytic authenticity, and e) tactical authenticity. Fairness is the extent to which the different constructions and their underlying value structures are honored.

Ontological authenticity refers to the extent to which the participants' own constructions are improved, matured, extended and elaborated over the course of the inquiry. Educative authenticity refers to the extent to which individual participants' understanding of and appreciation for others' views outside of their stakeholding group are enhanced. Catalytic authenticity is the extent to which action is stimulated and facilitated by the evaluation process. Tactical authenticity refers to the extent to which the stakeholders and participants are empowered to act.

Procedure: Timeline and Steps in the Research Before Creating the Action Tools: Documenting the Community

\section{Initial Stage: Understanding the Research Context and Goals}

This participatory action research began in October 2005 when I started recruiting Villagers to participate and plan the research. Figure 4 illustrates the timeline and steps (see area labeled I for this stage). 


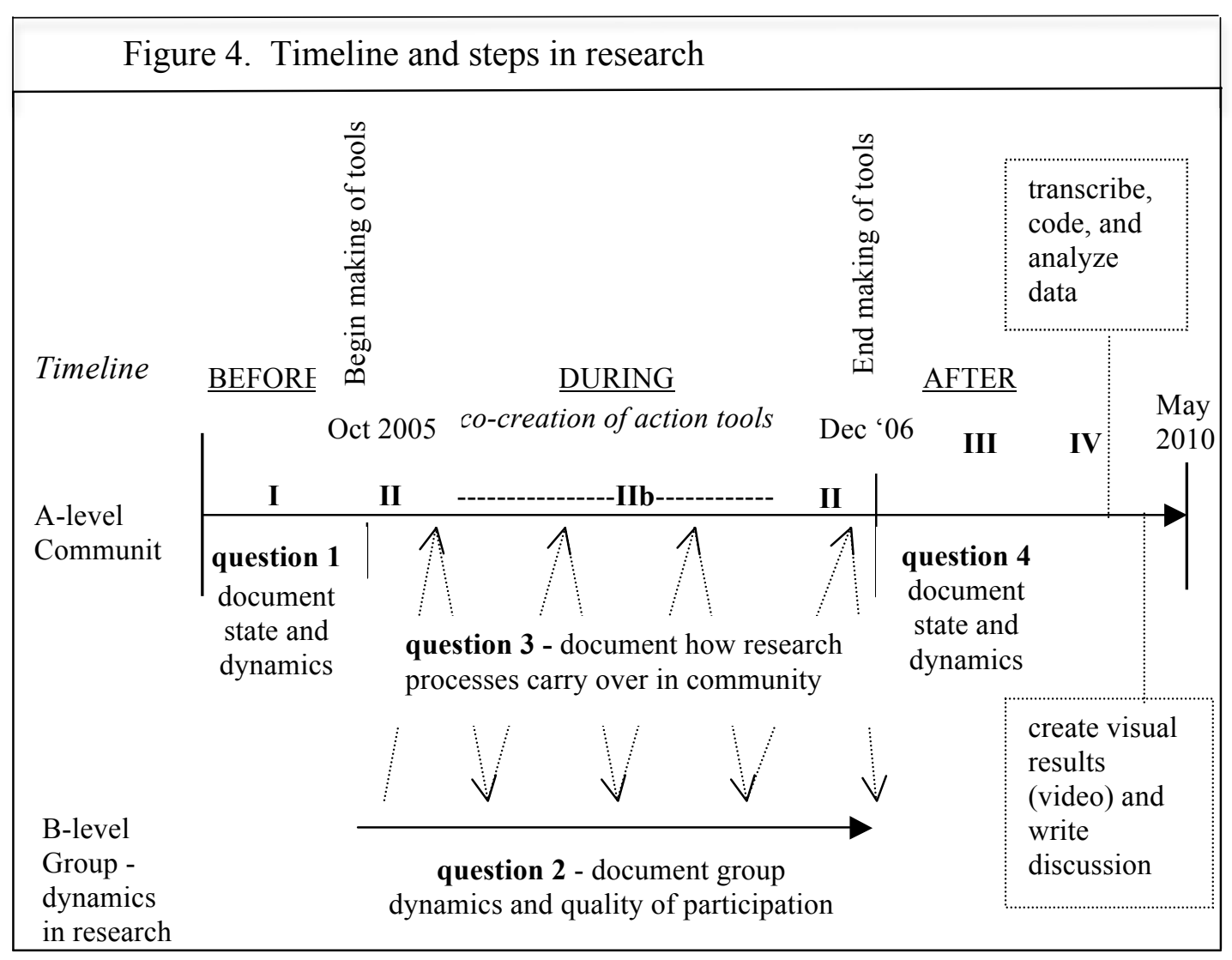

At this initial stage, I spoke with individuals about their experiences and their perception of the state of the community at that time, and the goals and need for the research. My first goal in the research was to understand the state and dynamics in the community prior to creating the action tools. I developed an understanding of the participation problem at Dignity Village by: (a) studying the setting's social dynamics, (b) identifying groups and key people that had different perspectives and experiences of the participation problem at Dignity Village, (c) understanding the nature of the community and the quality of relationships between and among individuals and groups, and (d) reflecting on and learning the history of 
the situation. Since I am a long-time supporter of the Village, I already had an initial understanding of the situation based on my experiences, discussions, and observations at the Village over several years. However, I gained a deeper understanding by informal conversations and interviews with members of the community on an ongoing basis. Individual interviews and group discussions were videotaped, and informal conversations were recorded in field notes. I also wrote a personal reflection on my history of experiences and reflections that seemed relevant to understanding the possible dynamics throughout the history of Dignity Village that may have led to the state of disaffection. I used these data in describing the dynamics leading up to the state of disaffection in the community in "Chapter Two: Framing of the Research." The context of the research is also introduced in Chapter Eight and the first question of Chapter Nine: Visual Results (in the video portion of the report).

In addition to developing a preliminary understanding of the dynamics and state of the community during this initial phase, I also spoke to the Dignity Village membership at a meeting and discussed who would like to participate, and how they could participate, and set up a weekly schedule for 2-3 hour group meetings nearly every Sunday afternoon. 
During: Documenting the Process and Community while Making Action Tools

\section{IIa. Beginning the Co-creation of the Action Tool}

The core research group (co-researchers) began our initial meetings by setting up ground rules and processes that supported empowerment and that limited disempowering processes in the research group, and by developing a research context that facilitated individuals' and group empowerment (i.e., working conditions needed to maintain positive working relationships, and enhanced participants' feelings of dignity, autonomy, competence, and ownership). See Figure 4, label IIa, for the timing of this stage.

Once ground rules were established, we decided whether co-researchers would like to co-facilitate. Together, we continued to decide on the direction of the research and a general agenda for the research. Throughout the research period, ground rules and processes were revisited and discussed for continuous improvement. As facilitator, I attempted to provide structure that would maximize participation by those involved. I also planned and adapted weekly agendas and research processes to maximize efficiency of group work (e.g., when frustration became high, I chose to use the next meeting to either open dialogue about the issue or utilized group-building exercises to promote positive working relationships). At this stage, a primary focus of my role as facilitator was to maintain supportive conditions for positive working relationships and to assist in protecting process and managing conflicts when they arose. 
This stage also involved promoting inclusion and a diversity of multiple perspectives in the research (see "Chapter Seven: Methodology"). The challenges in promoting inclusion and diversity were documented during this process both to guide reflection in the research and to address research questions with respect to social dynamics in the research and in the community.

\section{IIb. During the Co-creation of the Action Tools}

Figure 4, label IIb, indicates the timing of this stage in which we co-created the action tools as part of the research process. The core group carried out a series of steps in the research process that allowed the core group to continuously refine the focus of the research and create action tools that the community could use in the future to improve the orientation process (see Figure 5 for a diagram of the process).

The five action tools include: (1) a diagram of the Dignity Village orientation process, protocols and practices at the start of the research; (2) a list of "problem areas" or "areas for improvement" in the orientation process where changes might help to increase participation in the community; (3) possible options for solutions to improve the process; (4) a step-by-step implementation action plan for one of the solutions which was considered a top priority; and (5) an orientation video. These action tools can be used in continued efforts (actions and research) to improve the orientation process that is considered a core factor driving low morale and participation, and a lack of sense of community. To view the text-based action 
tools, please see either Disc 3 (DVD) or Appendix D within the Dignity Village Participatory Action Research Booklet. Each action tool is described briefly below.

Figure 5. Diagram of Process Involved in Creating Action Tools

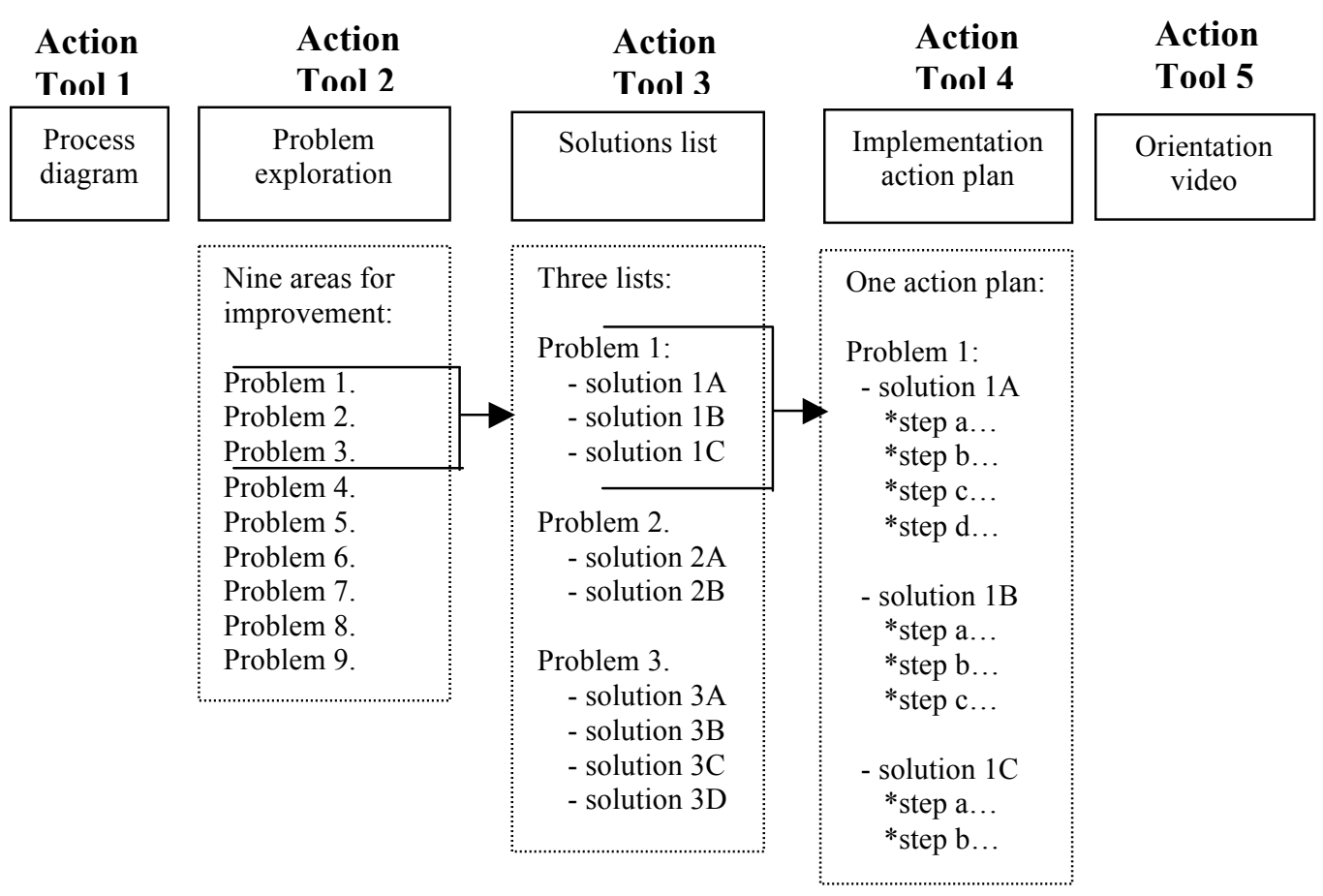

Action Tool 1: Process diagram. The diagram of the orientation process was developed collaboratively during the research to provide structure for group dialogue in clarifying and describing the practices in Dignity Village's orientation process. The group used the diagram as a tool for exploring and identifying areas for improvement. As the diagram is updated with new policies and procedures, it can be used in future action research toward continual improvements to the Village orientation process. 
Action Tool 2: List of "Areas for Improvement". The research group created this list of "areas for improvement" in the orientation process as we explored the participation problem and how certain practices might be changed in Villager orientation to increase participation and a sense of community. The areas for improvement were ranked by priority, with "ineffective orientation of newcomers" considered first priority for addressing the problem of low morale and participation. This research addressed the chosen first priority, leaving eight additional areas for future research. This list can be used as a tool for these future undertakings.

Action Tool 3: Solutions List to Improve the Process. The research group developed a list of possible solutions for the first three prioritized areas for improvement as an initial step toward developing implementation action plans for each solution. Because of time limitations, this research created only one implementation action plan, as a model for creating other implementation action plans in the future. The additional "solutions lists" that were created are a tool for future efforts in implementing action plans for two other areas of improvement: "unclear communication/information" and "negativity/lack of support/rumors."

Action Tool 4: Step-By-Step Implementation Action Plan. The group selected one of the three solutions lists to use in creating a step-by-step implementation action plan. The chosen solutions list was the one created for solving the priority problem of "ineffective orientation of newcomers." The group also expanded their definition of "orientation" to include a "re-orientation" process for all residents 
and members of the community. The research group developed a step-by-step action plan that detailed the sequential steps needed to implement the identified solutions. The steps in the process involved: a) discussing the feasibility of the solutions list created in the brainstorming session regarding possible ways to improve orientation; b) prioritize the feasible solutions for order of implementation; and c) create specific action steps that identified order of implementation, specific tasks, who carries out the task, and when the task will be carried out. As Villagers completed the steps in the implementation action plan, we used feedback from the group as they implemented the plan for guiding continued research efforts.

\section{IIc. Creating Action Tool 5: Orientation Video}

Figure 4, label IIc, indicates the timing of this stage. The research group identified the orientation video as one of the priority components in the overall action plan to address the low participation and morale. The process of creating the orientation video action tool also served as a vehicle for recognizing community strengths, building relationships, and encouraging collaboration around community problem solving and collective action. Please see Disc 3 (DVD) to view the orientation video. 
The process for creating the video involved the following steps:

1. As facilitator, I assisted the research group in identifying the specific purpose and message of the video, and target audience (e.g., the group wanted to communicate to newcomers the vision and goals, services, rules and regulations, and history of Dignity Village, targeted to all Village members, newer or long-term).

2. The research group created a storyline that described the style, visuals, and community narrative.

3. The research group created a shot-list and action steps for production. The "shot-list" described the new footage they wanted to collect, already recorded footage that they wanted to access and review from archives, and who was planning on participating in the different types of production tasks.

4. As co-facilitators, Wendy and I held a filmmaking workshop open to the entire community to learn basic filmmaking skills, both for use in filming the orientation video, and to provide skills for individuals interested in recording their own stories using the Village camcorder.

5. As facilitator, I assisted the research group in videotaping new footage, collecting interview footage from each other and from members of the community, and filming scripted scenes. Individuals from the community also videotaped interview and captured general visuals of community life. 
6. The core group choreographed two "scripted" scenes that involved participation by the broader community.

7. The core group recruited community members and held a rehearsal day to test out and practice the production of scripted scenes.

8. On Production Day 1, we filmed the scripted scenes.

9. The core group and co-facilitators reviewed footage from Day 1 and provided feedback and additional direction for second production day.

10. On Production Day 2, we filmed a final version of the scripted scenes.

11. We hosted a 2-day retreat off-site with core group members to review video clips and select key interview content for the orientation video.

12. As facilitator, I edited a first draft of the video based on the group's selected footage and written storyline.

13. The core group presented the video to the broader community and asked for their feedback.

14. The core group and facilitator reviewed feedback from the community and decided on final changes for the video.

15. The research group and facilitator created the final version of the orientation video based on community feedback and final group decisions. 
After Creating the Action Tool: Documenting the Community \& Analyzing Data

\section{Documenting the Community}

Figure 4, label III, indicates the timing of this stage of the research. During a two-month period following the research, I continued to visit the Village and document the processes and state of the community after the creation of the action tool. There were seven remaining core group members who had consistently participated in the research meetings, and I interviewed each one. Individual interviews were used as a way of gauging participants' experiences in the research process, and their perspective of the situation at Dignity Village and how it had changed or not changed over the course of the research. I continued to observe and videotape community activities, such as community elections and meetings. As significant changes occurred in the community after the research, I interviewed individuals with different perspectives in the community about these changes.

\section{Analyzing the Data}

I used an inductive approach to analyze the data, identifying key themes, perspectives, and processes that appeared to influence participation and empowerment. When coding and analyzing qualitative data, many researchers use qualitative software (e.g., NUDIST, NVivo) that allows the researcher to organize and integrate multiple data formats, develop themes, create an index, and note memos for tracking insights and choice-points. Our media studio developed specialized database software that provides similar organizational and tracking 
features but allows more seamless integration with Apple's Final Cut Pro software for video editing. The tracking features allowed for documenting decision-making processes for selecting video clips, which can be accessed for external audit. The specific methods of analysis are described below.

Procedure for Thematic Data Analysis

1. The first step in the process was to transfer the digital video footage to a hard-drive and into the custom database.

2. The second step involved transcribing the video footage in the specialized database software. Figure $6 \mathrm{a}$ is a screenshot of the custom software for transcription ("Shot Log Pro").

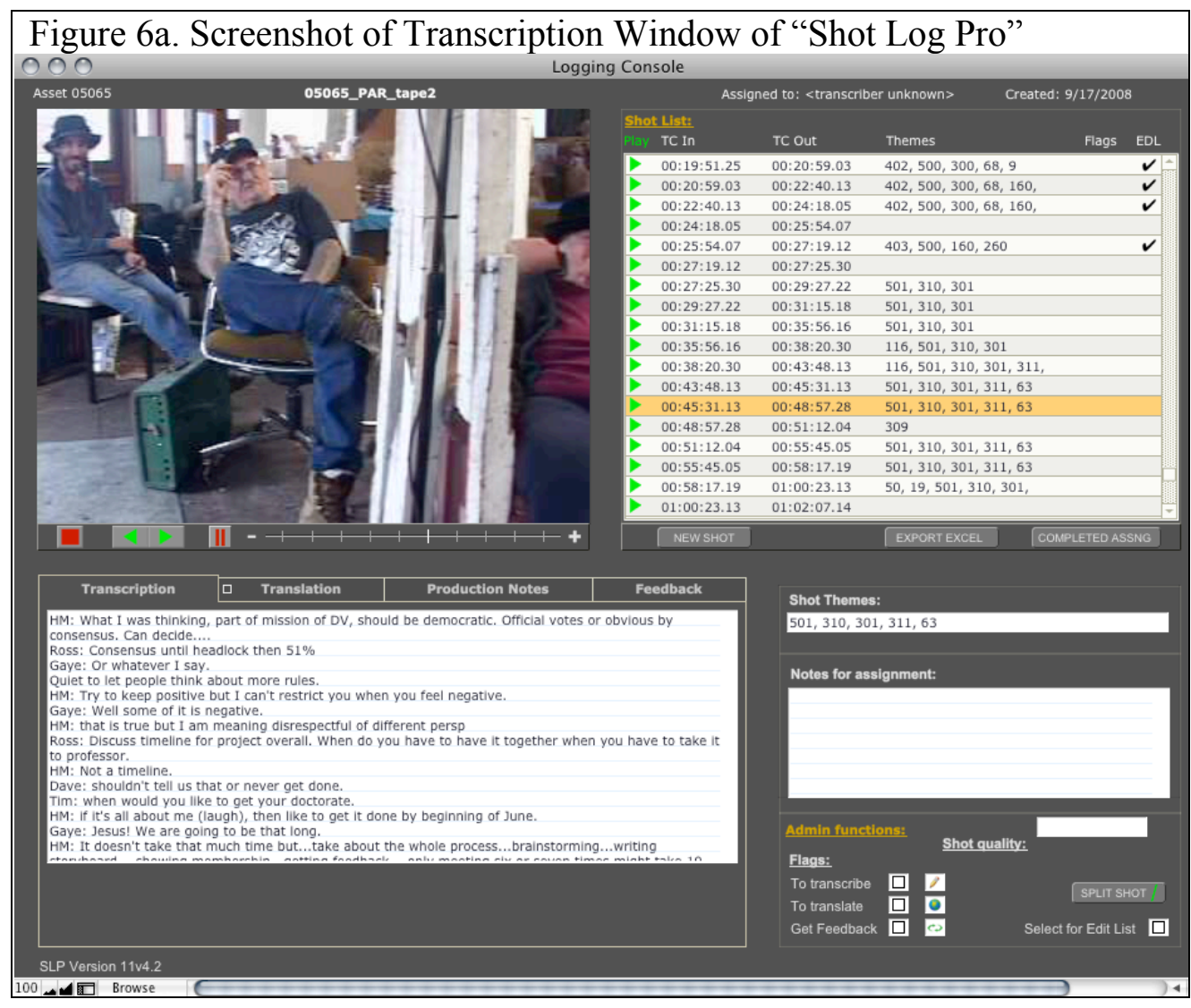


3. The third step involved identifying preliminary themes from the data, and developing a coding index that delineated the identified themes (please see Appendix G for a copy of the coding index used in my analysis).

4. The fourth step involved applying the set of index terms to the videotape footage data ${ }^{3}$ in the specialized database software. I selected relevant video clips that represented a main perspective in the community for use in the results section as examples of responses; these were tagged and selected for export to Final Cut Pro (see Figure $6 \mathrm{~b}$ for a screenshot of the coding window. The red circle shows the area where coding indices were input for each transcribed video clip).

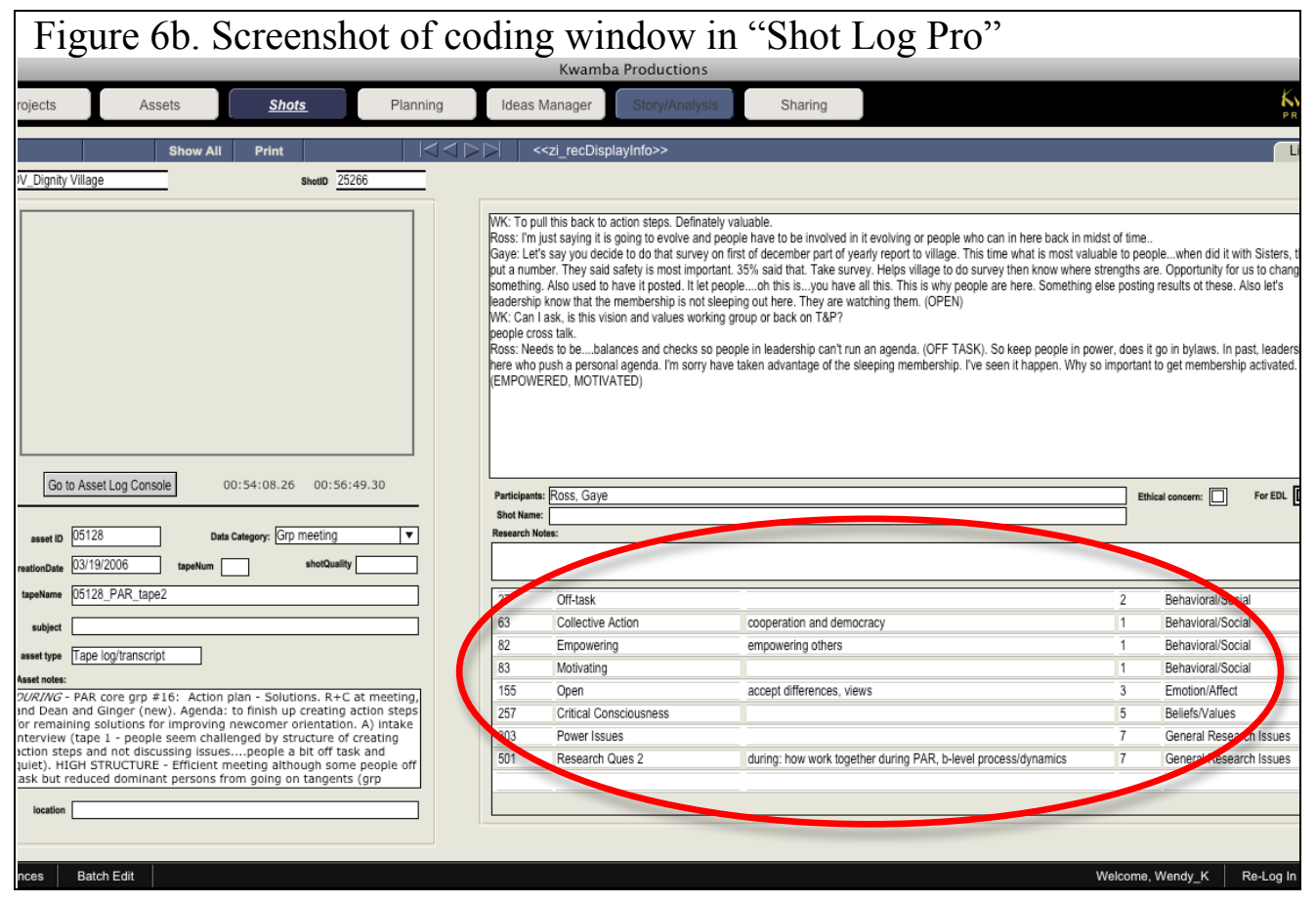

\footnotetext{
${ }^{3}$ Index terms are part of developing an analytic framework, essentially categories that reflect common themes in describing events or processes in data.
} 
5. In step five, thematic analyses were run to obtain a general idea of how participation in the research changed over time and how attributes within each coding index changed over time (See Figures $6 c-6 e$ on the next several pages to obtain a general sense of how analyses and reports were run.)

6. Step six involved examining Dignity Village's organizational documents to identify possible indicators of community empowerment (as an outcome), comparing and contrasting these data with video interviews and footage of group dialogue.

\begin{tabular}{|c|c|c|c|c|c|c|c|c|}
\hline \multicolumn{9}{|c|}{$\begin{array}{l}\text { Figure 6c. Analysis Report } \\
\text { Meetings }\end{array}$} \\
\hline \multicolumn{9}{|c|}{ Attributes Over Time } \\
\hline \multicolumn{9}{|c|}{$\begin{array}{l}\text { Phases: } 501 \\
\text { Data Categories: Grp meeting } \\
\text { Participants: All }\end{array}$} \\
\hline $\begin{array}{l}\text { Phase } \\
\end{array}$ & 501 & 501 & 501 & 501 & 501 & 501 & 501 & \\
\hline Date & 10/23/05 & 10/30/05 & $11 / 6 / 65$ & $11 / 13 / 05$ & $11 / 20 / 05$ & $11 / 27 / 05$ & $12 / 4 / 05$ & $12 / 1$ \\
\hline DataCategory & Grp meeting & Grp meeting & Gip meeting & Grp meeting & Grp meeting & Grp meeting & Grp meeting & Gip meet \\
\hline Participants & $\begin{array}{l}\text { Gaye, Tim, } \\
\text { Ross, Ken, } \\
\text { Chelle, } \\
\text { Randy2, Dog } \\
\text { Dave, Big Al, } \\
\text { Michael, Tami, } \\
\text { Josh, Ivan, Al }\end{array}$ & $\begin{array}{l}\text { Dog Dave, } \\
\text { Ken, Gaye, } \\
\text { Tim, Michael, } \\
\text { Alfred, Tami, } \\
\text { Al, Wendy, } \\
\text { Stephie, Dave } \\
\end{array}$ & $\begin{array}{l}\text { Ross, Dog } \\
\text { Dave, Ken, } \\
\text { Sue, Tim, } \\
\text { Dean, Gaye, } \\
\text { Laura, Tami, } \\
\text { Alan } \\
\end{array}$ & $\begin{array}{l}\text { Tim, Gaye, } \\
\text { Jon, Ross, } \\
\text { Josh, Laura, } \\
\text { Tami, Alan, } \\
\text { Chelle, } \\
\text { Stephie, } \\
\text { Michael, Ken }\end{array}$ & $\begin{array}{l}\text { Tim, Gaye, } \\
\text { Laura, Sue, } \\
\text { Ross, Jon, Big } \\
\text { Al, Tami, } \\
\text { Lydia, Ron, } \\
\text { Randyl, } \\
\text { Michael, } \\
\text { Randy, Alan, } \\
\text { Dog Dave, } \\
\text { Steve } \\
\end{array}$ & $\begin{array}{l}\text { Tim, Josh, } \\
\text { Tami, Gaye, } \\
\text { Big Al, Lydia, } \\
\text { Randy1, Alan, } \\
\text { Ross, Michael, } \\
\text { Laura, Travis, } \\
\text { Randy, Sue, } \\
\text { Dean, Gary, } \\
\text { Chelle } \\
\end{array}$ & $\begin{array}{l}\text { Chelle, } \\
\text { Michael, Alan, } \\
\text { Ross, Laura, } \\
\text { Ken, Tim, } \\
\text { Gaye, Tami, } \\
\text { Micheal, } \\
\text { Lydia, Big Al, } \\
\text { Dean, Ron }\end{array}$ & $\begin{array}{l}\text { Tami, L } \\
\text { Ken, Su } \\
\text { Alan, Cl } \\
\text { Ross, M } \\
\text { Tim, Ly } \\
\text { Gaye, H } \\
\text { Alfred, } \\
\text { Big Al, } \\
\text { laura, S }\end{array}$ \\
\hline \multirow{11}{*}{ Index } & & & & & & & & \\
\hline & Conflict (24239) & \begin{tabular}{|l|l|}
$\begin{array}{l}\text { Controlling } \\
(24254)\end{array}$ \\
\end{tabular} & Argue (24360) & Argue (29170) & Argue (24402) & $\begin{array}{l}\begin{array}{l}\text { Break rules } \\
(24510)\end{array} \\
\end{array}$ & Conflict (24615) & \begin{tabular}{|l|l|} 
Break rul, \\
$(24669)$
\end{tabular} \\
\hline & Conflict (24240) & $\begin{array}{l}\text { Controlling } \\
(24255)\end{array}$ & Argue (24366) & Argue (29184) & Conflict (24451) & $\begin{array}{l}\text { Break rules } \\
(24511)\end{array}$ & Conflict (24618) & \\
\hline & \begin{tabular}{l|} 
Controlling \\
$(24239)$
\end{tabular} & $\begin{array}{l}\text { Controlling } \\
\text { (24283) }\end{array}$ & \begin{tabular}{|l|}
$\begin{array}{l}\text { Break rules } \\
(24364)\end{array}$ \\
\end{tabular} & Argue (29199) & $\begin{array}{l}\text { Controlling } \\
(24451)\end{array}$ & $\begin{array}{l}\text { Break rules } \\
(24512)\end{array}$ & Conflict (24626) & $\begin{array}{l}\text { Controllit } \\
(24680)\end{array}$ \\
\hline & $\begin{array}{l}\text { Controlling } \\
(24240)\end{array}$ & $\begin{array}{l}\text { Controlling } \\
(24291)\end{array}$ & Conflict (24349) & $\begin{array}{l}\text { Controlling } \\
(29193)\end{array}$ & $\begin{array}{l}\text { Controlling } \\
\text { Cong } \\
(24452)\end{array}$ & $\begin{array}{l}\text { Beak rules } \\
\text { Breas } \\
(24513)\end{array}$ & $\begin{array}{l}\text { Controlling } \\
(24575)\end{array}$ & $\begin{array}{l}\text { Controllir } \\
(24704)\end{array}$ \\
\hline & Dominant (24241) & Exclusion (24265) & Conflict (24352) & $\begin{array}{l}\text { Controlling } \\
\text { (29199) }\end{array}$ & $\begin{array}{l}\text { Controlling } \\
\text { (24487) }\end{array}$ & $\begin{array}{l}\text { Bateak rules } \\
\text { Breats } \\
(24515)\end{array}$ & $\begin{array}{l}\text { Centrolling } \\
\text { Controll } \\
(24576)\end{array}$ & $\begin{array}{l}\text { Controllii } \\
(24705)\end{array}$ \\
\hline & $\begin{array}{l}\text { Insensitive } \\
(24239)\end{array}$ & Exclusion (24266) & Conflict (24353) & $\begin{array}{l}\text { Controlling } \\
(29200)\end{array}$ & $\begin{array}{l}\text { Insensitive } \\
(24462)\end{array}$ & Conflict (24505) & Dominant (24570) & \\
\hline & $\begin{array}{l}\text { No } \\
\text { communication } \\
(24189)\end{array}$ & & $\begin{array}{l}\text { Controlling } \\
(24356)\end{array}$ & $\begin{array}{l}\text { Controlling } \\
(29201)\end{array}$ & $\begin{array}{l}\text { Name-calling } \\
\text { (2451) }\end{array}$ & & & \begin{tabular}{|l} 
Manipula \\
$(24704)$
\end{tabular} \\
\hline & $\begin{array}{l}\text { No Structure } \\
(24224)\end{array}$ & Exclusion (24268) & $\begin{array}{l}\text { Dissuptive } \\
\text { (24348) }\end{array}$ & Dominant $(29170)$ & Off-task (24492) & Conflict (24538) & 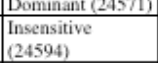 & \\
\hline & $\begin{array}{l}\text { Not listening } \\
(24228)\end{array}$ & $\begin{array}{l}\text { Name-calling } \\
(24279)\end{array}$ & $\begin{array}{l}\text { Dissuptive } \\
(24349)\end{array}$ & Dominant (29172) & $\begin{array}{l}\text { Unequal } \\
\text { enforcement } \\
(24462)\end{array}$ & Conflict (24544) & $\begin{array}{l}\text { Insensitive } \\
(24614)\end{array}$ & \\
\hline & & & & & Unequal & & & \\
\hline
\end{tabular}




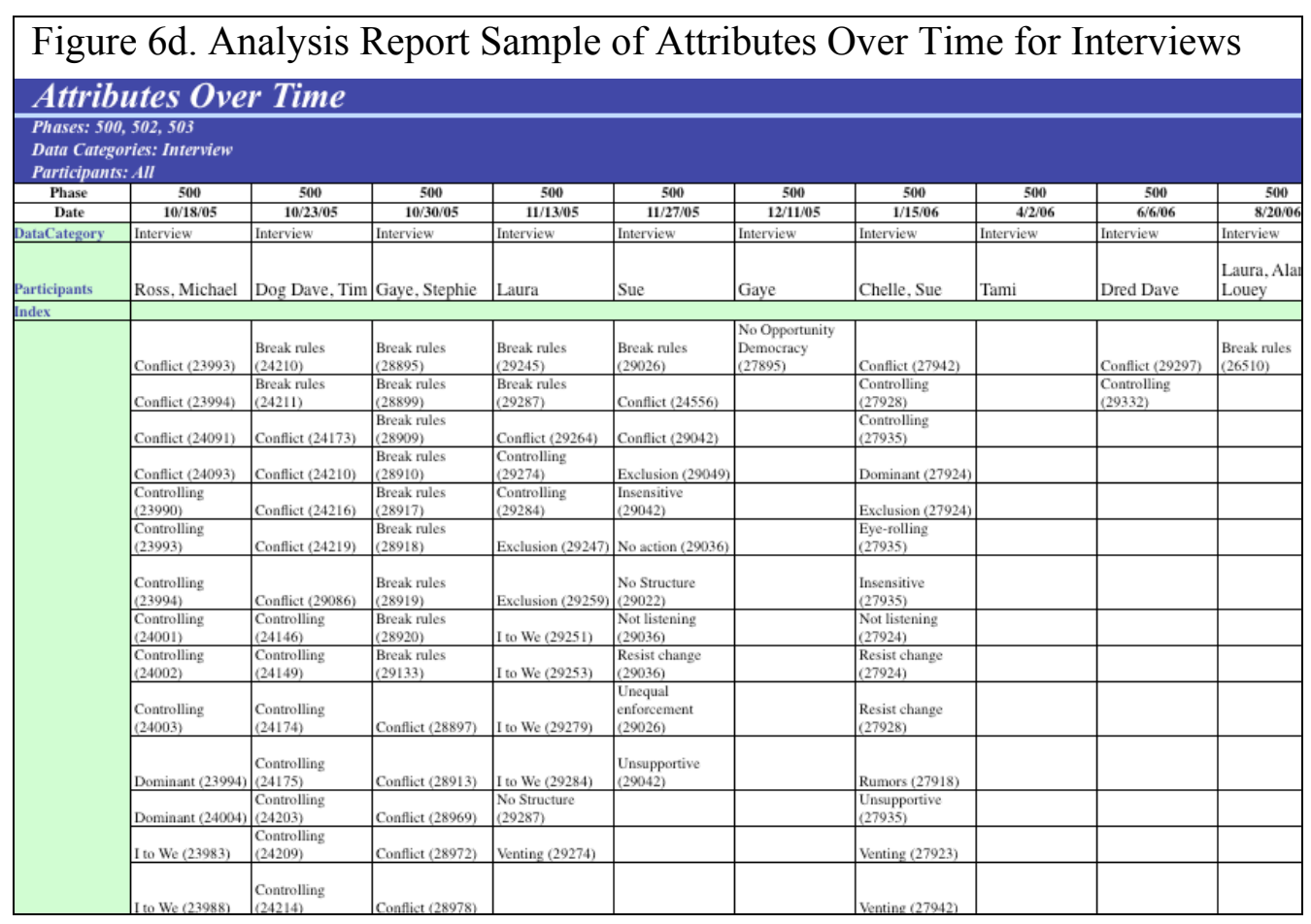

7. Step seven involved creating tables to integrate different data sources, and drawing diagrams to illustrate the crises and transformations that occurred during the research both in the core group (B-level) and community (Alevel). The diagrams were used to document ideas, decisions, and insights that came from reviewing video and reading field notes (e.g., consistencies, inconsistencies, tensions, community politics), and to write a general storyline of the results section. (A storyline is a general arrangement of scenes, content, themes, video clips and audio narrative that provides insights into my research questions.) 


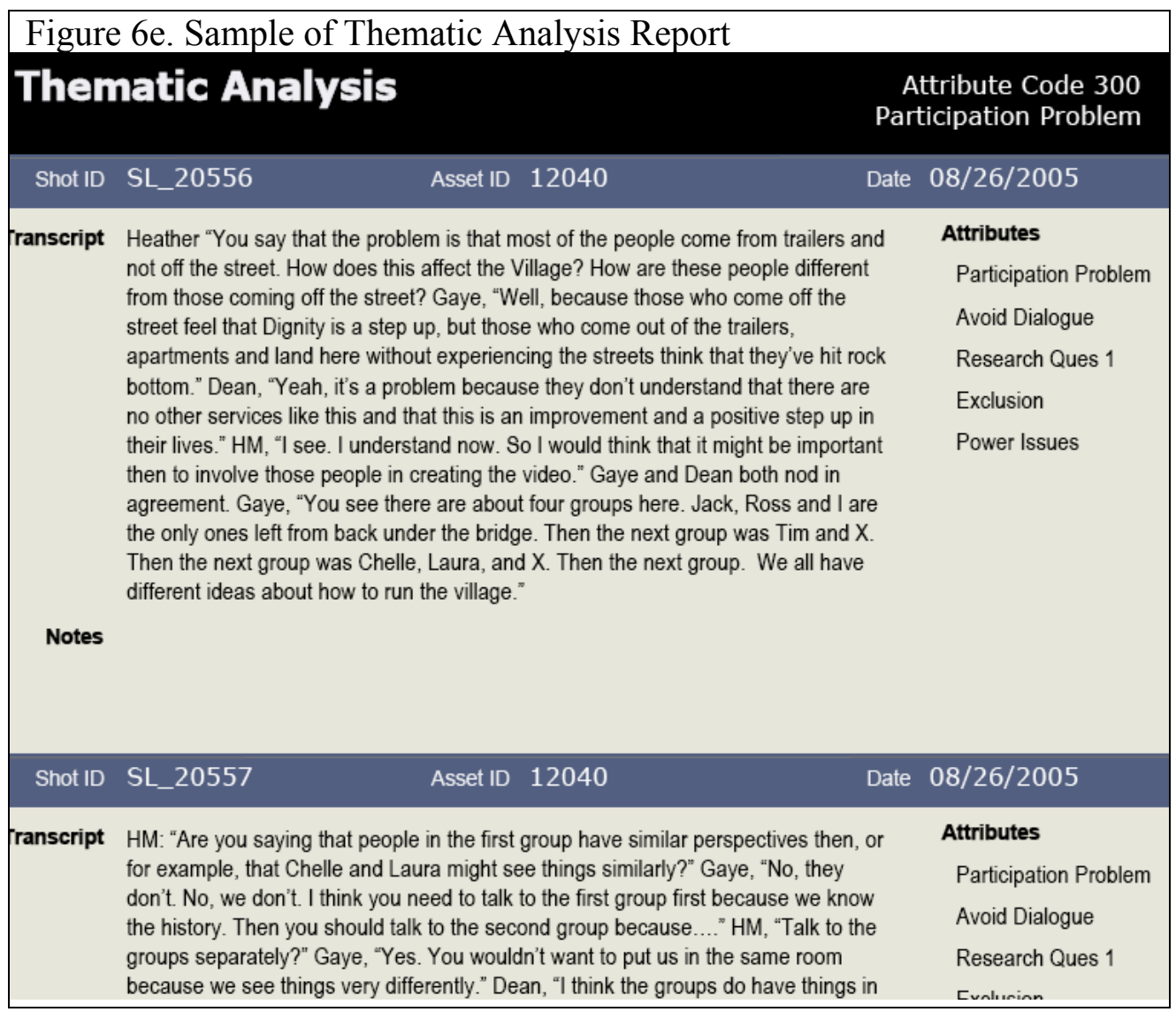

8. In step eight, data were exported from "Shot Log Pro" to Final Cut Pro video editing software to begin working with video clips and create a narrative based on the storyline.

9. In the final step, the audio narrative was recorded and the visual results section was edited using standard professional video editing techniques.

Estimated Time Involved in Data Analysis Activities. Although using video in research, both as a mode of data collection and in a report, can have significant benefits (e.g., data integrity, report accessibility, and research impact), researchers should be aware that working with video can be particularly intensive in regards to 
time and resources. Video equipment is much less expensive these days, but the cost adds up when research includes purchasing or renting equipment for production (e.g., camcorders, tripods, microphones, tape stock, etc) and post-production (e.g., computer with high processing power, large amounts of hard-drive storage for video [60 minutes of standard-definition video footage requires over four gigabytes of hard drive space], and specialized computer software for assets/data management, transcription, coding, analyzing and editing video).

In this research, post-production was especially costly and laborious since it involved designing and producing a custom database solution for transcription and analysis of the video data, as none were commercially available at the time with the appropriate specifications. I anticipate that this software would be helpful to other researchers and practitioners doing this type of work, so our company intends to continue to develop this software for eventual commercial release.

With the sheer magnitude of data collected throughout this yearlong research (organizational documents, fieldnotes, video), each step in this process involved significant time commitment. For example, capturing all digital tapes to a hard-drive required 205 hours (more than five weeks full-time), basically one hour of time to capture 60 minutes of tape. Importing digital files into the custom database required an addition ten minutes per tape (about 34 hours).

The process of transcribing video footage is a particularly arduous process. On average, transcription of one hour of interview and group research video footage took between four to six hours. Transcription of b-roll (outtakes) was less time- 
consuming, about 2-3 hours of time per hour of tape. Obtaining an accurate transcription of data was important since these transcriptions were then thematically coded and analyzed as "original" data. In total, for this project, the transcription stage required over 950 hours of time to complete (approximately 6 months, fulltime).

Analysis of visual data requires similar amounts of time as more traditional analyses once all video is transcribed and entered into a database. An additional layer of complexity is added, however, in that each piece of coded transcription representative of a specific theme also had to be evaluated visually for possible inclusion in the final report (e.g., the meaning of the visuals, and the ethical implications of including visuals of individuals or conflicts). I began creating the visual report by examining a large selection of potential clips based on the analyses and transcripts, and then assembling these into a general storyline, choosing the best and most representative clips for final inclusion. I wrote and then recorded a narrative script to provide my perspective and to create a comprehensible flow in describing the results. In general, I was able to create about 15-30 minutes of the visual text per week of full-time work. My final visual report is 6.5 hours in length, and took more than four months to edit.

A final additional task is required for visual texts in order to facilitate feedback from committee members or reviewers. I created a printed feedback sheet in a table containing an exact transcription of the spoken words and a description of the visuals, along with corresponding time-code, of the entire final edited visual 
Participatory Action Research

text. This provided committee members with an easy-to-follow worksheet to write their comments while watching and pausing the video. 


\section{CHAPTER EIGHT \\ INTRODUCTION TO VISUAL RESULTS \\ (VIDEO)}

This chapter utilizes video to provide a more accessible overview of the research for my community partner in this research, Dignity Village. This chapter includes three sections: (1) a brief introduction to the research and its theoretical framework, (2) the research process and methodology used during the research and (3) a description of the research questions in relation to time period of the research (before, during and after the creation of the orientation video) and research level (community and core group levels). Please use DISC 1: VISUAL RESULTS to view this chapter (for Technical Instructions on playing the DVD, please see Appendix H). 


\section{CHAPTER NINE}

\section{VISUAL RESULTS}

(VIDEO)

In this chapter, I present the "findings" of this research within the multiple perspectives and voices of the community that address my research questions. I narrate this visual text to describe my research process, my transformation and reflections during the research, and my interpretation of the findings in relation to the research questions. In this visual text, I use video recordings of (a) group research dynamics and dialogue, (b) individual interviews, and (c) out-takes of community life, social interactions, and community meetings to illustrate the processes and outcomes of this participatory research. This chapter presents a coherent and rich account of participants' experience and interpretation of events, and provides an empathetic understanding of participants' lived experiences of the issues investigated.

To view this chapter, please begin with Disc 1 and then end with Disc 2.

The outline structure of this visual text chapter is presented below:

Disc 1:

\section{Chapter 9: VISUAL RESULTS}

I. Introduction

II. Research Question 1

III. Research Question 2
a. Introduction
b. Paradox of Participation
c. Paradox of Power
d. Paradox of Embeddedness 
i. Ethical Dilemma 1: Should I recruit newcomers to the core group?

ii. Ethical dilemma 2: When and where do I intervene in my role as facilitator-researcher?

e. Learning from Paradoxes

Disc 2:

Chapter 9: VISUAL RESULTS

IV. Research Question 3

a. Overview

b. Collaborative Participation

c. Engagement - Sense of Community

d. Political Activism

e. Core Group's Perspective on Impact of Research on the Community

V. Research Question 4

a. Days later

b. One week later - leadership structure

c. One month later - community power shift

d. Summary and reflection

\section{Committee Feedback on Visual Texts}

Typically, committee members write their comments and feedback directly on students' papers. However, in the case of visual texts, a new method for feedback was necessary. I developed a feedback sheet that was structured for easy comprehension and efficiency in providing feedback. On the feedback sheet, I included a description of the visuals (including titles) and the audio corresponding to the video time-code. This provided committee members with an easy-to-follow worksheet to write their comments while watching and pausing the video. In the 
Participatory Action Research

materials for committee members, I included Feedback Worksheets for Disc 1 and Disc 2 (DVDs). 


\section{CHAPTER TEN}

\section{CRITICAL REVIEW \& DISCUSSION}

The focus of this participatory action research was to re-invigorate participation and a sense of community that would promote community empowerment at Dignity Village. The long-term aim of this research was to facilitate conditions and processes that support Dignity Village in obtaining more social power, in participating in and shaping public discourse on homelessness, and in organizing for long-term social change.

In this chapter, I discuss the implications of these research findings for empowerment theory and for practice, reflecting on how the community power shift that occurred after the research fits within the theory of community empowerment. In discussing implications for practice, I define key processes and lessons learned that could be transferred to other communities that are working on similar challenges, with the hope that this research will help to inform others in how to more effectively work together to build healthier communities. Second, I critically reflect on and discuss the credibility and limitations of this research and the final report. And finally, I reflect on the usefulness and relevancy of the developmental pathway model within the context of these research findings and the current sociopolitical context of homelessness. 


\section{Understanding the Power Shift in the Community:}

\section{Implications for Empowerment Theory}

The intent of this research was to facilitate an empowered and empowering community. As I observed the community, it appeared to me, even four months following the creation of the orientation video, that the community seemed reenergized and more oriented to a collective rather than an individualized approach. I felt that the community had taken steps towards a more empowered and empowering community. For example, the community seemed more supportive of newcomers and of each other, and individuals were beginning to recreate new patterns of interacting with each other. However, I also observed the community using power to manipulate and bully individuals in order to remove them from leadership. I saw this latter approach as possibly changing the trajectory of the community away from their goal of being a democratic and empowering community.

Theories of community empowerment make an important distinction between an empowered versus empowering communities and organizations (Gerschick, Israel, \& Checkoway, 1990, as cited in Peterson \& Zimmerman, 2004; Swift \& Levin, 1987; Zimmerman, 2000), and suggest that communities can have both or either outcomes. However, theories have been limited in their articulation of how empowerment processes and outcomes interact and shape each other over time to influence the emergence of empowerment at the community level. The 
findings from this research with Dignity Village have several implications for empowerment theory that may help to expand our theoretical understanding of empowerment with respect to: a) time and change, b) level of analysis, and c) researchers as observers and actors in the system.

\section{Time and Change in Empowerment Theory}

In the research with Dignity Village, the complex and contradictory qualities involved in the transformation of the community challenged my thinking about, and definition of, community empowerment. Theories of community empowerment continue to develop, but still remain limited in providing a clear sense of definition and attributes. Researchers in the field explain that empowerment involves an infinite variety of processes and outcomes (Maton \& Salem, 1995; Rappaport, 1984; Zimmerman, 1995, 2000), and that "we [may] not know what empowerment is [exactly], but like obscenity, we know it when we see it" (Rappaport, 1984, p. 2). While it is tempting to believe that I would recognize empowerment when I saw it, my experience in this research was not so clear-cut.

The findings of this research demonstrate the complexity of processes and outcomes involved in empowerment. For example, was the spike in collective action after the research that was aimed at forcing out certain "long-termer" leaders at Dignity Village a manifestation of community empowerment? Does community empowerment include processes that are coercive, conflictual and undemocratic? What are the values associated with an empowered community? 
My understanding of empowerment is that it embodies certain values or attributes that may contain both synergistic and conflictual properties, but always maintains values of democracy, equality, inclusion and cooperation. Other researchers within the field have shared my understanding of the values linked with empowerment, and imply that empowerment embodies these values because they are crucial to the growth of a healthy and stable community or organization (Florin, Chavis, Wandersman, \& Rich, 1990; Swift \& Levin, 1987; Zimmerman, 2000). However, when understanding empowerment with respect to change over time, it becomes more challenging to conceptualize how these values may be related to the complex and often contradictory processes that are involved in its emergence. For example, it's not always the case that an empowered community is also empowering to its members (Zimmerman, 1995).

An important conceptual distinction has been made between empowering and empowered organizations (Gerschick, Israel, \& Checkoway, 1990, as cited in Peterson \& Zimmerman, 2004; Swift \& Levin, 1987; Zimmerman, 2000). [Note: Although theoretical distinctions have been made between community empowerment and organization empowerment (Zimmerman, 2000), I believe that the literature on organizational empowerment is applicable to this research with Dignity Village, as Dignity Village is both a voluntary non-profit organization and a community.] Empowering organizations promote personal empowerment for individual members, while empowered organizations influence the larger system in 
which they are embedded (Zimmerman, 2000). So what does it mean when organizations seem to exhibit one without the other? Does empowerment as a theoretical construct occur only when defined based on static, point-in-time observations? Given that the main scientific interest in empowerment involves understanding the continuous process of change and what causes this change, stable states or plateaus are not particularly useful concepts (Swift \& Levin, 1987).

The relationship between empowering and empowered processes is unclear, particularly when attempting to understand the relationship longitudinally, and how these distinct processes may provide feedback and shape empowerment outcomes in a community or organization. This research with Dignity Village raises the question as to whether a community can remain empowered for long if it continues to be disempowering to its members. In this research, I documented processes and outcomes of empowerment in Dignity Village over a period of 15 months. Based on my observations and thinking about these processes, Figure 7 depicts four possible states of empowerment or disempowerment that represent points in time, and serve to illustrate the potential direction of change over time in a community.

It does not seem as likely that a community moves naturally from a disempowering and disempowered state to one that is empowered. In addition, states I and IV in Figure 7 may be states that are more stable than II and III, as these latter seem inherently unstable, and more likely "snapshot" states of a 
Figure 7. Possible Direction of Change Over Time for Empowerment

(I)

Empowered

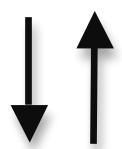

Empowering
(II)

Empowered

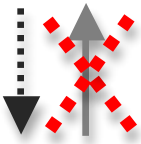

Disempowering
(III)

(IV)

Disempowered

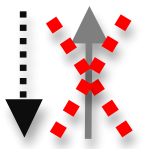

Empowering

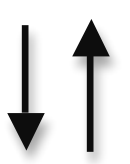

Disempowered

Disempowering

process that is moving in one direction or another. In a real world scenario, empowering and empowered processes interact with one another, and shape each other over time. A way of representing these states more accurately might be an image such as Figure 8, which illustrates the dynamic nature of the different states of community empowerment.

Figure 8. Dynamic Illustration of States of Community Empowerment

=community

$\longleftarrow$ =effort required to movelchange

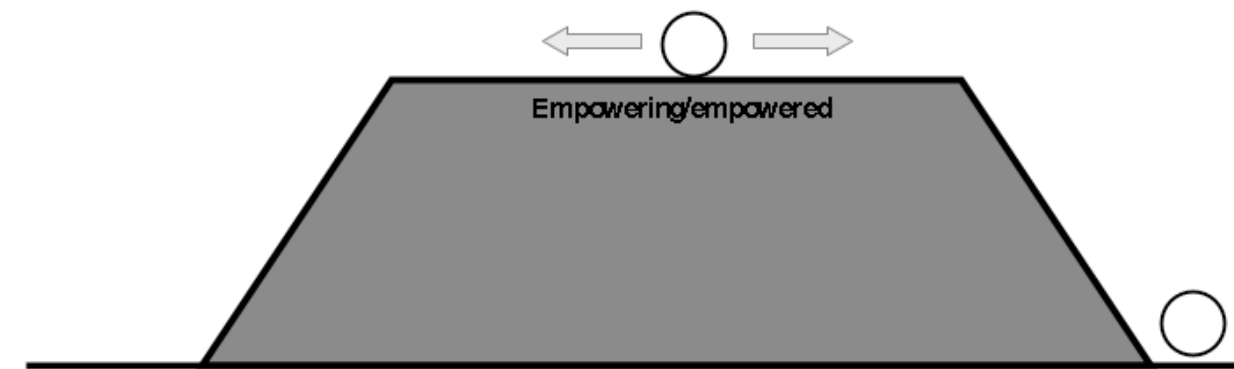

Disempowering/disempowered

Disempowering/disempowered

In the above illustration, an empowered and empowering community is linked together as a stable state resting on the flat surface of the plateau, in which 
empowering dynamics provide feedback and support the emergence and maintenance of an empowered community. An empowered and empowering state is relatively stable, but is readily disrupted by negative factors (disempowering processes) that may lead to unintentionally "falling off" the edge of empowerment and spiraling down into a disempowered state.

In comparison, a disempowered community that is also disempowering to its members is also illustrated as a stable state. The idea is that disempowering processes most likely provide feedback and inhibit the emergence or endurance of an empowered community, and ultimately results in a stable "disempowered" state that is difficult to escape. In this illustration, the disempowered/disempowering state rests in the valley at the bottom of empowerment for the reason that, in comparison to an empowered state, disempowered/disempowering states may more likely require an "uphill battle" to break the feedback cycle of disempowerment and to climb toward a more empowered and empowering community.

This mountain-like illustration supports the notion that promoting community empowerment may require significantly more powerful interventions and pressure for change, as compared to the easier shift for communities to fall backward to a disempowered state. A community that is empowered but remains disempowering to its members is a community on the edge (an unstable state). Like the ball resting on the edge of the hill, the community will likely fall quickly into a disempowered/ disempowering state. This illustration points out the importance of 
researchers and communities becoming aware of these dynamics, and that it may be much less effort to bring the community back from the edge of the mountain, than to take the long upward walk back to the top. With continuous dialogue, critical awareness and reflection, communities can adjust their practices to continuously support empowering processes, so that the community remains safely away from the edge and able to uphold the empowered state. Obviously, such a model requires testing and more theoretical exploration than provided here, but it does present an intriguing option for looking at ways that these states interact in communities. My observations of Dignity Village and findings from this PAR study support this general dynamic conceptualization of community empowerment. Before the research started, Dignity Village had at one point become an empowered and empowering community. However, a number of factors may have conspired to change this state, including the transitional nature of the community, lower than average population size (so that small perturbations caused more significant community changes), the pressure to meet the City's external expectations of growth and empowerment, and the specific personalities and power structures within the Village community. For a number of reasons, individuals at Dignity Village became more disempowering to each other, which in turn caused a state of low morale and decreased participation, a general sense of negativity, and which ultimately resulted in a disempowered community. This is what initiated the PAR process. 


\section{A Tipping Point in Empowerment}

As we define the construct of empowerment as a continuous process, we may begin to see specific characteristics about the process. For example, is it common to experience or observe a tipping point in the empowerment process?

Empowerment implies a process of gaining control and power from within a situation of unjust lack of power, exclusion from majority society, or a situation of unequal distribution of, and access to, resources (Rappaport, 1990; Taylor, 1999; Zimmerman, 2000). Change is often difficult to produce, particularly structural change that is equitable and long lasting (Foster-Fishman \& Behrens, 2007; Swift \& Levin, 1987). In order to produce an empowered state in a community that has an unequal power structure, we may discover that this change in structure may often involve the use of disempowering processes, at least for a period of time, in order to push the state of community over a tipping point where such structural change can occur (see Figure 9).

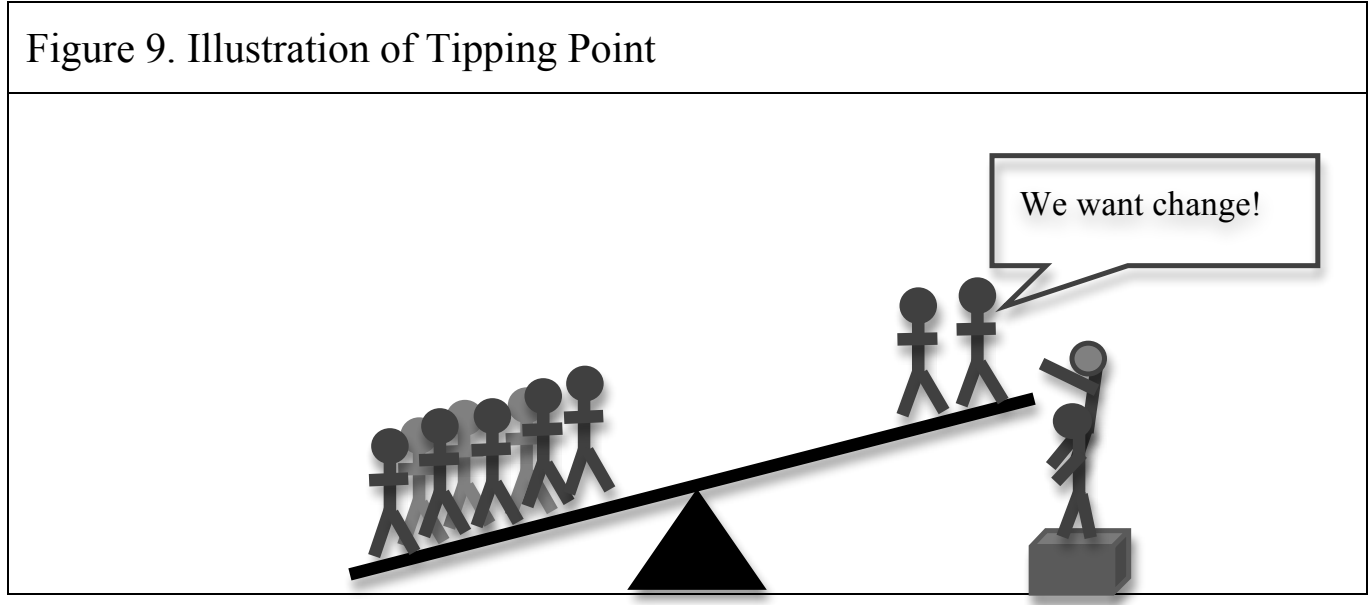


For example, Dale, a new member of Dignity Village involved in the "takeover" in leadership in the community, explained that the undemocratic process used to dethrone Tim as Chairperson was not really "unjust" or "coercive" because it was for "the good of the whole" and would lead to a more equal and democratic society. But does it truly lead to a more equal society if individuals can use whatever means necessary to achieve their ends and own agenda? Is this democracy? Just because the state emerged from "what the people wanted," or because it was believed to be for the well-being and growth of the community, can we assume it was empowerment? Or was it an example of community disempowerment with undemocratic processes at work along with threats of violence, fear, and withdrawal?

Since community empowerment depends largely on whether important stakeholders allow others to be empowered, power differentials within a community likely play an important role in whether a community remains in an empowered and empowering state, or slips over the tipping point to become disempowered and disempowering. At Dignity Village, the power differential between long-termers in leadership and others in the community may have perpetuated existing power dynamics that led to the seriously low levels of participation observed at the beginning of the research. Dignity Village might be a democratic society and all members have a vote, but perhaps when too many long-termers remain in the 
community in leadership positions, it becomes top-heavy, resulting in even larger power differences between members in the community.

Throughout my years of working with Dignity Village, I have witnessed quite a few Village leaders (mostly long-termers) who had commitment and passion for the concept of Dignity Village but who ended up being pushed out of the community. The pushing was sometimes a democratic decision to toss out a longtermer, but not always. Sometimes, the community used other means to motivate the long-termer to leave the community, such as through collectively expressing rejection, criticism, and blame to the long-termer for the lack of growth or for increased instability in the community. Why does this apparently contradictory process happen in a community? Is it an inevitable property of community growth and development? Are there more empowering and inclusive ways to accomplish this change in power structures?

In thinking more broadly about power and its various possible forms, I can understand how long-termers might have more power in a community. Power can have many forms, including voice, information, and relationships. The more time that a resident has in the community, the more opportunities they have to establish power, through close-knit relationships that can result in "coalitions" around specific policy changes at Dignity Village. With time, individuals may also gain increased knowledge of the bylaws and protocols that are in place, which helps to support the structure and stability of the community, but also has the potential for 
manipulation by those who hold knowledge over those who do not. Some forms of power, like voice and physical strength, are qualities that just about anyone in the community may hold, regardless of the length of time they reside in the community. All of these forms of power can create a large divide and power differential among residents.

Is it not inevitable that as long-termers grow and become more empowered themselves, that they lose tolerance for those who are not at the same developmental stage in their lives? And if there is a cohesive group of long-termers who are leaders in the community, would it not be natural for a divide to occur, where leaders begin to treat the newer members, the less empowered members, as "less sophisticated" or more like children who need guidance, rather than individuals who have valuable perspectives in the growth of the community? Several researchers suggest that these trajectories are common paradoxes that groups, communities, and organizations face in their development (Rappaport, 1981; Sarason, 1972; Smith \& Berg, 1987).

It may be that this phenomenon was inevitable for the growth of Dignity Village, even though enhanced in this particular case by Ross and Chelle's outspoken manner. Did the community need to break free from the divisions, to open space for different groups at different stages of empowerment to take steps toward empowerment without feeling controlled, judged, pushed, or rejected by those who were already feeling that empowerment? In the social dynamics and life of the community, Dignity Village may have reached a tipping point where "the 
levels at which the momentum of change becomes unstoppable," a point at which the community reached a "moment of critical mass, the threshold, the boiling point" (Gladwell, 2000, p. 12).

The moment when Tim appointed Ross as Beancounter was described by many co-researchers as a kind of tipping point where the community decided to "take back" their village, and to take steps to change the leadership in the community. But what made this even possible was that more people had become involved in leadership positions over the previous year. At the time of the selfdescribed tipping point at the Village, power was not as concentrated as it was at the beginning of the research in 2005 when many fewer people were in leadership positions. That year, in 2005, was also a time in Village history when they had the lowest numbers of individuals residing in the community (just 36 people, about half of their typical and legally restricted maximum number). But this low number of residents was more an artifact of long-termers' decision to temporarily stop the inflow of new people in the summer of 2005 because they were actively building houses and tearing down the older shanty-like structures.

The divide that occurred may have been a natural result of this decision to halt growth temporarily. If anything, the community shrank somewhat in numbers during this time period, because of normal attrition as individuals left the Village but no new members were accepted. As the community prepared for future growth by working on building houses and infrastructure, they became more tightly-knit as 
the remaining members experienced similar stages of empowerment and growth. Finally, when the community was "ready" structurally for restarting the inflow of newcomers, they encountered difficulties with integrating newcomers into what had become the established order. By the time the Village began allowing new people to come into the community, leadership roles were firmly established, coalitions were formed, and relationships were strong. Many of the existing leaders had difficulties tolerating newcomers and their inability to quickly integrate into community living. As the research continued through 2006, newer people became involved in leadership positions and power began to spread out. The research seemed at a minimum to have helped make the transition from "established" leadership to newer leadership a bit smoother and to begin to repair some of the divisive relationships that had been forming. Over the course of the research, the leadership structure slowly became more diverse and larger numbers of people became involved in the different departments or committees. Long-termers, however, continued to be involved in key leadership positions or participated in several leadership positions at once.

After the research, in 2007, the community structure seemed to have changed more dramatically, in that the only two people left who were both on council and a department head were Tim and Ross. Not only was holding multiple positions a form of power, but both Tim and Ross were also long-termers and had been leaders for many years in the community. Furthermore, they both were vocal 
about rules and procedures in the community, with Ross in particular considered one of the louder and more "fierce-some" leaders (a term used by the community). And with Ross came Chelle, who was just as opinionated and passionate about Dignity Village as Ross. Some members of the community explained that they were tired of this "three-man" power group. Since other members of the community were stepping up and wanting to be more involved and part of this power, they perceived this group of long-termers as holding all the power and blocking their path to becoming leaders.

After Ross, Chelle, and Tim were removed from leadership (Chelle may have been indirectly removed, but was deliberately targeted by the community), the leadership structure seemed to continue to change in the same direction that it was heading during the research. The leadership structure, and thus power, became more evenly distributed among individual members. No single individual at this point in time in the research was involved in more than one leadership position (other than individuals on the Board which by definition also requires being on the Council).

So even with the democratic ousting of Ross (and Chelle with him), and the use of coercion, threats and bully-tactics to remove Tim from leadership, the community appeared to be taking steps toward a more democratic society. It is impossible to scientifically determine whether this research was the source of these changes, but that was never the intent of this research or within the philosophy of using participatory action research. 
The philosophy of PAR is to challenge and ultimately shift the power inequities through cycles of action and reflection. The research opened up opportunities for group learning and change. Later, it was a "less empowered" and newer group of community members that drove the change in the community. I would like to think that the processes in the research affected these individuals in a way that promoted their empowerment and critical awareness of their situation in the community. However, many other factors were involved in this change, not just motivated and empowered individuals. Factors as simple as the number of residents may have influenced dynamics in the community and participation. The more people there are, the more people there are to get involved. Many studies of group dynamics consider group size as important contributors to group functioning and group cohesion (Beal, Cohen, Burke, \& McLendon, 2003; Eisenberg, 2007; Piper, Marrache, Lacroix, et al., 1983).

Over time, I observed and documented the state of the community growing more cohesive and empowered. The brief break from the democratic process after the research initiated an explosive change in leadership and power, and created what seemed to be a very unstable environment. I felt the situation was unstable because there was rumor that some new leaders were advocating for completely eliminating the rule prohibiting use of drugs and alcohol, and there was a general sense of distrust and paranoia regarding supporters and their motives. Perhaps my sense of the instability was inaccurate, but having observed the development of the Village 
through several leadership changes already, I believe that my perception was more accurate than not, because other members of the community also shared that perception. The instability from the rapid leadership changes could have easily resulted in a very bad ending for Dignity Village, but fortunately, it did not. I believe that the only reason it did not lead to catastrophe was the decision by the community to quickly renew their commitment to a democratic process.

Throughout the upheaval of rapid leadership change after the research ended, the community showed the beginnings of new patterns of interacting with each other. But as with any community, it remains a question as to whether they will be able to sustain the new patterns or whether they will eventually fall back to the older established patterns of interacting that were at the center of the problem of participation.

In summary, empowerment is a complex process that may be more accurately described through a longitudinal approach, rather than simply as a pointin-time description. There may be reasons to view empowerment as a more dynamic process, with differing pressures resulting in state changes from empowered to disempowered, and empowering and disempowering, and vice versa. My observations at Dignity Village lead me to postulate that empowerment may involve a tipping point, such that moving from one state to another may involve slower or less visible forces that lead to a crucial point where changes then occur more 
rapidly. The scope of this research was not intended to explore these questions, but they raise interesting points for future exploration.

\section{Group Level in Empowerment Theory}

Empowerment has been conceptualized as multilevel in nature, with most empirical work focusing on individual level empowerment, and a growing number focusing on organizational and community levels (Peterson \& Zimmerman, 2004). Missing in this multilevel conceptual framework is the group level. Parsons (1998) defines empowerment as an outcome and a process that emerges initially through peer validation and a perception of commonality. Identifying attributes that define group empowerment can guide its measurement and practice, and provide insight into how processes and outcomes at the group level are unique, yet interrelated, to other levels of empowerment.

For example, in this research with Dignity Village, we encountered a paradox related to the embeddedness of the research group within the broader community. The goal of the research was to change the dynamics in the core group in a way that would ultimately impact the community. But it became clear that it was just as likely that dynamics within the broader community would "spill over" into the core group, rather than the other way around. Given the embeddedness of the core group in the community, we found that our actions in the core group were self-limiting, and that broader change became nearly impossible without making efforts to spread collaborative activities across both levels. 
Findings from this participatory action research suggest that empowerment processes and outcomes contain unique attributes at the group level compared to the individual, community, and organizational levels (see Figure 10a for illustration of the specific levels and processes of focus during this research). For example, in this research, I observed that an increase in group cohesion in the core group through dialogue and relationship building resulted in unintended side effects on community empowerment. As the core group grew more cohesive, divisions and conflicts seemed to increase between groups in the community, with the newly formed "core group" now part of this negative dynamic in the community.

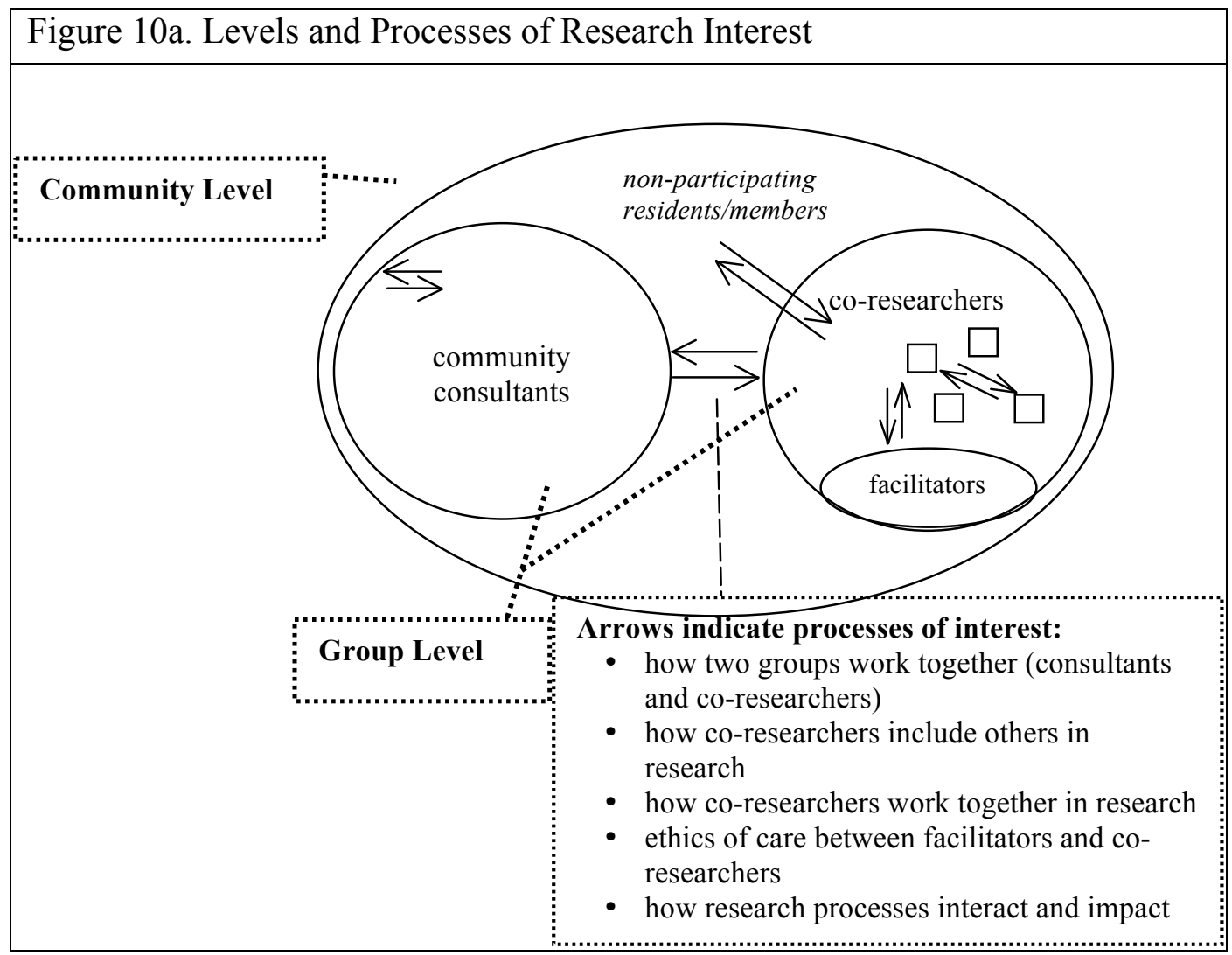


During the research, I expected an increased sense of community to emerge from newly formed relationships among diverse individuals who were members of these different groups in the community, as they worked together in the research and established supportive ways of working together as a team. However, findings from this research suggest that sense of community may have instead been weakened by a primary focus on strengthening "group" cohesion, rather than on strengthening cooperation between groups at the community level (this finding is discussed in more detail in the following "Research Limitations" section in this chapter).

One difference between group and community levels is that communities are comprised of numerous groups, and the functioning and empowerment at the community level likely depends at least in part on the relationship among these groups (see Figure 10b). Therefore, at the group level, empowerment can be defined as the processes between individuals in a group and how the focal group interacts with other groups. Whereas, at the community level, empowerment can be defined as processes between all groups in the community, and between the focal community and the broader community. Figure 10c provides a framework for understanding how each level of empowerment may involve different, yet related, attributes.

A definition and conceptualization of a group level of empowerment is important to include in future development of empowerment theory. Defining group empowerment and its attributes are important since it is from this level that much 
empowerment-based research is carried out. In participatory action research, working with groups is common and a practical and effective way to create change in a community. However, very little is known about the dynamics between group and community levels. And, as stated previously in my example of strengthening group cohesion during this research, what is effective at the group level will not necessarily have the intended impact at the community level.

Figure 10b. Processes Associated with Multiple Levels of Empowerment




\begin{tabular}{|c|c|}
\hline Levels & Attributes \\
\hline Organization & $\begin{array}{l}\text { - Structural supports (Swift \& Levin, 1987; Zimmerman, 2000) } \\
\text { - Equity (Swift \& Levin, 1987) } \\
\text { - Shared Leadership (Maton \& Salem, 1995; Minkler et al., 2001; } \\
\text { Zimmerman, 2000) } \\
\text { - Opportunity role structure / opportunities to participate in decision- } \\
\text { making (Maton \& Salem, 1995; Minkler et al, 2001; Peterson \& Hughey, } \\
\text { 2002; Peterson \& Speer, 2000; Speer, Hughey, Gersheimer, \& Adams-Lavitt, } \\
\text { 1995; Zimmerman, 2000) } \\
\text { - Committee/group linkages and collaboration (Bond \& Keys, 1993; Gruber } \\
\text { \& Trickett, 1987) } \\
\text { - Viability (Perkins, Brown \& Taylor, 1996; Prestby et al., 1990) } \\
\text { - Resource procurement (Zimmerman et al., 1991) } \\
\text { - Influence of public policy and practice (Fawcett et al., 1995; Speer \& } \\
\text { Hughey, 1996; Zimmerman, 2000) } \\
\text { - Participating in alliance building activities with other organizations } \\
\text { (Foster-Fishman, Salem, Allen, \& Fahrbach, 2001; Itzhaky \& York, 2002) } \\
\text { - Disseminating information to broader community (Bonal, 2000; Burstein, } \\
\text { 1999; Stevenson \& Greenberg, 2000) }\end{array}$ \\
\hline Community & $\begin{array}{l}\text { - Openness to change (Swift \& Levin, 1987) } \\
\text { - Sense of community (Bond \& Keys, 1993; Chavis \& Wandersman, 1990; } \\
\text { McMillan et al., 1995; Zimmerman, 1995) } \\
\text { - Access to resources (Zimmerman, 2000) } \\
\text { - Promote inclusion (Foster-Fishman \& Keys, 1997; Zimmerman, 2000) } \\
\text { - Collaborative leadership/Governance (Erickson et al, 2003) }\end{array}$ \\
\hline Group & $\begin{array}{l}\text { - Inclusion of diversity/Appreciation of alternative views } \\
\text { - Strong interpersonal relationships (Robinson \& Hanna, 1994; Speer et al., } \\
\text { 1995) } \\
\text { - Group cohesion (Holden, Messeri, Evans, Cranshaw, Ben-Davies, 2004) } \\
\text { - Collective participation (Holden et al., 2004) }\end{array}$ \\
\hline Individual & $\begin{array}{l}\text { - Participatory behaviors (Zimmerman, 2000) } \\
\text { - Perceived control (Zimmerman, 2000) } \\
\text { - Perceived competence (Kieffer, 1984; Zimmerman, 2000) } \\
\text { - Critical reflection (Kieffer, 1984; Zimmerman, 2000) } \\
\text { - Working with others (Zimmerman, 2000) }\end{array}$ \\
\hline
\end{tabular}

\section{Researcher as Observer and Actor}

Literature on empowerment practice and action research directs our attention

to the role of researchers in facilitating and hindering empowerment (Gaventa \&

Cornwall, 2001; Hall, 2001: Pease, 2002; Sohng, 1998; Solomon, 1982; Stringer,

1999; Van Beinum, 1998). Empowerment theory implies the important role of 
researchers in empowerment, but does not explicitly state how this role impacts empowerment processes and outcomes. Empowerment theory could be enhanced by explicitly acknowledging the researchers' role as inseparable from defining and perceiving empowerment processes and outcomes. Lendaris (1986) emphasizes the importance for systems practitioners to acknowledge the perceiving role in defining any system or problem to study, and for researcher-practitioners to become aware of the perceptual filters they are using during a research project. Researcher reflexivity should be presented as a key concept in defining empowerment theory as an important part of authenticating researchers' perceptions of an empowered or empowering system (see Figure 10d).

In applying the concept of "perceiving role" to this collaborative research with Dignity Village, it was imperative that I asked questions such as: "What was my role in the empowerment process and outcomes at Dignity Village? What was my role in the rise in collective action that "took over" the leadership and ousted most of the remaining "old guard" leadership during this change making? Was this process part of empowerment?" To more clearly understand empowerment at Dignity Village, it is important that I discuss my role in these processes and how they may have led to the outcome in the community that contained both undemocratic and democratic practices. 
Figure 10d. Perceiving Role in Empowerment Theory

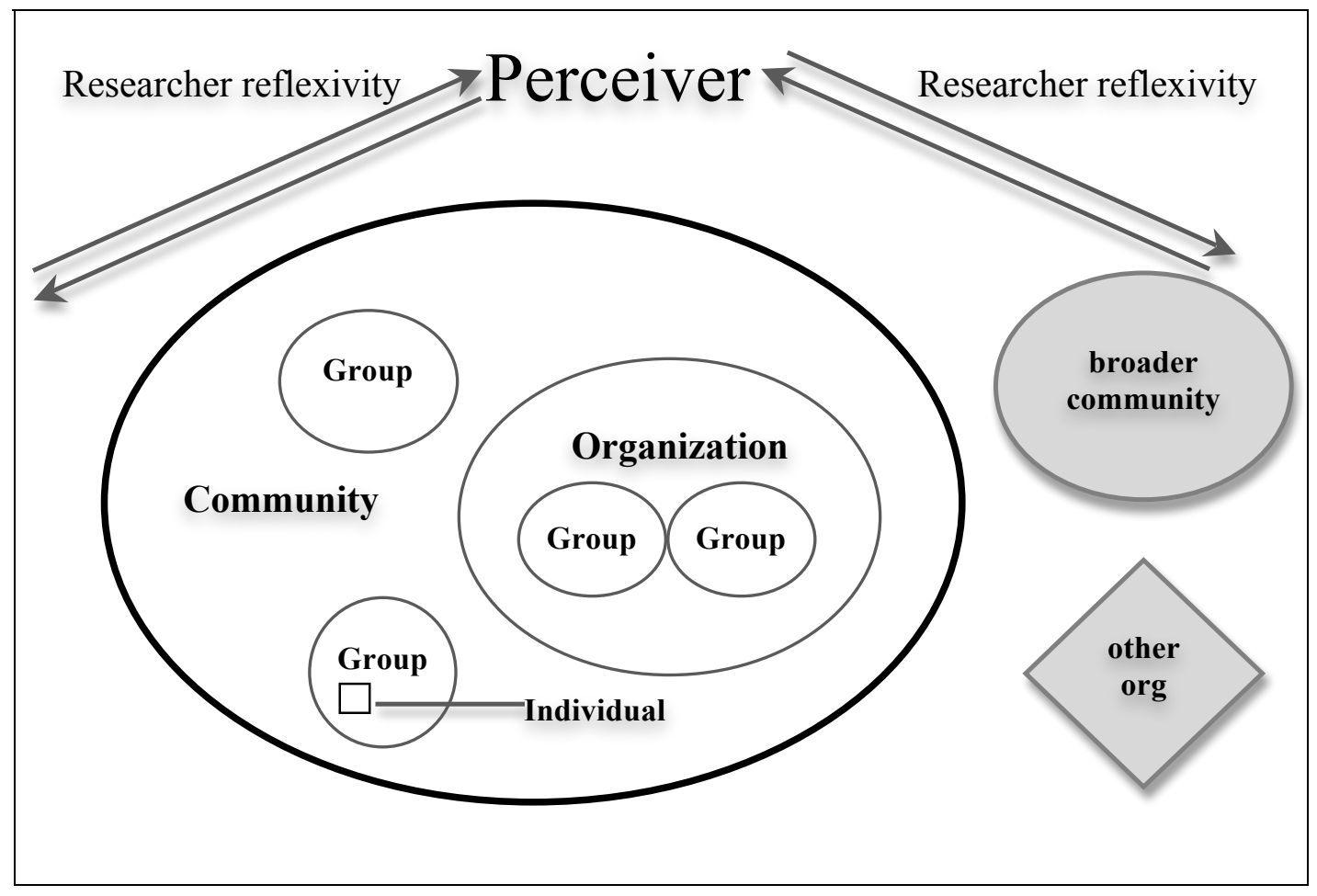

Throughout this project, I was always aware of my active participation in the research, but at the same time, I maintained an awareness of and reflective commitment to what I defined as important boundaries in my role and participation in the research and in taking action in the community. I faced several ethical dilemmas during the research where community members asked me to intervene in community conflicts on their behalf, or to take action in correcting and maintaining "justice" when Village council decisions seemed biased or unfair to certain groups in the community. According to other community researchers, these challenges are a natural consequence of participating in community settings, and it is common for 
community researchers to experience a pull by the community toward even greater inclusion and involvement with research participants (Adler \& Adler, 1987).

Although it may be a fairly common dynamic that occurs between researchers and participants, I found it often difficult to see these moral and ethical boundaries clearly. I constantly had to ask myself, "When and how should I intervene, if at all?" These moments of community crises were also key moments of critical reflection for me. When I considered intervening in broader community issues, I began to foresee my role as becoming more influential and powerful, and potentially feeding into the existing conflicts, making things worse in the long run, and giving me more of a leadership role in the community, which I considered problematic as far as providing processes for growth and empowerment of community members. I was aware of the power differential already present between researchers and participants and did not want to increase those differences by utilizing a process that relied heavily on collaboration and "outside" support.

As I reflected on this issue, I saw the importance of creating boundaries in my role and the necessity to communicate these boundaries to the community. I understood my role as primarily to facilitate the collaborative research (including the creation of the orientation video) in a way that would attempt to resolve conflicts and maintain a supportive working environment. I did not feel that it was my place to advocate for individuals, to strengthen some loyalties but not others, or to sit in judgment over disputes. I wanted to establish and maintain good working 
relationships with everyone, in the hope that we could all work together in an empowering, inclusive and supportive way. And, most importantly, I wasn't a Villager. I was somewhere in-between. I was an "insider" as part of the core group and as a long-term supporter of Dignity Village, but I was also an “outsider” because I did not live at Dignity Village, nor had I ever experienced homelessness.

I was aware of the lines that were drawn by the community between insiders and outsiders and between "supporters" and "villagers." The lines had been drawn clearly in the beginning stages of our relationship - mostly by Villagers to prevent supporters (who had their own agenda) from taking over and manipulating the Village. It was very important to the community to be self-reliant.

However, during the research, I began to realize that the community's perception of me and Wendy had changed as we developed a closer and more trusting relationship over the many years of working together. About halfway through the research, they began to call us "honorary villagers." When I first heard this, I was honored and felt that it reflected an important transformation in our relationship with the community. They trusted us, and wanted to bring us into their community as "insiders" and more equal partners. But even though I considered this a positive change and that it was reflective of a successful collaborative research process, I was aware of the responsibilities and risks that came with being more of an insider. I might gain something by this insider perspective, but what would I be losing or risking in this change? 
An insider perspective was important, but at the same time, I felt that it was also important to keep an outsider perspective in mind, to avoid becoming so engrossed in community affairs and group conflicts and debates that I became as confused and stuck as the rest of the community already felt. I did not want to risk losing my ability to be an effective facilitator in the research. I also did not want to risk losing my own perspective, because I felt that my perspective as an outsider was important for seeing the whole picture, and for maintaining data integrity. A risk with "going native," a term used when researchers become over-involved in the research setting, is that they begin to take the settings' ongoing activities and meaning for granted, and fail to recognize the theoretical significance of events that occur in the community (Adler \& Adler, 1987). Adler and Alder (1987) state:

"Scientific analysis does not occur within the realm of objective detachment (Peshkin, 1985; Reinharz, 1979). Rather, it falls within researchers' 'theoretical stance' (Douglas, 1970), or sociological perspective, where they periodically withdraw from the everyday life of actors' natural stance and engage in analytical self-reflection" (pg. 23).

For these reasons, I decided to take special care not to take sides, so much so that I missed the fact that my intentional withdrawal on some issues was seen in effect as taking the side of the long-term "establishment" at Dignity Village. As Paulo Freire (1970) wrote, "washing one's hands of the conflict between the power and the powerless means to side with the powerful, not to be neutral."

I first became aware of this perception of me (as aligned with the leadership and power-base in the community) after Ross was ejected from the Village, on the 
day that Tim resigned as Chairperson. On the night of Tim's resignation, I listened and videotaped while Sue explained the situation about Tim's non-compliance letters. I felt myself become angry about what was happening at the Village, even though I wasn't sure exactly what was happening (or going to happen) or why. I didn't want to take sides in the situation, but then I realized how naïve that was. I had a side: I believed in and valued the democratic process. And I thought what they had done to Tim was unjust.

As we were listening to people talking about what happened to Tim, I thought it was strange that Sue was (or acted) blind to this. I became annoyed when I heard Sue continuously state that she was unaware of what was going on, and that she was new to leadership and did not yet understand all of the bylaws. I felt that she, along with many others, were withdrawing from their social responsibilities to get involved and question what was going on around them! Practically no one was directly challenging the newcomers John and Dale or Sue (as acting Chairperson) about the legitimacy of what had happened. If no one else was asking questions, then did I have a social and moral responsibility to Dignity Village as a long-time supporter, honorary Villager, and co-researcher, to do something even if was simply to question authority and processes that were being used?

On the day of Tim's resignation, I decided that I did have a social responsibility to ask questions about the undemocratic and disempowering processes being used 
by certain groups in the community. The following paragraphs are extracted from a video transcript:

Wendy asked Sue, "So what's the process when you get letters of noncompliance for hours?"

"The first letter you, you get a letter of warning. The second time you lose your membership. The third time, you lose the home. And they can be given all at once. For every incident he has, and it's been over two years."

Wendy asks, "Has he gotten one for every incident, is that what you are saying?"

"They don't have to be given the letter one at the time. They can be given all at once."

"No they cannot," I calmly challenge her. I take my eyes away from my camera monitor, and look directly at Sue.

Sue seems surprised. I had been fairly quiet up to that point (some of that had to do with the task of operating the camera at the same time as talking...but that may be simplifying and rationalizing my nonparticipation too easily).

Sue says defensively, "Well, they've done that before. I've seen that done right here. I haven't been here that long to know. I just know from what I've seen done before and it's been done over and over. And it's been done by them."

Sheri, who had been listening for a couple of minutes from the sidelines, says, "I've never seen that happen..."

Sue interrupts, "Well, you've only been here a few months."

Sheri explains, "Well, I have been here a few months, and I've seen that you get a letter and you don't get kicked out. By the end of the month, you'd better...by the next month, you'd better get your hours in."

Wendy asks Sue, "Didn't you have to do this?" (The Council gave Sue a warning letter about hours and she was not kicked out.)

Sue argues, "I'm saying what they've done in the past. I don't know...I had my hours in and they gave me a letter of noncompliance. They put me out for a week and they gave me a letter of noncompliance because I didn't have 40 hours in that month. I was out for a week. I got a letter of noncompliance and that was..." (She was out for 7 days for disruptive behavior, not noncompliance of hours. She received a letter of warning about her hours when she returned to the Village). 
Wendy interrupts, "Didn't you make [the hours] up?"

"I did make them up but I should have never got a letter. In the last week of the month, I was kicked out for 7 days and when I got back, I was given a letter of noncompliance for non-hours. And then I was given a letter of noncompliance because I didn't move from Ron's house back to my wet tent. You know, they wouldn't let me sleep in the bus, the common area...I had a wet tent. I got a letter of noncompliance, and I was out for a week. So, two in a row and I got the third one while I was still here. They wouldn't let me move my stuff. They wouldn't let me move it nowhere. So, I know what's happened to me."

I speak again. "My opinion is that this [Tim's resignation as Chair] is completely fine, if the Village wants it...but the village won't last if nobody is keeping with the real process of doing things above board...Because if that's what happened to you..." While I speak, I notice that Sue is staring at me in bewilderment, and then interrupts, "But you know it's happened to me! I called you! I asked you to help me and nobody would stick up for me!"

Wendy says, "We're not helping anyone. We're not taking sides."

Sue is quiet, just looking at us. The last thing Wendy says lingers with me. This time I hear it differently. "We are not helping anyone. We are not taking sides." That was my research mantra, the clearly demarcated boundary that I drew for myself during the research. I told myself, "Listen but do not get involved in the personal conflicts. Try to understand and bring people together. Do not take sides. Bridge the divide by being inclusive and democratic. Encourage dialogue."

Sue is looking at me intensely. I am quiet. I am confused by my new awareness of my lack of participation and my role in what was happening, of the consequences of my inaction and avoidance in taking sides.

Sue breaks the silence. "See, I tried to ask you. Remember I called you at home? I said, 'how can they do this?' I mean, I didn't do anything and Laura has apologized and now I'm out with a letter of noncompliance. And now I have another letter of noncompliance for not moving. These things all took place when I wasn't even here... I called you because I didn't know who else to call. I didn't know what to do. And I was totally alone, remember? I had to go for my chemotherapy, and Dexter was in the hospital, and it was in the middle of winter, and they put me out... and that whole thing, when they put me out, was a lie. Gaye has apologized and Laura has apologized. They drove that train home. They wanted me out of here. I said, 'Gaye, why did you do that?' Oh, it was terrible. And I saw it happen and everyone said it was okay and I went along that road. I don't know. I have looked through the 
bylaws and I haven't been involved in the process. I've just barely been on the council."

She pauses for a moment and then continues, "It's hard because I don't know anything and I know where the village's heart is and the village wants to take itself back. Tim does not intimidate when Ross is here. And that's why they thought it was an opportune time to clean house. That's what they do [referring to current leadership - Ross, Chelle and Tim, who were getting ousted]. That's what I've seen them do in a 100 different cases. I haven't been here for all of it, but I've seen them take them out."

I remember when Sue asked us to step in and defend her at the Village and we said that we couldn't do that, and that it wasn't our place to interfere in the democracy and internal village affairs. I remember how shocked and bewildered I was by her comment when I saw her next. She said to me, "You're feeling awkward, huh, after what happened." I remember feeling none of those feelings, and then wondering whether I was missing something.

In retrospect, I now understand why she expected me to feel awkward or guilty when I next saw her. In the research in which we were partners, I urged dialogue, justice, supportive relationships, empowerment, and democracy, yet she felt she was getting none of these. In the past, when we first began the research together and she felt threatened and at risk to attend the research meetings because she was a newcomer and disliked by the leadership, I encouraged her to get involved. I promised her that I would do anything I could to make the research group environment safe and the process fair and democratic. She said to me, "It's not the research meetings that worry me. It's afterwards that worries me." At the 
time, I considered this an ethical dilemma. I realized that there were individual risks involved, particularly for those who had opposing viewpoints or who questioned current practices. Sue was a newcomer, and she voiced her opinion. She had experienced conflicts with long-termers from the start. I attempted to reduce the risks of participating to individuals by encouraging a group of newcomers to attend so that one person wasn't isolated or targeted. I didn't want to give up on bridging the divide, because the inclusion of diverse perspectives was critical to the effectiveness of participatory action research and to improving the community.

By the time I understood what Sue was trying to tell me, it was too late. Power dynamics were in motion that we clearly never adequately addressed in the research. Relationships had improved in the community, but not between Ross and Chelle and the rest of the Village (or at least a large group of Villagers). The positive energy of finally accomplishing our goal together and seeing how the orientation video had positive impact on newcomers blinded me to the seriousness of this conflict that had been weighing down the Village for some time. The divide had not been healed, but I hoped that in time, it would heal, through reflection, inclusion, and communion. I understood that change takes time. But while waiting, the divide seemed to worsen, and the community, including Sue, had had enough of some of the leadership.

Since the democratic process with the research didn't necessarily address the issue, I began to understand why the pot started to boil over, as it were. I had 
avoided and misunderstood Sue's pleas for help, rather than addressing the issue. In retrospect, I didn't have to take any particular side to address the issue or take "control" of the situation, but I did have a social and ethical responsibility to do something. I could have opened dialogue around Sue's issue so that either she could understand why she received seven days out by the Village council, or so that the Village could be aware of, and possibly change, their unfair practices. The least I could have done was spend more time with Sue, but I knew at the time that doing that in itself had some consequences. I didn't know Sue well because she was a newcomer, but I felt that if I spent more time with her than anyone else, it would appear that I was playing favorites or getting involved in and taking the "wrong" side (with newcomers). I did interview Sue twice during the research, but I was concerned about intervening directly, as I didn't want to jeopardize my relationships with others...I had a role and that was as facilitator of the research process, and I believed that it was unethical to get too involved and use my power as a facilitator / supporter / outsider / researcher to "solve" community problems. For better or worse, that was the boundary I committed to upholding throughout the research.

On the one hand, I modeled patience, understanding, and inclusiveness as a facilitator of the research. On the other, I was also an example of withdrawal and detachment from social responsibility. I was horrified by the observation that Villagers, friends of Tim, Ross, and Chelle, hid in their houses to save their own butts. I was bewildered when Laura and Sue and other co-researchers refused to get 
involved and really challenge what was happening. But then what did I do throughout the research when I observed conflicts and potentially unjust practices? The same damn thing.

I created an artificial boundary in my head about my role and my participation in the research. I was the facilitator, a participant, a researcher, a friend, an "honorary Villager" as I have been told. How could I not see it? I may not have lived at Dignity Village, but I was an insider. In fact, from the perspective of a newcomer (like Sue), I was a long-termer. I knew the founders of the Village. I participated in the social movement, the protests, and the growth of Dignity Village. I shared a history and relationship with long-termers. We often sat together and laughed, reflected and reminisced about the early days of Dignity Village. I was even aware that the more time I spent with Sue and other newcomers, some longtermers became more annoyed and distant from me as if I had "switched" my alliances or friendships.

At the same time that I was an insider, I was also an outsider. I didn't live at Dignity Village. I didn't vote or participate in the work and daily life as did everyone else who lived there. I never experienced what it was like to live in poverty, to live and survive homelessness on the streets. I didn't share the same stressors or burdens or experiences. I visited and listened, and didn't state my opinion or get involved in conflicts. I can honestly say that I liked everybody in the community, but I can understand how I might feel differently if all 60 people (any 
people, homeless or not) suddenly became my roommates and I relied on them as much as the community relied on each other at Dignity Village.

I understood the perspective of long-termers because I shared their vision and dreams of Dignity Village as a concept, but I also understood the perspectives of newcomers, since I was often "new" to the Village by being on the outside. I understood how it would feel to come into a community as a newcomer and have people express distrust, exclusion, and disempowerment.

As I reflect on this, I realize that I share some similarities with Dale and John, even though I do not share or agree with their approach. Since Dale and John were relatively new at the Village, they were both insiders and outsiders. They may have navigated this border differently than I did, but they also had to make decisions about whether to be a participant and agent of change, or to sit back and observe. Mirroring my own philosophy,

Dale said, "I don't pick sides. I listen to what everybody is saying because I guess, being that I'm relatively new as opposed to some others, I don't have those preconceptions in my mind."

John said, "I consider myself to be an outside factor and it took an outside factor to come in here and be neutral with all the different factions that are here, and exist here, and to bring some mess, to grab all that mess and find out and really analyze and understand what was really going on. It took awhile. It took me two months."

Was the shift in power dynamics only achievable through uprising and takeover, through the ousting of the "old guard"? What were the consequences of this power shift when the community used (or allowed) exclusion, bully tactics, and coercion as a process to achieve their means? We had been working to improve the Village for 
over a year, and we had been doing it together, democratically. The community had transformed slowly over time, but it had led to a tipping point that I hadn't expected where a large group in the community decided to take no more "oppression" from certain leaders. This decision, unfortunately, led to mass paranoia, instability and the feeling that "all" long-termers needed to leave the community, including us.

Within days of Ross and Chelle's departure, Wendy and I became the next targets. John started a rumor in the community that we had a hidden agenda that no one had seen before, but because he was a newcomer and outsider, he could see the reality of it. John believed that we hadn't finished the documentary because we were waiting for the perfect ending to emerge, and that perfect ending was the destruction of the community, and the spectacle of it falling apart. We had signed a contract with the Village years ago giving them all profits from the documentary. He searched through this legal document and determined that we had intentionally left a "hole" for us to wriggle out of, to not fulfill the contract in the end. He explained that if the Village fell apart and no longer existed, our contract with them would be void. Then, and only then, we could keep the profits from the documentary. His conspiracy theory seemed so absurd to me that at first I didn't take it seriously. I was astounded that others in the community were listening to John and beginning to question our intentions. 
The community was in a state of confusion and chaos. While I was recording some visuals of the Village, Laura walked over and began talking to me about how she was feeling.

Laura said, "I don't know what's going on. I just get all this misinformation. I don't know what's true or what's not. I know that something is going on...it would be easy for stuff to be going on right under our noses and not be aware because what kind of people do you have come in here. You have people like us coming off the streets out of the doorways, and you come in here and you are grateful. You are grateful that these people accepted you, that you have a home, that you have a place to keep your things. You've got a bathroom. You have all these things. Then once you are in, and they've accepted you, then you spend the rest of the time in fear of missing a meeting, or not getting your hours, or not breaking a rule. So once you get in here, then it's a rat race survival to not get kicked out, just to not get in trouble...things can be right under your nose, but you don't worry about it because you are just happy to be able to be here and to survive. So all this stuff sounds like it has been going on right under our noses and I was Vice Chair and I don't have a clue. I was never really allowed to do anything as Vice Chair."

We went to the next Village meeting (on February 20,2007) to address the rumors regarding our intentions. We opened the floor for dialogue and questions about our agenda and our relationship with the Village. Our openness and willingness to talk and answer questions was well received, and we encouraged the Villagers to address any concerns they had with us at any time. I realized how important it was that I was an active participant in the dialogue that was happening in the broader community. I may have needed to define boundaries early on during the research, but I could also see the importance of breaking these boundaries when they became too rigidly defined and potentially perpetuating some of the divide between "the powerful" and "the powerless" in the community, especially as I became more aware of "the 
powerless" perceiving me as aligned with the "dinosaurs/status quo/old-guard" in the community.

This is what I learned about my role in this research, and how it may have perpetuated the divide in the community that led to a tipping point where the community decided to "take back the Village" from the hands of the oldguard. From their perspective (as well as that of newcomers John and Dale), the research may have helped in some respects (e.g., increasing critical awareness, participation, dialogue and a sense of community among many), but lacked direct confrontation over the power dynamics in the community. I learned that defining my role rigidly as "facilitator of the research" may have led to a blinder and less reflective approach to facilitating community empowerment. As Dignity Village taught me long ago when I was a first year graduate student, withdrawn and disconnected from politics and community issues, I learned once again to see myself as an actor and participant. I learned that when I had decided not to get involved, it wasn't that I was taking myself out as an influencing factor in the community. My decision to avoid taking action still affected the community. It sent a message that I was taking a side: the side of the status quo.

There is no such thing as independent objective observers to record and analyze processes and outcomes of empowerment. Researchers are observers and actors, inseparable from the emergent wholistic stream of events that produce empowerment. Without acknowledging our own assumptions, biases 
and perceptual filters, there is a tendency to overuse the term empowerment to represent "anyone doing good in the world", and to hinder serious work on its conceptual development (Swift \& Levin, 1987, p. 77). Swift and Levin (1987) point out that "it is extremely difficult to modify significantly fundamental power relationships. The true phenomenon of empowerment occurs so infrequently and when it does, so transiently, that it has become acceptable to apply the term loosely to phenomena which can only approximate true empowerment" (p. 76). Reflexivity as a researcher-practitioner can be valuable to further developing empowerment theory. What is explicit can be examined.

\section{Implications for Practice}

As community partners, it is important that we identify basic processes that lead to empowerment in order to improve our ability to provide research contexts that facilitate its emergence. As a guide for facilitating the emergence of community empowerment in this collaborative work, I developed a preliminary framework before starting this project based on related areas of literature that identified five possible components in the empowerment processes. These components included: a) collaborative participation, b) autonomy, c) competence, d) collective identity, and e) critical consciousness (See Chapter Five). The framework I created to guide my facilitation process proved to be very useful in reflecting on questions of quality and ethics while conducting this collaborative research, and helped in locating areas of blockage that might have been limiting empowering processes during the research. 
However, the framework seemed to lack one key process that appeared to be critical in changing empowerment at the group and community level. What appeared to be missing from my framework was a key process that facilitated an awareness and shift in our own mental models that unintentionally impeded progress and prevented change from occurring.

Mental models are basically our cognitive frameworks, beliefs and assumptions that guide our decision-making and actions (Senge, 1990). As I reflect back on this, I can see how my own beliefs limited my ability to initially see the importance of this process in the research. I made the assumption that if individuals or a community wanted change and were committed to working for change, then it must also be true that individuals and the community would be ready and open to change. Because of my own limitations and experience with working in communities, I did not think to initially include the process of shifting mental models as a crucial component of facilitating community empowerment. However, during the research, I quickly became aware that our own perceptual filters hindered our progress in creating change. It appeared that key community transformations seemed to emerge from an awareness of our own flawed mental models and a shift in ourselves. In future research with communities, I plan to include "shift in mental models" as a sixth component to the framework for guiding my facilitation in participatory action research. 
In this section, I reflect on aspects of this component that I believe were critical to breaking the cyclical dynamics that resulted in the community feeling stuck in a disaffected state, and to leading the community toward positive transformational change and the next step down the pathway out of homelessness. The following examples identify what I believe to be the key shifts in awareness that opened up opportunities for real change to occur. I hope that the lessons learned over this year-long participatory action research project with respect to these key processes in facilitating empowerment may be useful to improving the quality and effectiveness of other community-based research projects that aim to build healthier and empowered communities. The aspects of the "shift in mental models" component that I found to be most relevant to this research include:

a. An openness to learning from others with different perspectives

b. A critical awareness of self and our interactions with others that create and/or perpetuate problematic social dynamics in the community

c. A shift from focusing on problems and the negativity in the community to focusing on potential solutions and strengths in the community

d. An awareness that the process of working together as a group is as important, if not more important, than just focusing on achieving the goal or creating the product (e.g., the orientation video) 
e. A shift in perception to seeing participation and cooperation as a developmental process where individuals (newcomers and long-termers) move from an "I" to "We" mentality

f. The use of systems thinking to analyze the community practices as a system and to identify and target multiple leverage points in the system to make the most impact

g. An awareness of how leadership structure impacts power differences and participation in the community

\section{Openness to Learning from Others with Different Perspectives}

According to many community researchers, the inclusion of diverse perspectives is critical to the quality and effectiveness of participatory action research (Greenwood \& Levin, 1998; Stringer, 1999). According to Greenwood and Levin (1998), groups commonly suffer from feeling stuck in a particular view of the situation, which in turn creates pessimism about the possibilities for change, thus limiting their ability to develop alternative courses of action that may be effective. This seemed to be a key process for shifting dynamics in the core research group to a more positive and supportive working context, which in turn helped to create real change in the community. PAR involves taking a deeper collective analysis of the reality of the situation in the community in order to change it, and the more homogenous the group, the more difficult it is to challenge the status quo and to force to the surface hidden assumptions and shared thinking in the group that limit a 
more multi-dimensional and accurate view of the problem (Gaventa \& Cornwall, 2001). Without challenging these status quo modes of thinking, there is danger that the existing power relations or social dynamics in the situation may simply be reinforced and perpetuate the problems being addressed (Gaventa \& Cornwall, 2001).

At first, there was resistance by the core group to increase the diversity of perspectives and to recruit more newcomers to the research group. This is when I first realized how entrenched the divide was between longer-term members of the community and newcomers. The exclusion of newcomers was a significant barrier to participation, and to forming positive social and working relationships with a diverse array of perspectives and approaches. I utilized several techniques to encourage diversity in the core group (e.g., setting up ground rules that supported dialogue and diverse perspectives, personally encouraging newcomers and others to participate in core group, interviewing and having informal conversations with community members who were not part of the core group to take new perspectives to the group, and interviews with core group members that encouraged reflection and tolerance of newcomers). Together, these processes seemed to have helped open the group to becoming more inclusive and supportive of newcomers participating in the research.

At the end of the research, many of the co-researchers stated that they had learned that they could work well with individuals whom they never expected to be 
able to work with before, and that they even learned to value different views because it challenged their own way of thinking. Without this change in attitude, I don't believe that that the other positive transformations that occurred in the community could have ever emerged as they had over time.

I observed the biggest impact on broader social dynamics and relationships when there were opportunities for the core group and community to come together and work with each other in an activity unrelated to routine community work. Creating the orientation video action tool was a unique and valuable process compared to the process of creating the other action tools. Villagers were already quite used to attending community meetings or participating on other working committees, so it was difficult to break the already established negative social dynamics. Because creating a video requires active participation by people with very diverse skill levels for a broad range of tasks (e.g., clapping the scene clapboard for each take, keeping extraneous people off-set, creating props, acting as an extra in a scene, memorizing lines and performing as a key actor, using the camera and audio equipment, among many others), the process required the participation of almost every person in the community, regardless of their perspective, skill set, or working style. I found the process of creating the orientation video to be a valuable vehicle for breaking down the established intergroup dynamics and for promoting team building, skills building, cooperation, and a sense of community and collective action. 


\section{Critical Awareness of Self and Interactions with Others}

Another key process that seemed to have positive impact on the community was an increased ability by co-researchers to see themselves as part of the system that they were "studying" and taking action to change. There is a natural tendency to separate ourselves from the problems that we see more broadly in groups and communities. During the first part of the research, co-researchers approached the research in a way that reflected their assumptions that their role as a core group was simply to solve the problem for the broader community system. However, one often can't be part of a system and not also part of the problem. Changing mindsets to view one's own actions as part of whole system can have an impact on other parts of the system and can create broad cultural change in a community (Ford, 2007; Foster-Fishman \& Behrens, 2007; O’Conner, 2007; Senge, 1990). This shift in awareness was important for allowing and promoting actual change in the community.

Consistent with research with communities, we found in this research project that honest and frank dialogue that made an effort to generate new knowledge and understanding about community life, and that occurred regularly in an on-going manner, challenged "frozen" and old mental models so that significant social change could take hold (Foster-Fishman \& Behrens, 2007). It is clear that change first begins within ourselves. 


\section{Role of Leadership}

Another lesson learned in this research was that leaders' ability to take on new roles and responsibilities such as change-agent, facilitator, and motivator had a major impact on the success of our change efforts. This lesson is consistent with what other community-based researchers have experienced (Ford, 2002; Kotter, 1990). Many researchers have noted the need for leaders to be willing to continually prepare the organization for what is to come next in the change process (FosterFishman \& Behrens, 2007). It was natural for leaders at Dignity Village to become more focused on pushing for the completion of urgent tasks, and thus losing sight of the value of building community capacity to support transformational change. What we learned was that leaders would burn out and become impatient and frustrated with how long it takes for successful and positive change to occur, and thus inadvertently perpetuate the same dynamic of negativity and "stuckness" that both the leaders and others in the community had been striving to overcome. When leaders understand that building capacity and change takes time and that patience is necessary to convince others in the community that the time investment is worthwhile for future outcomes, then long-term change has the chance to be successful.

\section{A Focus on Solutions Rather Than on Problems}

During the research, we became stuck when we focused too long on understanding the current situation and "problems" in the community. We wanted to 
be thorough about identifying all the potential problems, but as we spent more time discussing problems, I noticed an increase in tension and negativity in the core group and the community. Since the list of problems to solve in the community was becoming very lengthy, I decided to speed up the process by identifying the highest priority problems, and then shifting to focusing on possibilities for action and solutions to just those few problems.

What I observed was that the shift from focusing on problems to solutions did not come easily for the group. They suddenly seemed anxious and overwhelmed by this shift in thinking. They did not feel that they had the solutions, and so they were frustrated and stuck on the problems. It's a more natural tendency for people to complain and point out existing problems than it is to break free of the negativity, openly brainstorm, and shift to thinking about potential solutions. As a facilitator, I used several group exercises to attempt to reduce anxieties and promote creative brainstorming about possible solutions. As we got further into the brainstorming process, the group seemed to become more relaxed and enthusiastic about the process. I also noticed that when community members walked into the commons area during the research at these moments of brainstorming, they got caught up in the activity and participated in the meeting. I observed a positive change in attitude and dynamics when we began to focus on solutions and strengths of the community rather than on problems and community weaknesses. In general, these activities seemed to help increase positive morale of the core group and promoted dialogue in 
the core group, (and with others outside the core group) about ways to improve the community.

The Process of Group Learning is as Important as Achieving the Goal

During the research, we would often become stuck in negative dynamics as a group when we tried to push too quickly toward our goal to create the orientation video, rather than retaining our primary focus on group process. Because we had set up a process of inclusive participation, the arrival and departure of new individuals into the group (a common occurrence) necessarily slowed down progress toward the end goal of creating a video. This sometimes ignited more frustration from longerterm core group members toward those individuals who were beginning to get more involved in the research. Understandably, those who had been involved already had invested a lot of time in the research and wanted to make progress toward achieving their goal. As facilitator, I continued to emphasize the reasoning for encouraging this democratic and open process as being far more valuable to the end product than the resultant cost due to lack of efficiency. The challenge was in how to sustain commitment to the research and to achieving our goal when the democratic process slowed down progress significantly.

When frustrations and impatience were high, I attempted to shift the focus of the group from an outcome-driven to a process-driven focus. I did this by taking a small break from our weekly routine and research agenda, and used the time instead for group-building exercises. At first, the core group was a bit hesitant and resistant 
to these exercises or "breaks" from our agenda. But, at the end of each of these meetings, it seemed to make a significant difference in how individuals interacted with each other and perceived the value of group learning for creating an effective tool for change in their community. The core group became more relaxed, respectful and patient with one another. Over time, I saw the core group becoming more cohesive and cooperative and aware of the importance of group process. This was a key development, considering that this was one of the issues/barriers driving the community toward disempowerment and disaffection.

\section{Awareness of Participation and Cooperation as a Developmental Process}

At the beginning of the research, many Villagers had lost hope in Dignity Village, and had begun to see it as a failure. Long-termers in the community (especially those who had participated in the original political movement that made Dignity Village a legitimate entity) were frustrated with the lack of participation and loss of political awareness that once made Dignity Village an important changeagent in the struggle for social justice. As long-termers lost patience, newcomers and newer members in the community became a target of this frustration. And newer members also began to see Dignity Village as a failure because it was not following its mission of helping the homeless out of homelessness through a different helping model that was empowering, caring, and based on "love and respect." Long-termers wanted to protect Dignity Village from the "I" survival mentality of newcomers, where people had grown more focused on meeting their 
own needs rather than working together toward higher-order community needs. As a result, newcomers felt judged, controlled, rejected, and powerless in the community. It seems natural that the community would gradually develop divisions that were never present in the beginning days of Dignity Village. After several years, significant differences between residents created these deep divisions, increasing distrust and lack of cooperation and compassion between groups. When the research began, the community was struggling to break this negative dynamic and to take steps toward a community with a higher quality of participation, where people were willing and committed to doing their part, where Villagers worked together in cooperative, democratic, and supportive ways, and where Villagers participated in a community conversation on homelessness and on the history and future of Dignity Village, with a political awareness and a commitment to its future. Unfortunately, creating this desired change in the community was exceptionally challenging in practice.

A lesson that we learned during the research was that these divisions were perpetuated by the perception that individuals' attitudes, participation and level of empowerment were static personality traits that threatened the future of Dignity Village. As we began to diagram the community "participation" system and define the current policies and practices, there was a gradual shift in perception to seeing participation and cooperation more as a natural developmental process where individuals increasingly progress from an "I" to "We" mentality. This process in the 
research and shift in perception was critical to healing the divide between the groups, to seeing individuals in the "I" mentality as non-threatening and normal, to promoting tolerance and patience, and to understanding the importance of creating “supports" as a community for individuals to progress along this developmental pathway.

\section{Use of Systems Thinking to Identify and Target Multiple Leverage Points}

Before starting the research, individuals in the community saw the orientation video as the only leverage for change in the community. Although my belief was that the actual process of creating the video would be as important as the product itself in creating community change, the core group saw the product as the intervention rather than the process of creating it. The tool became artificially separated from community dynamics and interactions, leading to an initial feeling in the core group that "if we create it, they will come."

As we began the research, however, we saw the negative social dynamics in action within the core group, reflecting the broader problematic community dynamics leading to low morale and lack of participation. The divide in the core group, as between groups in the community, became overwhelmingly clear, and the idea of an orientation video as the sole solution was impractical for the kind of transformation the community had in mind. To be a successful tool, the creation of an orientation video needed to be directly enmeshed in and guided by the entire community processes and dynamics. 
All of the examples of shifting mental models mentioned in this section so far relate to perceptual changes by members of the core group, and I believe all were critical for effective community change. The process of creating the orientation video allowed for more interaction between the core group and the broader community, and a different type of leverage that had unique impact on the system. The group began to realize that multiple and diverse action tools were important to address problems that led to tensions, distrust, power struggles and community conflicts; without resolving these negative dynamics, no single tool would be able to create community change.

We learned that by utilizing multiple tools to target different parts of the system, we could better support and facilitate a natural developmental process that promoted personal growth as well as community growth. This is consistent with theories on systems thinking which remind us that a sole emphasis on a single part of the system is usually insufficient for sustained system transformation (FosterFishman \& Behrens, 2007). According to Foster-Fishman and Behrens (2007), "systems change happens when levers for change are targeted that can trigger shifts across system components" (p. 194-195). Community psychologists have found that targeting multiple and diverse levers was more successful in creating systems change (Campbell et al., 2007; Durlak et al., 2007; Emsoff et al., 2007; Ford, 2007; Foster-Fishman \& Behren, 2007; Kreger et al., 2007; O’Conner, 2007; Staggs et al., 2007; Suarez-Balcazar et al., 2007; Tseng \& Seidman, 2007). 


\section{Leadership Structure that Supports Participation and Equitable Power-Sharing}

During the research, I observed several small bursts of increased interest and participation by individuals in the community toward involvement in leadership positions. I expected these bursts of participation and enthusiasm for Dignity Village to be well-received and supported by the community and leadership, since this was the purpose of the research from the beginning. Instead, what I observed was resistance from leaders and distrust that this change in participation was "sincere." The leadership seemed to paradoxically want to protect the community from the possible disturbance of newer leaders emerging, which was clearly counter to the goals of the research in creating a more empowered and participatory community. Since the leadership was the one who had initially approached me about the participation problem, I never really expected this dynamic to be perpetuated when the positive changes that we were working towards began to occur as we had all hoped they would.

Understandably, though, an increase in participation adds some instability to the community and challenges to the leadership. More participation means adjusting to a change in social dynamics within the leadership, who in this case had been fairly cohesive for some time with fewer individuals participating in leadership. In most groups, new challenges arise when establishing new working relationships. New perspectives for leadership challenge existing practices and policies. As I became more aware of these issues, I began to see the importance of the leadership 
being more open to sharing power. I saw examples of this in the changes in Tim (Chairperson) toward the end of the research where he implemented a number of changes that opened opportunities for participation by newer members in leadership and on committees. These changes seemed to generate more empowerment and enthusiasm for participating in the community.

To increase community empowerment and participation, there must be a leadership structure that supports participation of newer members and allows for an equal sharing of power in the community. Without a change in perception among leaders to allow a more open structure, there will always be resistance to change that will significantly impact the state of the community and hinder its ongoing development.

\section{Credibility, Limitations, and the Final Report}

Judging the extent to which a qualitative research study is trustworthy and authentic is important to evaluating its worth (Guba \& Lincoln, 1994; Lincoln \& Guba, 1986). Lincoln and Guba (1985) developed criteria to assess trustworthiness and authenticity of qualitative research. In this section, I reflect on and discuss the quality of trustworthiness and authenticity of this research study with respect to Lincoln and Guba's (1985) set of criteria. 


\section{Evaluating Credibility and Trustworthiness}

In Chapter Seven, I describe in detail the series of techniques I carried out to establish credibility and trustworthiness of my research findings. Prolonged engagement, persistent observation, triangulation, peer debriefings, and member checks are activities that increase the likelihood that representations presented in the final research report are trustworthy reconstructions. This research involved prolonged engagement with, and persistent observation of, the community setting, Dignity Village. I joined the Dignity Village social movement as a supporter and organizational partner five years prior to the beginning of this research study. During the research, I met with co-researchers for at least half a day each week for approximately 15 months. During this time, I engaged in research meetings, conducted individual and group interviews, and observed community/organizational meetings (Dignity Village council and membership meetings). After the research, I have continued to be involved in the community, although my recent observations have not been as persistent and intensive as they were during and immediately following the PAR study.

In addition to prolonged engagement and persistent observation, I used data triangulation as a method for corroborating findings and testing for validity (Lincoln \& Guba, 1985) and the existence of consistent, distortion-free information (Denzin, 1978). For example, in this research, data were collected at different time periods and from different sources (different individuals with varying experiences and 
perspectives on the participation issue at Dignity Village). More than one method was used to facilitate deeper understanding of the participation problem in the community (observational field notes, video record of the group research process, individual interviews and organizational documents).

Peer review and debriefing are also advised for credibility (Lincoln \& Guba, 1985). This research involved more than one observer or investigator. As a cofacilitator of the research, Wendy reviewed my fieldnotes and reflexive journal and added her own perspective that challenged my bias, clarified my thinking, and provided me with a sense of consistency in the observations. Sometimes the review and debriefing resulted in a shift in my thinking and in the methodological approach for next steps.

Member checking (Lincoln \& Guba, 1985) is the ongoing process of testing the accuracy and meaning of the data collected and assessing the overall adequacy of the interpretation before the completion of the final version of the report. In the research, I constantly tested the accuracy of my interpretation of data during the research process with the core group and in interviews with individuals.

Transferability refers to how well the working hypothesis and findings of the inquiry might hold in other contexts (Lincoln \& Guba, 1985). To be transferable, the research report must contain extensive rich description of the issue, the place, the context, and the community culture to allow a reader to determine if transfer of the findings to another known context is possible. In the written portion of the 
research report, the context of the study and the characteristics of the participants were described extensively. Furthermore, the video portion of the research report provides rich visuals of the research context and environment as well as revealing the social dynamics in the research group and the interactions between myself and co-researchers from the community. Numerous video clips were provided to support findings and raise questions for future action and research in the community.

Confirmability addresses whether the findings and conclusions drawn are supported by the data (Lincoln \& Guba, 1985). To establish confirmability in this research study, data management and data analysis were documented in detail to provide an audit trail that traces findings through raw data, document evidence, interview summaries, data analysis, and methodological and reflexive journals. Related meta-data and analysis codes were stored for all data in the custom data analysis database. In this research study, confirmability was enhanced by keeping a reflexive journal of my procedures for checking and rechecking the data throughout the study, and keeping written and visual records of the process, including reflections, decisions and insights, to provide an audit trail for the possibility of an external audit that examines data collection and analysis procedures to judge the potential for researcher bias or distortion.

Finally, dependability is achieved by showing that findings are consistent and could be repeated (Lincoln \& Guba, 1985). During the research, I documented all methodological decisions in a log to create an audit trail for a dependability audit 
to allow a dependability assessment. In my fieldnotes and logs, I provided a detailed description of the specific processes that we undertook in the research, and the changes that occurred in the setting and how these changes affected the way we approached the research.

\section{Evaluating Authenticity}

Fairness and authenticity in research are established by confronting ethical and ideological issues that arise in research. Criteria for establishing authenticity have been developed by Lincoln and Guba (1986) that emphasize research processes that empower researchers and participants to gain a deeper understanding of their own and others' lives, and to take action to create more equitable social structures. Lincoln and Guba (1986) identified five dimensions of authenticity: fairness, ontological authenticity, educative authenticity, catalytic authenticity, and tactical authenticity.

In this research, I was committed to acting with fairness and authenticity, as demonstrated by my interaction with participants in the recruitment and research process, and in bringing the research findings back to the community in an accessible reporting style. My goal in working with the community was to facilitate the creation of a process that would assist them in creating a supportive and empowering environment more conducive to participating and engaging in community life. I intended the research report to provide insight and stimulate reflection and action towards continuous improvement in community life. The final 
PAR dissertation report was screened in the community to evaluate its accuracy, fairness, and authenticity.

\section{Fairness}

Fairness is the extent to which the research report reflects a balanced view and even-handed representation of all viewpoints (Lincoln \& Guba, 1986). I had documented a variety of perspectives during the research, interviewing all participants in the core group at least once. Interviewing was used as one way to member check in the process. For example, I interviewed participants who withdrew from participation in the community and from the research to gain insight into the processes that motivated individuals to participate or withdraw from the community and research. As part of the research process in the core group, member checking was a constant process to clarify understandings and viewpoints, and to encourage dialogue among these diverse participants. I used these multiple perspectives in the data to challenge my own thinking and interpretation of events and to represent a balance of perspectives in the report. The aim was to provide a fair representation of each opposing viewpoint in the community and to illustrate the complexity of the issue and how the dynamics between the two main opposing views in the community had impact on participation and morale.

\section{Ontological Authenticity}

Ontological authenticity refers to the extent to which the participants' own understanding and viewpoints are challenged, improved, matured, and extended 
over the course of the inquiry (Lincoln \& Guba, 1986). In this research, I attempted to set up a research environment and process that would promote learning and empowerment for all participants. Part of the process of learning and growth involved challenging our own perspectives through dialogue with individuals who had alternative views on the participation issue. The authenticity of the research process was evaluated at the end of each research meeting throughout the entire study. As a group, we reflected on and discussed how we could improve the research process in the next meetings.

Ontological authenticity was demonstrated by the growth of participants' perceptions as a result of their involvement in this research process. As a result of the inquiry, participants had an improved, more complete understanding of their impact in the broader community system. In the research, the act of defining processes and the system of participation in the organization helped raise understanding to a higher level of sophistication. Participants began to see the broader system, and the potential barriers and supports to increasing participation. This broader view of the system promoted self-awareness and critical consciousness in many participants. However, not all participants were able to see their own role in maintaining high levels of quality participation. Their growth was limited by a persistent view that others were to blame for the problem. Senge (1990) described this viewpoint as a common limitation to learning, and calls it the "enemy is out there" syndrome (p. 19). Senge (1990) writes, "The 'enemy is out there' syndrome 
is actually a by-product of...the nonsystemic ways of looking at the world that it fosters. When we focus on our position, we do not see how our actions extend beyond the boundary of that position. When those actions have consequences that come back to hurt us, we misperceive these new problems as externally caused" (p. 19). For the purpose of strengthening ontological authenticity, I continued to make efforts to encourage reflexivity among those participants who maintained this "enemy is out there" viewpoint, gently challenging belief systems in an attempt to expand understanding of the broader system.

\section{Educative Authenticity}

Educative authenticity refers to the extent to which individual participants understand and appreciate others' views (Lincoln \& Guba, 1986). In the research, participants in the core group expressed that they had learned a lot from the process about themselves, about others and about the community in general. Participants grew more confident in their ability to do research and make change in their community. They also said that they learned that they could work with diverse people in community that had very different viewpoints from their own. Furthermore, participants even learned to appreciate the alternative viewpoints in the community, seeing them as valuable to understanding the complexity of participation in the community. 


\section{Catalytic Authenticity}

Catalytic authenticity is the extent to which action is stimulated and facilitated by the inquiry process (Lincoln \& Guba, 1986). In the research, catalytic authenticity is demonstrated by the shift in willingness among participants to be involved in change. For example, the majority of participants in the core group became more engaged in the community, and even became involved in leadership positions in the community. This change in participation and engagement continued for at least four months after the research inquiry concluded. Moreover, catalytic authenticity is demonstrated by the spike in action among community members to get involved in leadership and to create change in the community by removing longterm individuals whom they saw as limiting the growth of the community.

The Dignity Village orientation video (one of the video-based action tools) was assessed for fairness and accuracy during the research, and in particular demonstrated catalytic authenticity. In making the orientation video, the core group defined their intended effect of the video on their audience (the Dignity Village community). The responses after watching the video supported all of their intended goals for many viewers. The core group wanted the video to light a fire under people, to motivate people to get more engaged and participate in the democracy and growth of the community, to stimulate dialogue, tolerance and understanding among different factions, and to arouse a sense of community and pride in being a Villager. Travis, a member of Dignity Village, commented, "I absolutely do think it 
will make a difference. If it can light a fire in my belly, in somebody like me, I don't know why it couldn't with somebody else because I'm not die-hard or anything. I have never been an activist in my life but seeing that has made me wanna do it." Keith, a newcomer to the community, stated that the video was "Lighting a fire and a passion. Seeing what the people fought for, the struggles they went through. For me, it made me want to get up and fight. Not only want to be here and be part of it, made me want to fight for it too."

And finally, strong evidence for catalytic authenticity and the impact of PAR is that, years later, Dignity Village continues to use the orientation video. It remains standard practice for the Intake Committee to show the orientation video to every new resident.

\section{Tactical Authenticity}

Tactical authenticity refers to the extent to which the stakeholders and participants are empowered to act (Lincoln \& Guba, 1986). In this research, tactical authenticity is demonstrated by the extent to which the community made changes in the leadership structure to redistribute power among members in the community. Over time, more individuals participated in leadership positions, including newer members and others who had previously withdrawn from participating.

\section{Research Limitations}

In reflecting on my research process, I identified several limitations in 
facilitating more positive and sustaining change in the community. In this section, I first explore the limitations of the research process in facilitating a sustainable process for the community. Second, I describe the limitations of the research process in creating unexpected outcomes that emerged from strengthening the cohesiveness of the core research group. Third, I summarize the challenges and limitations in creating a visual-text report for multiple audiences. And, finally, I reflect on a potential barrier and limitation of the research due to my own lack of insight into the importance of accepting conflict and paradoxes in community and group life.

\section{Limitations to Creating a Sustainable Process}

An important part of PAR and empowerment-based research is the ability of the community to sustain the collaborative research processes for a significant period of time without the assistance of the "outside" researcher-facilitator. The more the research is rooted in a community's values and practices, the more useful and valuable the research experience may be to their day-to-day problem-solving. In this research, I planned for termination and sustainability by encouraging individuals to take on different roles in the research process. Some of the roles that emerged during this research process included co-facilitating the group process, taking notes, keeping the time, and maintaining the list of individuals who would like to speak ("stack"). However, I observed that as the research progressed, core group members would trade off on keeping "stack," being a time-keeper or note- 
taker, but would shy away from facilitating the group work. Some individuals did not want to facilitate because they would lose out on stating their opinions and preferred to contribute more to the knowledge-making. Another reason I heard from some individuals for why they didn't want to facilitate was that the conflicts and tensions in the group made it more difficult for them to take on this role. As a result, they began to rely on us as outsiders to help them bridge the divide between groups and help them create processes to work together.

During the research, I continued to encourage but never pressured coresearchers to get more involved in facilitating the research. When I first realized that individuals were avoiding taking on this role, I considering requiring coresearchers to facilitate at least once during the research process as a way to promote reflection, skills-building and competence, but I reconsidered taking this direction because I thought such a structure might be perceived as controlling and thus potentially work against creating a context for the emergence of empowerment. In retrospect, I believe that I could have facilitated a more sustainable process rooted in a community's values and practices if I had articulated the value and importance of this role in transferring these skills to improve collaborative learning processes in broader community activities and organizational meetings. Dialogue about this topic may have released anxieties and concerns the core group members had toward learning facilitation skills. Improving facilitation skills could have 
helped community members foster increased openness, positive communication, democratic and collaborative learning, and change in their community.

Another way that I planned for the sustainability of the research process was by creating and giving to Dignity Village (and to each core group member) a Dignity Village Participatory Action Research Booklet that included the specific research processes in the collaborative group work and the specific steps involved in creating the action tools (see Appendix D). The PAR Booklet returned the research back to the community and even seemed to foster a sense of achievement from those who participated in the core group, but seemed be less useful as a tool for sustaining the research process. About a year after the research ended, I heard that the new Chairperson (who had not lived at Dignity Village during the time of the research) discovered the PAR Booklet tucked on a shelf in the office and he brought it to a Village meeting to talk about its continued value to the community. In the meeting, he held the folder in one hand as he told the community that he wanted to continue the work that had already been started with the research so that they could continuously improve as a community. Unfortunately, this was short-lived. Several months after his election, he was recalled from his Chair position, and the idea of using the action tools and PAR in the community processes seemed to have faded away.

In retrospect, my plan for sustainability lacked process. The PAR Booklet, although an important part of this plan, should not have been considered the key 
element to sustaining the process. I believe that I could have improved this process by involving core group members and other community members in developing good quality collaborative learning processes. Co-researchers and other community members might then have seen the value in applying practices to enhance communication, empowerment and democratic learning to the broader community and organizational practices. To address this limitation, I plan to screen and provide a copy of the Visual Text (video) to the community, and my hope is that the report will help to inspire renewed community dialogue and enthusiasm for improving collaborative learning practices in the community.

\section{Unexpected Outcomes of Increasing Core Group Cohesiveness}

Another lesson that I learned during the research was that my focus on increasing cohesiveness in the core group was effective but at the same time counterproductive to facilitating a broader sense of community and collective identity. Since the core group, although small, maintained enough diversity with respect to residency status, I believed that the social dynamics in the group were an accurate reflection of the broader community conflicts and divisions. I believed that by increasing the cohesiveness of the core group, these new relationships and skills at collaborating might transfer over to improve broader community dynamics. However, as the research progressed, I observed that if the core group spent too much time working together in relative isolation to the community (e.g., not finding ways to involve the broader community in research), then the core group appeared 
to become more divided and frustrated toward community members who were not part of the core group.

I also noticed that another split occurred toward the end of the research when only certain individuals from the core group participated in the weekend retreat (where they stayed up at our farm, camped out, and worked as a group to select video clips to include in the orientation video). This smaller subgroup of the core group became closer during the retreat, felt more connected, but also expressed frustration that other core group members seemed not to be as committed to the project because they didn't take part in the retreat experience. This split became quite obvious in the core group interactions during the following meeting.

What seemed to happen was that the boundaries of the groups kept changing, but the research process did not really address the underlying tensions or source of the problems that created this divide and split in the community in the first place. The first time I noticed it happening was during the first phase of the research when the core group had been working together for a couple of months before even attempting to involve the community (even though the core group was always open to the broader community for anyone to participate). The first time the core group asked community members to provide input to the research, many community members were reluctant to get involved, resulting in more negativity and a bigger divide between the core group and community. As I observed this happening, I attempted to address this limitation by planning more opportunities for community 
involvement in the research. It seemed that activities and events that were less emotionally arousing or related to "solving" or talking about community issues offered important and unique opportunities for positive relationships and cooperative behaviors to develop between the core group and community. Before starting the production phase of the research for the orientation video, we got the community involved by offering a filmmaking workshop. The filmmaking workshop seemed to be effective in beginning to break down group barriers that had been established over time. In general, as the research progressed, the process of creating the orientation video opened up valuable opportunities for building a broader sense of community. In retrospect, I should have utilized regular and more "neutral" community building activities during the research in an effort to strike a balance between group cohesiveness and isolation.

\section{Challenges to Creating a Visual Text Report for Multiple Audiences}

When I created the Visual Text Results section, I had three specific audiences in mind for this section of the report: (1) academics from multiple perspectives who are attempting to understand and conduct research on homelessness, (2) the Dignity Village community, and (3) my $\mathrm{PhD}$ dissertation committee (the report must address specific academic requirements relating to the fulfillment of a doctoral degree at PSU). Broadening the accessibility of the research to reach diverse audiences with one report has clear benefits. However, with this broadening, there are trade-offs in tailoring the video to the sometimes competing priorities of each audience. 
One example of a competing priority that I mentioned earlier in this report involved focusing on care for the community (protecting the community from potential harm), at the same time as maintaining transparency in an academic report (revealing potentially harmful incidents relevant to the research questions). Clearly, there is no simple guide for how to resolve these dilemmas, only that they must be kept in mind and constantly negotiated during the creation of the report.

As I created the Visual Results section, I took special care to address these competing priorities. Before creating the video, I thought that I would have to exclude a variety of video clips in an effort to protect participants in the research who still reside in the community. But once I began creating the Results video, I found that this was not such a big issue after all. There were only a few video clips that I excluded to protect an individual, and typically those clips were when individuals used specific examples and names of people in the core group or community to express their frustration or negativity about that person. In all of the instances when a clip was excluded, I was able to include a clip of the same individual expressing the same message but in a more general way about social dynamics, without using names or specific events. In one case with an interview with co-researcher Laura, I retained a clip in which she refers to another coresearcher, Chelle, as an example of how certain ways of approaching people in the community are not motivating as intended but actually have the opposite effect. I left this clip in because, in this case, Laura did not simply judge Chelle's approach 
as "bad," but rather, she reflected on Chelle's point of view and then found some similarities between her behavior and Chelle's behavior.

I faced another challenge in creating the Visual Text Results report for diverse audiences when I began to select visuals of the community to illustrate my narration and interpretation of the research processes and outcomes. As I selected visuals to pair with specific parts of my narration that described negative social dynamics, tensions, and lack of participation, I realized that I faced another important editing decision. For the greatest impact, visuals should directly illustrate the message being narrated. However, if the narration was specifically pointing out negative traits, I did not want to show visuals of any one particular individual, or of specific instances with individuals. I had two main reasons for this. First, I do not believe that it is ethically acceptable for individuals to be deliberately selected as specific "examples" to illustrate my narration, particularly when describing specific negative traits. In video editing, placing clips of individuals over narration lends the visuals more relevance or "truth" than might actually have occurred in reality, as if my narration was specifically talking about that particular incident or person shown visually. Second, the intention of my narration was to provide a more general understanding of community and group dynamics and how it contributed to participation, rather than pointing out problem personalities or specific individuals.

To address these concerns, I decided to select general video clips of the Dignity Village environment to illustrate my narrative (e.g., broad scenes of the "natural" 
environment from a wide perspective, such as people walking through the community, into their houses, talking in groups, etc). As a result, the narration is a bit more difficult to follow because it feels less directly connected to the visuals. My narration may have less impact on audiences, but in the end, I found it more important to protect individuals from potential harm.

Another major challenge that I faced during editing the Visual Results section for multiple audiences dealt with the issue of the accessibility of the report to my community partner. I realized that presenting the Visual Results section (video portion) without an overview of the research as part of the video created a barrier for my community partner to understand and join in the dialogue about this research. I tried to keep my community partner in mind as an audience as I wrote the text portion of my dissertation report, but when I thought about it realistically, how many non-academic individuals would take the time to read such a long and extensive written report? The more I reflected on this issue, I began to see this as a real limitation of the Visual Results section. If I kept the Visual Results as the only video section of the research, I believed that I would risk losing its potential impact on the community as a learning tool to incite dialogue and continued improvements in the community. Therefore, I added a new visual text chapter (Chapter Eight) that provides an overview of the research prior to the Visual Results section. I found this to be a great learning experience for me with regards to how to engage and include 
my community partner in the dialogue around issues of homelessness, their community, and the research.

Despite the challenges and limitations of addressing competing priorities inherent in communicating to diverse audiences, I found that there was real value in sacrificing depth in order to traverse the more expansive terrain necessary to connect diverse audiences. Creating a report for diverse audiences forced me to focus on the essential elements and core messages that I wanted to communicate, which perhaps helps to create a more effective report in the end. I believe that the format of this research report sustains the original commitment and goal of the research to create processes to sustain the growth and empowerment of Dignity Village. With a report that is more engaging and accessible to the community, Dignity Village can use the report as a tool to adapt PAR as part of ongoing collective efforts to improve their community.

\section{Conclusions and Future Research}

To summarize, the state of the Dignity Village community during and after this participatory action research project appeared to have gradually transformed into a more empowered and empowering community, with an increase in:

- Positive morale

- Participation

- Sense of community

- Critical consciousness

- Collective action in politics inside and outside of community 
- Supports for participation and democracy (especially for newcomers), and

- A leadership structure with more equitable power-sharing

In spite of this, within three months after the research ended, a large group in the community utilized coercive and undemocratic processes to create a drastic change in the leadership structure. It was not clear to me whether the community would sustain the newly improved and empowered state in the community or whether they would again fall back to a disempowered state.

I would like to think that what participants learned in the research about themselves and about collaborative learning processes would continue to help the community get through the inevitable conflicts and growing pains, but the challenge with Dignity Village is that already, many of the individuals who participated in the research no longer reside at Dignity Village. So my hope is that the accessibility of this report, using video to disseminate the "results" of this research, will allow a format for those community members who were not directly involved in the research to learn about the processes and experiences, stimulating dialogue and continued growth within the community. The orientation video continues to be used at the Village, even three years after the research has ended, providing a "standard" message of Village ideals and philosophy to incoming residents. I hope that the video results and the other documented action tools provided in this research report will also serve as useful templates across "generations" of leaders and members of 
the community in managing and understanding community dynamics at Dignity Village and similar communities.

\section{The Developmental Pathway Model}

I began this dissertation with a description of a developmental pathway model for moving out of homelessness, and I would like to summarize its direct impact on the research and the broader implications as a societal model for ending homelessness. The model served as a useful framework for my research, and helped guide the research process and creation of the orientation video in promoting community empowerment as a developmental process. The model was applicable to the developmental processes for residents, as they got more involved in Dignity Village. For example, long-term community members began to see participation as a developmental process for individuals in the community. Through dialogue with newcomers in the research, long-termers learned that newcomers had to meet their basic and psychological needs first, before they could become interested in gaining an awareness of their socio-political context and becoming active in the political aspects of Dignity Village. The research group began to acknowledge that increased participation and empowerment took time for newcomers and that Dignity Village as a community was needed to provide supports to newcomers in moving along the pathway. This new awareness and understanding helped increase tolerance and patience toward newcomers and motivated long-termers to identify and begin to create additional stepping-stones for individuals to progress in the community. 
Quality participation was dependent on supporting individuals as they gained skills, learned about the community, developed relationships, and joined the community as a responsible and active member.

This research identified some of the barriers on the developmental pathway model that blocked the community from becoming more empowered, such as internal divisions and conflicts, lack of shared vision, and low morale and participation. Further empirical research is needed to characterize the variety of processes and barriers that create these "crises" (see Figure 1j, lines 1, 2, and 3) along the pathway, and to suggest effective actions and interventions to break through the barriers toward social change (Figure $1 \mathrm{j}$, line 4). The barriers and processes that are identified in research can further illuminate the pathway for researchers, practitioners, communities and organizations that are pursuing social justice and long-term social change to end homelessness.

Even now, in the current socio-political context of homelessness, I believe the developmental pathway model remains relevant and useful. Since 2005, at the beginning of this research, the socio-political response to homelessness has changed fairly significantly. During the Obama administration, there has been a shift in focus from short-term fixes to long-term changes to end homelessness. While the Bush administration endorsed the idea of creating a ten-year plan to end homelessness and challenged 100 cities to create such a plan, the Obama administration went further. On June 22, 2010, the Obama administration unveiled the first national strategic 
plan to prevent and end homelessness by 2020. Opening Doors: The Federal

Strategic Plan to Prevent and End Homelessness creates a roadmap for

collaborative leadership at all levels of government to end chronic and veteran

homelessness in five years, and among families, youth, and children in ten years.

The plan focuses on five main areas: 1) increasing leadership, collaboration, and

civic engagement, 2) increasing access to stable and affordable housing, 3)

increasing economic security, 4) improving health and stability, and 5) retooling the homeless crisis response system.

Figure $1 j$. Focus of PAR: overcoming blockages in moving from a home-base to an empowered tent city community.

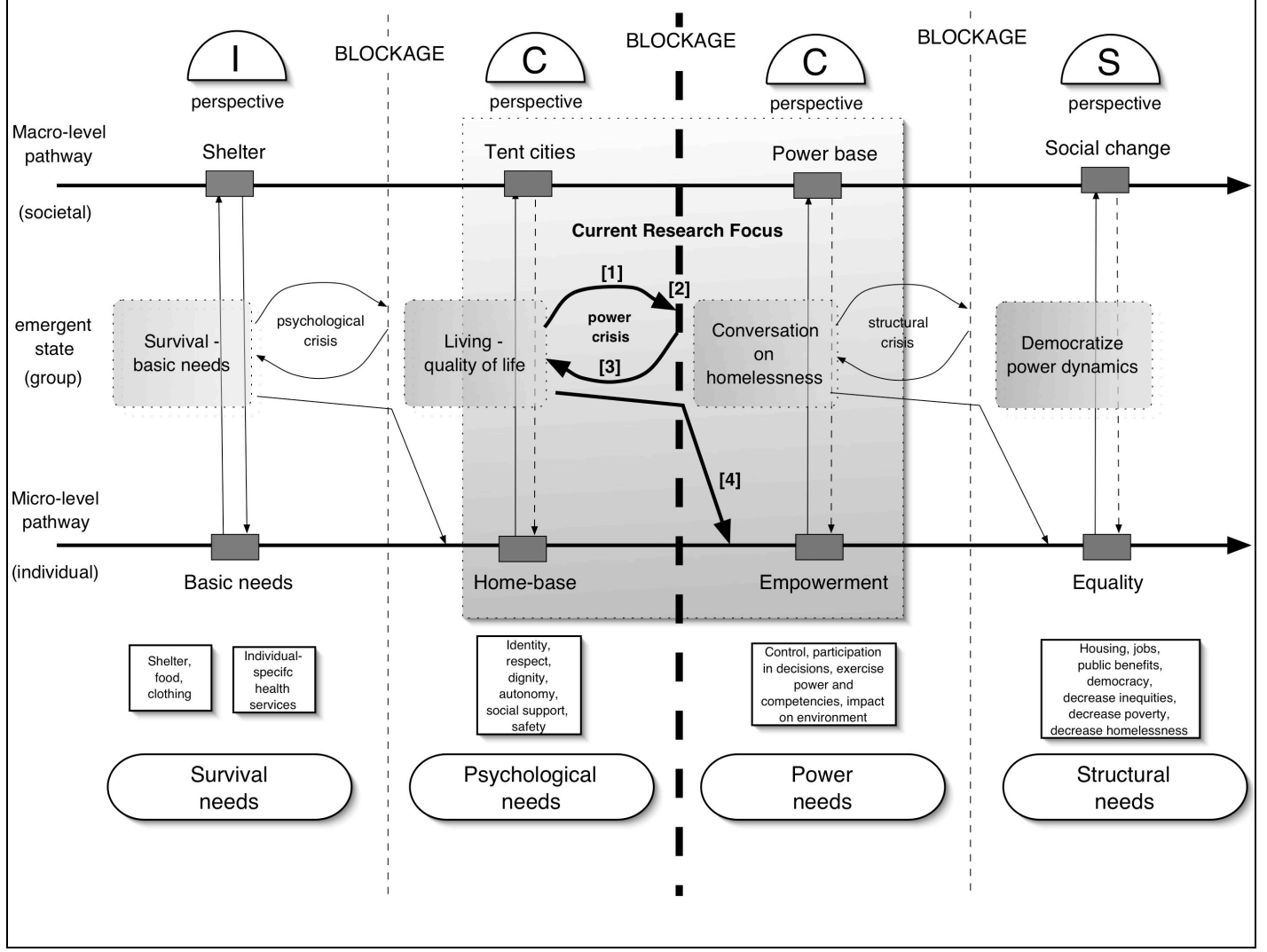


This responsiveness from the top-down is significant, and if maintained, will likely help to resolve the situation much faster than a pure bottom-up approach. This Democratic administration is more likely than a Republican administration to be a part of a larger power base among homeless advocates, but the economic recession also means that more and more people are on the edge or themselves homeless, creating a rising tide of people who are concerned about these issues and who want to find ways to end homelessness altogether. My developmental pathway is perhaps a step toward understanding the variety of factors that contribute to the intractable problem of homelessness.

As the National Alliance to End Homelessness notes on its website, "for the first time in two decades, communities have a plan and homelessness is a problem with a clear solution." While this newly energized top-down approach and roadmap from policymakers and government is promising, the national roadmap does not clearly indicate how homeless people themselves can be part of the solution. Alternative community-based models such as Dignity Village currently have no place on this road map. Furthermore, more than 300 communities around the country have developed Ten-Year Plans to end homelessness, but nearly two-thirds of those focus almost exclusively on the those people experiencing chronic homelessness (Interagency Council on Homelessness website: http://www.ich.gov/). This research with Dignity Village and the developmental pathway to end homelessness can help to advocate for continued steps that are humane, dignified, 
and pragmatic, and that focus on ending all kinds of homelessness by supporting the developmental steps necessary for people to move out of homelessness. While the allocation of funds may be shifting to support solutions, perceptions still remain the same about solutions coming from the bottom up, directly from homeless people themselves. We must continue to work to change society's perceptions of homeless people, approaching the end to homelessness as developmental steps where society provides support for people to move through developmental stages on their way out of homelessness, rather than as a pure provision of services at federal, state, and community levels without the direct participation by the homeless themselves.

Future research would involve further development of the pathway model to determine the specific processes and barriers at each step and at various levels to help elucidate how we might provide interventions and supports to people moving along this pathway. Such research would lead to understanding and promoting the processes involved in community capacity building to expand a large enough power base to take the next step on the pathway out of homelessness toward broader social change. 


\section{POST SCRIPT}

As a continued supporter of Dignity Village since the end of the research (more than three years ago), I have had the fortuitous opportunity to observe the community as it has changed over time. From my brief observations, in 2010, Dignity Village appears to have successfully moved to the next step on the developmental pathway toward a more empowered and empowering community. My continued observations of the community are of course casual and not a part of continued research, but nevertheless represent intriguing "point-in-time" observations of community development.

The community has become more politically active in the conversation on homelessness and has increased their power base and support network in the broader Portland community toward promoting more respectful, dignified, and humane housing models to address homelessness. For example, in July 2010 the Village participated in an Iron Tribe event at Pioneer Square raising funds and awareness for people living in poverty. Some Villagers connected with Oregon State Senator Chip Shields and convinced him to allow them and supporters to present a proposal on Aug 26, 2010 for creating a second Dignity Village-type community in Oregon. Over the past year, several Villagers have consistently been attending and actively participating in the monthly Coordinating Council for Ending Homelessness, a community planning group of social service agencies and local citizens who meet to provide feedback on implementing the City's Ten-Year Plan to End Homelessness. Over the past three 
years, the Village started a Facebook page and updated their website with the help of a local volunteer, and they are continuing to work with the City to update and renew their contract to manage the Sunderland Yard site as a transitional campground.

Physically, the Village has continued to grow and update their community, with the addition of a greenhouse built with the assistance of local schools. Many of the houses now feature beautifully painted murals as part of the Dignity Village Mural Project by the Wooster Collective which links local artists with Village residents to paint murals on the sides of their houses. The Village connected with Greenbox Designs, a local eco-friendly designer of pre-fab housing kits who is donating a 12'x16' unit to replace the Village's very run-down office trailer. Although funding remains a big hurdle for the Village, they have continued to work on expanding their microbusinesses, selling items at their weekly yard sales, raising and selling nursery plants, running a hot-dog cart (Dignity Dogs) and a coffee/pastry stand near the Sellwood Bridge bike path.

Internally, progress is somewhat harder to monitor, particularly since we hear a variety of opinions and information but have no way to be sure what is truly accurate, since we do not live there and cannot observe the nuances of events and behaviors directly. Still, in general there do seem to be positive changes. In the past 6 months, there have been several attempted recalls of the Chairperson. This may be an indicator of an organization with non-oppressive leadership, where individuals feel empowered to exercise their democratic rights to recall leadership with whom they disagree. This 
is in comparison to the general sense during the research, when individuals did not use recall procedures to remove leadership because a) there was a lack of collective action and cohesion on issues, with people fearing that no one would really end up voting for change in the end, and b) individuals were afraid of the consequences of voting against leadership, believing that there would be retaliation by leaders if they were voted against.

On the other hand, the numerous recall attempts could also be seen as negative, limiting the effectiveness of working together to improve the community, similar to the bipartisan bickering in the US Senate and Congress which limits the effectiveness of legislating and governing. Are Villagers feeling empowered to attempt to change leadership as often as they disagree with something, rather than trying to negotiate and work with other viewpoints to find a general compromise? In the words of a former Villager, "everyone here by definition is a rebel and hates authority." Finding an effective leader who can manage a group who lives by that definition is a significant challenge. It is a positive sign that the democratic processes set in place at the Village seem to be at work, but democracy is a messy process full of fits and starts, and its success or failure may best be viewed from a distance and over a longer period of time.

One conclusion that I can draw from my observations of Dignity Village over the years is that a leadership skills program would seem likely to provide significant benefit. With a transitional population, the quality of available leadership is dependent 
on who happens to be a current member and willing to take on the job, without any training or transition. The system is set up to be more about power than effective leadership. Without any training or network to transition between leaders, each year starts out completely from scratch, rather than building on what previous leaders have accomplished or set in place. Obviously, each new set of leaders brings particular ideas and approaches, but a general leadership skills seminar would at least make it unnecessary to prevent relearning the Village's basic democratic processes with each new election. 


\section{ENDNOTES}

${ }^{\mathrm{I}}$ We Need a Tent City (by Jack Tafari in October 2000 issue of street roots)

Winter will soon be upon us, homeless people, and it is time to begin thinking about getting ourselves a sanctioned campsite. Sleeping in doorways, under bridges and in parking lots, concealing ourselves in shrubbery in parks and in back yards, this is not so bad on warm, dry summer nights. But shivering all night in a TPI blanket under the marquee of the Guild Theater in February is not nice at all. Seattle has a tent city. Los Angeles had one fourteen years ago called Justiceville and it evolved into Dome Village. Portland needs a tent city now.

The missions are not an option for many of us. The missions are crowded and the lines are long. Many of us prefer sleeping on the streets to the sanctimony we often encounter in the missions, many find the missions too regulated and New Testament Christianity is not everyone's religion.

Not that the missions do not provide some good services. They provide clothing for those who need them. They provide showers which, though woefully inadequate for those who work, are often the only showers many of us are able to get. And they feed a lot of hungry people. But many of us resent the force-fed humble piety that often goes along with the meal. Often it seems that the missions create a kind of dependency, a client/provider cycle that many homeless people seem to get stuck in and never seem able to break.

A sanctioned campsite would provide a place where we could store our things, it would give us a break from the constant hassle and harassment we get living on the streets. We could regulate our campsite ourselves. Once we had that break we could go about our business, deal with whatever we have to deal with. It is not easy getting and holding a job when you live on the streets. The respite a campsite would give us would allow us all to improve our livity and condition, it would allow some of us to get the steady jobs that would get us up out of homelessness.

Street dwellers in India do not push around shopping carts with their belongings in them. They have dharamshalas, campsites where they keep their things and get on with their lives. It is the same in Rio where people who would otherwise be homeless have their favellas, on the outskirts of Capetown in South Africa people have their Crossroads. Homelessness is a Third World feature that has attached itself to a developed country and it is not going away. Other cities in this country have their sanctioned sites. Portland needs a sanctioned tent city now.

We need showers open between 6 am and 6 pm like the ones at Compass Center in Seattle where working homeless people have a greater window of opportunity to get a daily shower. We will get these in time if we work toward getting them ourselves. We need a lot of things. But first we need a sanctioned campsite.

We at street roots are just now putting together a campaign for a sanctioned site. Let us capture a piece of fallow ground if necessary and hold it for ourselves for doesn't the Bible say that the earth is the Lord's and the fullness thereof? We urge all homeless people and activists interested in getting a sanctioned campsite to drop by the street roots office or to phone us at 228-xxxx.

Out of the Doorways by Christmas (by Jack Tafari, staff writer, in November 2000 issue of street roots)

Have you heard the good news, homeless people? We are coming out of the doorways, coming out from under the bridges. We are setting ourselves up a tent city. We are coming in from the cold.

We homeless people in Portland, Oregon, have initiated a campaign to get ourselves out of the doorways by Christmas. The first organizational meeting of our campaign, Out of the Doorways, was held on Oct 12, 2000. It was well-attended. At that meeting we set up our legal, media and fund-raising teams. We are looking for a piece of fallow public land.

In the wake of the landmark decision of Sept 27, 2000, by Multnomah County Judge Steven Gallagher, who ruled unconstitutional Portland's nineteen-year-old camping ban, we homeless people 
have decided to set up a tent city here in Portland. We are hoping to get official sanction for this site. We intend to first set up a sanctioned tent city, which we will then shore up and permanentize. We shall rely on our own creativity and abilities. Ultimately, if left to our own devices and with the goodwill of our neighbors, we shall build a self-sustaining community in tune with the natural environment, along the lines of the Dome Village/Justiceville community in Los Angeles, complete with gardens, vineyards, and orchards. Our vision and ultimate goal is to begin building the new Jerusalem, a new Mount Zion, right here in Portland, Oregon. This is our ultimate goal.

Right now we need to get ourselves out of the doorways, out from under the bridges and into a tent city. We of the Out of the Doorways campaign are mobilizing toward accomplishing this first step by Christmas, 2000. We need shelter and a secure place to store our things. There is much work to be done. We know that the only way we will get these things is that if we get them ourselves. We appreciate all solidarity and support in the community, be it informational, financial or technical. Come to our fourth organizational meeting at the Martial Art Gallery on Thursday, Nov 9, 2000, between 6 and 8 PM. The Martial Art Gallery is located at 18 NW Third Avenue near Burnside. We want to hear from all good people in the community, homeless and otherwise.

Contact us at outofthedoorways@streetroot.org or phone us at (503) 228-5657. Or stop by street roots, 1231 SW Morrison, Portland, Oregon 97205. Everybody is welcome.

ii The Out of the Doorways campaign to form a tent city in Portland, inspired by the operation of Dome Village in Los Angeles, was initiated by street roots staffers Jack Tafari, Bryan Pollard, Remona Cowles and Brent Snyder in September 2000. The campaign quickly grew support and involvement from many organizations, including City Repair Project, Outside In, Bethel African Methodist Episcopal Church, Sisters of the Road Cafe, Martial Art Gallery, JOIN, Transition Projects, Inc. and the Oregon Law Center, not to mention hundreds of individuals, businesses, churches, and schools (Pollard, 2001).

iii When the city recognized the dilemma of finding land for the Village, they gave Dignity Village the choice to either disband or pay rent of $\$ 2,000$ each month (the funds they were losing with the resulting smaller space for compost which the City sells to its residents). A supporter paid rent to the city so that Dignity Village could remain on the space until July 2002. In 2004, the Sunderland Yard site where the Village is located was designated an official "transitional campground" by the City. There are current negotiations between Dignity Village and the City on a contract that would allow the Village to remain on the property as managers in exchange for services provided to the City's homeless population, among a set of other conditions.

${ }^{\text {iv }}$ Resident status is different from membership status at Dignity Village. Residents are individuals who are granted residency by the intake committee, and who then have access to the whole village (including working on security), but they do not have voting rights on a committee or in Village meetings. Membership status offers individuals the important right to vote and to serve in leadership positions, but at the same time, imparts individuals with more responsibilities as a core part of the community.

v “HATE, VIOLENCE, AND DEATH ON MAIN STREET USA, 2005 Annual report,” National Coalition for the Homeless, February 2006

Summary of Hate Crimes/Violence Data for 1999-2005:

Total number of violent acts over 7 years: 472 
Total number of deaths over 7 years: 169

Total number of non-lethal attacks over 7 years: 303

Number of cities where crimes occurred over 7 years: 165

Number of states where crimes occurred over 7 years: 42 states plus Puerto Rico

Age ranges of the accused/convicted: from 11 to 75 years of age

Age ranges of the victims: from 4 months old to 74 years of age

Gender of victims: male: 358 female: 48

${ }^{v i}$ The waiting list for entry into Dignity Village has fluctuated in length over the years. Over the past two years, the waiting list has become smaller and smaller. Some Villagers have heard that the word on the street is that the Village is "hard-ass" with all their rules and all the work that they require. A year ago, when Wendy and I were interviewing on the street, we asked several people experiencing homelessness what they had heard of Dignity Village. They said that they would never go out there. They had heard that Dignity Village was unsafe with a lot of drugs and violence. Another few people had never even heard of Dignity Village. 


\section{REFERENCES}

Adler, P. A., \& Adler, P. (1987). Membership roles in field research. Qualitative Research Methods, Volume 6. Newbury Park, CA: Sage.

Alexander, B. K. (2005). Performance ethnography: The reenacting and inciting of culture. In N. K. Denzin, \& Y. S. Lincoln (Eds.), The Sage handbook of qualitative research, third edition (pp. 411-442). Thousand Oaks, CA: Sage.

Amster, R. (2002). Spatial anomalies: Street people, sidewalk sitting, and the contested realms of public space. Unpublished doctoral dissertation, Arizona State University.

Anderson, G. L. (1998). Toward authentic participation: Deconstructing the discourses of participatory reforms in education. American Educational Research Journal, 35(4), 571-603.

Anderson, I., \& Christian, J. (2003). Causes of homelessness in the UK: A dynamic analysis. Journal of Community and Applied Social Psychology, 13, 105-118.

Andrus, G., \& Ruhlin, S. (1998). Empowerment practice with homeless people/families. In L. Gutierrez, R.J. Parsons, \& E.O. Cox (Eds.), Empowerment in social work practice: A sourcebook (pp. 110-129). Pacific Grove, CA: Brooks/Cole.

Arnold, K. R. (2004). Homelessness, citizenship, and identity: The uncanniness of late modernity. Albany, NY: State University of New York Press.

Balcazar, F. E., Garate-Serafini, T. J., \& Keys, C. B. (2004). The need for action when conducting intervention research: The multiple roles of community 
Participatory Action Research

References 362

psychologists. American Journal of Community Psychology, 33(3/4), 243252.

Balcazar, F. E., Keys, C. B., Kaplan, D., \& Suarez-Balcazar, Y. (1998).

Participatory action research and people with disabilities: Principles and challenges. Canadian Journal of Rehabilitation, 12, 105-112.

Beal, D. J., Cohen, R., Burke, M. J. \& McLendon, C. L. (2003). Cohesion and performance in groups: A meta-analytic clarification of construct relation. Journal of Applied Psychology, 88, 989-1004.

Berger, P., \& Luckman, T. (1967). The Social Construction of Reality, London: Allen Lane.

Biswas-Diener, R. (2002). [Subjective well-being of DV residents compared to homeless living on streets]. Unpublished report for Dignity Village, Portland, OR.

Blasi, G. L. (1994). And we are not seen: Ideological and political barriers to understanding homelessness. American Behavioral Scientist, 37, 563-586.

Blau, J. (1992). The visible poor. New York: Oxford University Press.

Bonal, X. (2000). Interest groups and the stake in contemporary Spanish education policy. Journal of Education Policy, 15, 201-216.

Bond, M., \& Keys, C. (1993). Empowerment, diversity, and collaboration:

Promoting synergy on community boards. American Journal of Community Psychology, 21(1), 37-57. 
Boog, B. W. M. (2003). The emancipatory character of action research, its history and the present state of the art. Journal of Community \& Applied Social Psychology, 13, 426-438.

Bradbury, H., \& Reason, P. (2001). Conclusion: Broadening the bandwidth of validity: Issues and choice-points for improving the quality of action research.

In P. Reason, \& H. Bradbury (Eds.), Handbook of action research:

Participative inquiry \& practice. Thousand Oaks, CA: Sage.

Buck, P. O., Toro, P. A., \& Ramos, M. A. (2004). Media and professional interest in homelessness over 30 years (1974-2003). Analyses of Social Issues and Public Policy, 4(1), 151-171.

Burstein, P. (1999). Social movements and public policy. In M. Giugni, D. McAdam, \& C. Tilly (Eds.), How social movements matter (pp. 3-21). Minneapolis, MN: Minnesota Press.

Burt, M. (1992). Over the edge: The growth of homelessness in the 1980s. New York, NY: Russell Sage Foundation.

Campbell, C., Nair, Y., \& Maimane, S. (2007). Building contexts that support effective community responses to HIV/AIDS: A South African case study. American Journal of Community Psychology, American Journal of Community Psychology, 39(3/4), pp. 347-364.

Casanova, R., \& Blackburn, S. (1996). Each one teach one: Up and out of poverty memoirs of a street activist. Willimantic, CT: Curbstone Press. 
Charmaz, K. (2005). Grounded theory in the $21^{\text {st }}$ century: Applications for advancing social justice studies. In N. K. Denzin, \& Y. S. Lincoln (Eds.), The Sage handbook of qualitative research, third edition (pp. 507-536). Thousand Oaks, CA: Sage.

Chase, S. E. (2005). Narrative inquiry: Multiple lenses, approaches, voices. In N.K. Denzin, \& Y.S. Lincoln (Eds.), The Sage handbook of qualitative research, third edition (pp. 651-680). Thousand Oaks, CA: Sage.

Chavis, D. M., \& Wandersman, A. (1990). Sense of community in the urban environment: A catalyst for participation and community development. American Journal of Community Psychology, 18, 55-81.

Checkoway, B., \& Zimmerman, M. A. (1992). Correlations of participation in neighborhood organizations. Administration in Social Work, 16(3-4), 45-46.

Christian, J. (2003). Homelessness: Integrating international perspectives. Journal of Community \& Applied Social Psychology, 13, 85-90.

Clapham, D. (2003). Pathways approaches to homelessness research. Journal of Community \& Applied Social Psychology, 13, 119-127.

Cohen, M. B. (1988). Social work practice with homeless mentally ill people: Engaging the client. Social Work, 34, 505-509.

Cohen, C. I., \& Sokolovsky, J. (1989). Old men of the bowery: Strategies for survival among the homeless. New York: Guilford.

Cohen, C. I., Teresi, J., Holmes, D., \& Roth, E. (1988). Survival strategies of older homeless men. Gerontologist, 28, 58-65. 
Cohen, M. B., \& Wagner, D. (1992). Acting on their own behalf: Affiliation and political mobilization among homeless people. Journal of Sociology and Social Welfare, 19, 21-40.

Connell, J. P., \& Wellborn, J. G. (1991). Competence, autonomy, and relatedness: A motivational analysis of self-system processes. In M.R. Gunnar, \& L.A. Sroufe (Eds.), Self processes and development: The Minnesota symposia on child development, volume 23 (pp. 43-77). Hillsdale, NJ: Lawrence Erlbaum Associates.

Coser, L. (1956). The Functions of Social Conflict. New York: Free Press.

Cottrell, L. S. (1983). The competent community. In R. Warren, \& L. Lyon (Eds.), New perspectives on the American community. (pp. 398-432). Homewood, IL: Dorsey.

Cowles, R. (2000, October). Camping ban overturned. Street roots. Retrieved April 7, 2006, from http://www.outofthedoorways.org/articles/04.html.

Deci, E. L., \& Ryan, R. M. (2000). The what and why of goal pursuits: Human needs and the self-determination of behavior. Psychological Inquiry, 11(4), 227-268.

Della Porta, D., \& Diani, M. (1999). Social movements: An introduction. Malden, MA: Blackwell Publishing.

Denzin, N. K. (2003). Performance ethnography: Critical pedagogy and the politics of culture. Thousand Oaks, CA: Sage. 
Denzin, N. K., \& Lincoln, Y. S. (Eds.). (1994). Handbook of qualitative research. Thousand Oaks, CA: Sage.

De Ollos, I. Y. (1997). On becoming homeless: The shelterization process for homeless families. Lanham, MD: University Press of America.

Dick, B. (2001). Action research: Action and research. In S. Sankaran, B. Dick, R. Passfield, and P. Swepson (Eds.), Effective change management using action learning and action research: Concepts, frameworks, processes, and applications (pp. 21-27). Lismore, Australia: Southern Cross University Press.

Dowell, D. A., \& Farmer, G. (1992). Community response to homelessness: Social change and constraint in local intervention. Journal of Community Psychology, 20, 72-83.

Dunst, C., Trivette, C., \& Deal, A. (Eds). (1988). Enabling and empowering families: Principles and guidelines for practice. Cambridge, MA: Brookline Books.

Durlak, J. A., Taylor, J. D., Kawashima, K., Pachan, M. K., DuPre, E. P., Celio, C . I., Berger, S. R., Dymnicki, A. B., \& Weissberg, R. P. (2007). Effects of positive youth development programs on school, family, and community systems. American Journal of Community Psychology, 39(3/4), pp. 269-286.

Eisenberg, J. (2007). Group Cohesiveness, in R. F. Baumeister \& K. D. Vohs (Eds.), Encyclopedia of Social Psychology, 386-388. Thousand Oaks, CA: Sage. 
Eisner, E. W. (1998). The enlightened eye: Qualitative inquiry and the enhancement of educational practice. Upper Saddle River, NJ: Prentice-Hall.

Emsoff, J. G., Darnell, A. J., Darnell, D. A., Erickson, S. W., Schneider, S., \& Hudgins, R. (2007). Systems change as an outcome and a process in the work of community collaboratives for health. American Journal of Community Psychology, 39(3/4), pp. 255-268.

Erickson, J. I., Hamilton, G. A., Jones, D. E., \& Ditomassi, M. (2003). Measuring the impact of collaborative governance: Beyond empowerment. Journal of Nursing Administration, 33(2), 96-104.

Fabricant, M., \& Kelley, M. (1986). No haven for homeless in a heartless economy. Radical America, 20, 23-34.

Fals-Borda, O. (1991). Some basic ingredients. In O. Fals-Borda \& A. Rahman (Eds.), Action and knowledge: Breaking the monopoly with participatory action research (pp. 3-12). New York: Apex Press.

Fawcett, S. B., Paine-Andrews, A., Francisco, V., Schulz, J., Richter, K., Lewis, R., et al. (1995). Using empowerment theory in collaborative partnerships for community health and development. American Journal of Community Psychology, 23, 677-698.

Feldman, L. C. (2004). Citizens without shelter: Homelessness, democracy, and political exclusion. Ithaca: Cornell University Press.

Finley, S. (2003a). The faces of dignity: Rethinking the politics of homelessness and poverty in America. Qualitative Studies in Education, 16(4), 509-531. 
Finley, S. (2003b). Arts-based inquiry in QI: Seven years from crisis to guerilla warfare. Qualitative Inquiry, 9(2), 281-296.

Finley, S. (2005). Arts-based inquiry: Performing revolutionary pedagogy. In N.K. Denzin, \& Y.S. Lincoln (Eds.), The Sage handbook of qualitative research, third edition (pp. 681-694). Thousand Oaks, CA: Sage.

Fischer, P. J., \& Breakey, W. R. (1991). The epidemiology of alcohol, drug, and mental disorders among homeless persons. American Psychologist, 46, $1115-$ 1128 .

Fishman, J. (1993). Organizing the homeless in Connecticut. Political Affairs, 72(8), 24-32.

Flood, R. L. (2001). The relationship of systems thinking to action research. In P. Reason, \& H. Bradbury (Eds.), Handbook of action research: Participative inquiry and practice (pp. 133-144). London, UK: Sage.

Florin, P., Chavis, D., Wandersman, A., \& Rich, R. (1992). A systems approach to understanding and enhancing grassroots organizations: The Block Booster Project. In R. Levine, \& H. Fitzgerald (Eds.), Analysis of dynamic psychological systems, volume two, (pp. 215-243). New York: Plenum.

Ford, J. K. (2002). Organizational change and development. In M. Morash, \& J. K. Ford (Eds.), The move to community policing: Making change happen (pp. 126-151). Thousand Oaks, CA: Sage. 
Ford, J. K. (2007). Building capability throughout a change effort: leading the transformation of a police agency to community policing. American Journal of Community Psychology, 39(3/4), pp. 321-334.

Foster-Fishman, P. G., \& Behrens, T. R. (2007). Systems change reborn: rethinking our theories, methods, and efforts in human services reform and communitybased change. American Journal of Community Psychology, 39(3/4), 191-196.

Foster-Fishman, P. G., \& Keys, C. B. (1997). The person/environment dynamics of employee empowerment: An organizational cultural analysis. American Journal of Community Psychology, 25(3), 345-369.

Foster-Fishman, P. G., Salem, D. A., Allen, N. A., \& Fahrbach, K. (2001). Facilitating interorganizational collaboration: The contributions of interorganizational alliances. American Journal of Community Psychology, $29,875-905$.

Freire, P. (1970). Pedagogy of the oppressed. New York; Continuum.

Friedman, D., \& McAdam, D. (1992). Collective identity and activism: Networks, choices, and the life of a social movement. In A. D. Morris \& C. M. Mueller (Eds.), Frontiers in social movement theory. New Haven: Yale University Press.

Gaventa, J., \& Cornwall, A. (2001). Power and knowledge. In Reason, P., \& H. Bradbury (Eds.), Handbook of action research: Participative inquiry and practice (pp. 70-80), London: Sage Publications. 
Gerschick, T. J., Israel, B. A., \& Checkoway, B. N. (1990). Means of empowerment in individuals, organizations, and communities. Ann Arbor, MI: University of Michigan, Program on Conflict Management Alternatives.

Giamartino, G. A., \& Wandersman, A. (1983). Organizational climate correlates of viable urban block organizations. American Journal of Community Psychology, 11(5), 529-541.

Gladwell, M. (2000). The Tipping Point: How Little Things Can Make a Big Difference. Little Brown.

Golden, S. (1992). The women outside: Meanings and myths of homelessness. Berkeley, CA: University of California Press.

Goodman, L., Saxe, L., \& Harvey, M. (1991). Homelessness as psychological trauma: Broadening perspectives. American Psychologist, 46, 1219-1225.

Gounis, K. (1992). The manufacture of dependency: Shelterization revisited. New England Journal of Public Policy, 8, 685-693.

Greenwood, D. J., \& Levin, M. (1998). Introduction to action research: Social research for social change. Thousand Oaks, CA: Sage Publications.

Gruber, J., \& Trickett, E. J. (1987). Can we empower others? The paradox of empowerment in the governing of an alternative public school. American Journal of Community Psychology, 15, 353-371.

Grunberg, J., \& Eagle, P. F. (1990). Shelterization: How the homeless adapt to shelter living. Hospital and Community Psychiatry, 41, 521-525. 
Grundy, S. (1982). Three modes of action research. Curriculum Perspectives, 2(3), $23-24$.

Guba, E. G., \& Lincoln, Y. S. (2005). Paradigmatic controversies, contradictions, and emerging confluences. In N. K. Denzin, \& Y. S. Lincoln (Eds.), The Sage handbook of qualitative research, third edition (pp. 191-216). Thousand Oaks, CA: Sage.

Hall, B. L. (1992). From margins to center: The development and purpose of participatory research. American Sociologist, 23(4), 15-28.

Hall, B. L. (2001). I wish this were a poem of practices of participatory research, In P. Reason, \& H. Bradbury, Handbook of action research: Participative inquiry and practice (p. 171-178). Thousand Oaks, CA: Sage.

Harper, G. W., Lardon, C., Rappaport, J., Bangi, A. K., Contreras, R., \& Pedraza, A. (2004). Community narratives: The use of narrative ethnography in participatory community research. In L. A. Jason, C. B. Keys, Y. SuarezBalcazar, R. R. Taylor, \& M. I. Davis (Eds.), Participatory community research: Theories and methods in action (pp. 199-217). Washington, DC: American Psychological Association.

Hayward, C. R. (1998). De-facing power. Polity, 31, 22-34.

Hellegers, D., \& Mercier, L. (2003). A brief history of tent city movements. Encyclopedia of American Social Movements. Retrieved January, 22, 2005, from www.outofthedoorways.org/dictionary.html. 
Heron, J., \& Reason, P. (2001). The practice of co-operative inquiry: Research with rather than on people. In P. Reason, \& H. Bradbury (Eds.), Handbook of action research: Participative inquiry and practice (pp. 179-188). London: Sage.

Hill, R. P. (2003). Homelessness in the US: An ethnographic look at consumption strategies. Journal of Community \& Applied Social Psychology, 13, 128-137.

Hoch, C., \& Slayton, R. (1989). New homeless and old: Community and the Skid Row hotel. Philadelphia: Temple University Press.

Holden, D. J., Messeri, P., Evans, W. D., Crankshaw, E., \& Ben-Davies, M. (2004). Conceptualizing youth empowerment within tobacco control. Health Education \& Behavior, 31(5), 548-563.

Hopper, K. (1998). Housing the homeless. Social Policy, 28(3), 64.

Hopper, K. (2003). Reckoning with homelessness. Ithaca: Cornell University Press. Hopper, K., \& Baumohl, J. (1994). Held in abeyance: Rethinking homelessness and advocacy. American Behavioral Scientist, 37(4), 522-552.

Hopper, K., Susser, E., \& Conover, S. (1985). Economies of the makeshift: Deindustrialization and homelessness in New York City. Urban Anthropology, 14, 183-236.

Humphries, B., Mertens, D. M., \& Truman, C. (2000). Arguments for an emancipatory research paradigm. In C. Truman, D. Mertens, \& B. Humphries (Eds.), Research and inequality (pp. 3-23). London: UCL Press. 
Huttman, E., \& Redmond, S. (1992). Women and homelessness: Evidence to need to look beyond shelters to long-term social service assistance and permanent housing. Journal of Sociology and Social Welfare, 19, 89-111.

Institute of Medicine. (1988). Homelessness, health, and human needs. Washington, DC: National Academy Press.

Interagency Council on the Homeless. (1999, December 8). Homelessness:

Programs and the people they serve. Findings of the national survey of homeless assistance providers and clients. Retrieved on April 17, 2006, from http://www.huduser.org/ publications/homeless/homelessness/contents.html.

Itzhaky, H., \& York, A. S. (2002). Showing results in community organization. Social Work, 47, 125-131.

Jahiel, R. I. (1992). Services for homeless people: An overview. In R. I. Jahiel (Ed.), Homelessness: A prevention-oriented approach. Baltimore, MD: Johns Hopkins University Press.

Johnson, A. K., \& Cnaan, R. A. (1995). Social work practice with homeless persons: State of the art. Research on Social Work Practice, 5(3), 340-382.

Kelly, J. G. (1986). Context and process: An ecological view of the interdependence of practice and research. American Journal of Community Psychology, 14, 581-589.

Kemmis, D. (1990). Community and the politics of place. Norman, OK: University of Oklahoma Press. 
Kemmis, S. (1993). Action research and social movement: A challenge for policy research. Education Policy Analysis Archives, 1(1). Retrieved December 15, 2005, from http://epaa.asu.edu/epaa/v1n1.html.

Kemmis, S., \& McTaggart, R. (2005). Participative action research: Communicative action and the public sphere. In N. K. Denzin, \& Y. S. Lincoln (Eds.), The Sage handbook of qualitative research, third edition (pp. 559-604). Thousand Oaks, CA: Sage.

Kessler, R. C., McGonagle, K. A., Zhao, S., \& Nelson, C. B. (1994). Lifetime and 12-month prevalence of DSM-III psychiatric disorders in the United States: Results from the National Comorbidity Study. Archives of General Psychiatry, 51, 8-19.

Keune, L. (1998). The strategic role of adequate relationships in action research: Final remarks. In B. Boog, H. Coenen, L. Keune, \& R. Lammerts (Eds.), The complexity of relationships in action research (pp. 195-201). Tilburg: Tilburg University Press.

Kidd, S. A., \& Kral, M. J. (2005). Practicing participatory action research. Journal of Counseling Psychology, 52(2), 187-195.

Kieffer, C. H. (1984). Citizen empowerment: A developmental perspective. Prevention in Human Services, 3, 9-36.

Koberg, C. S., Boss, W., Senjem, J. C., \& Goodman, E. A. (1999). Antecedents and outcomes of empowerment: Empirical evidence from the health care industry. Group and Organization Management, 34(1): 71-91. 
Koegel, P. (1992). Understanding homelessness: An ethnographic approach. In R. I. Jahiel (Ed.), Homelessness: A prevention-oriented approach (pp. 127-138). Baltimore, MD: Johns Hopkins University Press.

Koegel, P., \& Burnham, M. A. (1987). Traditional and nontraditional homeless alcoholics. Alcohol Health and Research World, 11(3), 28-34.

Kotter, J. P. (1990). A force for change: How leadership differs from management. New York: Free Press.

Kreger, M., Brindis, C. D., Manuel, D. M., \& Sassoubre, L. (2007). Lessons learned in systems change initiatives: Benchmarks and indicators. American Journal of Community Psychology, 39(3/4), pp. 301-320.

Lara, S., \& Molina, E. (1997). Participation and popular democracy in the committees for the struggle for housing in Costa Rica. In M. Kaufman \& H. D. Alfonso (Eds.), Community power \& grassroots democracy (pp. 27-54). London, UK: Zed Books.

Lendaris, G. G. (1986). On systemness and the problem solver: Tutorial comments. IEEE Transactions on Systems, Man, and Cybernetics, 16(4), 604-610.

Levine, M., \& Perkins, D. V. (1997). Principles of community psychology: Perspectives and applications, second edition. New York, NY: Oxford University Press.

Levy, L. H. (2000). Self-help groups. In J. Rappaport, \& E. Seidman, (Eds.), Handbook of community psychology (pp. 591-613). Dordrecht, Netherlands: Kluwer Academic Publishers. 
Lewin, K. (1946). Action research and minority problems. Journal of Social Issues, 2, 34-46.

Lewin, K. (1948). Resolving social conflicts: Selected papers on group dynamics. G. W. Lewin (Ed). New York, NY: Harper \& Row.

Lewin, K. (1951). Field theory in social science: Selected theoretical papers. D. Cartwright (Ed.). New York, NY: Harper \& Row.

Lincoln, Y. S., \& Guba, E. G. (1985). Naturalistic inquiry. Beverly Hills, CA: Sage. Lincoln, Y. S., \& Guba, E. G. (1986). But is it rigorous? Trustworthiness and authenticity in naturalistic evaluation. In D. D. Williams (Ed.), Naturalistic evaluation: New directions for program evaluation, no. 30 (pp. 73-84), San Francisco: Jossey-Bass.

Link, B., Phelan, J., Bresnahan, M., Steuve, A., Moore, R., \& Susser, E. (1995). Lifetime and five-year prevalence of homelessness in the United States: New evidence on an old debate. American Journal of Orthopsychiatry, 65, 347354.

Linstone, H. A. (1984). Multiple perspectives for decision making: Bridging the gap between analysis and action. North-Holland, NY: Elsevier-Science Publications.

Linstone, H. A. (1999). Decision making for technology executives: Using multiple perspectives to improve performance. Boston, MA: Artech House. Maguire, P. (1987). Doing participatory research: A feminist approach. Massachusetts: University of Massachusetts. 
Mankowski, E., \& Rappaport, J. (1995). Stories, identity, and the psychological sense of community. In R. S. Wyer, Jr (Ed.), Advances in social cognition, volume eight. Hillsdale, NJ: Lawrence Erlbaum.

Martin, A. W. (2001). Large group processes as action research. In P. Reason, \& H. Bradbury (Eds.), Handbook of action research: Participative inquiry and practice (pp. 200-208). London: Sage.

Maslow, A. H. (1943). A Theory of Human Motivation. Psychological Review, 50, 370-396.

Masters, J. (1995). The history of action research. Action Research Electronic Reader. Retrieved January 13, 2005, from AROW@cchs.usyd.edu.au.

Maton, K. I. (1988). Social support, organizational characteristics, psychological well-being, and group appraisal in three self-help group populations. American Journal of Community Psychology, 16, 53-78.

Maton, K. I., \& Salem, D. A. (1995). Organizational characteristics of empowering community settings: A multiple case study approach. American Journal of Community Psychology, 23, 631-656.

McCall, M. M. (2000). Performance ethnography: A brief history and some advice. In N. K. Denzin, \& Y. S. Lincoln (Eds.), Handbook of qualitative research, second edition (pp. 421-434). Thousand Oaks, CA: Sage Publications.

McChesney, K. Y. (1990). Family homelessness: A systemic problem. Journal of Social Issues, 46(4), 191-205. 
McMillan, B., Florin, P., Stevenson, J., Kerman, B., \& Mitchell, R. E. (1995).

Empowerment praxis in community coalitions. American Journal of Community Psychology, 23, 699-727.

McMillan, D. W., \& Chavis, D. M. (1986). Sense of community: A definition and theory. American Journal of Community Psychology, 14(1), 6-23.

Melucci, A. (1995). The process of collective identity. In H. Johnston, \& B.

Klandermans (Eds.), Social movements and culture (pp. 41-63), Minneapolis, MN: University of Minnesota Press.

Metraux, S., \& Culhane, D. P. (1999). Family dynamics, housing, and recurring homelessness among women in New York homeless shelters. Journal of Family Issues, 20, 371-397.

Miller, A. B., \& Keys, C. B. (2001). Understanding dignity in the lives of homeless persons. American Journal of Community Psychology, 29(2), 331-354.

Miller, H. (1991). On the fringe: The dispossessed in America. Lexington, MA: D.C. Health.

Minkler, M., Thompson, M., Bell, J., \& Rose, K. (2001). Contributions of community involvement to organizational-level empowerment: The federal healthy start experience. Health Education \& Behavior, 28, 783-807. Morrell-Bellai, T., Goering, P. N., \& Boydell, K. M. (2000). Becoming and remaining homeless: A qualitative investigation. Issues in Mental Health Nursing, 21, 581-604. 
Morse, G. A. (1992). Causes of homelessness. In M. J. Robertson, \& M. Greenblatt (Eds.), Homelessness: A national perspective (pp. 3-18). New York, Plenum Press.

Multnomah County Citizens Commission on Homelessness (2004, December). Home Again: A ten-year plan to end homelessness in Portland and Multnomah County. Portland, OR: The Citizens Commission on Homelessness.

National Coalition for the Homeless (2003, April). Hate, violence, and death on Main Street USA: A report on hate crimes and violence against people experiencing homelessness in 2002. Washington, DC: The National Coalition for the Homeless.

National Coalition for the Homeless (2004, November). Illegal to be homeless 2004 report: The criminalization of homelessness in the United States. Washington, DC: The National Coalition for the Homeless.

National Coalition for the Homeless (2006, January). A dream denied: The criminalization of homelessness in U.S. cities. Washington, DC: The National Coalition for the Homeless and The National Law Center on Homelessness \& Poverty.

National Law Center on Homelessness and Poverty. (1997). Access delayed, access denied: Local opposition to housing and services for homeless people across the United States. Washington, DC: National Law Center on Homelessness \& Poverty. 
National Law Center on Homelessness and Poverty. (1999). Out of sight, Out of mind. Washington, DC: National Law Center on Homelessness \& Poverty.

Nelson, G., Ochocka, J., Griffin, K., \& Lord, J. (1998). Nothing about me without me: Participatory action research with self-help/mutual aid organizations for psychiatric consumers/survivors. American Journal of Community Psychology, 26(6), 881-912.

O'Connell, M. E. (2003). Responding to homelessness: An overview of US and UK policy interventions. Journal of Community \& Applied Social Psychology, 13, $158-170$.

O’Conner, P. A. (2007). Using system differences to orchestrate change: A systems-guides intervention model. American Journal of Community Psychology, 39(3/4), pp. 393-404.

Osborne, R. E. (2002). I may be homeless, but I'm not helpless: The costs and benefits of identifying with homelessness, Self and Identity, 1, 43-52.

Park, P. (2001). Knowledge and participatory research. In P. Reason, \& H. Bradbury (Eds.), Handbook of action research: Participative inquiry and practice (pp. 81-90). Thousand Oaks, CA: Sage.

Parsons, R. J. (1998). Evaluation of empowerment practice. In L. Gutierrez, R. J. Parsons, \& E. O. Cox (Eds.), Empowerment in social work practice: A sourcebook (pp. 204-219). Pacific Grove, CA: Brooks/Cole.

Parsons, R. J., Gutierrez, L. M., \& Cox, E. O. (1998). A model for empowerment practice. In L. Gutierrez, R. J. Parsons, \& E. O. Cox (Eds.), Empowerment in 
social work practice: A sourcebook (pp. 3-23). Pacific Grove, CA:

Brooks/Cole.

Paschke, B., \& Volpendesta, D. (1991). Homeless not helpless. Berkeley, CA: Canterbury Press.

Pease, B. (2002). Rethinking empowerment: A postmodern reappraisal for emancipatory practice. British Journal of Social Work, 32(2), 135-147.

Perkins, D. D., Brown, B. B., \& Taylor, R. B. (1996). The ecology of empowerment: Predicting participation in community organizations. Journal of Social Issues, 52, 85-110.

Peterson, N. A., \& Hughey, J. (2002). Tailoring organizational characteristics for empowerment: Accommodating individual economic resources. Journal of Community Practice, 10, 41-59.

Peterson, N. A., \& Speer, P. W. (2000). Linking organizational characteristics to psychological empowerment: Contextual issues in empowerment theory. Administration in Social Work, 24, 39-58.

Peterson, N. A., \& Zimmerman, M. A. (2004). Beyond the individual: Toward a nomological network of organizational empowerment. American Journal of Community Psychology, 34(1/2), 129-145.

Phelan, J. C., \& Link, B. G. (1999). Who are the homeless: Reconsidering the stability and composition of the homeless population. American Journal of Public Health, 89, 1334-1338. 
Phillips, A., \& Hamilton, S. (1996). Huts for the homeless: A low-technology approach for squatters in Atlanta, Georgia. In A. L. Dehavenon (Ed.), There's no place like home: Anthropological perspectives on housing and homelessness in the United States (p. 81-103). Westport, CN: Bergin \& Garvey.

Piper, W., Marrache, M., Lacroix, R., Richardson, A. \& Jones, B. (1983). Cohesion as a basic bond in groups. Human Relations, 36, 93-108.

Polkinghorne, D. E. (1989). Phenomenological research methods. In R. S. Valle, \& S. Halling (Eds.), Existential-phenomenological perspectives in psychology (pp. 41-60). New York: Plenum Press.

Prestby, J. E., \& Wandersman, A. (1985). An empirical exploration of framework of organizational viability: Maintaining block organizations. The Journal of Applied Behavioral Science, 21, 287-305.

Prestby, J. E., Wandersman, A., Florin, P., Rich, R., \& Chavis, D. M. (1990). Benefits, costs, incentive management, and participation in voluntary organizations: A means to understanding and promoting empowerment. American Journal of Community Psychology, 18, 117-149.

Prilleltensky, I., \& Nelson, G. (2002). Doing psychology critically: Making a difference in diverse settings. Macmillan Press.

Rahman, A. (1991). The theoretical standpoint of PAR. In O. Fals-Borda \& A. Rahman (Eds.), Action and knowledge: Breaking the monopoly with participatory action research (pp. 13-23). New York: Apex Press. 
Rappaport, J. (1977). Community psychology: Values, research, and action. New York, NY: Holt, Rinehart \& Winston.

Rappaport, J. (1981). In praise of paradox: A social policy of empowerment over prevention. American Journal of Community Psychology, 9, 1-25.

Rappaport, J. (1984). Studies in empowerment: Introduction to the issue. In J.

Rappaport, C. F. Swift, \& R. E. Hess (Eds.), Studies in empowerment (pp.17). New York: Haworth Press.

Rappaport, J. (1990). Research methods and the empowerment social agenda. In P.

Tolan, C. Keys, F. Chertok, \& L. Jason (Eds.), Researching community psychology (pp. 51-63). Washington, DC: American Psychological Association.

Rappaport, J. (1998). The art of social change: Community narratives as resources for individual and collective identity. In X. B. Arriaga, \& S. Oscamp (Eds.), Addressing community problems (pp. 225-246). Thousand Oaks, CA: Sage. Rappaport, J. (2000). Community narratives: Tales of terror and joy. American Journal of Community Psychology, 28(1), 1-24.

Reason, P. (2006). Choice and quality in action research practice. Journal of Management Inquiry, 15(2), 187-203.

Reason, P., \& Bradbury, H. (2001). Introduction: Inquiry and participation is search of a world worthy of human inspiration. In P. Reason, \& H. Bradbury (Eds.), Handbook of action research: Participative inquiry and practice (pp. 1-14). London, UK: Sage. 
Ridgway, P., Simpson, A., Wittman, F. D., \& Wheeler, G. (1994). Home making and community building: Notes of empowerment and place. The Journal of Mental Health Administration, 21(4), 407-418.

Riger, S. (2002). What's wrong with empowerment. In T. A. Revenson, A. R. D’Augelli, S. E. French, D. L. Hughes, D. Livert., E. Seidman, M. Shinn., \& H. Yoshikawa (Eds.), A quarter century of community psychology: Readings from the American Journal of Community Psychology (pp. 395-408). New York: Kluwer Academic/Plenum Publishers.

Riggs, E. H., \& Coyle, A. (2002). Young people's accounts of homelessness: A case study analysis of psychological well-being and identity. Counseling Psychological Review, 3, 5-15.

Rivlin, L. G., \& Imbimbo, J. E. (1989). Self-help efforts in a squatter community: Implications for addressing contemporary homelessness. American Journal of Community Psychology, 17, 705-728.

Roberts, L. J., Luke, D. A., Rappaport, J., Seidman, E., Toro, P. A., \& Reischl, T. M. (1991). Charting uncharted terrain: A behavioral observation system for mutual help groups. American Journal of Community Psychology, 19, 751737.

Robinson, B., \& Hanna, M. G. (1994). Lessons for academics grassroots community organizing: A case study - the Industrial Areas Foundation. Journal of Community Practice, 1, 63-94. 
Robnett, B. (2002). External political change, collective identities, and participation in social movement organizations. In D. S. Meyer, N. Whittier, \& B. Robnett (Eds.), Social movements: Identity, culture and the state (pp. 266-288). New York, NY: Oxford University Press.

Rocha, E. (1994). Empowerment and organizations: Inside the homeless social movement. Unpublished doctoral dissertation, University of Southern California.

Ropers, R. H., (1988). The invisible homeless. New York: Human Sciences Press.

Rosenberg, A. A., Solarz, A. L., \& Bailey, W. A. (1991). Psychology and homelessness. A public policy and advocacy agenda. American Psychologist, 46(11), 1239-1244.

Rosenthal, R. (1994). Homeless in paradise: A map of the terrain. Philadelphia: Temple University Press.

Rosenthal, R. (2000). Imaging homelessness and homeless people: Visions and strategies within the movement(s). Journal of Social Distress \& the Homeless, 9(2), 111-126.

Rossi, P. H. (1989). Down and out in America: The origins of homelessness. Chicago: University of Chicago Press.

Rossi, P. H., Wright, J. D., Fisher, G. A., \& Willis, G. (1987). The urban homeless: Estimating composition and size, Science, 235, 1336.

Ryan, R. M., \& Solky, J. A. (1996). What is supportive about social support? On the psychological needs for autonomy and relatedness. In G. R. Pierce, B. R. 
Sarason, \& I. G. Sarason (Eds.), Handbook for social support and the family (pp. 249-267). New York, NY: Plenum Press.

Saegert, S., \& Winkel, G. (1996). Paths to community empowerment: Organizing at home. American Journal of Community Psychology, 24(4), 517-550.

Sarason, S. B. (1972). The creation of settings and the future societies. San Francisco, CA. Jossey-Bass.

Sarason, S. B. (1974). The psychological sense of community: Prospects for a community psychology. San Francisco: Jossey-Bass.

Selener, D. (1997). Participatory action research and social change. Ithaca, NY: Cornell Participatory Action Research Network, Cornell University.

Seltser, B. J., \& Miller, D. E. (1993). Homeless families: The struggle for dignity. Urbana, IL: University of Illinois Press.

Senge, P. M. (1990). The fifth discipline: The art and practice of the learning organization. New York, NY: Doubleday.

Senge, P. M., Kleiner, A., Roberts, C., Ross, R. B., \& Smith, B. J. (1994). The fifth discipline fieldbook: Strategies and tools for building a learning organization. New York: Doubleday.

Senge, P., \& Scharmer, O. (2001). Community action research: Learning as a community of practitioners, consultants, and researchers. In Reason, P., \& H. Bradbury (Eds), Handbook of action research: Participative inquiry and practice (pp. 238-249). London: Sage Publications. 
Shinn, M. (1992). Homelessness: What is a psychologist to do? American Journal of Community Psychology, 20, 1-24.

Shlay, A. B., \& Rossi, P. H. (1992). Social science research and contemporary studies of homelessness. Annual Review of Sociology, 18, 129-160.

Smith, K. K., \& Berg, D. N. (1987). Paradoxes of group life: Understanding conflict, paralysis, and movement in group dynamics. San Francisco, CA. Jossey-Bass.

Smock, K. (2010). An evaluation of Dignity Village. A report prepared for the Portland Housing Bureau.

Snow, D. A., \& Anderson, L. (1987). Identity work among the homeless: The verbal construction and avowal of personal identities. American Journal of Sociology, 92, 1336-1371.

Snow, D. A., \& Anderson, L. (1993). Down on their luck: A study of homeless street people. Berkeley: University of California Press.

Snow, D., Anderson, L., \& Koegel, P. (1994). Distorting tendencies in research on the homeless. American Behavioral Scientist, 37(4), 461-77.

Snow, D., Baker, S. G., Anderson, L., \& Martin, M. (1986). The myth of pervasive mental illness among the homeless. Social Problems, 33(5), 407-423.

Snow, D. A., Zurcher, L. A, \& Elkind-Olson, S. (1980). Social networks and social movements. American Sociological Review, 45, 787-801. 
Sohng, S. (1998). Research as an empowerment strategy. In L. Gutierrez, R. J. Parsons, \& E. O. Cox (Eds.), Empowerment in social work practice: A sourcebook (pp. 187-203). Pacific Grove, CA: Brooks/Cole.

Solarz, A. L. (1992). To be young and homeless: Implications of homelessness for children. In M. J. Robertson, \& M. Greenblatt (Eds.), Homelessness: A national perspective (pp. 275-286). New York, NY: Plenum Press.

Sommer, H. (2000). Homelessness in urban America: A review of the literature. Berkeley, CA: Institute of Governmental Studies Press.

Sosin, M. R. (2003). Explaining adult homelessness in the US by stratification or situation. Journal of Community \& Applied Social Psychology, 13, 91-104.

Speer, P. W., \& Hughey, J. (1995). Community organizing: An ecological route to empowerment and power. American Journal of Community Psychology, 23, 729-748.

Speer, P. W., Hughey, J., Gensheimer, L. K., \& Adams-Leavitt, W. (1995). Organizing for power: A comparative case study. Journal of Community Psychology, 23, 57-73.

Spreitzer, G. M. (1995). An empirical test of a comprehensive model of intrapersonal empowerment in the workplace. American Journal of Community Psychology, 23(5), 601-629.

Staggs, S. L., White, M. L., Schewe, P. A., Davis, E. B., \& Dill, E. M. (2007). Changing systems by changing individuals: The incubation approach to 
systems change. American Journal of Community Psychology, 39(3/4), pp. $365-380$.

Stake, R. E. (2005). Qualitative case studies. In N. K. Denzin, \& Y. S. Lincoln (Eds.), The Sage handbook of qualitative research, third edition (pp. 443466). Thousand Oaks, CA: Sage.

Stark, L. R. (1994). The shelter as total institution: An organizational barrier to remedying homelessness. American Behavioral Scientist, 37(4), 553-562.

Stevenson, W. B., \& Greenberg, D. (2000). Agency and social networks: Strategies of action in a social structure of position, opposition, and opportunity. Administrative Science Quarterly, 45, 651-678.

Stokowski, P. A. (2002). Languages of place and discourses of power: Constructing new senses of place. Journal of Leisure Research, 34(4), 368-382.

Stoner, M. R. (1995). The civil rights of homeless people: Law, social policy, and social work practice. Hawthorne, NY: Aldine de Gruyter.

Stringer, E. T. (1999). Action research, second edition. Thousand Oaks, CA: Sage.

Suarez-Balcazar, Y., Redmond, L., Kouba, J., Hellwig, M., Davis, R., Martinez, L. I., \& Jones, L. (2007). Introducing systems change in the schools: The Case of school luncheons and vending machines. American Journal of Community Psychology, 39(3/4), pp. 335-346.

Swift, C., \& Levine, G. (1987). Empowerment an emerging mental health technology. Journal of Primary Prevention, 8, 71-94. 
Takahashi, L. M. (1997). The socio-spatial stigmatization of homelessness and HIV/AIDS: Toward an explanation of the NIMBY syndrome. Social Science and Medicine, 45(6), 903-914.

Tandon, R. (1988). Social transformation and participatory research. Convergence, 21(2), 7-15.

Taylor, G. (1999). Empowerment, identity and participatory research: Using social action research to challenge isolation for deaf and hard of hearing people from minority ethnic communities. Disability \& Society, 14(3), 369-384.

Taylor, R. R., Jason, L. A., Keys, C. B., Suarez-Balcazar, Y., Davis, M. I., Durlak, J. A., \& Isenberg, D. H. (2004). Introduction: Capturing theory and methodology in participatory research. In L. A. Jason, C. B. Keys, Y. SuarezBalcazar, R. R. Taylor, \& M. I. Davis (Eds.), Participatory community research: Theories and methods in action (pp. 3-14). Washington, DC: American Psychological Association.

Tessler, R., \& Dennis, D. (1989). A synthesis of NIMH-funded research concerning persons who are homeless and mentally ill. Washington, DC: National Institute of Mental Health.

Tompsett, C. J., \& Toro, P. A. (2004). Public opinion. In D. Levinson (Ed.), Encyclopedia of homelessness, volume two (pp. 469-474). Thousand Oaks, CA: Sage Publications. 
Toro, P. A., \& Janisse, H. C. (2004). Patterns of homelessness. In D. Levinson (Ed.), Encyclopedia of homelessness, volume one (pp. 244-250). Thousand Oaks, CA: Sage Publications.

Toro, P. A., \& Warren, M. G. (1999). Homelessness in the United States: Policy considerations. Journal of Community Psychology, 27(2), 119-136.

Tseng, V., \& Seidman, E. (2007). A systems framework for understanding social settings. American Journal of Community Psychology, 39(3/4), pp. 217-228.

U. S. Conference of Mayors (2001). A status report on hunger and homelessness in America's cities. Washington, DC: U. S. Conference of Mayors.

U. S. Conference of Mayors. (2005). A status report on hunger and homelessness in America's cities: A 24-city survey. Washington, DC: U.S. Conference of Mayors.

U. S. Department of Housing and Urban Development. (1989). A report on the 1988 national survey of shelters for the homeless. Washington, DC: U.S. Department of Housing and Urban Development, Office of Policy Development and Research.

Van Beinum, H. (1998). Engaging in action research. In B. Boog, H. Coenen, L., Keune, \& R. Lammerts (Eds.), The complexity of relationships in action research (pp. 65-79). Tilburg: Tilburg University Press.

Viswanathan, M., Ammerman, A., Eng., E., et al., (2004). Community-based participatory research: Assessing the evidence. Agency for Healthcare 
Research and Quality, Rockville, MD. Retrieved April 4, 2005, from http://www.ahrq.gov/clinic/epcsums/cbprsum.htm.

Wagner, D. (1993). Checkerboard square: Culture and resistance in a homeless community. Boulder, CO: Westview Press.

Wagner, D., \& Cohen, M. B. (1991). The power of the people: Homeless protesters in the aftermath of social movement participation. Social Problems, 38(4), $543-561$.

Wandersman, A., \& Florin, P. (2000). Citizen participation and community organization). In J. Rappaport, \& E. Seidman (Eds.), Handbook of community psychology (p. 247-272). New York, NY: Kluwer Academic/Plenum.

Wandersman, A., \& Giamartino, G. (1980). Community and individual differences characteristics as influences on initial participation. American Journal of Community Psychology, 8, 217-228.

Wandersman, A., Jakubs, J. F., \& Giamartino, G. (1981). Participation in block organizations. Journal of Community Action, 1, 40-48.

Wong, I. Y. L., Piliavan, I., \& Wright, B. R. E. (1998). Residential transitions among homeless families and homeless single individuals: A comparison study. Journal of Social Service Research, 24, 1-27.

Wright, J., Rubin, B., \& Devine, J. (1998). Beside the golden door: Policy, politics and the homeless. New York: Aldine De Gruyter.

Wright, J., \& Weber, E. (1987). Homelessness and Health. New York: McGraw Hill. 
Wright, T. (1995). Tranquility City: Self-organization, protest, and collective gains within a Chicago Homeless encampment. In M. P. Smith (Ed.), Marginal spaces, volume five (37-68). New Brunswick, NJ: Transaction Publishers.

Wright, T. (1997). Out of place: Homeless mobilizations, subcities, and contested landscapes. Albany, NY: New York Press.

Wright, T., \& Vermund, A. (1996). Suburban homelessness and social space: Strategies of authority and local resistance in Orange County, California. In A. L. Dehavenon (Ed.), There's no place like home: Anthropological perspectives on housing and homelessness in the United States (p. 121-143). Westport, CN: Bergin \& Garvey.

Zimmerman, M. A. (1990). Taking aim on empowerment research: On the distinction between individual and psychological conceptions. American Journal of Community Psychology, 18(1), 169-177.

Zimmerman, M. A. (1995). Psychological empowerment: Issues and illustrations. American Journal of Community Psychology, 23, 581-600.

Zimmerman, M. A. (2000). Empowerment theory: Psychological, organizational, and community levels of analysis. In J. Rappaport, \& E. Seidman (Eds.), Handbook of community psychology (pp. 43-63), New York: Kluwer Academic/Plenum.

Zimmerman, M. A., Reischl, T. M., Seidman, E., Rappaport, J., Torro, P. A., \& Salem, D. A. (1991). Expansion strategies of a mutual help organization. American Journal of Community Psychology, 19, 251-278. 
Zimmerman, M. A., \& Rappaport, J. (1988). Citizen participation, perceived control, and psychological empowerment. American Journal of Community Psychology, 16, 725-750.

Zwick, M. (2002). Elements and relations: Aspects of a scientific metaphysics. Manuscript in preparation, Portland State University. 


\section{Appendix A: Preface Getting Oriented A guide to the participatory action research with Dignity Village}

\section{Dignity Village Facts}

\section{Dignity Village is:}

- a 501(c)3 non-profit organization

- membership based

- governed democratically by its members

- volunteer based

- founded on 5 basic rules to ensure safety

- houses up to 60 homeless adults
- a community that promotes civic participation

- a service provider

- based on a "no time-limit" philosophy

- cost-efficient (<\$5 pp per night)

- funded through Dignity Village microbusinesses, and donations from private individuals and foundations

\section{Facts}

Membership. Membership is by application. Dignity Village states that membership is not limited "based on religion, race, sex, sexual orientation, handicap, age, lifestyle choice, previous (criminal) record or economic status."

\section{Democratic Governance.}

There are bylaws and a board of directors with an elected

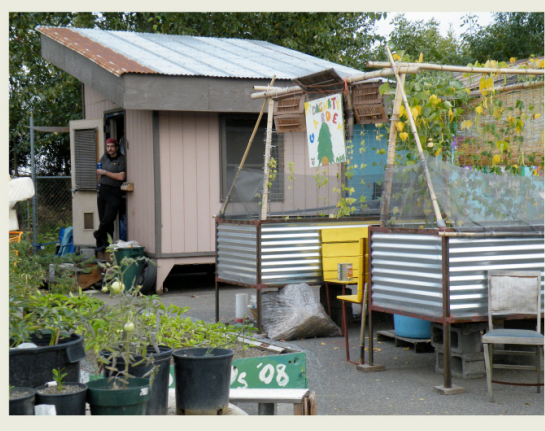

Dignity Village is the only legally sanctioned, city-recognized encampment of homeless people in the United States.

officers. Every Wednesday evening, the democratically elected board and council members of Dignity Village meet to conduct business. Twice a month, the entire
Village gathers to discuss and vote on community concerns.

\section{Volunteer-based.}

There is no paid staff; Dignity Village is fostered through democratic selfgovernment and sweat equity. The majority of Villagers work part- or fulltime jobs to save money and pay for their food and propane for heat; local businesses and individuals donate additional food, blankets, and building materials, among other items. Village residents work on-site ten hours per week maintaining the Village 


\section{Facts continued...}

in exchange for rent.

\section{Five Basic Rules.}

Each Village resident must adhere to a code of conduct established in the Membership Agreement. The five basic rules are: (1) no violence toward yourself or others; (2) no illegal substances or alcohol or paraphernalia on the premises or within a one-block radius; (3) no stealing; (4) everyone contributes to the upkeep and welfare of the village and works to become a productive member of the community; and (5) no disruptive behavior of any kind that disturbs the general peace and welfare of the village. Breaking the agreement acts as grounds for removal from the Village. Dignity Village provides 24-hour security,

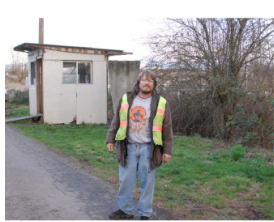
and maintains a good working relationship with the police. The Village implements a comprehensive fire safety plan. From 2007-09, the annual rate of 911 calls resulting in the dispatch of Portland Police to Dignity Village was lower on a per capita basis than the citywide average (Smock, 2010).

\section{For Adults.}

Because past criminal convictions (including sex crimes) are not considered negative criteria for membership, and because of dangers presented by continuing construction, children are not allowed to reside in the community.

\section{Civic Participation.}

Dignity Village regularly hosts school, religious, neighborhood, and other groups, as well as individual visitors and the press. The community is also involved in neighborhood association meetings, public forums, and

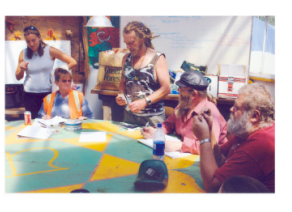

classes on poverty, homelessness, and ecological sustainability, participates in the City of Portland's planning process to end homelessness, and events related to sustainable development.

\section{Service Provider.}

Dignity Village offers the following services to residents: showers, sanitary facilities, private and communal food, flower gardens,

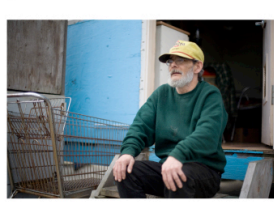
communal cooking and refrigeration facilities, emergency transport, access to education or counseling, access to technology and communications (TV, internet, telephone), distribution of donated food, personal items and construction material, community meetings, on-site veterinary and medical care on a scheduled basis by volunteers, access to prescription medication assistance, doctors and nurses, and rudimentary first aid.

\section{"No Time-Limit" Philosophy.}

Dignity Village holds to a philosophy that the time needed for growth is different for each person, and they therefore place no time limit to how long a person can live at Dignity Village, as long as the basic rules are not broken. Some people need only a short time

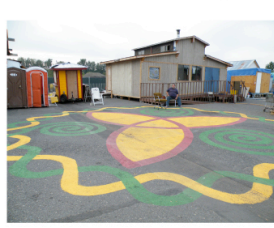
at the Village before moving on to achieve their goals, while others who face obstacles such as accrued debt, parole, depression or drug/

alcohol addictions require more time, perseverance and support from the community before they are ready to leave Dignity's gate. In 2008-09, 


\section{Facts continued...}

$79 \%$ of residents stayed at Dignity Village for two years or less, which is the usual time limit for formal Transitional Housing programs. More than $60 \%$ were there for six months or less (Smock, 2010).

\section{Cost-Efficient.}

Dignity Village has sheltered 60 homeless people each night, year-round, at a cost per bed night that is one-third the cost of the cheapest and most basic shelter option within Portland (Smock, 2010).
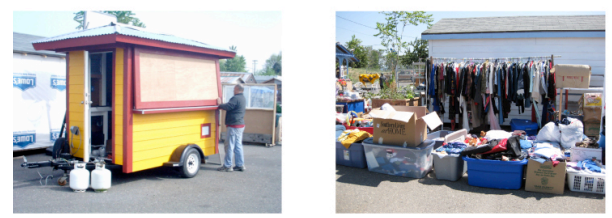

\section{Funding.}

Dignity Village pays for its own utilities, trash services, port-a-potties, and liability insurance. Dignity Village does not receive money from taxpayers or through government grants. Funds are raised through donations, grants, and micro-businesses such as a hot-dog cart, snack stand, eBay store, yard-sale, and greenhouse/nursery.

\section{Terminology \\ in Research:}

Long-termers:

2 yrs +

Mid-termers:

6 mos - 2 yrs

Newcomers:

0 - 6 mos

\section{Leader:}

individual on 1 or more committees, council, board

\section{Visitor/Guest:}

just arrived; restricted access to DV

Resident:

permission to stay; cannot vote; restricted participation

\section{Member:}

voted by majority members; can vote; no restrictions 


\section{Main Co-Researchers}

Villagers who participated regularly in the core group research meetings.

*Asterisks indicate those who no longer reside at Dignity Village.

Participatory Action Research with Dignity Village

(October 2005 - February 2007)

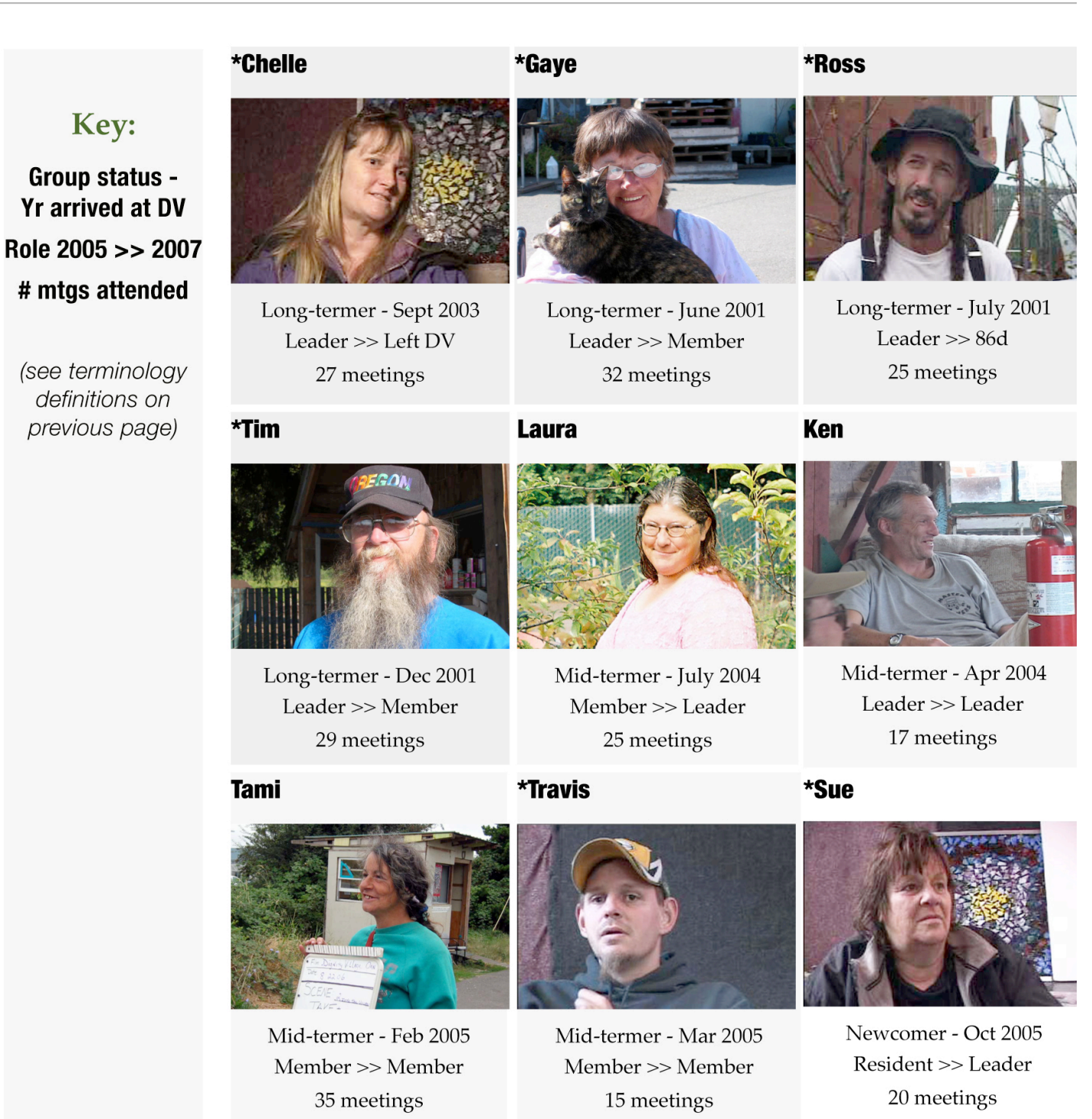




\section{Occasional Co-Researchers}

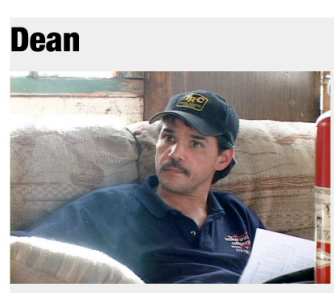

Long-termer - Aug 2003 Member $\gg>$ Leader 8 meetings

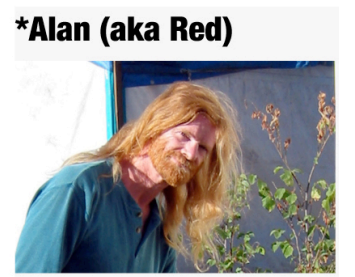

Mid-termer - July 2004 Member $\gg$ Member 4 meetings

\section{*Cami}

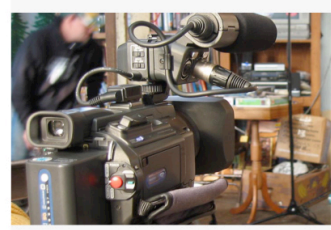

Mid-termer - 2005 Member $\gg$ Leader 4 meetings

\section{*Roe}

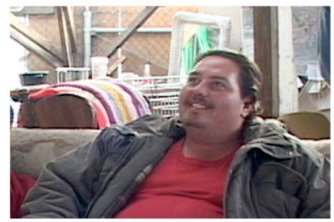

Newcomer- Feb 2006

Visitor $>>$ Leader 6 meetings

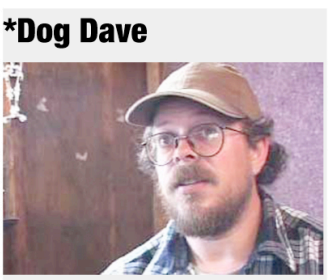

Long-termer - 2001/ 2005 Resident $\gg$ Left DV 3 meetings

\section{*Alan (aka Big Al)}

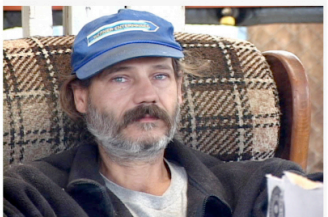

Mid-termer- Feb 2005 Member $\gg$ Leader 12 meetings

\section{Dave (aka Dread)}

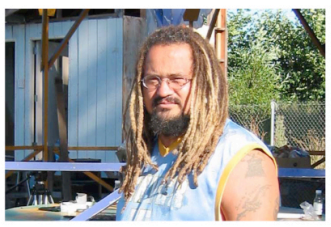

Newcomer - Feb 2006

Visitor $\gg$ Leader 6 meetings

\section{*Stephie}

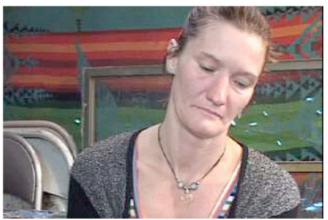

Newcomer - Oct 2005 Resident $>$ Left DV 2 meetings

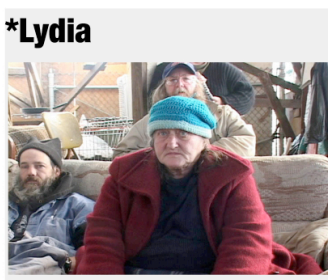

Long-termer - 2001/ 2005 Resident $>$ Left DV 10 meetings

\section{*Alfred}

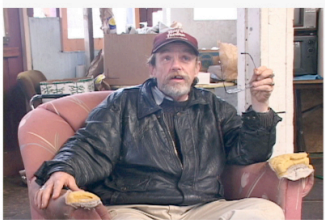

Mid-termer - 2002/ 2005 Resident $>$ Left DV 2 meetings

*Louey

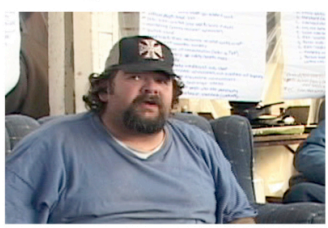

Newcomer - Feb 2006 Visitor $\gg$ Leader 6 meetings

*Thomas

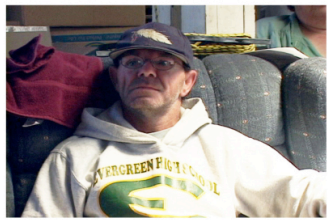

Newcomer - May 2006

Visitor $>$ Left DV 2 meetings

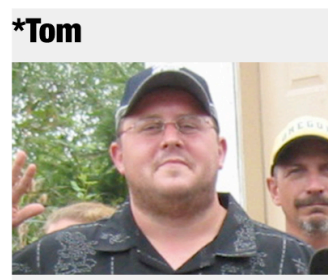

Long-termer - June 2001 Member $\gg$ Leader 2 meetings

*Bob

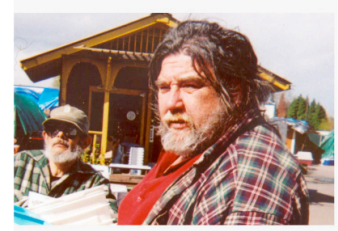

Mid-termer - Sept 2004

Member $\gg$ Member 4 meetings

\section{*Mike}

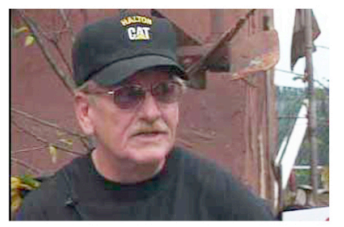

Newcomer- Oct 2005 Resident $\gg$ Member 9 meetings 


\section{Timeline Summary \\ Dignity Village timeline before and after the research \\ $2000-2010$}

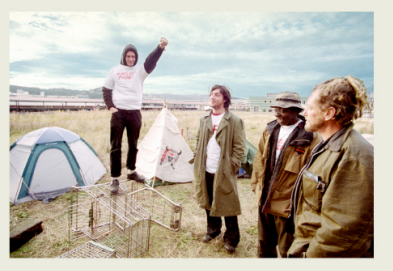

2000 (Sept - Dec)

Initial formation of Camp Dignity and Out of the Doorways campaign; campers chased by police from site to site every few weeks.

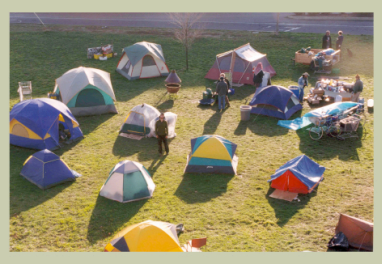

2001

Jan

Evictions from four camping sites, growth to 40 tents, shopping cart parades and media attention

Feb-Apr Return to site under Fremont Bridge; police discontinue evictions. Meeting with officials, discontinue evictions. Meeting with officials, fundraisers, submissions of proposal "Dignity Village: 2001 and Beyond" to City.

May-Aug State allows stay under Fremont Bridge during negotiations. Multiple deadlines and extensions of stay as negotiations proceed. Kwamba Productions begins filming interviews. City and Village in search for temporary site to establish Village as "one year pilot project." Village creates Bylaws.

Sept Kwamba provides video for City Council meeting. City Council accepts Village as pilot project at Sunderland Composting Yard. Press conference to announce DV decision to stay under Fremont Bridge. Police post 24-hour eviction notices. Villagers scatter and then reconvene at Sunderland Yard. Tents, flag tower, and Dome of Democracy erected by City Repair Project.

Oct-Dec Village incorporates and files for non-profit status. Continues search for land for permanent location. Supporter, Lee Larson, pays $\$ 20 \mathrm{~K}$ for 6-month extension at Sunderland Yard. First formal elections of Village Council and Officers. 

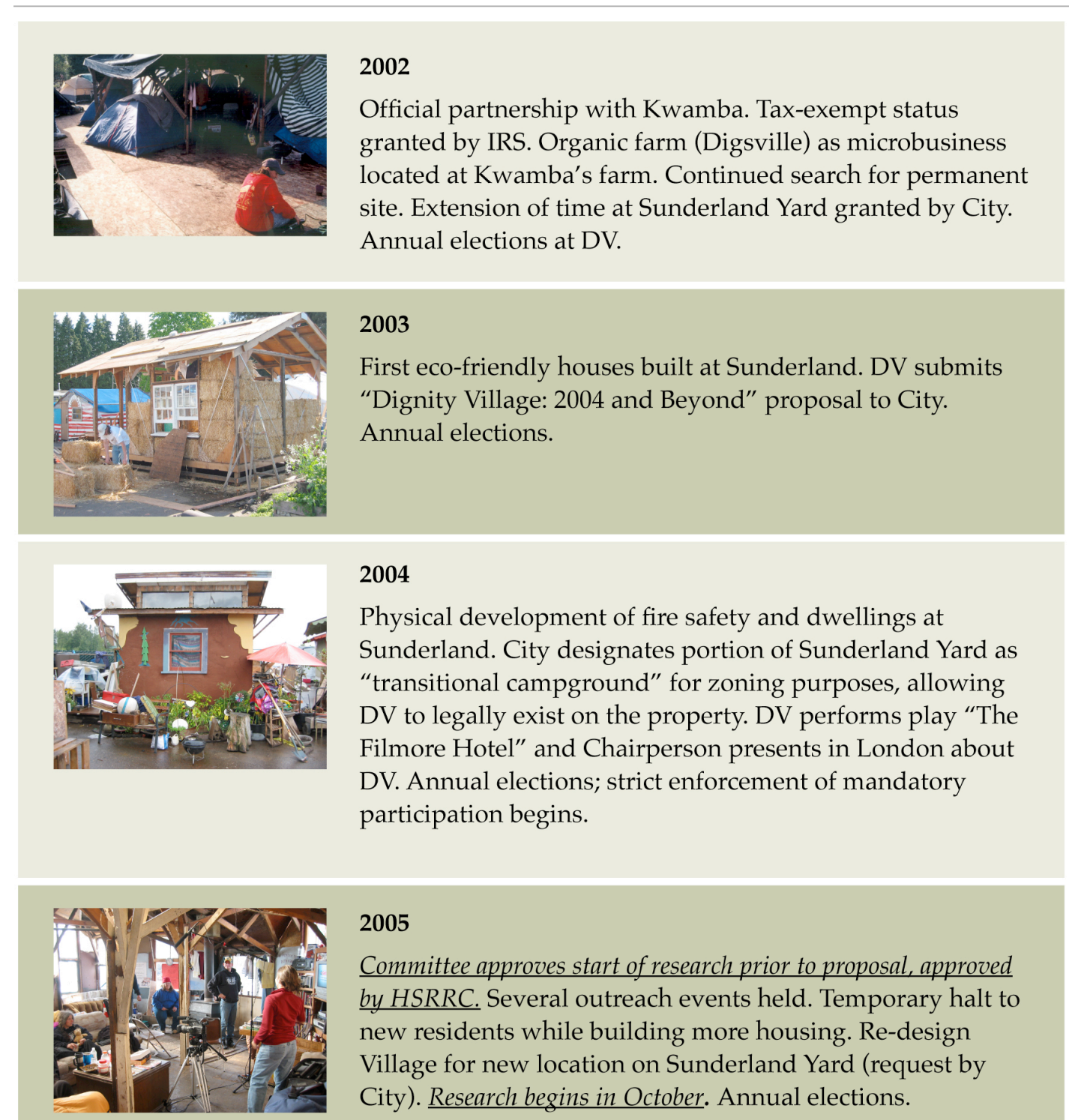

2005

Committee approves start of research prior to proposal, approved by HSRRC. Several outreach events held. Temporary halt to new residents while building more housing. Re-design Village for new location on Sunderland Yard (request by City). Research begins in October. Annual elections.

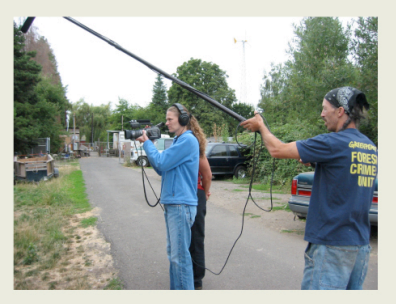

2006

Fundraiser/shoe drive. Continue replacement of old shacks with new micro-housing. Participatory action research and creation of action tools, including orientation video. Dissertation proposed in June. Orientation video screened at DV and core group meetings end in Dec. Annual elections. 


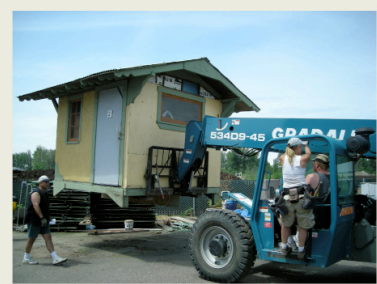

2007

Post-research interviews in January. Street Roots/DV

fundraiser. Ross ejected, he and Chelle leave DV, Chairperson resigns. End research observations in March. Village completes move to another section of of Sunderland. City and DV sign 3-year agreement. Annual elections.

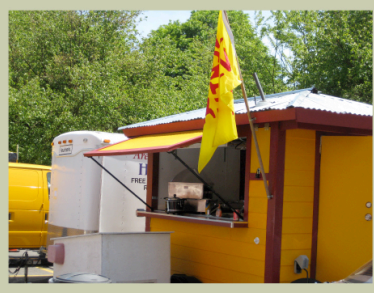

2008

Design/begin building new commons area. Outreach event with Kwamba, DV performs play and launch of Tent Cities Toolkit. New microbusiness, Dignity Dogs hot dog cart. Annual elections.

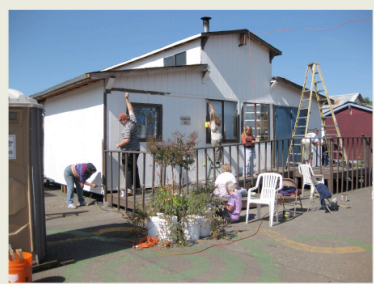

2009

Finished new commons area and all tents/shacks replaced by code-compliant micro-houses. Several new microbusiness started. Villagers begin attending City meetings on homelessness. City evaluation for contract renewal. Holiday Bazaar fundraiser. Village passes rule requiring $\$ 20 /$ month rent from residents. Annual elections.

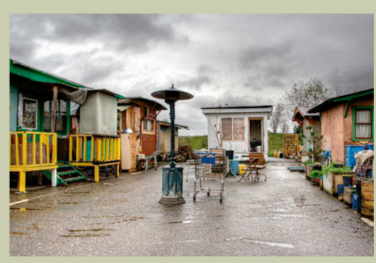

2010

New greenhouse. Donation of Greenbox building for office space. Met with State Senator about additional DV-style tent city in Oregon. Christmas in July Bazaar. 


\section{Detailed Timeline}

$2000-2010$

2000

Sept 19

Sept 27

Dec 16

Dec 20

Dec 25

Jan 15

Jan 16

Jan 23

Feb 26

Mar 23

Apr 6

Apr 30
Street Roots initiates Out of the Doorways campaign

Judge Gallagher rules camping ban is unconstitutional, enabling Out of Doorways campaign to move forward with Camp Dignity.

Street Roots submissions editor, Jack Tafari, with original crew and 6 tents starts Camp Dignity near Broadway Bridge.

Campers get rousted by police. They move to Fremont Bridge at 18 \& NW Savier and begin to receive attention from media.

Evicted again. Police Sgt. Powell tells campers that the last 5 days was their Christmas present, camp moves to Morrison St. site.

\section{1}

Camp grows to 40 tents strong, and they are again forced to move. They decide to bring attention to the issue by moving in one long line of shopping carts with signs attached to them (calling it a "shopping cart parade") to Riverplace. This demonstration was highly televised, and City Hall took notice.

Commissioner Erik Sten met with representatives from the newly named “Dignity Village." Sten pledged conditional support.

Dignity Village agreed with City Hall to move to a low-profile site, back to 18th and NW Savier to grow as a community. DV submits 40-page planning proposal and architectural blueprint to City titled, "Dignity Village: 2001 and Beyond."

DV fundraiser "An Evening Fast" raised about \$5,000 towards land purchase.

DV met with Mayor Katz.

Dignitaries from the village met with ODOT representatives who discuss possibility of formal land lease deal.

ODOT extended stay for another 60 days at Savier site. 
May 9 ODOT, city and police gave DV July $1^{\text {st }}$ eviction deadline to move off of ODOT property.

June $\quad$ First met residents of Dignity Village

Dignity Village's micro-business, Digsville Farm, was started

Dignity Village met with City Officials (DV wanted to avoid stand-off on July 1 deadline)

DV wrote an open letter to Mayor Vera Katz asking her to give them a chance

Jun 28 City officials announced that they will not sweep the village on July 1st and will continue "good faith" negotiations.

July 5 First day of filming interviews at Dignity Village (as part of documentary)

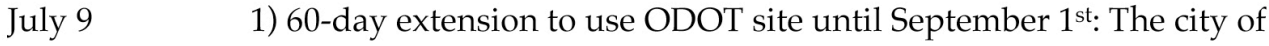
Portland asked ODOT (owner of current site) to grant DV a 60-day extension to remain on the site at 17th and NW Savier. The extension was granted.

2) Possible one-year lease on public land: The offices of the Commissioner and Mayor, along with Village leadership and supporters attempted to identify public land on which to relocate the Village under a one-year lease agreement. Under this agreement, DV must meet a number of conditions (related to size/demographics of population, relations with neighbors, code issues, cooperation with police, etc.).

3) Continued negotiations / possible pilot project: The city continued negotiations with village residents/supporters to explore incorporating the Dignity Village self-governance model (as a "one-year pilot project)" as part of the city's continuum of care for working with homelessness. July $6^{\text {th }}$ marked the first in a series of meetings to discuss conditions and strategies for locating land.

Aug By-law/Articles of Incorporation were created for 501(c)(3) status; Kwamba creates short video in collaboration with Villagers to be used at City Council meeting.

Aug $30 \quad$ The City Council voted 4-1 in support of a resolution granting official support Dignity Village. At the same meeting Dignity Village made clear its intention to accept the temporary site that the City has chosen for Dignity. The site was offered to Dignity only for the next 60 days, and its location forty minutes outside of Portland urban core as well as its other features came as a disappointment for Villagers.

Sept 3 Dignity Village announced at a press conference that it reversed its decision to move to the Sunderland Yard site, which the City has offered as a temporary location for Dignity for 60 days. The village reversed its decision 
in reaction to new information regarding water drainage and possible environmental hazards at the proposed site. Villagers were also upset by Bureau of Maintenance's decision to surround the site with a barbed wire fence.

Sept $4 \quad$ Police arrived at Dignity Village's current location at 17 th and Savier to post a 24-hour notice demanding villagers vacate that location. Police informed Villagers that they would be returning the following morning to evict everyone or put them in jail.

Sept 5 At dawn, one Villager and a supporter pitched two tents at Sunderland Yard and posted a sign on the gate that read "a deal's a deal." This act was without permission from DV, and out of the democratic process. Mayor Katz drove out to Sunderland Yard, shook hands with the individuals and thanked them for keeping their word, and recognized the two people at Sunderland as representing the Village. Shocked and angered, the Villagers lost their united voice. Dignity Village's residents packed up their belongings, and dispersed to different areas:

1) Fifteen Villagers and all the Village pets camped in tents on our farm near Forest Grove.

2) Several members of Dignity Village, homeless activists and members of the Homeless Liberation Front camped on public land in a peaceful protest of Portland's anti-camping law.

3) Everyone else scattered across Portland streets.

\section{Key Events at Sunderland Yard}

\section{1}

Sept $7 \quad$ Villagers slowly regrouped in ones and twos to the new legal city-owned site.

Sept 9 Supporters and villagers collected pallets for tents and erected a tower and dome donated by the City Repair Project. The pallets were used to keep tents off the pavement, which was subject to flooding, and Dignity Village's flag was placed on top of the dome.

Oct 22 DV filed articles of incorporation with the State of Oregon

Oct 27 DV had looked at over 100 locations; no one wanted to sell to "homeless" people even with a supporter ready to donate money to buy land. Possible leasing opportunity in SE Portland, however met harsh resistance from neighborhood association. DV could not move from city-owned property. 
Nov 1 Supporter, Lee Larson donated \$20,000 to the city for a 6-month extension to July $1^{\text {st }}$ (funds compensated the City for the loss of space and profit from composting leaves). The members of DV held a democratic vote, which narrowly passed, to stay at Sunderland for the next six months. Some members left in protest of the decision.

Dec DV filed application for 501(c)3 nonprofit status with the IRS

Dec 16 First formal elections for Village Council and Officers (Chairman, ViceChairman, Secretary, Treasurer, Sergeant-at-arms, and Security Coordinator) for one-year terms.

\section{2}

Jan 23

Feb 5

April

June

July

Dec 16

Jan

Feb 7

May 12

Nov 10

Dec 16

Jan

Jan 17

\section{Official partnership between Kwamba and DV}

Granted 501(c)3 tax exempt status from the IRS

Digsville Farm moved to our farm for five months

Press release by DV and faith based community to ask City for a 3-month extension on their lease which ended in July. DV provided a proposal to the City. DV had reviewed over 40 sites just as interim sites for 18 month until they found land to purchase. This would give time for city to change zoning laws to allow them to exist on land.

The City granted the extension

annual elections for Council and Officers

\section{3}

Kwamba hosts "DV Supporters' Retreat" at farm

DV became official fiscal sponsors for Kwamba's documentary

Strawbale house is built as part of the Village Building Convergence

DV submits 2004 proposal to the City of Portland

annual elections for Council and Officers

\section{4}

In response to a fire at DV, Villagers and supporters from City Repair built three fire stations, which featured a rainwater catchment system with gutters, downspouts, plumbed rain barrels, fire line buckets, and fire extinguishers.

Finish new promo trailer for From Doorways to Dignity documentary on Dignity Village 
Jan 24 Presentation of Dignity Village and new documentary trailer at WSU-V 2005 Honor Lecture Series, "Globalization of Homelessness and Poverty." Laura Brown (later core group research member) watches trailer for the first time.

Feb DV holds press conference to present new proposal to City of Portland (which advocates for new zoning of Sunderland Yard to allow Dignity Village to exist legally on the property)

Feb 26 In Resolution No. 36200, the City Council designated a portion of Sunderland Yard as a Designated Campground under the terms of ORS 446.265. This State statute allows 6 municipalities to designate up to two sites as campgrounds to be used for "transitional housing accommodations" for "persons who lack permanent shelter and cannot be placed in other lowincome housing." The statute clarifies that these transitional campgrounds may be operated by private persons or nonprofit organizations.

May $25 \quad$ Built many code-compliant, earth-friendly dwellings in conjunction with $4^{\text {th }}$ annual Village Building Convergence

Oct Dignity Village performed in The Filmore Hotel, directed by Helen Hill

Oct $11 \quad$ Built several more cob dwellings

Oct Jack Tafari, Chairperson, presented as keynote speaker at Crisis Innovations Fair in London, UK.

Dec 16 Annual elections for Council and Officers. Village elected 7 members for council. Board officers were elected: Jack Tafari as Chair, Tim reelected as Treasurer. Chrysler Chelle as new Vice Chair and Dean Marchioni as new Village Secretary.

Dec Chairperson (Jack Tafari) appointed Gaye Reyes (later a core group research member) as hours-keeper (also called Beancounter). Began more strict enforcement of participation requirement.

2005

Mar $16 \quad$ Sought permission from committee to apply for Human Subjects approval and begin research prior to proposing my dissertation. Permission was granted.

Mar $28 \quad$ Relocated showers

April $18 \quad$ Literary works between Village writers help raise funding

April Dean Ogden, LA music composer, in collaboration with Kwamba Productions and Dignity Village recorded the Dignity Village music album

May $15 \quad$ Established (along with other TCs) the International Tent City Day 
May 16

May - Sept

June 6

Oct 10

Oct 18

Oct 23

Dec 16

Jan

April

June

Dec 7

Dec 12

Dec 16
Kwamba Productions and DV present "Community with Dignity" at the Hollywood Theatre. Panelists include Village Vice Chair Chrysler Chelle, Washington State Professor Susan Finley, The City Repair Project's Co-Director Mark Lakeman, Village Treasurer and Outreach Coordinator Tim McCarthy, and Professor Tracy Prince of PSU's Department of Urban Planning.

Village places temporary halt to allowing new residents because building new housing. Village population decreases from a maximum of 60 to about 35 residents.

Research approved by the Human Subjects Research Review Committee Officially began research: Recruited participants for research at Village meeting First interviews with two Villagers (newcomer + long-termer) for research

Dignity Village holds "sherette" with Villagers, supporters, City representative, and architect to design Village for new location on Sunderland Yard

First core group research meeting

Annual elections for Council and Officers. New Council: Steve (Chairperson), Tim (Treasurer; core group), Ross (Secretary; core group), Laura (core group), Paul, Ken (core group), Ron (Vice-Chair)

\section{6}

Vice-Chair ejected due to noncompliance of mandatory hours. New ViceChair: Laura Brown (core group)

Chairperson ejected from position due to "disruptive behavior." New Chairperson: Tim McCarthy (core group). Big Al (core group) becomes Treasurer. KBOO radio show and shoe drive around Kinky Boots movie

\section{Proposed dissertation research to committee}

Orientation Video screening to community

Last core group research meeting

Annual elections for Council and Officers. New Council: Ken (core group), Roe (core group), Ross (core group), Bob, Donna, Randy Curl, Louey (core group), Sheri, Tim (Chairperson re-elected; core group), Sue (Vice-Chair; core group), Becky (Treasurer), and Ed (Secretary) 
2007

Jan $\quad$ Post-research interviews with core group members. Street Roots and DV fundraising benefit. Long-termer Ross was ejected from DV (Chelle left with him); Chairperson (Tim) and Secretary (Ed) resigned. Sue Parker (core group) became Acting Chair. Dean M became Secretary.

Mar End research observations

May Successfully completed moving half the Village to newly designated site at Sunderland Yard, as part of the 3-year contractual agreement with the City.

Dec 16

Annual elections for Council and Officers

2008

- Design and begin construction on a new common area building

- Kwamba Productions organizes "Thinking Outside the Cardboard Box" event at the Hollywood Theatre, funded by Regional Arts $\mathcal{E}$ Culture Council. DV writes and performs a 15-min play for the event.

- Kwamba Productions, in collaboration with Dignity Village, complete the Tent Cities Toolkit, which provides DV with a small source of income (half the proceeds go directly to DV)

- DV rolls out their new microbusiness, Dignity Dogs (hot dog cart)

2009

- Finished construction on new commons area.

- Last of the shacks/tents taken down and replaced by code-compliant micro-houses

- Opened new microbusiness, Springwater Express (coffee/pastry cart)

- Opened new microbusinesses, “yard sale” and nursery plants

- Start regularly attending Portland's Coordinating Committee to End Homelessness

- $\quad$ Evaluated by City of Portland - part of process for renewal of contract with the City

- First annual Holiday Bazaar (fundraiser)

- $\quad$ DV members democratically pass rule that requires every resident of DV to contribute \$20 per month towards the Village's operating expenses.

\section{0}

- Built a new greenhouse for microbusiness (plant starts, etc)

- Approval and donation of a Greenbox house to be used as their office

- Meet with Oregon State Senator Chip Shields about second Dignity Village

- Christmas in July bazaar (fundraiser) 


\title{
APPENDIX B: PRESENTATION OUTLINE FOR RECRUITMENT
}

\author{
Recruiting Script - General Membership meeting (October 6, 2005) \\ Introduction
}

Note: Ask Tim or Gaye to introduce me and Kwamba's long time partnership with the Village, how we work together with the Village participates in creating media products to promote Dignity Village.

\section{Background}

Over the past year, the Village has been talking about the importance of creating an orientation video. What I've heard from several Villagers is that it is difficult to maintain a sense of community and vision when Village membership changes so frequently. The purpose of the orientation video is to help inform new residents about what it means be a Villager, where the Village came from, how and why it formed, its vision. The idea would be for the video to be a useful tool in maintaining a sense of unity and vision among the Village over the long term, showing newcomers how they can contribute to (participate in?) this community.

\section{Dissertation Research}

Some of you may know that I've been a student at PSU for many years now, and I've finally come to the end with my dissertation research as the Grande finale. And I wanted my research to be something that I feel strongly about, and that for me would be to work in partnership with the Village to create a media tool that will be useful and effective for the community. In talking with a number of you, it seems that the orientation video is the tool to create for this research.

The type of research I am proposing to do is called community-based action research which is collaborative and an approach much like how we've been working together. The key to this type of research is in the word "action" which places importance on participants as being co-researchers and the researcher as facilitating. The belief is that you are in the best position to be experts on solving your own day to day problems in the Village.

So, the process of creating the video would be similar to how we've traditionally worked together in that it will continue to be collaborative and inclusive and will involve meeting as a group a number of times to brainstorm over what should be included in the video, to write the script or narration, to select video footage from our archives, and give feedback on different drafts of the video as we create it. 
How the process is different from our typical working relationship is that as part of my dissertation research, I will be documenting the process by videotaping all of our discussions as we create the video and maybe some additional interviews to get multiple viewpoints from the entire village. Another difference in the process is that as part of my research, I will be completing two products for my degree: 1) a written manuscript that introduces and discusses the research process, and 2) a separate video documenting the research process. These are in addition to the orientation video which we will create together. All of these will be viewed by my dissertation committee members and archived in the university library system which can be accessed and loaned to other students and community members throughout the U.S.

\section{Conclusion}

I think that's all I want to say today. I don't want to talk too much. I just wanted to introduce the research, answer questions, and get a sense of who would like to participate in creating the video. I can see at least two ways you can participate (but I'm sure there may be more): (1) as part of the core "research" group who meets as a team to create the video (maybe about 10 times over the next few months - but we should decide timing together during our first meeting), or (2) as a community consultant who provides insight and feedback on drafts of the video. I was hoping that 7-10 people would like to be part of the core group, and as many as possible as consultants. If you want to be part of the core group, it's best if you can make it to every meeting. As consultants, it will be more flexible but may involve meeting about two times.

I'm going to pass the sign up sheet around. Let me answer any questions, and then if you don't mind, let's set up the first time/date to meet if you want to be part of the core group (and we can name it something else later if you'd like.)

DATE TO MEET: Suggested date for our first meeting: Sunday, October $23^{\text {rd }}$ at about noon (two weeks) 


\title{
APPENDIX C: CONSENT FORMS
}

\author{
Core Group Consent
}

You are invited to participate in a research study conducted by Heather Mosher in partial fulfillment of the requirements for a doctoral degree, which is under the supervision of Dr. Ellen Skinner, Professor of Psychology at Portland State University. The purpose of this study is to assist Villagers in developing an orientation video to re-energize participation at Dignity Village.

If you decide to participate in this research, you will be asked to do the following as part of the research team:

- Assist in gathering relevant Village records

- Participate in two interviews in which you will be asked about your participation in Dignity Village, the general level of participation at the Village, and your experiences in the research

- Assist in recruiting other participants

- Help to create and keep team work a positive experience for everyone

- Assist in interviewing other Villagers about their participation in Dignity Village

- Discuss important points and relevant video materials to include in the orientation video

- Search through the Village archives database to select portions of video materials to review

- Review and select portions of video materials to use in the orientation video

- Arrange the video materials in order to create a story for the orientation video

- Review and discuss the weaknesses and strengths of the roughly edited video

- Show the orientation video several times to other Villagers to get their feedback

- Modify the orientation video based on feedback and group discussions

You will be asked your permission for videotaping your interviews as well as the team's work and community discussions during the research process. All video records will be added to the Village video archives to be used in future research and in other media products about Dignity Village and homelessness.

There are potential risks to participating in research. While participating in this study, it is possible that you may suffer from emotional arousal/distress due to this 
research process. To try to protect against these risks, Heather will assist in creating a group climate in which emotional states can be managed, openly accepted and processed. It is also possible that you may suffer from emotional arousal after the completion of the action tool if you are featured in it. To try to protect against these risks, you will participate in making these decisions about which portions of video materials to include in the final orientation video. In the case of any questions or concerns, all participants will be encouraged to contact Heather.

You may benefit personally from your participation in the research process. The main focus of this type of research is to facilitate personal growth and learning. As a result, you may experience enhanced energy, creativity, pride, and a sense of worth. Throughout the research, you may also learn new skills and build positive relationships with others. As a result of your participation, you may also help to improve the level of participation by others at Dignity Village. The potential benefits of the project far outweigh the risks.

If you give permission to be shown in the orientation video, you will be given the option to be identified by name or pseudonym. Otherwise, if you are not featured in the orientation video, your name will remain confidential.

All videotapes, documents, and other archived media will be stored in a locked closet at Heather's office at Kwamba Productions, located at 7140 SW Lee Road, Gaston, Oregon. Access to these materials will be restricted to appropriate cases. Heather will collect and copy relevant footage onto VHS tapes for participants to review during the research. The final version of the orientation video will be stored in a locked media safe, and several copies will be given to Dignity Village. All data and records will be kept on file for a minimum of three years after the completion of the research. All talent release forms and consent forms will be stored in a locked safe and kept separate from the video records.

In the case of showing or giving any product of this research to some place other than Dignity Village, Heather will ensure that your name and personal details are not passed on to third parties (for example broadcasters) without your consent. Portland State University will not become involved in any business arrangements that may result from such contacts.

Your participation is voluntary. Your participation or non-participation will not affect your relationship with Portland State University, Kwamba Productions, or with Dignity Village. You may also withdraw from this study at any time.

If you have concerns or problems about your participation in this study or your rights as a research participant, please contact the Human Subjects Research 
Review Committee, Office of Research and Sponsored Projects, 111 Cramer Hall, Portland State University, (503) 725-4288. If you have questions about the study itself, contact Heather by phone at 503-985-3337 or by mail at 7140 SW Lee Road, Gaston, OR 97119.

Your signature indicates that you have read and understand the above information and agree to take part in this study. Please understand that you may withdraw your consent at any time without penalty, and that, by signing, you are not waiving any legal claims, rights or remedies. You will be provided with a copy of this form for your own records.

(please print your name) 


\section{Community Consultant Consent}

You are invited to participate in a research study conducted by Heather Mosher in partial fulfillment of the requirements for a doctoral degree, which is under the supervision of Dr. Ellen Skinner, Professor of Psychology at Portland State University. The purpose of this study is to assist Villagers in developing an orientation video to re-energize participation at Dignity Village.

If you decide to participate in this research, you will be asked to:

- Participate in two interviews in which Heather will ask you about your participation in Dignity Village, the general level of participation at the Village, and your experiences in the research.

- Participate in several community meetings to review the orientation video. You will be asked to give your reactions and feedback on the video.

You will be asked your permission for videotaping your interviews as well as the community discussions during the research process. All video records will be added to the Village video archives to be used in future research and in other media products about Dignity Village and homelessness.

There are potential risks to participating in research. While participating in this study, it is possible that you may suffer from emotional arousal/distress due to this research process. To try to protect against these risks, Heather will assist in creating a group climate in which emotional states can be managed, openly accepted and processed. It is also possible that you may suffer from emotional arousal after the completion of the action tool if you are featured in it. To try to protect against these risks, you will participate in making these decisions about which portions of video materials to include in the final orientation video. In the case of any questions or concerns, all participants will be encouraged to contact Heather.

You may benefit personally from your participation in the research process. The main focus of this type of research is to facilitate personal growth and learning. As a result, you may experience enhanced energy, creativity, pride, and a sense of worth. Throughout the research, you may also learn new skills and build positive relationships with others. As a result of your participation, you may also help to improve the level of participation by others at Dignity Village. The potential benefits of the project far outweigh the risks.

If you give permission to be shown in the orientation video, you will be given the option to be identified by name or pseudonym. Otherwise, if you are not featured in the orientation video, your name will remain confidential. 
All videotapes, documents, and other archived media will be stored in a locked closet at Heather's office at Kwamba Productions, located at 7140 SW Lee Road, Gaston, Oregon. Access to these materials will be restricted to appropriate cases. Heather will collect and copy relevant footage onto VHS tapes for participants to review during the research. The final version of the orientation video will be stored in a locked media safe, and several copies will be given to Dignity Village. All data and records will be kept on file for a minimum of three years after the completion of the research. All talent release forms and consent forms will be stored in a locked safe and kept separate from the video records.

In the case of showing or giving any product of this research to some place other than Dignity Village, Heather will ensure that your name and personal details are not passed on to third parties (for example broadcasters) without your consent. Portland State University will not become involved in any business arrangements that may result from such contacts.

Your participation is voluntary. Your participation or non-participation will not affect your relationship with Portland State University, Kwamba Productions, or with Dignity Village. You may also withdraw from this study at any time.

If you have concerns or problems about your participation in this study or your rights as a research participant, please contact the Human Subjects Research Review Committee, Office of Research and Sponsored Projects, 111 Cramer Hall, Portland State University, (503) 725-4288. If you have questions about the study itself, contact Heather by phone at 503-985-3337 or by mail at 7140 SW Lee Road, Gaston, OR 97119.

Your signature indicates that you have read and understand the above information and agree to take part in this study. Please understand that you may withdraw your consent at any time without penalty, and that, by signing, you are not waiving any legal claims, rights or remedies. You will be provided with a copy of this form for your own records.

(please print your name) 


\section{APPENDIX D: DIGNITY VILLAGE P.A.R. BOOKLET}

\section{Dignity Village \\ Participatory Action Research Booklet}

We came armed with a vision of a better future for ourselves and for all of Portland, a vision of a green, sustainable urban village where we can live in peace and improve not only the condition of our own lives but the quality of life in Portland in general.

For more information:

Dignity Village

9325 NE Sunderland Rd

Portland, OR 97211

www.dignityvillage.org
Kwamba Productions

7140 SW Lee Road

Gaston, OR 97119

www.kwamba.com 


\section{Acknowledgements}

We would like to acknowledge the contributions and participation of everyone involved in our collaborative work towards improving our community. It started from seeds of hope - anchored in the story of Dignity Village, its roots and vision. We hope that both the process of storytelling and the story itself will bind the community together and re-invigorate and align our vision once again.

The action researchers in this participatory action research project include the following individuals:

Core Group (alphabetical order by first name):

Alan Rocheleau (Big Al)

Chrysler Chelle (Chelle)

David Carpenter

Gaye Reyes

Heather Mosher

Kenneth McMichael (Ken)

Laura Brown

Louis Wilhelms

Lydia Kushner

Michael Moore

Roeac Crotzer

Ross Bennett

Stephanie van Houten

Susan Smith (Sue)

Tami Jaha

Timothy McCarthy (Tim)

Wendy Kohn

Community Consultants (alphabetical order):

Alan Shipley

Alfred

Dave Hirschman (Dog Dave)

Dean Marchioni

Jon Fredricks

Juli Preston

Travis Ougheltree 


\section{Statements by Several Core Group Members}

\section{Chrysler Chelle}

The continuation of an active, healthy and functioning Dignity Village is imperative to the homeless community, both in Portland and throughout the world. I became involved in Core Group hoping to help facilitate positive changes in the current system because I see our lack of activism, participation, desire to achieve and personality conflicts are becoming extremely detrimental to the ongoing operation and sustainability of the Village. The 'Status Quo' is no longer acceptable because it is leading us directly down the path of ultimate failure in our mission to the citizens of Portland, and therefore to other potential tent cities who are attempting to adopt our model. If we fail, they may get no opportunity to try at all.

Change is difficult even if it is necessary and desirable. We spend too much time passing the buck to 'someone else' to enact the work of change. This is a worthy project as some improvements are sure to come about inspiring the continuation of a newly functioning, working Village. Our new people are destined to become the leadership of the future and their participation in this project is to their credit, they are rapidly becoming acquainted with the areas we are lacking in, are approaching problems with a fresh perspective and show the incentive and willingness to improve upon the foundation that is in place. With new guidance we may be able to overcome and turn our Village to a newly successful, exciting future.

Changing, growing, improving, coming together to serve.

\section{Gaye Reyes}

One of the reasons I got involved with the core group was to give the present villagers a say-so in how the village is run. The core group has made an outline on what the village needs to do to keep it running and running the way that it needs to go. More like a reference book that all future department heads, board officers, counselors, and villagers will have at their disposal to help them stay on track. I would like to see this to continue so it covers all departments. We seemed to concentrate on the intake, but much of this can be geared to others as well.

Thanks to you and Wendy for your help. I think this is something we have needed for some time. Hope we have been a help to you as well. 


\section{Heather Mosher}

Several months ago, I was asked by Sue (at the time, a newcomer at the Village and now a continuing core group member) why I am so involved with Dignity Village. Surprisingly, I found myself floundering in my answer, when just a couple years ago, I answered it with ease. As I attempted to articulate my reasons for my involvement, I discovered that something had changed for me over the years. I lacked not only the words, but also the self-awareness to answer this question in a way that fully captured my reasons. It no longer felt cognitive (e.g., "I am involved because it is important that the world hear Dignity Village's story"). What I have discovered is that my role in Dignity Village has somehow slowly seeped into my very identity, values, view of the world, and actions. I am as dumbfounded by the question as if the question were "Why are you the way you are?" Nevertheless, the question is indeed relevant, as it concerns being explicit about my agenda to those that I work with at Dignity Village.

I believe that at the heart of my answer is the empowering influence that Dignity Village has had on me. Dignity Village lit a fire under my feet to take action and to become an active citizen. My understanding of homelessness developed through my experiences with Dignity Village. They were my teachers. (It is only in the past couple of years that I have begun to extensively read literature on the subject.) My studies in a classroom at Portland State University have been about my individual quest for knowledge and information; Dignity Village is about relationships and a shared understanding, and most of all, a hope for something better and more just. It did not depend on me and my performance; it depended on us.

As I became part of Dignity Village, it became a part of me. I now understand that I am an activist, as this part of me surfaced and took shape through my experiences as a participant in Dignity Village. Like a religious awakening, I began to believe in something greater and beyond myself, to see myself connected to a larger whole, and then to understand my responsibilities as a citizen and community member to take action for social justice. Now, as a nascent activist and community psychologist, the intent of my work is to awaken others into seeing possibilities for social change, and then acting on these visions. As this is my agenda, I continue to be involved because I am involved; I am committed to the vision of Dignity Village and to the relationships within the community, and this bond gets to the heart of why I chose to facilitate and participate in this research and in Dignity Village. 


\section{Ross Bennett}

I think the value of this research is immeasurable and crucial to the viability of the Village heartbeat.

In the year 2001 I wandered into Dignity Village and was in awe, of the People of the Streets taking control of their lives collectively, finding and fighting for rights to exist.

When Rosa Parks sparked a movement there was fire burning hot in many oppressed people's souls, and that same spirit of non-violent disobedience arose again radiating the many faces of homeless people. Dignity Village is a living organism that one person cannot control, although not for the lack of trying. The Village has endured patriarchal leadership in the past that moved personal agendas and it wasn't just the guys, the other side of the gender balance has pulled a few doozies also. But the safety zone is this: We have discovered ourselves, established rules, found rights and defended them. And now as any organism depends on its health and ability to grow, we must evolve into a stronger member of our community as a flagship of social change. And that's exciting!

So healing starts at home and sometimes it is good to look at all perspectives to weigh and reason them. I have given your research extreme validation, and found it frank and credible as to what I have learned in my time here at Dignity. The collaboration is centered around a "Core Group" and individual Villagers and has been a Labor of Love over 6 years in the running. Also, I acknowledge that Kwamba is a vital part of the Village vision and truly are Villagers themselves.

\section{Tami Jaha}

I came out of the doorways and into Dignity Village with a wish that I could find funding and grants to purchase a small piece of property, one-quarter to an acre, that I could park my van or small trailer on, which is my goal or vision of dignity as a responsible village: so as not to put a person back on the street to risk persecution or even death. So far, I've saved up $\$ 700$ to help in this venture as my part. This is not only a dream, but a vision, besides leaving the doorways to dignity open forever, and researching other villages to visit or stay. My times with Wendy and Heather have helped in the development of the Village filming process, and have provided in my success as a happy camper at Dignity. I look forward to you always being here and researching my success. Thank you. 


\section{Timothy McCarthy (Tim)}

This research has been valuable because we have been learning how to do something that we have never done before. None of us really had any knowledge or skills in creating a video, so the process has been really interesting and important. I think that when we show the orientation video to newcomers, it will make a difference.

Before coming to Dignity Village, I had been a manager of a business, so I had experience with action plans; we created and implemented them all the time. Although developing an action plan is not new to me, I still think it has been very helpful to the Village, and plus, the fact that it is part of research brings even more credibility to it.

\section{Wendy Kohn}

During the nearly five years so far that we have worked with Dignity Village, I have had numerous occasions to admire the incredible strength and focus of the people who live there every day. They shrug off the non-stop physical challenges of living in tents in a cold and wet environment (conditions that reduce me to a whiny, shivering mess) and the daunting obstacles put in front of them by an uncaring society, and manage somehow to work and laugh and create a community, not without tears and anger and even violence, but a community nonetheless, and their own. I may perhaps never know how I might respond under such pressures, but I can only hope that I will have even half the dignity and pride I have seen in this community. And so I am deeply gratified to be known as an "honorary" member of Dignity Village. 
Introduction to the Participatory Action Research Project

(Note: This section of the booklet was adapted from the dissertation written by Heather Mosher and submitted in partial fulfillment of the requirements for her PhD in System Science/Psychology at Portland State University, Portland, Oregon.)

\section{Background}

The prevailing response to homelessness in this country implies that homeless persons are to blame for their own plight. This attitude leads to unhoused individuals often experiencing a loss of self-worth, a sense of powerlessness and a loss of hope. For many individuals experiencing homelessness, their situation means a loss of dignity and control, standing in countless lines to receive basic needs, sometimes being sent away empty-handed after a long wait, without a bed, a meal, or even a blanket to keep from freezing on cold winter nights. With the ongoing lack of shelter beds or transitional housing, homelessness for many individuals means learning to look for a place to sleep outside, hoping that you won't be kicked awake and told to move along by a police officer or harassed by housed citizens who detest you and want homeless persons out of their sight. ${ }^{\text {vii }}$ Homelessness means learning to depend on others to meet one's basic needs because any efforts to "do it yourself" are discouraged and often punished, as for example, when creating a safe place to sleep outside. Homeless individuals commonly report their experience of homelessness as associated with a lack of permanent housing or a secure place for physical possessions, a feeling of isolation, rejection or alienation, a lack of emotional attachment to or identification with a place and a lack of a safe space for psychological belonging. ${ }^{\text {viii }}$ These experiences, combined with the lack of control over one's own time, space and options and the inability to be included in decision-making that directly affects one's life, can lead to a sense of powerlessness individually ${ }^{\text {ix }}$ as well as a clear lack of social power relative to other classes in society.

The tent city social movement, in which Dignity Village takes part, addresses these issues of power and discrimination as well as addressing the practical needs of homelessness, such as the lack of available low-income housing. Dignity Village addresses these issues both through their resistance against the undignified 
"help" from the dominant homeless helping system, as well as through their vision of self-help and grassroots democracy. With a philosophy of self-sufficiency, residents help each other build their settlements "out of waste spaces and discarded materials," creating a safe environment to live and grow together as a community. ${ }^{\mathrm{x}}$ "People with no property except what they scavenge- have turned these outlaw spaces into places of habitation, respite, and even hope. They do so even in the face of the constant threats of eviction, fire, and filth." ${ }^{\text {, }}$ A small body of literature on encampments consistently finds that residents experience an increased sense of control and privacy, safety, a self-image of independence, friendship and mutual support, a sense of solidarity, hope for change, autonomy, and empowerment. ${ }^{\text {xii }}$ These self-help communities appear to provide fertile grounds for establishing collective identity and collective action. ${ }^{\text {xii }}$ As residents participate equally in the process of creating rules and policies that govern their community, they begin to develop a collective identity based on shared values and needs that are often centered on issues of social justice for other homeless people and collective action in helping each other acquire housing and needed services. ${ }^{\text {xiv }}$

Tent cities provide more than services and hope for their residents. Tent cities are political by challenging the nation's core assumptions about homelessness through tent cities' emphasis on self-determination and democracy. ${ }^{\mathrm{xv}}$ Harris, the Director of Real Change, emphasizes that "...there is a distinction to be made between organizing that empowers homeless people as individuals, and that empowers them as a class."xvi People experiencing homelessness have been excluded from the dialogue on homelessness and restricted from the ability to control their lives as well as their path out of homelessness. While affordable housing is the long-term solution to ending homelessness, tent cities are a costeffective and community-based solution in the interim, providing safety and shelter in a supportive, dignified, and democratic environment. Within the tent city model, residents collectively gain voice and the social power necessary to sit at the "policy table" and participate in the dialogue and decision-making that affects them. Dignity Village has demonstrated how a self-organized community can give people room to hope and room to organize for real change. The challenge now lies in sustaining the energy and collective action required for its survival and continued effectiveness for social and political change. 
Currently just over five years old, Dignity Village faces the challenge of sustaining a shared vision and the active participation of its members, a problem commonly faced by most volunteer organizations, ${ }^{\text {xvii }}$ tent city encampments, ${ }^{\text {xiii }}$ and social movements for housing. ${ }^{\text {ix }}$ At Dignity Village, participation and a sense of community waxes and wanes, but more recently, it has dwindled to levels lower than ever before, becoming problematic for the community as a whole. The common vision and intense collective energy that once existed and helped to sustain the struggle to build Dignity Village into its own powerful and legally legitimate entity has slowly degenerated into disparate visions, a generally negative mood, low morale, and in some cases, frustration and withdrawal of individuals from the community. A small group of active participants see themselves as carrying most of the weight and responsibilities of running the organization, while the majority of members and residents fulfill only their minimum required work of ten hours per week, avoiding or withdrawing from the self-governance activities of the Village that occur through participating on committees and on the Village council. Long-term Villagers (Villagers who have stayed more than a few years) also describe a change in the quality of interpersonal relationships, collective action, and an overall disinterest in political critiques or action.

The community has taken efforts to boost participation, but they have not seen any significant change in residents' emotional investment and actions. If they do not get to the root of the problem, many Villagers foresee a gloomy fate for Dignity Village, that of short-lived success. Several Villagers have explained that the loss would impact more than the members of Dignity Village. It would be a serious step backward for social change. As Dignity Village is considered one of the longest surviving, entirely grassroots and democratically self-governed tent cities currently in the US, it is a model and inspiration for many newly emerging tent cities and homeless activists. A core group at Dignity Village, aware of the significance of this community problem, is determined to understand the complex dynamics that have given rise to this state of disaffection, in hopes of discovering the means to improve their situation. 


\section{The Research Context and Focus}

We must indeed all hang together, or, most assuredly, we shall all hang separately.

- Benjamin Franklin

Because of the complexities in solving this issue of low morale and participation, Villagers are seeking multiple effective avenues to re-invigorate community participation and a collective identity. The Village desires to restore the emotional engagement, participation, and empowerment that have been slowly deteriorating. Most everyone at the Village has heard one story or another about being "under the bridge" (during the first months of Dignity Village's inception). One main element emerges as a common thread through the various community stories about this period of Village history: a belief in a larger purpose or cause, a shared vision of community beyond the individual-focused task of finding a home. The vision of Dignity Village is that all people in their community are participants and community members in a long-term action plan for social change. Under the bridge, external conflict and necessity strengthened their ties. Now, what is the tie that binds them together? This question guides both our exploration and action in this research, in which the community has turned to storytelling as a vehicle to reinvigorate a sense of community with emotional connection, history and continuity, identity, and meaning. ${ }^{\mathrm{xx}}$

Several community members at Dignity Village have pointed to the transformative power of video in this regard. They explain their intense feelings of pride and ownership when they had the opportunity to see themselves, their history, and their story pulled from their own Village archives, in videos created for outreach or portions of the documentary. The videos elicited strong feelings in both longer-term residents who were reinvigorated by remembering their early efforts, and inspiring to those who had not been part of the original group. As Villager Laura noted, "The video made me see that at Dignity Village, I am part of something really important, something much bigger than myself."xxi

Given their experiences with the impact of video, the community has defined as a goal of the research to develop a video-based action tool that tells the 
community narrative, which will act as a catalyst for re-establishing a sense of community and identity, along with enhanced community participation and empowerment in Dignity Village. The intent of this research is aligned with the Village's long-term goal of providing supportive conditions and empowering processes that allow individuals to obtain more social power and to organize for long-term social change.

\section{Collaborative Research Methodology}

The current research project is rooted in the philosophy and practice of participatory action research (PAR). This form of research is not just a means of acquiring knowledge for knowledge's sake, but rather is a process of collaborative learning through taking action towards reaching a goal or solving a problem significant to the well-being of the community, and is therefore particularly suited to the situation at Dignity Village. Communities learn from a process of taking action, studying the processes and consequences of these actions, and constantly striving to improve and develop effective solutions. The research follows a cyclical process by which change and understanding can be pursued within a process of action and critical reflection. ${ }^{\text {xii }}$

Participatory action research is considered to be an orientation and approach more than a research methodology. Although definitions and approaches to PAR vary, the paradigm shares a set of core principles: it aims to be empowering and collaborative with a goal of acquiring practical knowledge and social change. ${ }^{\text {xiii }}$ It is founded on the recognition that participants are researchers themselves in pursuit of answers to the questions of their daily struggle and survival. ${ }^{\text {xiv }}$ As a community-based research approach, it is embedded in the values and practical concerns of communities. ${ }^{x x}$ It assumes a strengths-based approach consistent with principles embraced by community psychology in which participants are encouraged to recognize, use and build on their own strengths and existing resources to accomplish their goals, as well as the strengths and power of their collective communities. ${ }^{\text {xxvi }}$

The term "action" in PAR represents Kurt Lewin's concept of action research and social action ${ }^{\mathrm{xxvii}}$ which involves increasing citizen voice and power, building sociopolitical awareness, and facilitating social or systemic change. ${ }^{\text {xxviii }}$ 
Lewin viewed social research as both scientific and socially engaged, and that "the best way to understand something is to try to change it."xxix Action represents the idea that there are different ways of learning, and one way is through "knowledgein-action." ${ }^{\mathrm{xxx}}$ Taking "action" means working toward practical outcomes, and creating new forms of understanding. "Action without reflection and understanding is blind, just as theory without action is meaningless."xxxi A major goal of PAR is to provide a means for marginalized communities to re-establish power and control in their own lives, ${ }^{\text {xxii }}$ helping people to understand themselves as agents of change. ${ }^{\text {xxiii }}$

As part of the process of re-establishing power and control, there must be a shift in the role of the researcher from "expert" to "researcher-facilitator" and from "participants" to "co-researchers." This change in terminology represents a shift both in researchers' working relationship with participants and in their assumptions about knowledge production and who is the "expert." Researchers engage "participants" as equal and full research partners in the entire research process, ${ }^{\text {xxxiv }}$ from defining the problem based on what is useful and worthwhile, to formulating mutually acceptable solutions to the stated problems. ${ }^{\mathrm{xxx}}$ Participants are seen as competent social actors and co-researchers who are the experts on the topic and its direction, while the researcher-facilitator is an expert in the sense of consultant, facilitator, and protector of process. The role of a researcher-facilitator is to help create and facilitate a process that amplifies diverse voices in the dialogue, ${ }^{\text {xxxi }}$ expands choices, ${ }^{\text {xxvii }}$ and provides space for individuals to reflect and realize their power as a member of a collective community within a broader social change agenda. ${ }^{\text {xxviii }}$ Researcher-facilitators help to create and maintain a context and process that stimulates people to change, supports positive working conditions that are empowering and productive for participants, enables people to develop their own analysis of their issues, and assists in planning and implementing their plan by raising issues and helping to locate resources. ${ }^{\text {xxix }} \mathrm{A}$ researcher-facilitator's main focus is to facilitate human development and learning. The research is a collective learning process in which the community coresearchers engage actively in dialogue and action to understand their situation and take steps toward improving their community and exercising their power. 


\section{The Current Research}

The intent of this research is aligned with the long-term goal of providing conditions and processes that support Dignity Village in participating as equals in public discourse and policy debates on homelessness, in obtaining more social power, and in organizing for long-term social change. The immediate goal and focus of the current study is to address community issues that currently undermine participation, a sense of community, and empowerment, giving rise to the current state of disaffection within Dignity Village. The research has been carried out within a collaborative approach of participatory action research, which involves democratically creating and maintaining research processes that promote community empowerment.

The research procedures focus on process with goals of implementation of action steps and the creation of products, which are referred to as "action tools." Action tools are developed through a democratic process by which a core group of Dignity Village residents meet and plan research activities together, with a focus on creating an effective and context-relevant tool. The action tool is envisioned as an orientation video that portrays the community narrative, including where they came from, who they are, and future visions of possibilities for their community and for social change. Village members intend to use the action tool in their orientation process for "newcomers" as well as for "long-termers" in the community, with the hope that the tool will help to re-establish a sense of community and identity, participation, and cooperation that may make Dignity Village, once again, an empowered community with a shared vision for social change.

\section{Ground Rules for Group Work}

One of the goals of participatory action research is to create a working context that is supportive, empowering, and allows for individuals to learn and develop. 


\section{Ground Rules}

The ground rules that we developed throughout the research were inspired by and adapted from Gaye's love of "Robert's Rules of Order" as well as from Dignity Village meeting protocols, and basic guidelines for facilitation and group work. The ground rules were developed to provide some level of structure that promotes effective communication, efficiency, individual learning and empowerment, and participation by everyone. We believe the following ground rules and procedures for process have been useful:

First ten minutes of meeting:

- Welcome newcomers to the group

- Review ground rules (for newcomers or if group needs to review or change ground rules based on experience)

- Review progress - get everyone up to date

- Describe and get group agreement on agenda and direction for meeting

- Set a reasonable time schedule / goals for meeting (group member takes role of time keeper - to keep group moving forward and aware of schedule)

\section{Meeting process:}

- Facilitator asks broad question related to goals of meeting

- Go-round - give opportunity for everyone in group to talk on topic

- Then either (a) allow free-flow discussion (if small group or brainstorming) or (b) talk in turn by raising hands (a facilitator or group member keeping the order, or "stack," on a note pad)

- We set a 2-3 minute time limit per person / topic (for efficiency)

- Decisions by consensus (if deadlock, then $51 \%$ vote)

- Respect and value others, their opinions, views and contributions to the group work

- Encourage participation by everyone in group; begin another "go-round" process as needed

\section{Last 10-15 minutes of meeting:}

- Reflect on group process: (a) what did we accomplish, (b) what are concrete action plans for a specific time period, (c) what worked and didn't work, and (d) what should we improve on for next time? 
Available Roles for Protecting Group Process (but not limited to these roles)

- Facilitator(s) - to assist in keeping the group on-task, accomplishing goals, and promoting communication and supportive relationships for group work

- Note-taker - to write down important points either on an easel to facilitate group process, or in a notebook for record-keeping

- Schedule Monitor - to monitor time according to the meeting schedule

- Time-keeper - to monitor an individual's time speaking using a timer (2-3 minutes)

- Stack Monitor - to write down and manage the order of those who would like to speak.

\section{Specific Goals of Research}

The group decided on two main goals for the research, and for improving the orientation process at Dignity Village. These goals were to: a) create an implementation action plan for improving newcomer orientation, and b) produce an orientation video as a tool for welcoming newcomers and sharing the community vision. Several steps were involved to accomplish each goal. The next section describes the steps involved in creating an implementation action plan for orientation. See page 35 for a description of the steps involved in producing the orientation video. 
Steps to Create Action Plan for Newcomer Orientation

The following steps were involved in creating an implementation action plan for newcomer orientation.

1 - Process and Ground Rules for Group Work

Goal: To collaboratively develop a research context that facilitates coresearchers' empowerment (i.e., working conditions need to maintain positive working relationships, and enhance participants' feelings of dignity, autonomy, competence and ownership). During our first meeting, we discussed and identified ground rules for meetings to minimize the possibility of conflict and to provide conditions conducive to productive work. Once ground rules were established, we decided who would facilitate the meeting, and whether facilitation would rotate to different individuals across meetings. Together, we decided on the direction of the research and a general agenda for the research. Throughout the research period, ground rules and processes were revisited and discussed for continuous improvement on processes. The role of the facilitator is to provide structured ways to maximize participation by those involved, plan meeting procedures and assist in creating weekly agendas to maximize efficiency of group work. A primary focus of the facilitator is to maintain supportive conditions for positive working relationships and to assist in protecting process.

\section{2 - Understanding the Current State of Low Morale at Dignity Village}

Goal: To systematically and jointly build a picture of the state of the organization which will lead to an extended understanding of what and how the general state of disaffection occurred, identifying the best places for leverage and most impact, and creating an action map of specific action steps to address the issues. As a group, we created an initial plan for this process to enhance the group understanding of the problems and potential solutions. This process included:

(a) creating a process diagram of the orientation process that illustrates current process, protocols and practices 
(b) problem exploration - identifying "problem areas" or "areas for improvement" in the orientation process that may help to increase participation in the community

(c) brainstorming and ranking possible options for solutions to improve the orientation process

(d) creating a step-by-step implementation action plan for one of the solutions which was considered priority

(e) creating an orientation video

Each of these steps provides a process that refines the focus of the research and describes concrete action steps to implement, as well as providing action tools along the way that the community can use in the future to continue the research process and planning in order to improve the orientation process. The remaining part of this section describes each of the steps in the process (see Figure 1 for an overview):

(Figure 1)

(a)

Process diagram (b)

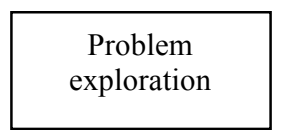

\begin{tabular}{l} 
Nine areas for \\
improvement: \\
\hline Problem 1. \\
Problem 2. \\
Problem 3. \\
Problem 4. \\
Problem 5. \\
Problem 6. \\
Problem 7. \\
Problem 8. \\
Problem 9.
\end{tabular}

(c)

Solutions list

Three lists:

Problem 1:

- solution 1A

- solution 1B

- solution $1 \mathrm{C}$

Problem 2. - solution 2A

- solution 2B

Problem 3.

- solution 3A

- solution 3B

- solution $3 \mathrm{C}$

- solution 3D (d)

Implementation action plan

One action plan:

Problem 1:

- solution $1 \mathrm{~A}$

*step a...

*step b...

*step c...

*step d...

- solution 1B

*step a...

*step b...

*step c...

- solution $1 \mathrm{C}$

*step a...

*step b.. (e)

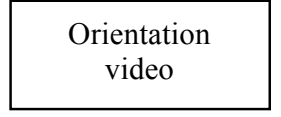




\section{(a) Process Diagram of Current Orientation Process, Protocols and Practices}

The diagram was developed to provide structure for group dialogue in clarifying and describing the current practices in Dignity Village's orientation process. The group used the diagram as a tool for exploring and identifying areas for improvement. As the diagram is updated with new policies and procedures, it can be used in future action research toward continual improvements to the process.

\section{(b) Problem Exploration - List of "Areas for Improvement"}

This list of areas for improvement in the orientation process was created by the research group as we explored the participation problem and how certain practices might be changed in Villager orientation to increase participation and a sense of community. The areas for improvement were ranked by priority, with "ineffective orientation of newcomers" considered first priority for addressing the problem of low morale and participation. The current research will undertake this first priority, leaving eight additional areas for future research. This list can be used as a tool for these future undertakings.

\section{(c) Solutions List to Improve the Process}

The research group developed a list of possible solutions for the first three prioritized areas for improvement as an initial step toward developing implementation action plans for each solution. As this current research will create only one implementation action plan, the additional "solutions lists" that were created will be a tool for future efforts in implementing action plans for two other areas of improvement: "unclear communication/information" and "negativity/lack of support/rumors."

\section{(d) Step-By-Step Implementation Action Plan for Newcomer Orientation}

The group selected one of the three solutions lists to use in creating a step-bystep implementation action plan. The chosen solutions list was the one created for solving the priority problem of "ineffective orientation of newcomers." The group also expanded their definition of "orientation" to include a "re-orientation" process for all residents and members of the community. The research group developed a step-by-step action plan that detailed the sequential steps needed to implement the identified solutions. The steps in the process involved: a) discussing the feasibility of the solutions list created in the brainstorming session regarding possible ways to 
improve orientation; b) prioritize the feasible solutions for order of implementation; and c) create specific action steps that identify order of implementation, specific tasks, who carries out the task, and when the task will be carried out. As it will take some time for Villagers to complete the steps in the implementation action plan, their continued feedback to the group as they implement the plan will be used in guiding continued research efforts. 
Participatory Action Research

Appendix D 436

Document revision date: November 22, 2005

\section{ACTION TOOL 1:}

Diagram of Current Orientation Process, Protocols and Practices

External pressures:
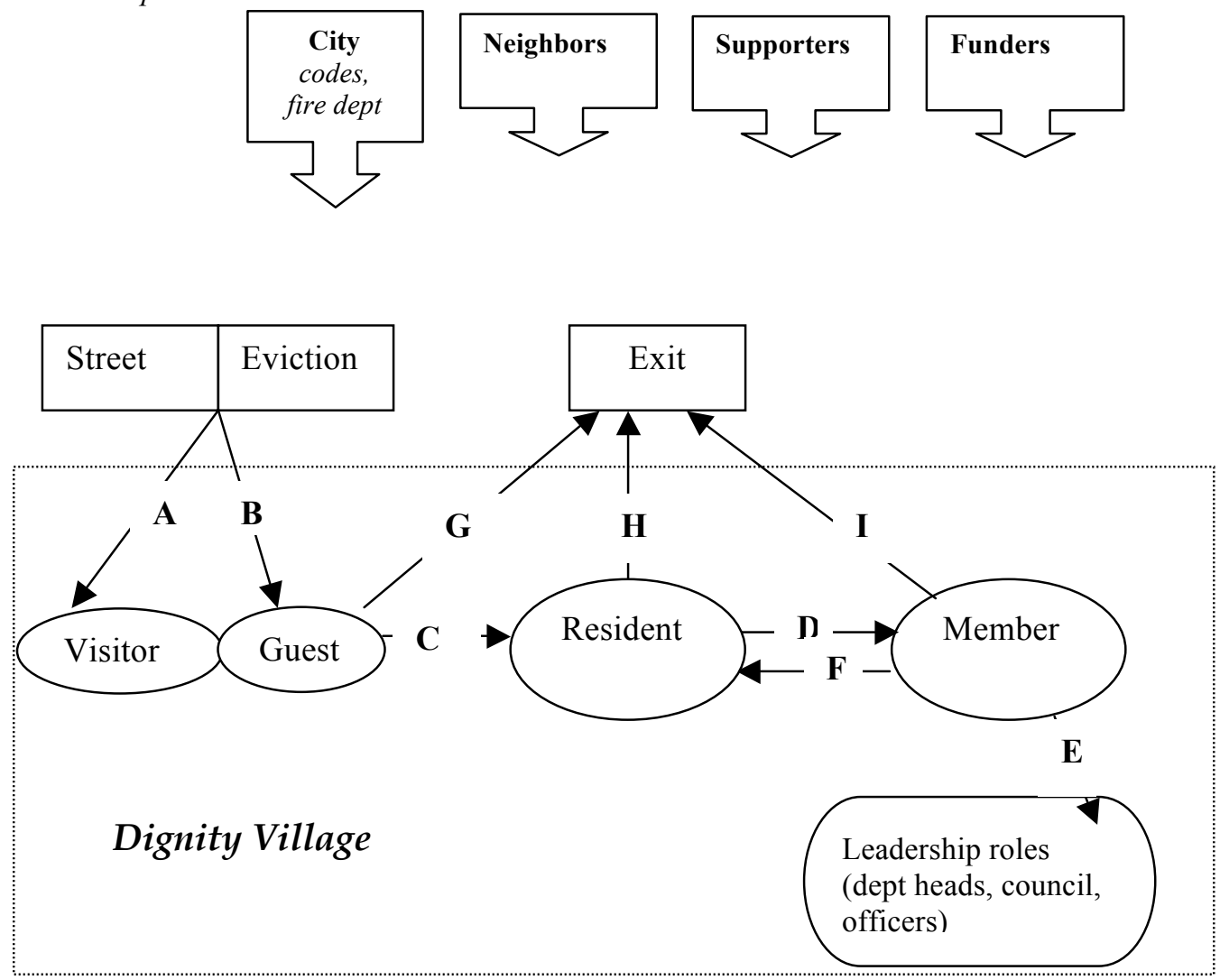

CURRENT PROTOCOLS AND PROCEDURES FOR ORIENTATION PROCESS:

\section{A. VISITOR}

Current actual or intended process:

Definition of a Visitor: An individual who is a supporter, off the streets, and/or a friend of a member who visits for the day or for less than three nights within 30 days. 


\section{When Visitors arrive at the Security Shack:}

- Security signs Visitor into the log (who they are visiting and purpose of visit), and gives the Visitor information on the protocols. Security also checks ' 86 ' list to confirm that Visitor is not on the list (this list is posted by the Security Coordinator)

- Security then walks the Visitor to the commons area

Visitor restrictions: (1) Visitor cannot walk past the Donations Center without a member; (2) they must stay with the member that they are visiting (residents cannot have visitors); (3) Visitor is allowed to stay three days total in Village (not per member) in 30 days at a member's home; and (4) If the Visitor is a blood relative or spouse, they s/he is allowed to stay 14 days out of 30 .

- Restrictions are monitored through the security sign-in sheet

Night and Day Visitors can receive: (1) Access to the all facilities (e.g., donations, showers, etc). [Although members have first priority with regard to the showers (there are set hours for Visitors to use showers, so that members have first access), donations, and parking spaces (no parking vehicle unless space is open because a member is absent)].

\section{B. ENTRY (FROM STREET/EVICTION) TO GUEST}

\section{Current actual or intended process:}

Definition of Guest: An individual who requests to stay at Dignity Village overnight and is not a visitor of a member. Must work 10 hours per week (one of basic rules for everyone), but cannot work on security or in a leadership role (e.g., department head, council, officer, Intake committee)

If a person contacts $D V$ via email or phone, Intake committee writes their name, date, and phone number (if they have one) on the waiting list. Currently, because of the long waiting list (and difficulties in managing it), the person is told that they should call DV weekly to check their status on the list or they will lose their place (Intake will not take person off list until after 2-3 weeks of no contact from individual). Intake committee can try to contact the individual if they have their contact information and have the time available to take on this task.

If a person shows up at DV and requests to stay, security logs them into the security log and then takes them to someone on Intake committee.

Intake committee member then talks with person informally, and then walks around and talks with at least $50 \%$ of the committee to make decision about whether person can stay overnight (24 hours) or until the next Intake meeting. Intake committee makes a decision based on the following considerations, with the committee being as accommodating as possible for the individual:

If the answer is NO on any of three questions below, then the person cannot stay.

1. Is there space available?

2. Do they appear to be sober? 
3. Are they over 18 years old?

If the answer is YES on any of questions 4-9 below, then the person cannot stay.

4. Do they have medical needs? (If Village does not have ability to meet these particular needs)

5. Are they on the ' 86 ' list?

6. Do they have children?

7. Do they have dogs? (currently there is a moratorium on dogs)

8. Do they have a vehicle or current housing status? (The request is too soon. In the past, Village has found that it does not help the individual if give them space before they are evicted. Individuals oftentimes can find alternative housing before they are evicted. If they do not, then they can request to stay at Village when they have been evicted.)

9. Do they seem to be free-loading, or want to free-load?

If individual is allowed to stay as a Guest, s/he is given the same Visitor protocols

Notes: Guests used to be placed on couches in commons area, then on bus, and now put on decks because of space problems.

- If Guest would like to stay at DV, s/he is required to attend the next occurring Intake committee meeting.

- The Intake committee meeting takes about $1 / 2$ hour with each person (Intake committee is about 3-7 people). The initial meeting consists of the following:

- The purpose of the meeting is to assess compatibility between individual and Village.

- Committee: (a) describes how DV is different from shelters, (b) explains rules and sweat equity hours (roles and positions should be told to guest residents in packet of info given by Intake committee, e.g., list of department heads), (c) provides warnings about drugs and who to associate with, (d) tells the individual what their status is (and as a Guest, where they can go, etc), (e) tells the Guest at that time that they can stay 10-30 days for evaluation before becoming a Resident; (f) gives a 5-page reading packet, which includes welcome/responsibilities, rules, T\&P description, medical questionnaire, (g) assigns the individual a mentor/advisor for two weeks, and (h) encourages the Guest to ask questions, tell their story and talk about their needs.

\section{GUEST > RESIDENT}

\section{Current actual or intended process:}

Definition of Resident: An individual who is permitted residency by the Intake committee, and has access to whole village. A resident can work on security. (If the resident is having problems, s/he should go to the council rather than to the Intake committee.)

- Guests are required to meet with T\&P weekly (to check in, ask questions, raise concerns, committee may give advice to Guest about how to become a Resident, etc), and are also required to put in 10 hours per week. 
Requesting Residency: Guests can request residency to Intake committee after 10-30 days. Intake committee meets to discuss Guest and compatibility (as well as whether they are meeting required hours). Intake committee votes on acceptance as a Resident.

\section{RESIDENT $>$ MEMBER}

\section{Current actual or intended process:}

Definition of Member: Person who has been voted as a member by the majority of the current membership. Members can vote, serve in leadership positions (e.g., committees and as department heads), and have first priority to resources/facilities.

Requesting membership: Resident can request membership after 14 days - This is based on the bylaws which state that any resident can request membership.

1. Resident submits request for membership to the Intake committee

2. Intake committee finds out if resident has completed three requirements: (1) must attend one council and one membership meeting before can get membership, (2) has fulfilled required sweat equity hours (bean-counter report); and (3) has no infractions of rules.

3. Intake committee (even if resident has not met criteria) is required to give resident's request for membership to council.

4. Council should, but is not required to, ask whether the Intake committee recommends the resident's membership, and if the resident has met the criteria for membership. Council will then decide, based on this information, whether to put resident's name on the ballot for voting his/her membership at the next membership meeting.

5. If council decides not to put resident's name on ballot, then council will explain to resident why this is so, and will provide suggestions to resident for becoming a member (waiting time, etc). At this time, there is no time limit to how long a person can stay as a resident.

6. If council decides to put resident's name on ballot, the members at the membership meeting will then vote on whether the resident can become a member at that time.

7. At the membership meeting, the members can ask the Intake committee and others about the resident, and can ask the resident why s/he would like to become a member. After this, the members vote.

Timeframe for decision on membership: Normally, it takes no more than six weeks to get put on a ballot for membership, from the time the resident requests membership to the time of the meeting (if council decides to do this). However, there are special circumstances whereby it may take more time after requesting membership. For example, residents' cannot become members in the December elections.

\section{E. MEMBER > POSITIONS/ROLES (DEPTS, COMMITTEES, COUNCIL, OFFICERS)}

Current actual or intended process:

What does it mean to be a member? Why do people want to become a member? 
- Most people want voice about where they live, how rules are made, want to be part of decision-making, have a sense of control over their home. Voting is a big advantage.

- Members can have overnight guests

- Member in good standing for 90 days are eligible for council

- Members vote on council

- Have to do more things wrong to get kicked out if a member

- Members get first priority with donations

What is the process in place to promote people to take leadership roles?

- Currently, we have an informal process of orienting people for the different leadership roles: during Guest status, individuals are told (or should be told) about the different roles and departments, and who to connect with for training or helping out in that area. Another way we promote participation is by peer pressure.

- Members want to take leadership roles to make a difference, to improve or maintain skills, self-esteem, etc.

- Many members get involved in areas of the Village that they are familiar with, have past experience with, or job that they are genuinely interested in and would like to gain more skills in that area. Past experiences and skills can be used and appreciated in leadership roles. Personal benefits that were mentioned included: (a) keeps the mind active, (b) career building, interest or honing skills, (c) feels good to work and stay active, (d) sense of ownership and empowerment, and (e) on the job training by learning from others.

\section{How do you monitor good membership/participation?}

- Sweat-equity participation (a required $10 \mathrm{hrs}$ per week if not employed full-time) is monitored through the following process: (a) individuals write down hours and have a witness sign their hours, (b) every week, individuals give their hours to the beancounter, (c) at the end of the month, the bean-counter calculates the number of hours for each person and gives a report to the membership at the monthly membership meeting.

- Decision-making participation (required attendance to monthly membership meeting; cannot miss two consecutive meetings) is monitored by the Secretary who takes roll during the membership meetings and provides individuals with written warnings if they are not meeting the requirement.

Is there a problem with participation, people not contributing?

- One problem is that there are a lot of chiefs that want to give you advice on what you are doing, but they don't stick around to help out. Not seeing reciprocity - when one person helps another, shouldn't help be returned?

- Internally, we often perceive that there is a bigger problem with people not contributing than there really is. We are actually getting stuff done, and people from outside the Village (e.g., city, supporters) notice this. We are our biggest critic-maybe the problem isn't that people aren't contributing enough - maybe the problem is with us and our own impatience and having expectations for others. The problem is not that no 
work is done...it's more that the work is not what you wanted at that time or didn't happen when you wanted it to. How we see it is that there is "orderly disorder" or "controlled chaos" here. How we monitor and promote our participation is different at DV than from typical organizational management, and for a good reason. Some of the reason it happens this way is that most of us here rebel against authority, and some of us are at DV because of this attitude. We think that the more controlling the community becomes, the more people will rebel and not contribute. As a way to promote participation, it seems to be important is that we can work at our own pace and that nothing is forced upon you. Respecting others and being flexible and understanding is also important in supporting and promoting participation. For example, Jon was sick with the flu for over a month, and people didn't harass him about a certain amount or type of work he should be doing. He felt the community cared about him and his health, and many people advised him to rest for his health. As a result, Jon felt good about participating and doing his part as he got well. He said that when he started to feel better, "then I wanted to get up and do it." Once you realize that you are responsible, you own it and are in control. Overall, people felt that they have a choice at DV and that each individual just needs to know what they want from their time at DV. DV helps people get back to reality through this increased responsibility.

- In addition, some of the work is not obvious or seen by others, unlike heavy labor or construction that is more obvious for people to see. We have all types of work here that are important and valuable to the operation of the Village, but not all work is being recognized as valuable/important or even noted as work for that matter (e.g., office work).

\section{F. MEMBER > RESIDENT (reverse - infraction of rule)}

\section{Current actual or intended process:}

- Council can vote to remove member if there is an infraction. In this case, the member (now resident) can re-apply for membership after 90 days (unless it is stated otherwise in the punishment). For example, if the member is noncompliant with hours two months in a row, then they automatically lose membership (no need for council to vote). If person loses membership because of non-compliance, they can come into compliance and stay at Village as resident for 90 days, and then can re-apply for membership.

\section{MEMBER NOT IN GOOD STANDING}

\section{Current actual or intended process:}

- Person has all benefits and requirements of membership (including hours), except they cannot vote or serve on any committees (e.g., Intake) or as any head of a department (no voice in decision-making).

- There is no time limit to how long one can stay as a member not in good standing. 


\section{G/H/I. GUEST / RESIDENT / MEMBER > EXIT}

Current actual or intended process:

Exit-Infraction of rules

- Most common way of exit is infraction of Rule \#5 (no contributing). If break rule, a person gets a letter of warning first. Individual has 30 days to fix the problem (get the 40 hours of work for the month). If the individual is a resident and does not fix the problem, they are give 72 hours for eviction. If the individual is a Member and does not fix the problem, they lose their membership and are on 90 days probation. They can reapply for membership after 90 days.

- The only automatic 86 is if a person breaks the violence rule

- If an individual breaks any other rules, an IR is filed, and the person goes in front of council. Then, the council votes on a solution to problem.

Exit - Transitioning out

- Another reason for leaving is by individual's choice (e.g,; get housing, job, reunion with family, finishing school).

For Residents who are denied Membership (uncommon)

- If denied membership by vote then individuals stays as a Resident; no time limit for being a Resident. Individual is not forced to leave. 


\section{ACTION TOOL 2:}

\section{List of Areas for Improvement}

Problems or areas for improvement at Dignity Village, discussed by Core Research Group and ranked according to highest priority for working on first (higher \# = higher priority)

\begin{tabular}{|c|c|c|}
\hline Problems / Areas for Improvement & $\begin{array}{c}\text { Priority } \\
\text { Rank }\end{array}$ & Comments \\
\hline $\begin{array}{l}\text { Inconsistent information \& unclear communication } \\
\text { (e.g., no standardized code of conduct or guidebook, no } \\
\text { formal list of roles/positions, a lot of rumors and gossip, no } \\
\text { clerical/admin procedures for updates on protocols based on } \\
\text { membership decisions, inconsistent policies) }\end{array}$ & 3 & \\
\hline $\begin{array}{l}\text { Unclear guidelines and responsibilities of leadership } \\
\text { positions and committees } \\
\text { (includes: lack of training for leadership roles) }\end{array}$ & 1 & \\
\hline $\begin{array}{l}\text { Inconsistent enforcement of Village policies } \\
\text { (e.g., not following through with protocols, lack of warnings } \\
\text { for infractions, security not watching out for everyone) }\end{array}$ & 3 & \\
\hline $\begin{array}{l}\text { Lack of accountability and transparency in work } \\
\text { (no mechanism for confirming or seeing what others are doing } \\
\text { as part of Village work/jobs, e.g., "work is not acknowledged } \\
\text { if not seen," "corruption," "extortion," "popularity contest") }\end{array}$ & 0 & \\
\hline $\begin{array}{l}\text { Overall negativity, lack of support, criticism } \\
\text { (e.g., no peer support or community support for getting off } \\
\text { drugs/alcohol, or for managing anger, patriarchy, or diversity; } \\
\text { a lot of rumors and gossip, lack of tolerance, too much } \\
\text { infighting, many complaints but no solutions offered, people } \\
\text { put up obstacles instead of supporting) }\end{array}$ & 1 & \\
\hline $\begin{array}{l}\text { Lack of ownership, participation, motivation } \\
\text { (e.g., not getting quorum, biggest criticism is that people } \\
\text { aren't part of making decisions, there is lack of participation } \\
\text { beyond security work) }\end{array}$ & 3 & $\begin{array}{l}\text { More } \\
\text { discussion } \\
\text { needed }\end{array}$ \\
\hline $\begin{array}{l}\text { No clear exit strategy } \\
\text { (both positive exit for transitioning out of Village and } \\
\text { negative exit for infractions or incompatibility; e.g., no exit } \\
\text { interview) }\end{array}$ & 1 & $\begin{array}{l}\text { More } \\
\text { discussion } \\
\text { needed }\end{array}$ \\
\hline
\end{tabular}


Ineffective orientation for newcomers

(e.g., do not understand vision, too much information at one time, no way of measuring comprehension of orientation packet, no plan for illiterate or visually impaired people, lack of reliable peer mentoring) 


\section{ACTION TOOL 3:}

\section{Solutions List}

(NOTE: The lists below are from initial brainstorming sessions; all ideas were included and they are in no particular order; these are ideas and suggestions for future discussion.)

\section{Issue: Unclear/ineffective orientation for newcomers (2/4/06)}

- Post DV vision statement in commons area

- Create comprehensive intake/resource packet

- Create resource list (resources outside DV)

- Prioritize info and provide it to newcomers more slowly

- Create and show video on vision and history

- Provide Braille version of intake/resource packet

- Create wallet-size "rules and regulations" card

- Update T\&P policies more frequently

- Create T\&P binder with protocols and policies

- Delegate responsibilities - spread out workload among more people

- Create clear and precise policy sheet for intake process and work options

- Create list of department heads and officers, add to intake packet

- Develop jobs list (description of jobs at DV to get required hours, which depts)

- Develop mentoring system to pair newcomers with mentor

- Use a punch card system to monitor hours

- Get feedback (survey or questionnaire) from newcomers on what works and what doesn't work

- Increase the number of people on T\&P committee

- Provide more clarity on lines of communication (refer people to T\&P)

- Educate newcomers about health and safety issues

- Provide fire safety information and procedures to all Villagers, guests, residents

- Discuss DV Info Sheet with newcomers during interview process

- Review intake packet and video(s) with newcomers, ask questions at beginning

- Provide follow-up interviews or discussions with newcomers (formal or informal)

- Exchange stories/listen to newcomers' stories during intake interview

- Provide training for T\&P people on interviewing

- Create guidelines on behavioral standards and community expectations

- Have newcomers sign-off on DV Intro Sheet or other materials to indicate comprehension

Issue: Unclear Communication/Information (1/29/06)

- Create binder of regulations (member-approved)

- Post/create list of people who have left DV and their current standing (86'd, etc)

- Get an Information Robot that will have all the answers

- All proposals to membership should be formalized (in writing) 
- Post membership and council decisions in commons area

- Create newsletter (weekly or monthly) - with job search, resources, laws, etc

- Decide and note which rules are "hard and fast" and which are "flexible"

- Create panel of judges or judge to resolve issues

- Develop training manual for leaders and department heads

- Develop a staff/orientation manual

- Hold workshops on DV policies and protocols

- Create an informational video

- Have all leaders choose an assistant and train them (mandatory)

- Set up volunteer "advisors" from outside DV

- Use mentors for non-profit groups (TACS, SCORE, etc)

- Lines of communication - refer people to T\&P or other department heads

- Have law students hold classes or workshops at DV

\section{Issue: Negativity/Lack of Support/Rumors (1/29/06)}

Options to deal with negative/conflict situations:

- Write up IR

- Bring issue to Council/put it on agenda

- Ignore or shun the negative person/person who is venting

- Call police

- Call security or board officer

- Change the subject

- Use humor

- Live with it

- Speak up

- Work it out personally/direct communication

- Use more kindness and sensitivity

- Resolve conflict creatively with games or more innovative "punishment" - tug o' war, games, firewood cutting contest, community service

Options to for community building and positive feelings:

- Newsletter

- Etiquette lessons/workshop

- Set tighter parameters for behaviors

- Create a "behavioral standards" manual

- Create video on behavioral standards

- Diversity workshop

- Non-violence workshop

- Domestic abuse workshop

- Motivational/informational speakers at membership meetings

- Recognition: Villager of the Month, Recognition Photos, Drawings for Donations

- Community activities: coffee groups, community meals, music night, movie night, plays/theater, sleepover in the commons, birthday and holiday parties, dances, Village Olympics, community flag/mural/quilt, fundraisers (thrift shop, etc) 


\section{ACTION TOOL 4:}

Orientation for Newcomers Implementation Action Plan

Prioritized general action steps for improving Newcomer Orientation

(ranking decided by group on 2/19/06)

\begin{tabular}{|c|c|l|}
\hline Rank & Action steps created* & \multicolumn{1}{c|}{ Solution/Option description } \\
\hline 1 & $2 / 27 / 06$ & T \& P policy binder \\
\hline 2 & $2 / 27 / 06$ & Democracy and rights \\
\hline 3 & $3 / 19 / 06$ & Intake interview (full T\&P committee) \\
\hline 4 & $3 / 19 / 06$ & Rules and regulations \\
\hline 5 & $3 / 19 / 06$ & Vision and values \\
\hline 6 & $3 / 19 / 06$ & Intake/Resource packet \\
\hline 7 & $3 / 19 / 06$ & Mentoring \\
\hline 8 & $4 / 02 / 06$ & Re-orientation/refresher course \\
\hline 9 & $4 / 02 / 06$ & Follow-up discussion with newcomers \\
\hline 10 & $4 / 02 / 06$ & Increase T \& P members \\
\hline 11 & $4 / 02 / 06$ & Exit evaluation/binder \\
\hline
\end{tabular}

$\underline{\text { Newcomer Orientation Action Plan - Specific Action Steps }}$

\section{Solution/Option 1: T \& P Binder}

- clarify guidelines

\begin{tabular}{|l|l|l|}
\hline Who & When & \multicolumn{1}{c|}{ How (action steps) } \\
\hline T \& P & $\begin{array}{c}\text { Tues } \\
2 / 28 / 06\end{array}$ & Create/update policies - draft (working group decides) \\
\hline & & Find meeting space and computer resources \\
\hline & & Working group: collect materials (past and current policies) \\
\hline & & Define functions/jobs within T \& P and assign \\
\hline & & Approval from membership (ratify) \\
\hline & & Decide on how people access binder or files \\
\hline & & $\begin{array}{l}\text { Make copies for each T \& P member and get materials } \\
\text { benchmarks' - put in intake binder - discuss at T \& P }\end{array}$ \\
\hline
\end{tabular}

\section{Solution/Option 2: Democracy and Rights/Responsibilities}

- Educating individuals' legal and political rights inside and outside village

- Educate individuals about responsibilities as Villager

- Promote democracy 


\begin{tabular}{|c|c|c|}
\hline Who & When & How (action steps) \\
\hline \multirow[t]{10}{*}{ Laura } & $4 / 6 / 06$ & $\begin{array}{l}\text { Talk to Pirate Steve about holding second membership meeting } \\
\text { each month or weekly }\end{array}$ \\
\hline & & $\begin{array}{l}\text { Ask membership to change membership meetings to meet on the } \\
\text { day before Council meetings }\end{array}$ \\
\hline & & For Membership: Define/list rights within Village - specifics \\
\hline & & $\begin{array}{l}\text { For Membership: Define/lists rights outside of Village - collect } \\
\text { UN Rights materials }\end{array}$ \\
\hline & & For Membership: Create video showing democratic process? \\
\hline & & For Membership: Decide on trust-building exercises \\
\hline & & $\begin{array}{l}\text { For Membership: Define responsibilities/earned rights within } \\
\text { Village - membership meeting }\end{array}$ \\
\hline & & Create binder with membership decisions \\
\hline & & Task list (things to do around village) to encourage participation \\
\hline & & Create video on history and civil rights of Village \\
\hline
\end{tabular}

\section{Solution/Option 3: Intake Interview}

- Clarify purpose, timing, content, and order of operations

\begin{tabular}{|l|l|l|}
\hline Who & When & \multicolumn{1}{c|}{ How (action steps) } \\
\hline T \& P & $3 / 21 / 06$ & $\begin{array}{l}\text { decide on protocols and changes (see meeting discussion } \\
\text { points below) }\end{array}$ \\
\hline T \& P & & take changes to council \\
\hline T \& P & & give to attorney to review \\
\hline T \& P & & approval by membership \\
\hline
\end{tabular}

\section{Meeting Discussion Points for $T \& P$ about Intake Interview:}

- Decide timing and order of operations for intake (when should conduct interview)

- Should it be face-to-face interview or survey, or how much of each in process?

- What ways should we ask questions in the interview (do not want to be leading)?

- What should be the recruitment policy and the steps for recruitment?

- Review current questionnaire and revise.

- What is the protocol for using the questionnaire?

- Communicate with board officers to decide what additional info they need and how to separate the questionnaires (e.g., demographics for City Report, data for Secretary, etc)

- Get feedback from recent intakes (newcomers) to guide decisions on revisions, intake process, or how to conduct interview

- Define confidentiality. What are the protocols? Who can access and when (e.g., emergencies, non-emergencies, etc).

\section{Solution/Option 4: Rules and regulations}

- Accessibility of rules

- Communicate context or history of rules?

- Clarify consequences? 


\begin{tabular}{|l|l|l|}
\hline Who & When & \multicolumn{1}{c|}{ How (action steps) } \\
\hline DONE & DONE & List has been created and printed (last January) \\
\hline DONE & DONE & List has been posted on bulletin board \\
\hline T \& P & & Discuss accessibility of rules (see discussion points below) \\
\hline
\end{tabular}

$\underline{T \& P}$ Discussion Points for Rules and Regulations:

- How do we want to make rules and regulations accessible?

○ Post simple rules and consequences?

- Make copies for intake packets or resource shelf?

- Determine other ways of accessing info

- Gather history of rules and regulations, and decide on how to provide it to newcomers

- Do we want to have a sign-off sheet for comprehension?

- Decide on how much of judicial process to include for orientation and how to give the information to newcomers

- Overall decisions on keeping things short but informative

\section{Solution/Option 5: Vision and Values}

- Research community's vision and values

- Disseminate/communicate information over time

$W G=$ working group

\begin{tabular}{|l|l|l|}
\hline Who & When & \multicolumn{1}{c|}{ How (action steps) } \\
\hline Dean & by 3/26 & Create and post sign-up sheet for Vision/Values working group \\
\hline WG & & $\begin{array}{l}\text { Determine original mission/vision/values to post (to show how } \\
\text { values change over time; democracy) }\end{array}$ \\
\hline WG & $\begin{array}{l}\text { Decide on methodology to research current and future } \\
\text { vision/values of all individuals in the Dignity Village community } \\
\text { (e.g., What do you value in the Village? What is your vision of } \\
\text { Dignity Village?) }\end{array}$ \\
\hline WG & $\begin{array}{l}\text { Decide how often to conduct survey/research (evolution) } \\
\text { Decide how to disseminate/post/communicate vision info (e.g., } \\
\text { videotape people answering surveys and show this to Village and } \\
\text { newcomers in orientation; post values over time, etc) }\end{array}$ \\
\hline
\end{tabular}

\section{Solution/Option 6: Intake/Resource Packet}

- Decide on number of packets, content, and order of operations for packet distribution

\begin{tabular}{|c|l|l|}
\hline Who & When & How (action steps) \\
\hline T \& P & & Decide on number of packets and what to include in the packet \\
\hline T \& P & & Order of operations for packet distribution \\
\hline
\end{tabular}

\section{Solution/Option 7: Mentoring}

- Membership to define/decide on mentoring program 
- $\quad$ Training/info for mentors

\begin{tabular}{|c|l|l|}
\hline Who & When & \multicolumn{1}{c|}{ How (action steps) } \\
\hline $\begin{array}{l}\text { Laura - } \\
\text { T \& P }\end{array}$ & $4 / 6 / 06$ & $\begin{array}{l}\text { Present general idea of mentoring to membership; ask } \\
\text { membership to decide/define program; ask newcomers and } \\
\text { residents what they feel is needed or would be helpful (to assess } \\
\text { needs) }\end{array}$ \\
\hline
\end{tabular}

\section{Solution/Option 8: Re-orientation / Refresher Course}

- Switch order of membership and council meetings

- Formalize orientation process - show video

- Additional orientation for leaders and for everybody

- Pamphlet

- Benchmarks/goals strategy (survey) (see exit interview section)

\begin{tabular}{|l|l|l|}
\hline \multicolumn{1}{|c|}{ Who } & When & \multicolumn{1}{c|}{ How (action steps) } \\
\hline Gaye & $4 / 05 / 06$ & $\begin{array}{l}\text { Present idea of leadership training, re-orientation/refresher } \\
\text { course to membership (see presentation points below) }\end{array}$ \\
\hline Gaye & $4 / 05 / 06$ & $\begin{array}{l}\text { Ask members about changing order of operations - council } \\
\text { meeting after membership meeting }\end{array}$ \\
\hline & & $\begin{array}{l}\text { Adapt current orientation packet for current members } \\
\text { Interview training - create guidelines }\end{array}$ \\
\hline & & Survey for areas of training need \\
\hline & & Leadership training course/guidelines \\
\hline & & $\begin{array}{l}\text { Community/everybody-ship training (promote leadership and } \\
\text { participation) }\end{array}$ \\
\hline & $\begin{array}{l}\text { Show orientation video quarterly at membership meeting } \\
\text { (morale building) }\end{array}$ \\
\hline
\end{tabular}

Presentation/discussion points for membership meeting:

- Ask Chair to appoint someone as liaison for leadership course

- Members to decide how often course if taught

- Decision to show video at membership meeting or set-up to run in a loop (weekly, monthly, etc)

\section{Solution/Option 9: Follow-up Discussion with Newcomers}

- feedback form or informal

- timing for follow-up discussions

\begin{tabular}{|c|c|l|}
\hline Who & When & \multicolumn{1}{c|}{ How (action steps) } \\
\hline DONE & DONE & Formal interview with T \& P weekly \\
\hline T \& P & & $\begin{array}{l}\text { Develop/create specific questions/guidelines - open-ended - } \\
\text { ask questions for feedback when newcomers request } \\
\text { membership from T \& P (resident to member) } \\
\text { - Informal setting/venue for this? }\end{array}$ \\
\hline
\end{tabular}




\section{Solution/Option 10: Increase T \& P Members}

\begin{tabular}{|c|l|l|}
\hline Who & When & \multicolumn{1}{c|}{ How (action steps) } \\
\hline Laura (T \& P) & & Post job descriptions/T \& P functions and sign-up sheet \\
\hline T \& P & & $\begin{array}{l}\text { After a week, if no one signs up, decide on opening up } \\
\text { T \& P to residents/new members (take to membership } \\
\text { mtg) }\end{array}$ \\
\hline
\end{tabular}

\section{Solution/Option 11: Exit Evaluation Binder}

- interview during intake (personal goals)

- follow-up interviews during membership

- info on individuals as they exit Village

\begin{tabular}{|c|l|l|}
\hline Who & When & \multicolumn{1}{c|}{ How (action steps) } \\
\hline T \& P & $\begin{array}{l}\text { Create exit checklist on each person as they leave (e.g., } \\
\text { hours, circumstances, if broke rules, behavior) }\end{array}$ \\
\hline T \& P & Inspector job to implement checklist \\
\hline $\begin{array}{c}\text { Ross } \\
\text { (secretary) }\end{array}$ & $\begin{array}{l}\text { Update list of people who have been 86d - continue to } \\
\text { update whenever someone is 86d }\end{array}$ \\
\hline $\begin{array}{c}\text { Ross } \\
\text { secretary) }\end{array}$ & $\begin{array}{l}\text { Make a copy of updated 86 list - one copy in files, one } \\
\text { copy in security shack (one copy for T \& P?) }\end{array}$ \\
\hline & $\begin{array}{l}\text { Create survey/open-ended interview for 'goals and } \\
\text { benchmarks' - put in intake binder - discuss at T \& P }\end{array}$ \\
\hline & Same interview or discussion at periods throughout \\
\hline & $\begin{array}{l}\text { Exit interview (similar to follow-up interview) } \\
\text { (transition, achieved goals or not) }\end{array}$ \\
\hline
\end{tabular}




\section{ACTION TOOL 5:}

\section{The Dignity Village Orientation Video Process}

The research group considers the orientation video as one of the priority components in the overall action plan to addressing the low participation and morale. We intend to create this action tool as a way to maintain a collective identity. The process of creating the orientation video action tool will also serve as a vehicle for recognizing community strengths, building relationships, and encouraging collaboration around community problem solving and collective action.

Stages for Producing the Dignity Village Orientation Video

1. Identify the specific purpose of the video and what the group wants to communicate to newcomers (e.g., vision and goals, services, rules and regulations, history)

2. Construct a storyboard that describes the style, storyline or community narrative

3. Create a shot-list and action steps for production (this describes the types of new footage to collect, footage to access and review from archives, who will be involved in different types of work/production tasks, etc.)

4. Videotape the identified shots on shot-list

5. Log the footage in database (marking time-codes for visuals and writing a transcription of audio and visuals)

6. Review and select video footage (both new footage and archived footage)

7. Facilitator edits the assembly cut based on the group's selected footage and written storyline ${ }^{4}$

8. Review assembly cut as a group - make changes and select final shots

9. Facilitator edits the rough $c u t^{5}$ based on research group review and decisions

\footnotetext{
${ }^{4}$ An assembly cut is a rough assembly of main storyline / narrative footage.
} 
10. Research group presents the video to the broader community (community consultants) at a membership meeting, and asks for their feedback

11. Research group and facilitator revise and re-edit the video and show it again to the community for feedback in an iterative process until final version

12. Research group assesses the effectiveness of the completed action tool within the broader Village community

${ }^{5}$ A rough cut is cut to approx. length and includes both narrative-interview and voice over-and visuals. 


\author{
Purpose of Video / Action tool \\ (from original brainstorming session at beginning of research)
}

The purpose of the action tool will be to:

A. Support and empower individuals by:

- providing consistent information (internal consistency) so that every person has the same information and opportunity and expectations

- democracy and government

- rules / how enforced / consequences - why and how they came about (justice / fair)

- daily life / what is to be done / how to contribute and participate in Village (examples of ways to participate)

o internal resources (showing available resources both internal/external)

- providing role clarity / position expectations / accountability

- departments / roles and protocols within those roles (introduce department heads, council and officers, etc)

- train people how to be involved in daily work, and in various Village departments / roles

- educating people about their basic human rights as US citizen and how to protect them (in Village and in public - and how these are/may be denied on street)

- External training politically

B. Increase sense of community and commitment by:

- creating empathy / connection through community story and history of Dignity Village

- showing supportive community

- safety and security 
- illustrating connection to larger community / other tent cities \& villages (where they are, what they do, part of a larger network/movement, etc)

C. Energize action / participation of individuals both physically and politically (but not preaching one specific political view or area - just supporting individuals to become more active/involved internally and externally) by:

- showing how each person can make a difference

- showing what it takes to maintain Dignity Village

D. Increase shared vision and align action by:

- communicating Village goals / mission (e.g., green, sustainability (microbusinesses), security, safety)

Target audience(s) for tool: Internal (Dignity Village)

- Intake Committee (orient newcomers)

- Longer-term members (align vision, re-invigorate community and cooperation) 


\section{Exercise: Video Critique \\ Elements of storytelling}

Purpose of exercise: a) identify and become aware of elements of storytelling (message, style) that are effective and powerful; and b) to become more aware of other audiences' perspectives and experiences with specific styles of storytelling (audience, purpose).

Three short videos were shown: a) From Doorways to Dignity documentary trailer, b) introductory video for the Tent Cities Toolkit, and c) a documentary trailer on Darcelle and co.

Questions were asked after viewing the videos:

- In what ways did the story most impact you? Which parts impacted you most? How did you feel? What did you like about it?

- What was the message?

- What style choices did you think were effective in telling the story and having impact? (e.g., text, interview, narrative, poetry, narrative - delivery style)

- Imagine you are ___ who is interested in what Dignity is doing but knows very little about it, what aspects of the story might impact you most? How might you feel differently about the story? What would you like more or less from this point of view?

- Now imagine that you are (your intended audience) and do not know anything about Dignity Village, what aspects of the story might impact you most? How might you feel differently about the story? What would you like more or less from this point of view?

\section{Exercise: Core group responses on April 9, 2005}

\section{Effective/powerful elements of videos}

- Set-up conflict/opposition and prejudice

- city/Sten set-up conflict and opposition, opposing viewpoints in story

- visuals of Sgt Powell posting notice showed consequences - powerful because it showed what was happening, rather than telling

- showed how rights were violated (arrest scene)

- Story structure important

- Should have ups and downs. Escalation/emotion important and powerful, but also need down-time where you show different points of view, daily life, routine, teamwork, etc. 
- Delivery style

- Text boxes can be powerful - can use powerful quotes, drive home main points, and message.

- Audio/sounds of sirens, visuals of soup lines, street scenes draws you in and can identify with it.

- Pacing is important. The escalating pace of the story really grabs you. The fast-paced flash of street scenes draws you in.

- Music important. It is soft and then escalates in important places that create energy and emotion - more powerful.

- Visuals powerful. Showing (rather than telling) allows audience's to experience and interpret on their own (creates a portal)

- JP's "back and back" speech is powerful. Brings us to the political side of Dignity. The unity. The struggle. This scene was also powerful because of JP's emotion and delivery, and because it showed the public's response--many people watching (made it feel like a critical, important moment)

- Narrative

- Reverend Williams because he is calm, yet hits the point right on - the humanity of the situation. He is the "eye of the storm." He also has dignity and is respected, part of clergy.

- Jack (defend rights statement) was powerful because it was calm, right on target, and to the point.

- Use of personal stories powerful

Audiences, Purpose and Style of the Orientation video

Intended Audience(s) and Purpose:

- Newcomers - to light fire, catch dream/pride \& to answer questions

- Inactive long-termers - to light fire

- Been there, frustrated long-termers

\section{Purpose - Style of Video:}

INTRO: Identification, build trust, set up context--Need story that newcomers can identify with - emotion/personal; "we know what it is like" (e.g., new, scared, etc).

- Show streets - identification (not seen, sadness, broken)

- Use personal stories to connect with audience 


\section{Purpose: to light fire and catch dream--The focal point of the story is the struggle \\ - Tell history of Dignity Village - show great passion and collective action;}

- Show why and how Dignity Village got here, the challenges it faced and where the passion is coming from;

- Show personal stories (why individuals were angry and took action); important to show that the battle is not over.

- Show opposition-prejudice and how rights were violated.

- Show importance of collective efforts/mentality

- Show diversity of DV-how we are different - showing how we value differences (opinions and skills) and how this is powerful when "drawn into one accord" - when aligned.

- Show the necessary change from "I" (to survive streets in America and American individualistic mentality) to "we" which was necessary and made it possible for Dignity Village to exist.

- Show the strengths of collective effort/unity (e.g., working together). Show power of community, accomplishments, and increase in opportunities.

- Show the challenges/ hazards of maintaining a "collective" mentality. Show costs to lack of collective effort/unity - missed opportunities. People are human. Need compassion and forgiveness. Need to align efforts.

- Show commonality of people at DV - humanity basic rights, responsibilities: Commonality at DV is that everyone wants DV to exist

$$
\begin{array}{ll}
\circ & \text { Use humor, bloopers- human aspect } \\
\circ & \text { Talent (music, art, etc } \\
\circ & \text { Friendships and family }
\end{array}
$$

\section{Purpose: to answer questions}

- Shots of individuals' perceptions of DV (fears, questions, perceptions, myths)

Brainstorm Storyline: (a) 1-minute time-lapse; (b) Poem-personal/street; (c) Set-up context;

(d) Struggle; (e) End - completed house

Brainstorm Out-takes: (a) Title cards: Person holding cardboard sign instead of traditional 'title

card'; (b) Specific ideas for visuals: show different kinds of work; show time-lapse of tearing down a train-wreck, building deck and building a house (shows cooperation, different skills, etc) 
Storyline Script

\section{(Excerpt)}

(completed July 9, 2006)

Purpose: To light fire under people, and get people connected to Dignity Village

Audience: Newcomers (and other Villagers - internal use)

Length: $\quad 30-60$ minutes

\begin{tabular}{|c|c|c|c|}
\hline Section & Time & NARRATIVE STRUCTURE & VISUAL IMAGES \\
\hline \multirow[t]{3}{*}{ INTRO: } & $\begin{array}{l}{[10-} \\
\min ]\end{array}$ & $\begin{array}{l}\text { Purpose: "we know what you've gone } \\
\text { through" / "this is where we came from" / } \\
\text { "power of community in action" }\end{array}$ & \\
\hline & [2-min] & Street scenes & $\begin{array}{l}\text { Video/photographs: Dumpster diving, padlocked restrooms, } \\
\text { sleeping in doorway with Ghetto blanket, police harassment, } \\
\text { sleeping in tents, bushes, or in dumpster, raining downtown, } \\
\text { panhandling, fight on street, Laura's photos?, downtown welfare } \\
\text { office - accessing services } \\
\text { Sounds: sirens, street sounds } \\
\text { VO/audio: sound bites of diverse reasons why individuals are } \\
\text { homeless (record at Village membership meeting) }\end{array}$ \\
\hline & $1: 30 \mathrm{sec}$ & $\begin{array}{l}\text { Introduce Dignity Village though POV of Cami } \\
\text { (camera), a newcomer who just came out of the } \\
\text { doorways }\end{array}$ & $\begin{array}{l}\text { Video: } \\
\text { - Person on street, "now what the hell do I do?" (in response to } \\
\text { cycle of homelessness and barriers) } \\
\text { - B-roll of persons walking in DV front gate, meeting security } \\
\text { who greets and escorts to TNP } \\
\text { - Show front title credits over entrance video (produced } \\
\text { by...title of video, etc) } \\
\text { - TNP greets and individual asks, "what's this place about?" or } \\
\text { "how did this get started?" or "Is there room for me?" } \\
\text { (transition to showing history and context of DV }\end{array}$ \\
\hline
\end{tabular}




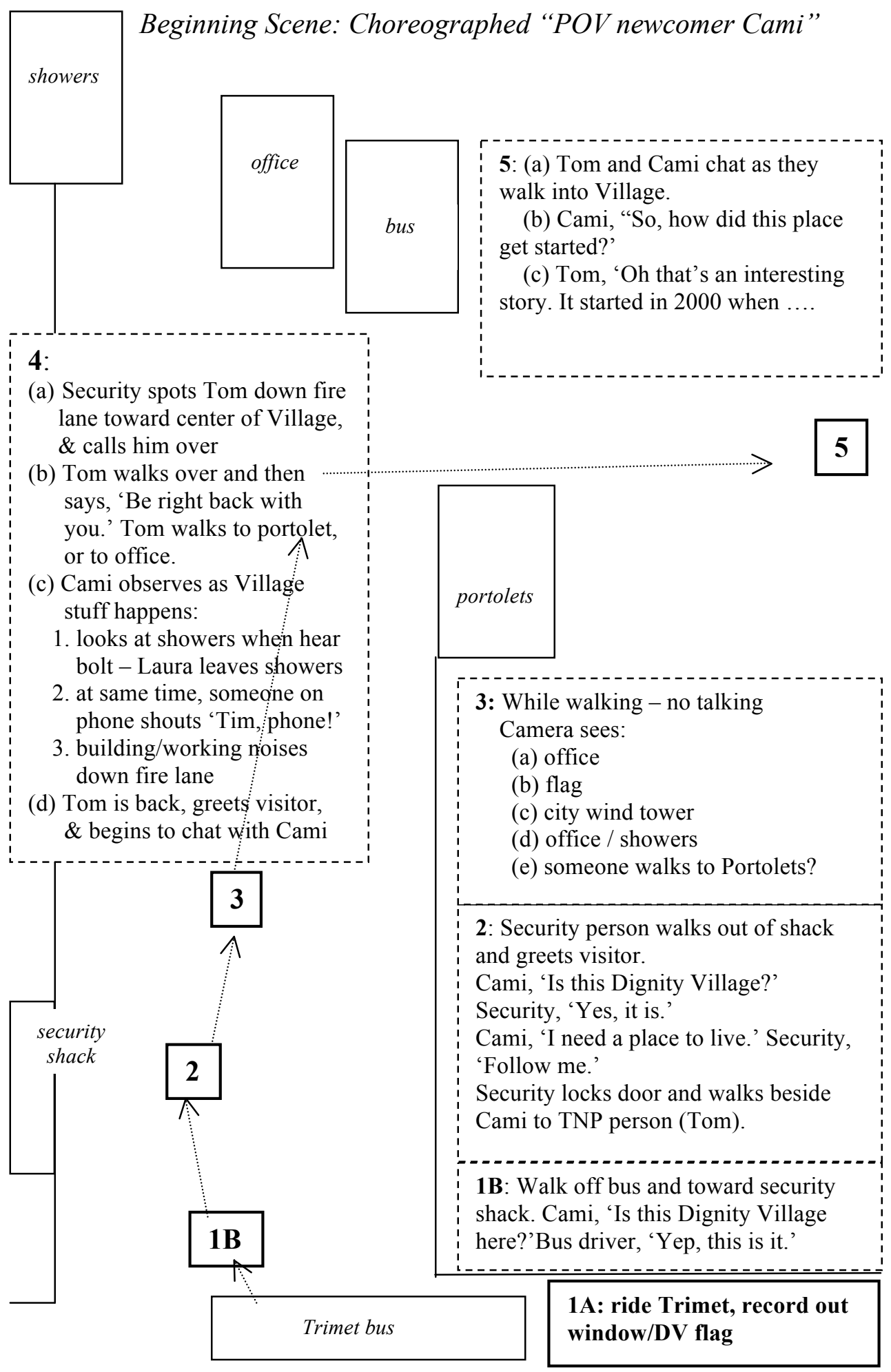




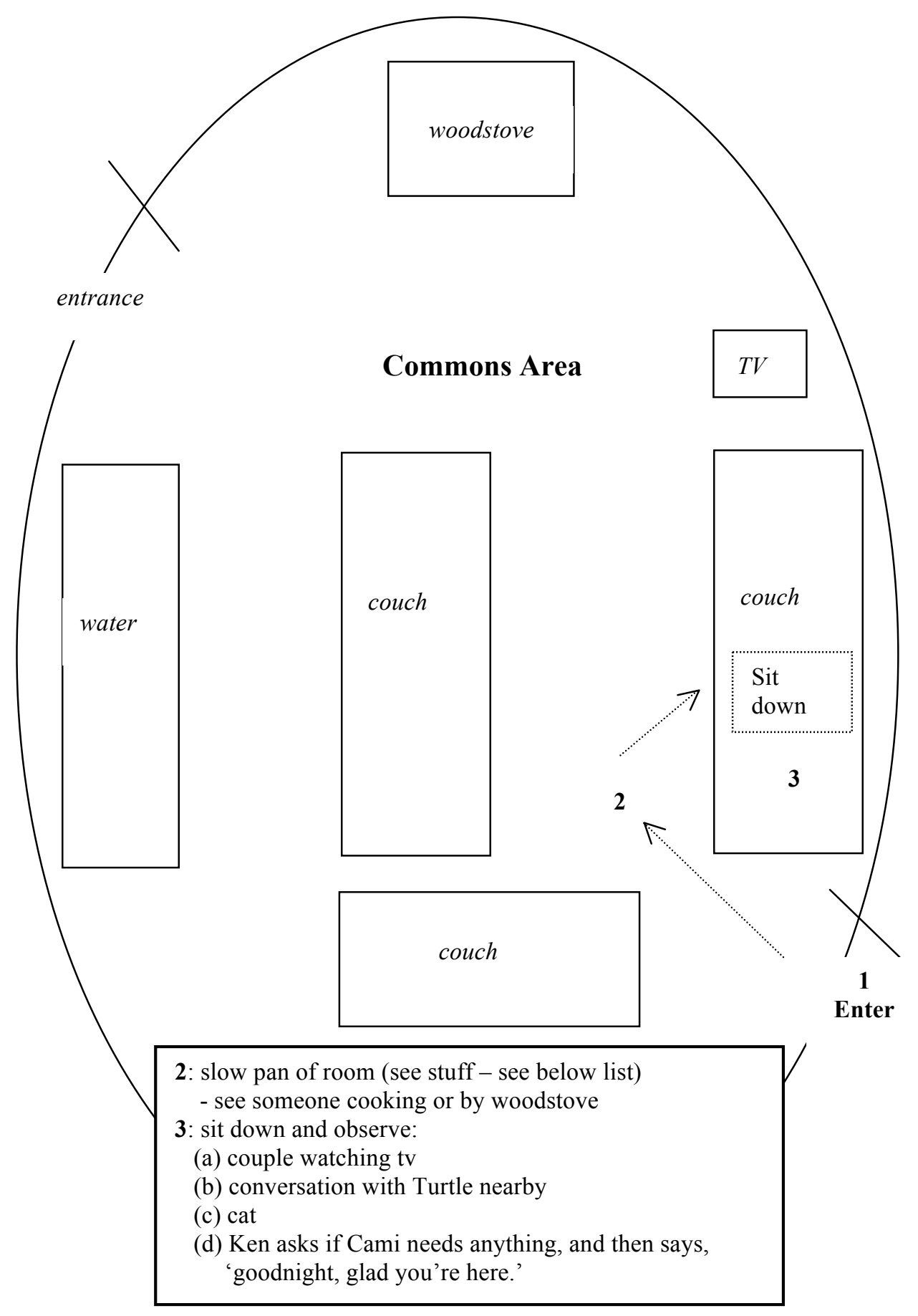




\section{Filmmaking Workshop \\ (Monday, July $17^{\mathrm{h}}, 4-8 \mathrm{pm}$ )}

We held a community filmmaking workshop to teach individuals basics in filmmaking and interviewing techniques so that individuals at Dignity Village (anyone) could use the camcorder (kept at Dignity Village) to help create the orientation video. We developed a Filmmaking Handbook adapted from several sources (note: I have not included this Handbook in this Appendix since I do not have authors' permissions to do so at this time). The workshop schedule and topics covered are listed below.

\section{Filmmaking Workshop Schedule for Community}

4:00-5:00

In Class: Learning the Basics

- Production phases and crew roles

- Camera operation/equipment

- Camera techniques

- Lighting and sound

- Interviewing

5:00-6:00 pm

In the Field: Doing the Basics

- Interview one person (limit to $10 \mathrm{~min}$ )

$\circ \quad$ Lighting and sound

- Camera techniques (limit to 5-min total)
- Long shot
- Wide shot
- Close up
- Pan
○ Zoom

6:00 - 7:30 pm

That's a Wrap: Screening and Group Discussion

7:30 - 8:00 pm

Sign up for Production Teams 
Production Teams (and Tasks)

We recruited teams of individuals in community to work together to conduct interviews, record b-roll, and participate in production days for scripted scenes.

\section{INTERVIEWS}

Interview Team Tasks:

1. Five interview questions / topics:

i. Why/how did individuals become homeless

ii. How and why does person participate in DV; why did they want to become a member

iii. What goals has the person achieved since they have been at DV (personal growth/success stories); how has DV helped them?

iv. Which rule is most important to you and why?

v. Explanation for why and how a person can become a member (narration or interview - somewhat scripted before interview)

2. Who to interview? (select interviewee)

3. When to interview? (schedule interview with person)

4. Where to interview? (location with good lighting, sound, textures, depth)

5. Camera Crew: Cameraperson, Director/Interviewer, Production Assistant

6. ACTION!

\section{SCRIPTED SCENES}

Scripted Team Tasks:

1. Write script for each scene with Cami (see handout)

2. Cast actors (Cami voice \& hands, T\&P, Security, Commons area Villagers)

3. Location scout

4. Art director/Lighting

5. Schedule shoot dates

6. Camera Crew: Director, Cameraperson, Sound, Lighting/Art Director

7. ACTION!

\section{$\underline{\text { B-ROLL }}$}

B-Roll Team Tasks:

1. Brainstorm possible images for shot-list on three selected topics (see handout)

2. Camera Crew: Cameraperson

3. ACTION! 


\section{Options for Community Feedback: Defining Feedback Process}

I used this worksheet as a guide to open dialogue about getting feedback from community on orientation video in a core group meeting.

Question: Who has the final decision over final edits to the video? Do we want to have a community screening, and then afterwards, hold a core group meeting to decide on changes, or do we want the core group and community to come together in the end and decide on changes together all at once?

If YES to deciding as a community, then see OPTIONS A and B.

If YES to the core group deciding on final changes, see OPTIONS C - E.

\section{Community Decides - Options for Process}

Question: How much feedback do we want? Do we want to hold two screenings of the video before deciding on changes?

\section{OPTION A}

12:00 introduction of video to community

12:15 $\quad 1^{\text {st }}$ screening of video

$1: 15-4: 15$ community feedback and discussion

4:15 - 5:15 core group and community members decide together (vote) on specific changes

HM edits

Community celebration / Party (screen final version of video)

\section{OPTION B}

12:00 introduction of video to community

12:15 $\quad 1^{\text {st }}$ screening of video

1:15 - 4:15 community feedback and discussion -dinner break-

6:00 $\quad 2^{\text {nd }}$ screening of video

7:00 - 9:00 feedback and discussion

$4: 15$ - 5:15 core group and community members decide together (vote) on specific changes

HM edits

Community celebration / Party (screen final version of video) 


\section{Core Group Decides - Options for Process}

Question: How much feedback do we want? Do we want to hold two screenings of the video before deciding on changes?

\section{OPTION C}

12:00 introduction of video to community

12:15 video

$1: 15-4: 15$ community feedback and discussion

next day core group meets, reviews and discusses feedback from community, and then decides on specific changes

HM edits

Community celebration / Party (screen final version of video)

\section{$\underline{\text { OPTION E }}$}

12:00 introduction of video

12:15 $\quad 1^{\text {st }}$ screening of video

$1: 15-4: 15$ community feedback and discussion

-dinner break-

6:00 $\quad 2^{\text {nd }}$ screening of video

7:00 - 9:00 feedback and discussion

next day core group meets, reviews and discusses feedback from community, and then decides on specific changes

HM edits

Community celebration / Party (screen final version of video)

\section{$\underline{\text { OPTION E }}$}

12:00 introduction of video

12:15 $\quad 1^{\text {st }}$ screening of video

1:15 - 4:15 community feedback and discussion

- Leave DVD for more feedback. Volunteer from core group shows video to specific groups in community and gets feedback (set time limit).

days later core group meets, reviews and discusses feedback from community, and then decides on specific changes

HM edits

Community celebration / Party (screen final version of video) 


\section{Community Feedback Event: Schedule \& Presentation Script}

(event held on 12/7/2006)

Timeline for event:

5:00-5:15 Heather introduces research

5:15 - 6:15 Show "Doing it with Dignity" video

6:15 - 6:30 Wendy sets context for constructive critique and feedback

6:15 - 9:15 Feedback from community

\section{Heather's Introduction (main points):}

A group of us have been working together now for over a year now. We came together because Villagers wanted to address the low morale in the Village. We felt that newcomers weren't getting good quality orientation into the Village and this was impacting the sense of community and morale in the Village as a whole.

We decided to improve the orientation process, and worked for over six months on creating an implementation action plan for improving the orientation process. This action plan was given to the Tents and Population committee to use, and I believe they've been using it. We also identified a need for an orientation video to give newcomers a sense of the Village history, and the importance and value of Dignity Village. We hoped that this orientation video would be used as a tool in orientation to answer some questions and to get newcomers connected to Dignity Village, and motivated to becoming part of the Village.

After over six months of hard work in creating the video, we finally have something to look at together. This is the first draft of the video, and we wanted to get your feedback on the video, so that we can make the final version better, and to create a tool that is really valuable to the Village. The video is nearly 60 minutes long. After we watch it, we'd like to hear what you think about it. We have five questions we'd like to ask you to get your feedback on the video. And these five questions are really general, like what you liked and didn't like about the film.

We are only watching this version once together, so it will be important for all of us to be respectful of one another while watching the movie. You are going to recognize each other and laugh and joke. But it will be better if people do not make comments during the film at the viewing so that we can get through it and everybody can hear because this is the only time that we have to get feedback on it. 
I also ask you to wait until the credits of the film are finished before leaving if you don't want to be here to give feedback at the end. It's another way of being respectful to those who put their hearts and souls into creating the film. And plus there's some fun stuff and you'll not want to miss it.

Just to remind you, the audience for this film is newcomers, so keep this is mind when you are watching it.

Wendy: Setting context for feedback (main points):

Want to get feedback from you. Have five questions that we want to ask you, and we will be recording your comments about the film. Then we will take all the feedback that we get and then decide which changes are feasible to make.

Describe how to be respectful, and give feedback in constructive way. All worked very hard to create this film, and we know it's not perfect and that's why we are asking for your feedback, and to get another perspective on it. But, because we've worked so hard on it, it can be difficult to hear criticisms from people. This makes it a delicate situation, and it's important to lay some ground rules for discussion so that we can be respectful of each other and make this a positive experience.

And those ground rules are:

- Talk one at a time

- Keep stack

- As a point of courtesy, helpful if you direct your comments generally, not at one particular person

- To balance your criticisms with some positive comments as well

- How to criticize: Ask things didn't like and it how it impacted you. Don't say, "I hated it when Gaye said this, or I hated the fade to black." Please say, "I didn't like X because it made me feel like this." Be careful with inflammatory language.

- Going to ask the core group not to respond to comments or feedback unless someone specifically has a question. And in the case of a question, the facilitator will ask someone from the core group to respond if needed.

- Core group can give feedback like everyone else, but not the time to discuss we will change or not change, or respond to comments and critiques for sake of time and reducing potential negativity. 
- One of the core group will be taking notes on everyone's input, collecting all this information and then the core group will be meeting in a few days to digest all this information and feedback and decide what's feasible.

- Any more ground rules that you think are important or would make this more comfortable for everyone? Do you feel comfortable getting feedback?

- Not a debate - everyone's opinion is important. Can say "I disagree with so and so because X, but not that someone else is wrong.'

We want this to be productive, open, and positive experience. People to be honest, but respectful. This is a creative, exciting and interesting process.

Recruit:

note-taker

stack recorder (co-facilitator)

Heather will be recording the dialogue with cameras. This is part of her dissertation research. Will be used in her dissertation document for academic purposes only. If there is anyone who does not want to be on video, then let's find a way that you can participate but not get on video.

\section{Community Feedback Questions for Orientation Video}

(questions used to guide feedback session after community screening)

1. What is your overall impression of the film?

a. What do you like about the film?

b. What do you dislike about the film?

2. What is the message of the film?

3. Does the film answer questions that you might have as a newcomer?

4. Did the film flow well?

5. Is the film too long, too short, or okay as is? 


\section{Community Feedback on Rough Cut Version of Video}

(notes taken by Chrysler Chelle on 12/7/2006)

Comments about Video's Strengths

- Defined the work of progress from camp to village

- Produced high emotion, informational, and structured

- Addressed winning the war against homelessness

- Showed how much work is required to progress

- Draws you in immediately, good explanation of personal responsibility

- Answered more questions than the trailer or toolkit

- Showed the hard work in the early days

- Has changed attitude of older residents

- Feeling of need to join in now, should have seen it the day of entry

- Bryan Pollard's failure statement made major impact toward residents insisting on doing well to prove themselves.

- Good explanation of why community has specific rules

- Brady Bunch music is good

- Message was clear

- Humor was good

- Lots of unseen footage was added and appreciated

- Excellent orientation from beginning to present

- Created excellent cooperation at the viewing

- Excellent film!!!

- Will give residents the desire to fight for the cause

- Will help give more respect to elders, invokes pride

- Excellent orientation, rules were impressive

- Title discussion: okay with title? Yes.

- Music need more work? Most people like the music.

- Hour time is well spent.

- Shows DV is completely different from any other program

- Flows really well

- Makes you be quiet and listen. Gripping.

- Wonderful, wonderful, wonderful.

Changes to be made:

- Add some more discrimination scenes 
- Add visuals to show transition from tents to trainwrecks to houses at Sunderland

\section{Appendix D Endnotes}

Prestby, JE., Wandersman, A., Florin, P., Rich, R., \& Chavis, DM. (1990). Benefits, costs, incentive management, and participation in voluntary organizations: A means to understanding and promoting empowerment. American Journal of Community Psychology, $18,117-149$.

G. Reyes, personal communication, December 15, 2004

Chawla, 1992, Rubenstein \& Parmelee, 1992, Twigger-Ross \& Uzzell, 1996, as cited in Riggs, E.H., \& Coyle, A. (2002). Young people's accounts of homelessness: A case study analysis of psychological well-being and identity. Counseling Psychological Review, 3, 5-15.

Andrus, G., \& Ruhlin, S. (1998). Empowerment practice with homeless people/families. In L. Gutierrez, R.J. Parsons, \& E.O. Cox (Eds.), Empowerment in social work practice: A sourcebook (pp. 110-129). Pacific Grove, CA: Brooks/Cole.

Hopper, 2003, p. 191, Reckoning with Homelessness. Ithaca: Cornell University Press.

Hopper, 2003, p. 191

Cress, 1990, as cited in Wright, 1997; Rosenthal, 1994; Wagner \& Cohen, 1991;

Rosenthal, R. (1994). Homeless in Paradise: A Map of the Terrain. Philadelphia: Temple University Press.

Wagner, D., \& Cohen, M.B. (1991). The power of the people: Homeless protesters in the aftermath of social movement participation. Social Problems, 38(4), 543-561.

Wright, T. (1997). Out of Place: Homeless Mobilizations, Subcities, and Contested Landscapes. Albany, NY: New York Press.

Wagner, 1993; Wright, 1995, 1997

Wright, T. (1995). Tranquility City: Self-organization, protest, and collective gains within a Chicago Homeless encampment. In M.P. Smith (Ed.), Marginal Spaces, Vol. 5, (37-68). New Brunswick, NJ: Transaction Publishers.

Wagner, D. (1993). Checkerboard Square: Culture and Resistance in a Homeless Community. Boulder, CO: Westview Press.

Rivlin \& Imbimbo, 1989; Wright, 1997

Rivlin, L.G., \& Imbimbo, J.E. (1989). Self-help efforts in a squatter community: Implications for addressing contemporary homelessness. American Journal of Community Psychology, 17, 705-728.

Hellegers, D., \& Mercier, L (2003). A brief history of tent city movements. Unpublished.

as cited in Rosenthal, 2000, p. 123. Imaging homelessness and homeless people: Visions and strategies within the movement(s). Journal of Social Distress \& the Homeless. 9(2), 111-126.

Wright, 1997

Casanova \& Blackburn, 1996; Lara \& Molina, 1997

Casanova, R., \& Blackburn, S. (1996). Each One Teach One: Up and Out of Poverty Memoirs of a Street Activist. Willimantic, CT: Curbstone Press. 
xxxiv Stringer, E.T. (1999). Action Research (Second Edition), Thousand Oaks, CA: Sage.

xxxv Greenwood \& Levin, 1998

xxxvi Greenwood \& Levin, 1998; Reason \& Bradbury, 2001

xxxvii Nelson, G., Ochocka, J., Griffin, K., \& Lord, J. (1998). 'Nothing about me without me': Participatory action research with self-help/mutual aid organizations for psychiatric consumers/survivors. American Journal of Community Psychology, 26(6), 881-912.

xxxviii Charlton, 1998, Freire, 1993, Minkler, 1985, as cited in Greenwood \& Levin, 1998

xxxix $\quad$ Stringer, 1999 


\title{
APPENDIX E: INTERVIEW SCHEDULE
}

\author{
Individual interviews (semi-structured)
}

Introduction: The purpose of the interview is to hear different perspectives and experiences related to being a part of Dignity Village.

Interview length: approximately one hour

\section{Interview questions:}

1. Are you a member/resident/visitor? What is your current role at DV?

2. When did you first come to DV, and what was that like coming here?

3. How has your perception of DV and your role changed since you first arrived?

4. How do you understand DV's history, why it was here, and what it has accomplished?

a. Do you feel that the Village has accomplished what it had meant to accomplish? (If don't know bc new, then what have you heard others saying about this?)

5. How has DV helped you (in accomplishing your goals)?

6. How do you think that DV can help you accomplish your goals?

7. How did you think you can help DV accomplish its future goals?

a. Do you see your role changing in the future?

b. How able is DV to accomplish these goals?

8. Many people here have said that individual enthusiasm and participation in Village activities waxes and wanes.
a. Why do you think that is?
b. What do you think gets people excited, what gets you wanting to participate?
c. What gets you feeling down, like you don't want to participate?
d. What have you heard from others?
e. When do you think this began and why? (if not a core participant)

9. When you imagine the Village at its best/succeeding, what do you see and how do you know?

10. When you imagine the Village struggling/failing, what do you see and how do you know?

11. Do you consider yourself a Villager?

a. What does that mean to you? 


\title{
APPENDIX F：POST-RESEARCH INTERVIEW SCHEDULE
}

\author{
(After the Creation of the Orientation Video)
}

Individual interviews with Core Group members (semi-structured)

Introduction: The purpose of the interview is to understand how participating in the core group had impact on participants and on the community.

Interview length: approximately one hour

Interview questions:

- What did you like about participating in the core group?

- What did you dislike about participating in the meetings?

- Do you feel that being involved in the core group has changed you in any way?

- How about relationships with others?

- How do you see yourself?

- How you participate in community now compared to before?

- Has your interest or enthusiasm in Dignity Village changed?

- How has the research been useful to the community? How do you think it has helped the Village?

- Negativity? Low morale?

- $\quad$ Strengthened relationships? Weakened relationships? More supportive?

- Increased cooperation?

- Transparency and communication?

- Consistency? (distribution of resources, enforcement of rules)

- Vision?

- $\quad$ Opportunities and support different ways of participating in Village

- $\quad$ Shift thinking to 'we'

- Belief in power of the community and goals that we can achieve together

- Activism

- Do you think that DV is capable of accomplishing its goals and vision? Why?

- What will your role be in this? 


\section{APPENDIX G: CODING INDEX (THEMES) FOR ANALYSIS}

\begin{tabular}{|c|c|c|}
\hline & $\underline{\text { D: }}$ Disaffection / Disempowering & $\underline{\mathbf{E}}$ : Empowering \\
\hline & $\begin{array}{c}\underline{\mathbf{b}}: \text { B-level (group); } \mathbf{a}: \text { A-level } \\
(\text { community })\end{array}$ & $\begin{array}{c}\underline{\mathbf{b}}: \text { B-level (group); } \mathbf{a}: \text { A-level } \\
\text { (community) }\end{array}$ \\
\hline $\begin{array}{l}\text { Behaviors / } \\
\text { Social } \\
\text { Interactions }\end{array}$ & 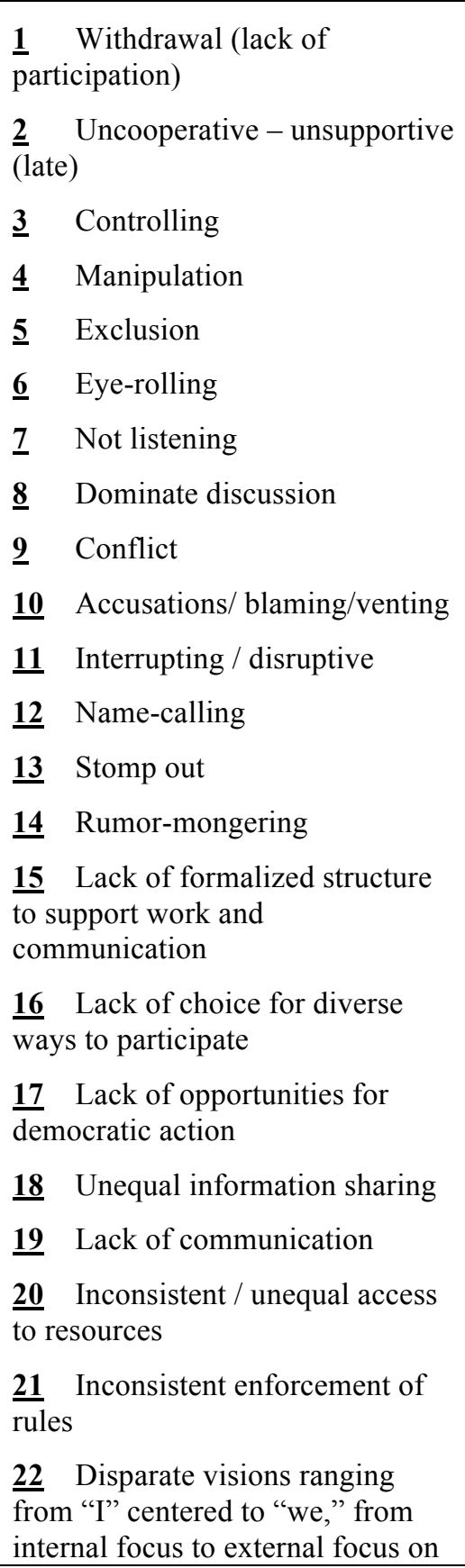 & 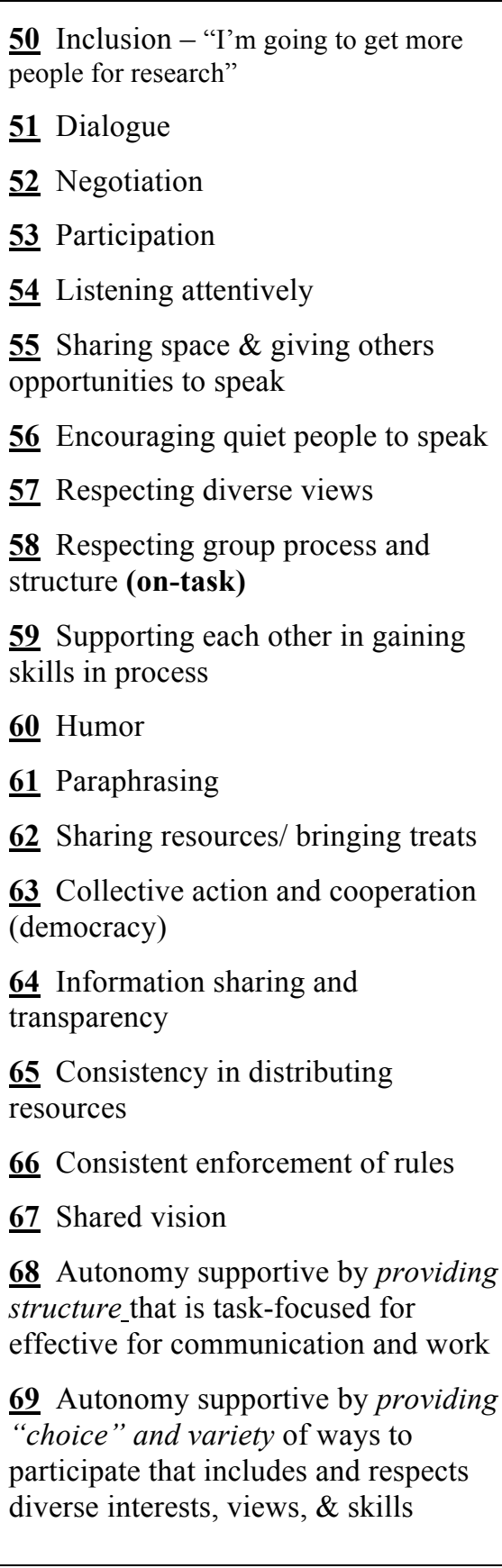 \\
\hline
\end{tabular}




\begin{tabular}{|c|c|c|}
\hline & 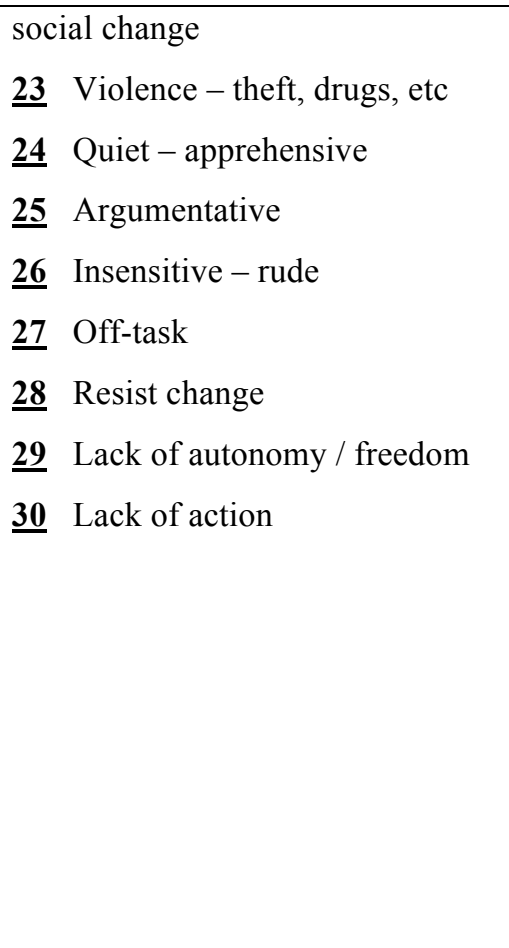 & 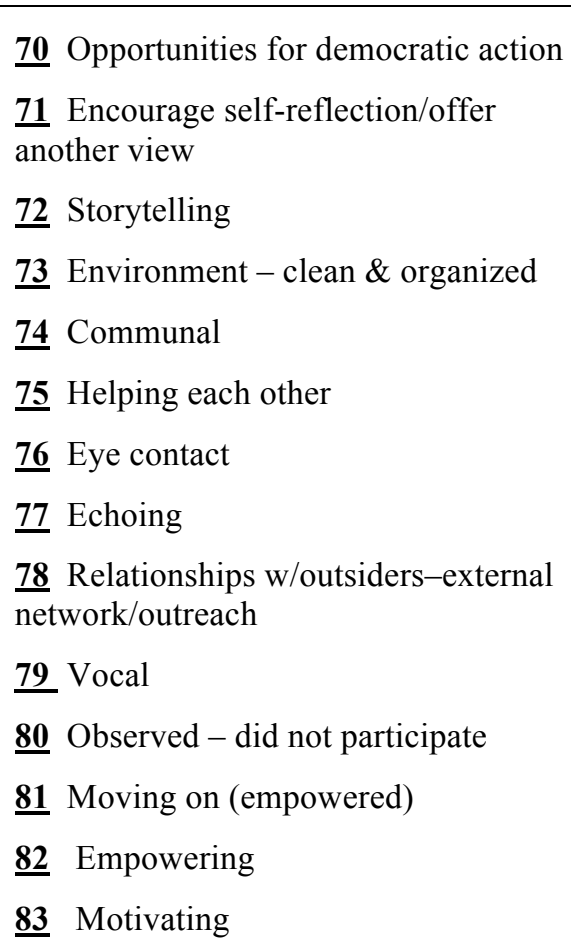 \\
\hline $\begin{array}{l}\text { Quality of } \\
\text { Emotion / } \\
\text { Affection }\end{array}$ & $\begin{array}{l}\underline{\mathbf{1 0 0}} \text { Apathy - withdrawal - } \\
\text { disengaged } \\
\underline{\mathbf{1 0 1}} \text { Fear } \\
\underline{\mathbf{1 0 2}} \text { Frustration } \\
\underline{\mathbf{1 0 3}} \text { Humiliation } \\
\underline{\mathbf{1 0 4}} \text { Anger } \\
\underline{\mathbf{1 0 5}} \text { Closed - defensive } \\
\underline{\mathbf{1 0 6}} \text { Exclusion of different } \\
\text { perspectives } \\
\underline{\mathbf{1 0 7}} \text { Unsupportive and } \\
\text { disrespectful relationships } \\
\underline{\mathbf{1 0 8}} \text { Lack of emotional } \\
\text { connection and commitment } \\
\text { to community / DV } \\
\underline{\mathbf{1 0 9}} \text { Negativity - Low morale } \\
\underline{\mathbf{1 1 0}} \text { Hostility }\end{array}$ & $\begin{array}{l}\underline{\mathbf{1 5 0}} \text { Friendly \& supportive } \\
\underline{\mathbf{1 5 1}} \text { Engaged - energized } \\
\underline{\mathbf{1 5 2}} \text { Good mood } \\
\underline{\mathbf{1 5 3}} \text { Curious } \\
\underline{\mathbf{1 5 4}} \text { Welcoming } \\
\underline{\mathbf{1 5 5}} \text { Open - accept differences } \\
\underline{\mathbf{1 5 6}} \text { Polite } \\
\underline{\mathbf{1 5 7}} \text { Sharing stories } \\
\underline{\mathbf{1 5 8}} \text { Inclusion \& care for diverse } \\
\text { views and democratic action } \\
\underline{\mathbf{1 5 9}} \text { Supportive and respectful } \\
\text { relationships } \\
\underline{\mathbf{1 6 0}} \text { Emotional connection and } \\
\text { commitment to community / } \\
\text { Dignity Village } \\
\underline{\mathbf{1 6 1}} \text { Positive morale }\end{array}$ \\
\hline
\end{tabular}




\begin{tabular}{|c|c|c|}
\hline & $\begin{array}{l}\underline{111} \text { Distrust } \\
\underline{112} \text { Impatience - Intolerance - } \\
\text { lack of empathy } \\
\underline{\mathbf{1 1 3}} \text { Disappointed - let down } \\
\underline{\mathbf{1 1 4}} \text { Newcomers } \\
\underline{\mathbf{1 1 5}} \text { Resentful } \\
\underline{\mathbf{1 1 6}} \text { Distracted } \\
\underline{\mathbf{1 1 7}} \text { Intimidated } \\
\underline{\mathbf{1 1 8}} \text { Down mood } \\
\underline{\mathbf{1 1 9}} \text { Criticism } \\
\underline{\mathbf{1 2 0}} \text { Guilty - embarrassed } \\
\underline{\mathbf{1 2 1}} \text { Overwhelmed - Burn-out } \\
\underline{\mathbf{1 2 2}} \text { Boredome } \\
\underline{\mathbf{1 2 3}} \text { Dirty environment }\end{array}$ & $\begin{array}{l}\frac{162}{16 m} \text { Emathy } \\
\underline{163} \text { Ill } \\
\underline{164} \text { Tired-stressed } \\
\underline{165} \text { Patient - tolerance } \\
\underline{166} \text { Sensitive - caring } \\
\underline{167} \text { Pride / confidence } \\
\underline{168} \text { Sincere / honest feedback } \\
\underline{169} \text { Self-worth } \\
\underline{170} \text { Sense of accomplishment } \\
\underline{171} \text { Safe } \\
\underline{172} \text { Home - sense of belonging }\end{array}$ \\
\hline $\begin{array}{l}\text { Cognitive } \\
\text { Beliefs }\end{array}$ & $\begin{array}{l}\underline{\mathbf{2 0 0}} \begin{array}{l}\text { Negative thinking - "What's } \\
\text { the point? It will never } \\
\text { change" }\end{array} \\
\underline{\mathbf{2 0 1}} \begin{array}{l}\text { Self-serving beliefs - here } \\
\text { to use the resources and get } \\
\text { out; "I'm just here to get a } \\
\text { helping hand" }\end{array} \\
\underline{\mathbf{2 0 2}} \text { "I'm just not political" } \\
\underline{\mathbf{2 0 3}} \text { "I don't want to hear } x \text { go } \\
\text { off in the meeting" } \\
\underline{\mathbf{2 0 4}} \text { "I don't want to be } \\
\text { humiliated by } x \text { " } \\
\underline{\mathbf{2 0 5}} \text { Low self-concept - "I'm not } \\
\text { good enough to take a } \\
\text { leadership position" } \\
\underline{\mathbf{2 0 6}} \text { "My opinion is not worth } \\
\text { anything, I'm just a }\end{array}$ & $\begin{array}{l}\underline{\mathbf{2 5 0}} \text { "Together, we might be able to } \\
\text { make a difference" } \\
\underline{\mathbf{2 5 1}} \text { value in diversity } \\
\underline{\mathbf{2 5 2}} \text { See other people wanting } \\
\text { change too } \\
\underline{\mathbf{2 5 3}} \text { Being part of group will get } \\
\text { people motivated } \\
\underline{\mathbf{2 5 4}} \text { "We can learn how to work } \\
\text { better together" } \\
\underline{\mathbf{2 5 5}} \text { "We can begin to understand } \\
\text { each other" } \\
\underline{\mathbf{2 5 6}} \text { "I understand more about their } \\
\text { traditions and practices at DV" } \\
\underline{\mathbf{2 5 7}} \text { Critical consciousness } \\
\underline{\mathbf{2 5 8}} \text { Community thinking - "we" } \\
\underline{\mathbf{2 5 9}} \text { Belief in the power of }\end{array}$ \\
\hline
\end{tabular}




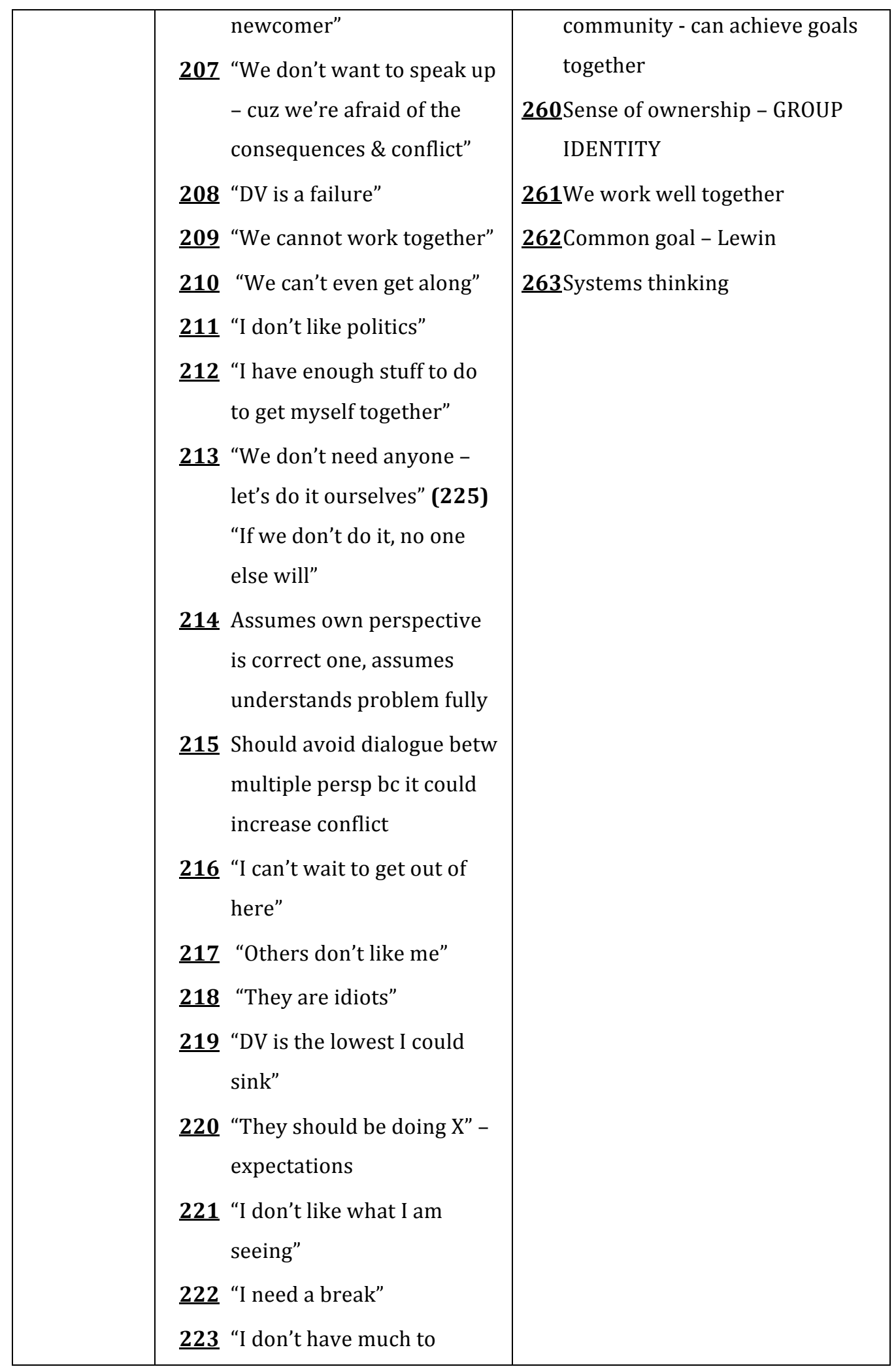




\begin{tabular}{|c|c|c|}
\hline & $\begin{array}{l}\text { contribute" } \\
\underline{\mathbf{2 2 4}} \text { "There are too many rules" } \\
\underline{\mathbf{2 2 5}} \text { You can't do that - you } \\
\text { don't know how }\end{array}$ & \\
\hline $\begin{array}{l}\text { Other } \\
\text { research } \\
\text { issues }\end{array}$ & 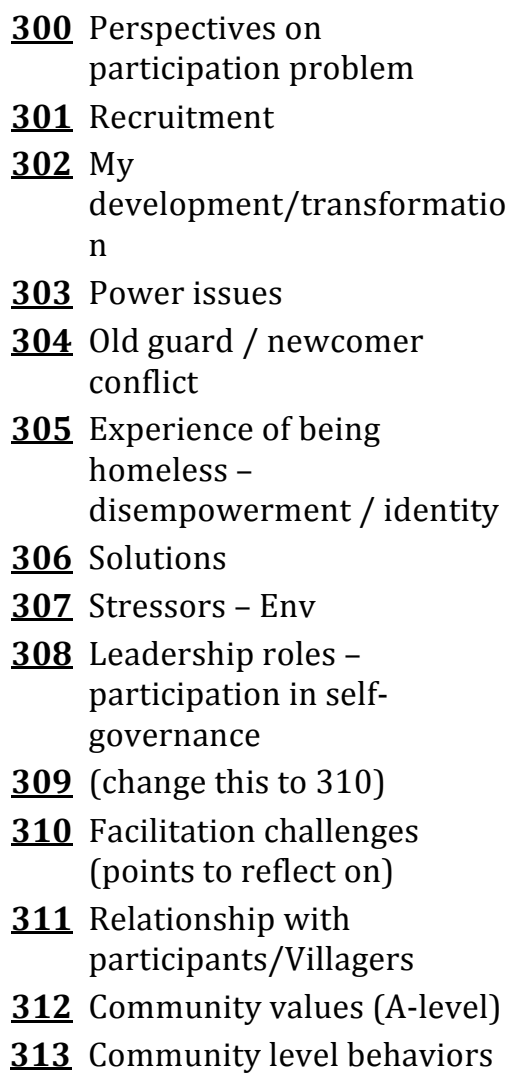 & 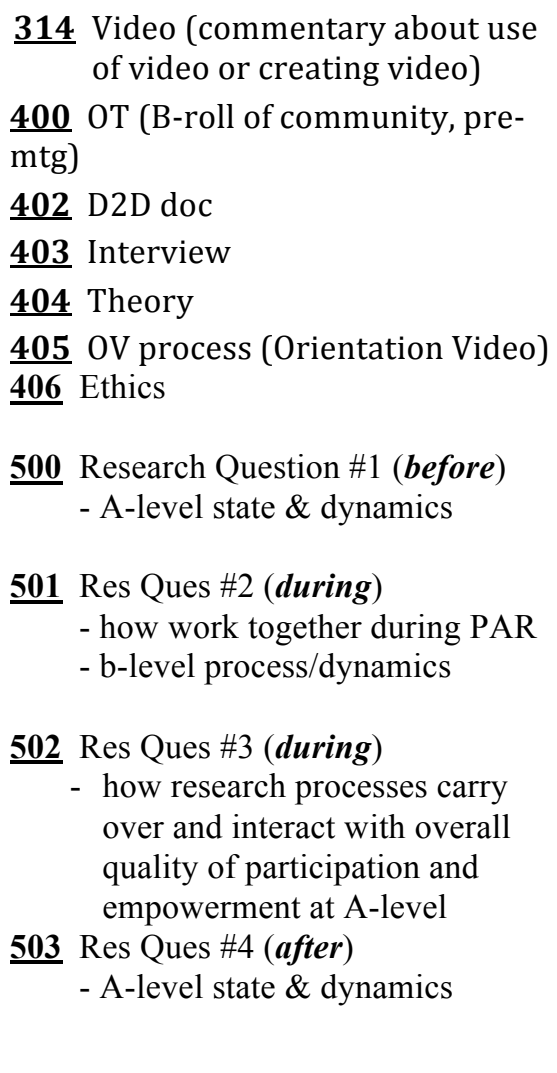 \\
\hline
\end{tabular}


Participatory Action Research

Appendix $H \quad 480$

\title{
APPENDIX H: TECHNICAL INSTRUCTIONS FOR PLAYING DVD
}

\author{
TECHNICAL \\ INSTRUCTIONS \\ for video portion of dissertation
}

Instructions to play movie:

1. Insert DVD into DVD player on computer (Mac or Win) or on DVD player hooked to a TV.

2. The DVD should automatically launch (it may take a little longer than usual to load this DVD since it is a dual-layer disc which holds more data).

Trouble shooting for computer: a) be certain that you have a DVD drive; b) if have a DVD drive, make sure you have DVD software such as WinDVD, Windows Media Player 9, or Quicktime (Mac or Win) installed. These programs are free and they can be downloaded from the web and installed.

3. Use a remote (or mouse) to click on menus to view individual sections or "play all" to view entire movie

4. For the evaluation/feedback forms, you can use the numbers for "timecode" in the video as it is playing to identify where you are at within the entire movide. The timecode numbers are listed in first column of the Evaluation Sheet to help you locate each video clip.

Computer: timecode is usually at bottom of DVD viewer DVD player with TV: timecode can be viewed on the physical DVD player display, or you can press the "display" button on the remote to show timecode numbers on the TV screen as the video is playing. 